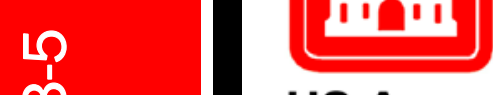

US Army Corps

of Engineers $\mathrm{B}_{\circledast}$

Engineer Research and

Development Center

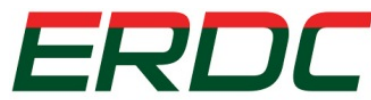

INNOVATIVE SOLUTIONS

for a safer, better world

Great Lakes Coastal Flood Study, 2012 Federal Inter-Agency Initiative

\title{
Lake St. Clair: Storm Wave and Water Level
} Modeling

Tyler J. Hesser, Mary A. Cialone, and Mary E. Anderson

June 2013 
The US Army Engineer Research and Development Center (ERDC) solves the nation's toughest engineering and environmental challenges. ERDC develops innovative solutions in civil and military engineering, geospatial sciences, water resources, and environmental sciences for the Army, the Department of Defense, civilian agencies, and our nation's public good. Find out more at www.erdc.usace.army.mil.

To search for other technical reports published by ERDC, visit the ERDC online library at http://acwc.sdp.sirsi.net/client/default. 


\section{Lake St. Clair: Storm Wave and Water Level Modeling}

Tyler J. Hesser, Mary A. Cialone, and Mary E. Anderson

Coastal and Hydraulics Laboratory

US Army Engineer Research and Development Center

3909 Halls Ferry Road

Vicksburg, MS 39180-6199

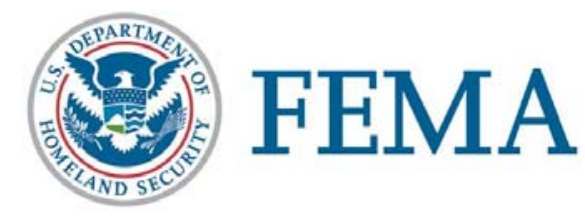

Final report

Approved for public release; distribution is unlimited.

Prepared for US Army Corps of Engineers

Detroit District

477 Michigan Avenue

Detroit, MI 48226 


\section{Abstract}

Lake St. Clair is a shallow water body located between Lake Huron and Lake Erie in the Great Lakes complex with coastline in both the United States and Canada. The numerical modeling of waves and water levels was performed to capture storm conditions along the United States coastline. The methodology presented in Jensen et al. (2012) for Lake Michigan was followed for the majority of the project. The NOAA/NCEP Climate Forecast System Reanalysis wind fields were adjusted for marine exposure wind speeds. The WAM wave model was validated and applied for production of all wind generated wave results, including ice when applicable. The ADCIRC model was forced with wind fields, flow rates at the St. Clair River boundary, and water levels at the Detroit River boundary and validated to water levels at St. Clair Shores and Windmill Point. The ADCIRC model was tightly coupled with four near-shore Full-Plane STWAVE model grids using CSTORM-MS. The results show good agreement between all validation data sets, and low errors in the production storms with which data was available. In total, 145 storm events were run with the full numerical system to quantify the water level response to extreme events in Lake St. Clair.

DISCLAIMER: The contents of this report are not to be used for advertising, publication, or promotional purposes. Citation of trade names does not constitute an official endorsement or approval of the use of such commercial products. All product names and trademarks cited are the property of their respective owners. The findings of this report are not to be construed as an official Department of the Army position unless so designated by other authorized documents. 


\section{Contents}

Abstract...................................................................................................................................... if

Figures and Tables............................................................................................................vi

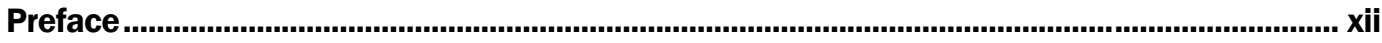

Unit Conversion Factors....................................................................................................... xifi

1 Wind and Pressure Field Generation ................................................................................ 1

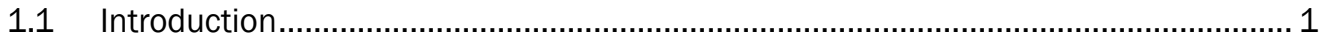

1.2 Mining wind data bases ................................................................................. 1

1.2.1 The Global Integrated Surface Hourly database: ISH ............................................. 1

1.2.2 Additional meteorological stations (NDBC/NOS/NWS/GLERL) ........................... 4

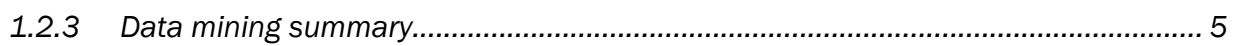

1.3 Natural Neighbor Method (NNM): wind and pressure fields................................. 5

1.4 NCEP Climate Forecast System Reanalysis (CFSR): wind and pressure fields..............8

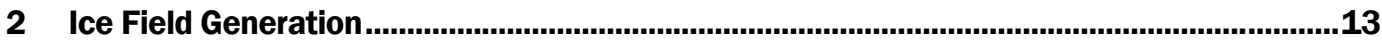

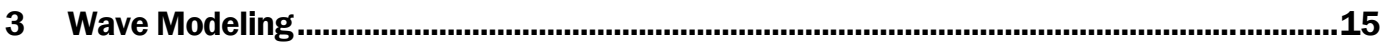

3.1 Wave modeling approach .......................................................................... 15

3.1.1 Model domain .............................................................................................. 15

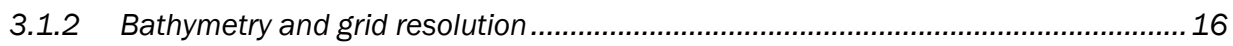

3.1.3 Frequency resolution ..................................................................................... 17

3.2 Initial wind-wave growth tests: constant winds ................................................ 17

3.3 Point-source wave measurements for model evaluation...................................... 21

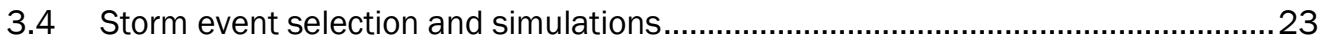

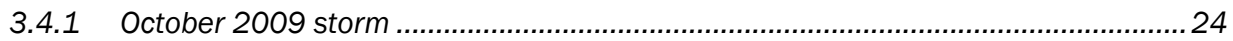

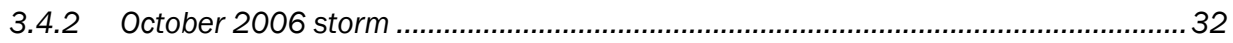

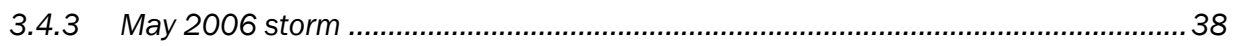

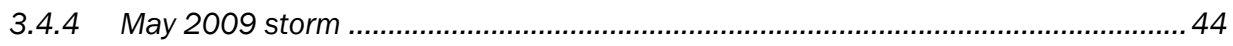

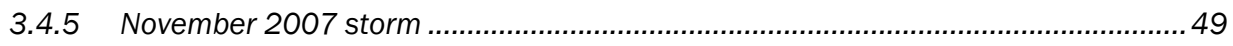

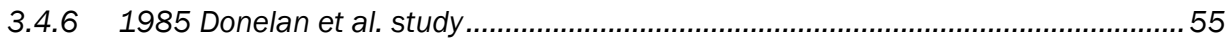

3.5 Summary of observations and recommendations ..............................................59

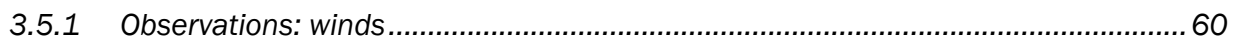

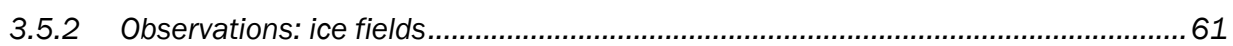

3.5.3 Observations: wave measurements.................................................................. 61

3.5.4 Observations: wave model and modeling effort................................................. 61

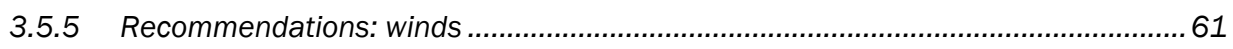

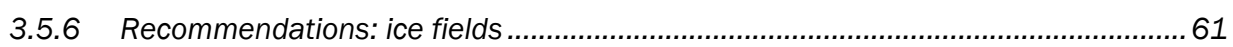

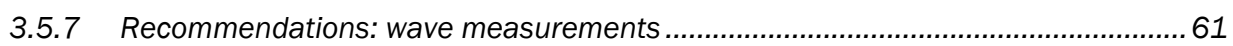

3.5.8 Recommendations: wave model and modeling effort ........................................... 62

4 Water Level Modeling.....................................................................................................63 


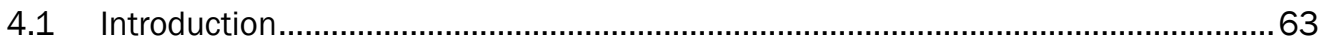

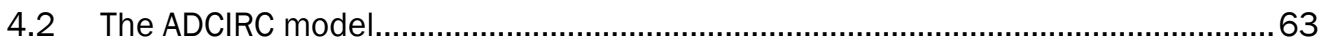

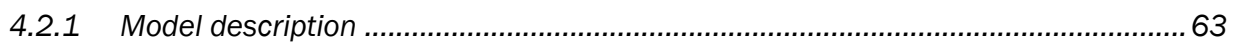

4.2.2 Storm surge modeling approach............................................................................ 64

4.2.3 Treatment of ice cover - method for specifying the coefficient of drag...................64

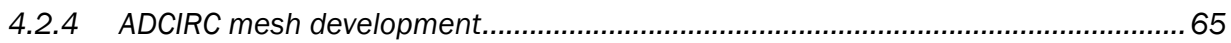

4.3 Validation of Lake St Clair ADCIRC mesh for storm simulations ............................68

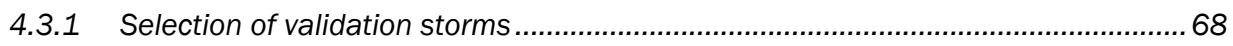

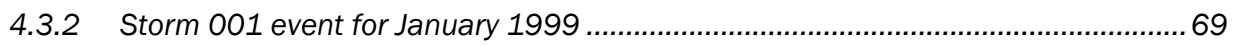

4.3.3 Storm 002 event for December 1990 ................................................................ 70

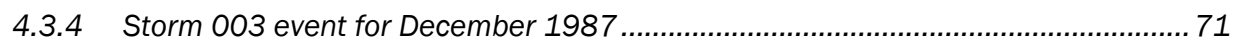

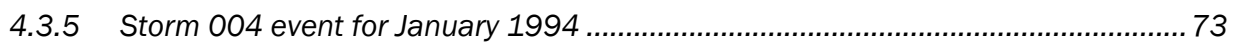

4.3.6 October 2008 simulation...................................................................................... 75

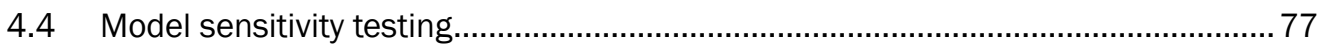

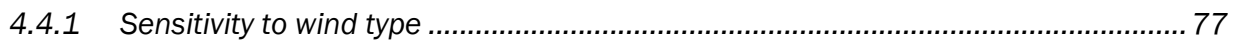

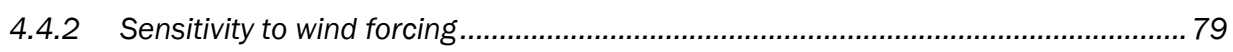

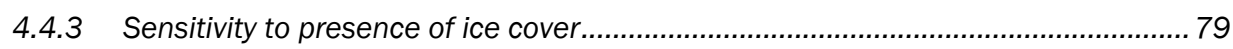

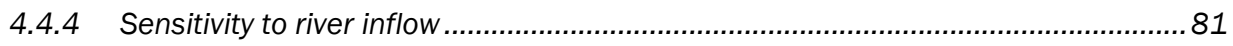

4.4.5 Sensitivity to bottom friction ............................................................................. 83

4.5 Summary of findings from Lake St. Clair storm surge validation ..........................83

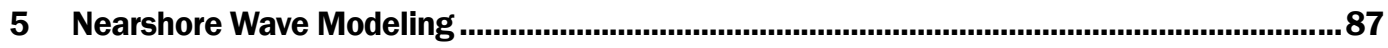

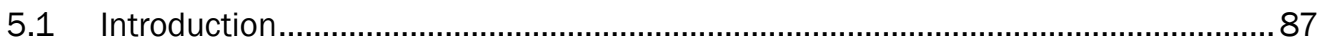

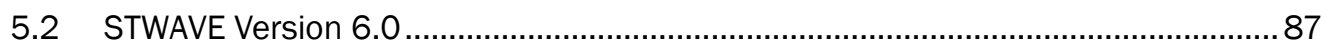

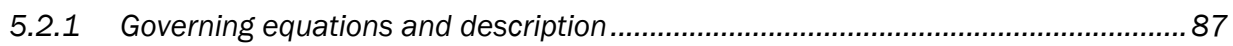

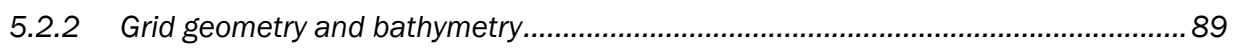

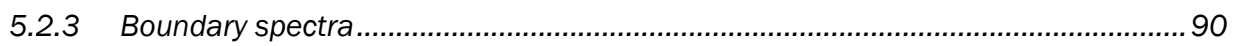

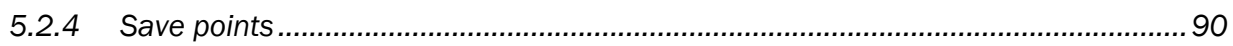

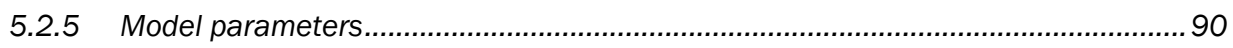

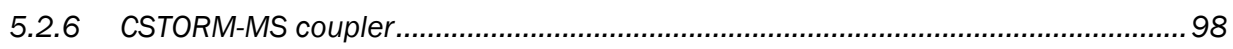

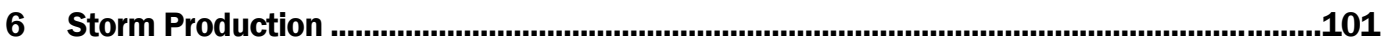

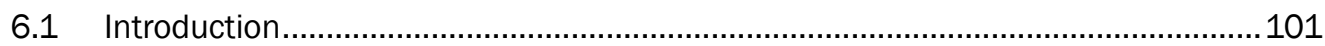

6.2 Wind field production .................................................................................... 106

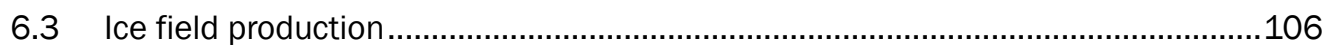

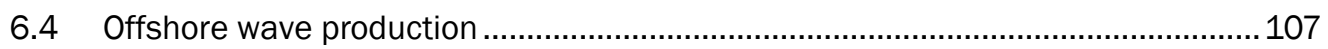

6.4.1 Post-processing QA/QC.......................................................................................111

6.4.2 Summary of Lake St. Clair offshore wave model production ................................117

6.5 Water level production ..................................................................................120

6.5.1 Post-processing QA/QC.......................................................................................... 123

6.5.2 Synopsis of Lake St. Clair water level modeling.......................................................123

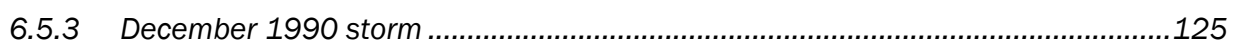

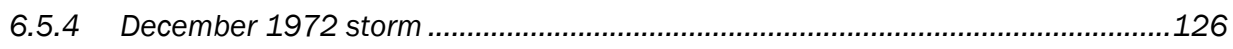

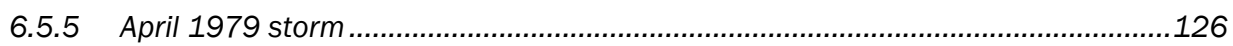

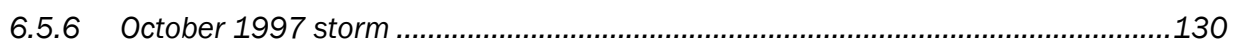

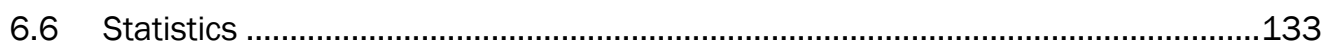




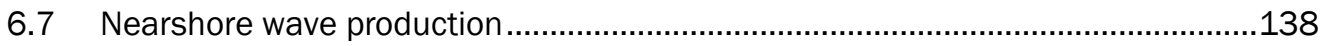

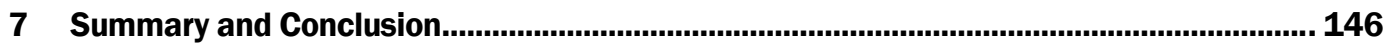

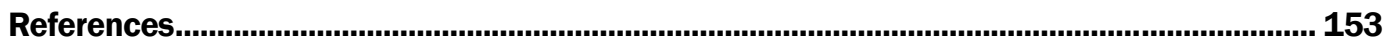

\section{Report Documentation Page}




\section{Figures and Tables}

\section{Figures}

Figure 1-1. Time variation of active airways stations found in the NCDC ISH data archive.

Figure 1-2. Available meteorological station locations accessed and preprocessed for Storm 2009-278.

Figure 1-3. Comparison of input wind speed, direction and temporally smoothed (1:1:1) for Storm 2009-278 at NWS Station St. Clair Shores, MI.

Figure 1-4. Snapshot of wind speed iso-tac color contour $(\mathrm{m} / \mathrm{sec})$ using NNM for the October 2009 validation storm.

Figure 1-5. Land-water mask for CFSR wind fields. Lake St. Clair is in the land mask inside the green box.

Figure 1-6. Location of meteorological stations used in the CFSR wind speed evaluation. (photographs from NOAA/NDBC)

Figure 1-7. Adjustment of CFSR wind speed at station LSCM4 using two linear trend lines.

Figure 1-8. Monthly and yearly mean of CFSR wind speed. A) Original CFSR wind speeds.

B) Adjusted CFSR wind speeds.

Figure 2-1. Interpolated ice field output for a water-level validation storm. Grey region identifies ice coverage.

Figure 3-1. Domain and bathymetry for the Lake St. Clair WAM model.

Figure 3-2. Maximum wave height envelope generated from WAM forced with constant 25-m/sec northwest wind, wind direction yellow arrow, northeast region outlined in red.

Figure 3-3. Output locations for WAM starting at 1 in the Southwest corner continuing in a clockwise direction.

Figure 3-4. Statistical calculations at all output locations around lake for WAM forced with a constant South wind.

Figure 3-5. Location of Canadian Buoy 45147 in Lake St. Clair. ......................................................... 22

Figure 3-6. Mean zeroth moment wave height for each year at Canadian buoy 45147 without cutoff (blue) and with cutoff (red).

Figure 3-7. Available meteorological station locations accessed and preprocessed for the October 2009 storm.

Figure 3-8. Maximum wind speed envelope for the October 2009 storm derived from the NNM wind field generation routine.

Figure 3-9. Maximum wind speed envelope for the October 2009 storm derived from the CFSR wind field.

Figure 3-10. Maximum significant wave height envelope for the October 2009 storm derived from the NNM wind field generation routine.

Figure 3-11. Maximum significant wave height envelope for the October 2009 storm derived from the CFSR wind field.

Figure 3-12. Time plots of significant wave height, peak and mean wave period, vector mean wave direction wind speed and direction at Canadian Buoy 45147 for the October 2009 storm. 
Figure 3-13. Energy density spectrum for Canadian buoy 45147 and WAM output for the October 2009 storm.

Figure 3-14. Time series of wave heights calculated from full spectrum and reduced frequency range spectrum for the October 2009 storm.

Figure 3-15. Available meteorological station locations accessed and preprocessed for the October 2006 storm

Figure 3-16. Maximum wind speed envelope for the October 2006 storm derived from the NNM wind field generation routine.

Figure 3-17. Maximum wind speed envelope for the October 2006 storm derived from the CFSR wind fields.

Figure 3-18. Maximum wave height envelope for the October 2006 storm derived from the NNM wind fields.

Figure 3-19. Maximum wave height envelope for the October 2006 storm derived from the CFSR wind fields.

Figure 3-20. Time plots of significant wave height, peak and mean wave period, vector mean wave direction wind speed and direction at Canadian Buoy 45147 for the October 2006 storm

Figure 3-21. Energy density spectrum for Canadian buoy 45147 and WAM output for the October 2006 storm.

Figure 3-22. Time series of wave heights for calculated from full spectrum and cut spectrum for the October 2006 storm.

Figure 3-23. Available meteorological station locations accessed and preprocessed for the May 2006 storm.

Figure 3-24. Maximum wind speed envelope for the May 2006 storm derived from the NNM wind fields.

Figure 3-25. Maximum wind speed envelope for the May 2006 storm derived from the CFSR wind fields

Figure 3-26. Maximum wave height envelope for the May 2006 storm derived from the NNM wind fields.

Figure 3-27. Maximum wave height envelope for the May 2006 storm derived from the CFSR wind fields.

Figure 3-28. Time plots of significant wave height, peak and mean wave period, vector mean wave direction wind speed and direction at Canadian Buoy 45147 for the May 2006 storm

Figure 3-29. Energy density spectrum for Canadian buoy 45147 and WAM output for the May 2006 storm.

Figure 3-30. Time series of wave heights for calculated from full spectrum and cut spectrum for the May 2006 storm.

Figure 3-31. Available meteorological station locations accessed and preprocessed for the May 2009 storm.

Figure 3-32. Maximum wind speed envelope for the May 2009 storm derived from the NNM wind field generation routine.

Figure 3-33. Maximum wind speed envelope for the May 2009 storm derived from the CFSR wind field generation routine.

Figure 3-34. Maximum wind speed envelope for the May 2009 storm derived from the NNM wind field generation routine. 
Figure 3-35. Maximum wind speed envelope for the May 2009 storm derived from the CFSR wind field generation routine.

Figure 3-36. Time plots of significant wave height, peak and mean wave period, vector mean wave direction wind speed and direction at Canadian Buoy 45147 for the May 2009 storm

Figure 3-37. Energy density spectrum for Canadian buoy 45147 and WAM output for the May 2009 storm.

Figure 3-38. Time series of wave heights for calculated from full spectrum and cut spectrum for the May 2009 storm.

Figure 3-39. Available meteorological station locations accessed and preprocessed for the November 2007 storm.

Figure 3-40. Maximum wind speed envelope for the November 2007 storm derived from the NNM wind field generation routine.

Figure 3-41. Maximum wind speed envelope for the November 2007 storm derived from the CFSR wind field generation routine.

Figure 3-42. Maximum wind speed envelope for the November 2007 storm derived from the NNM wind field generation routine.

Figure 3-43. Maximum wind speed envelope for the November 2007 storm derived from the CFSR wind field generation routine.

Figure 3-44. Time plots of significant wave height, peak and mean wave period, vector mean wave direction wind speed and direction at Canadian Buoy 45147 for the November 2007 storm.

Figure 3-45. Time series of wave heights for calculated from full spectrum and cut spectrum for the May 2009 storm.

Figure 3-46. Location of wave towers during the 1985 Donelan et al. (1992) study.....

Figure 3-47. Compendium time plots of significant wave height at all six stations for segment 1 of 1985 Donelan et al. (1992) study.

Figure 3-48. Time plots of significant wave height, peak and mean wave period, vector mean wave direction wind speed and direction at Station 85005 for segment 1 of 1985 Donelan et al. (1992) study.

Figure 4-1. ADCIRC mesh for Lake St. Clair and a detailed mesh inset. 67

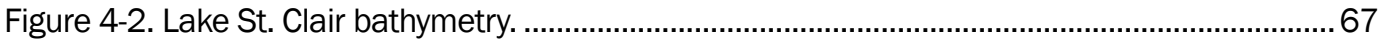

Figure 4-3. NOAA NOS water level stations in Lake St. Clair and adjoining rivers. ............................ 69

Figure 4-4. Comparison of Storm 001 observed and modeled water levels at St. Clair Shores. .............. 70

Figure 4-5. Comparison of Storm 002 observed and modeled water levels at St. Clair Shores................71

Figure 4-6. Comparison of Storm 002 observed and modeled water levels at Windmill Point................. 72

Figure 4-7. Comparison of Storm 003 observed and modeled water levels at St. Clair Shores................ 72

Figure 4-8. Comparison of Storm 003 observed and modeled water levels at Windmill Point..................74

Figure 4-9. Comparison of Storm 004 observed and modeled water levels at St. Clair Shores...............74

Figure 4-10. Comparison of October 2008 observed and modeled water levels at New Baltimore.

Figure 4-11. Comparison of October 2008 observed and modeled water levels at St. Clair Shores.

Figure 4-12. Comparison of October 2008 observed and modeled water levels at Windmill Point. 
Figure 4-13. Comparison of Storm 002 water level response at St. Clair Shores when ADCIRC is forced with CFSR and NNM winds.

Figure 4-14. Comparison of Storm 002 water level response at Windmill Point when ADCIRC is forced with CFSR and NNM winds.

Figure 4-15. (a) Comparison of water level response to a nine percent change in wind speeds, (b) Comparison of water level response to elimination of wind forcing.

Figure 4-16. St. Clair Shores water level time series with and without ice coverage.

Figure 4-17. St. Clair Shores water level time series for October 2008 with full river inflow, 85 percent river inflow, and 62 percent river inflow.

Figure 4-18. Windmill Point water level time series for October 2008 with full river inflow, 85 percent river inflow, and 62 percent river inflow.

Figure 4-19. St. Clair Shores water level time series for October 2008 with variation in friction coefficient.

Figure 4-20. Windmill Point water level time series for October 2008 with variation in friction coefficient.

Figure 5-1. Location of the Lake St. Clair northwest (NW), midwest (MW), southwest (SW), and northeast (NE) STWAVE grids.

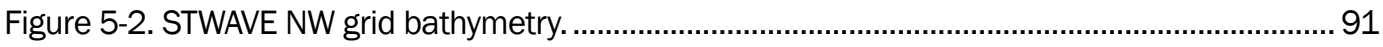

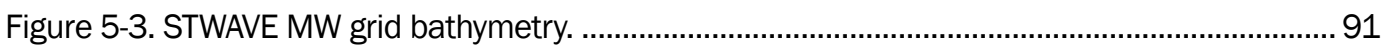

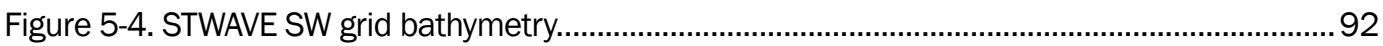

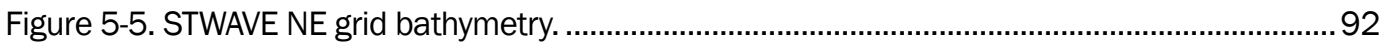

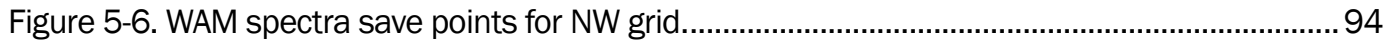

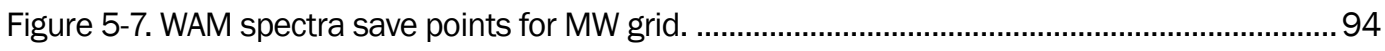

Figure 5-8. WAM spectra save points for SW grid. .......................................................................... 95

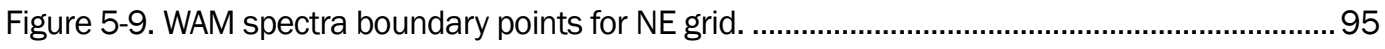

Figure 5-10. STWAVE save points for NW grid. ................................................................................96

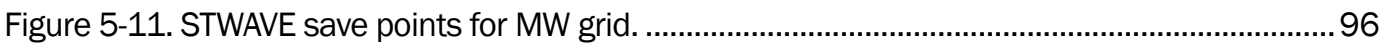

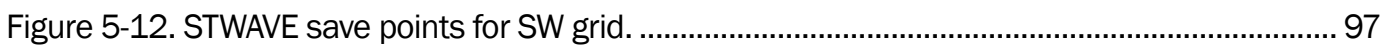

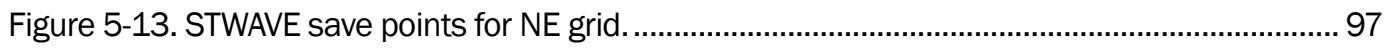

Figure 5-14. Diagram of timing between ADCIRC and STWAVE. ...................................................100

Figure 6-1. Location of wave measurements and water level sites. ................................................ 101

Figure 6-2. Special output locations for the WAM simulations......................................................108

Figure 6-3. Zoom of the Southwestern area. The STWAVE boundary is identified by the red circle.

Figure 6-4. Zoom view of the northwestern domain of Lake St. Clair, red and yellow ovals identify the boundary input locations for STWAVE simulations.

Figure 6-5. Zoom view of the northeastern domain of Lake St. Clair, red oval identifies the boundary input locations for STWAVE simulations.

Figure 6-6. Maximum wind speed envelope for ST0143 (14-26 Oct 2009).................................112

Figure 6-7. Maximum significant wave height envelope for STO143 (14-26 Oct 2009).................112

Figure 6-8. Time plot of WAM (blue line) versus measurements at 45147 for Storm 143.

The top panel is the significant wave height, next is the parabolic fit peak wave period, mean wave period, vector mean wave direction, wind speed and direction. 
Figure 6-9. Time plot of WAM (blue line) versus measurements at 45147 for Storm 143 using $0.2-0.3$ frequency range. The top panel is the significant wave height, next is the parabolic fit peak wave period, mean wave period, vector mean wave direction, wind speed and direction.

Figure 6-10. Scatter and Q-Q plots of WAM versus measurements at 45147 for Storm 143. Top two panels: significant wave height, followed by parabolic fit peak wave period and mean wave period. Statistical test results are given between the plots.

Figure 6-11. Scatter and Q-Q plots of WAM versus measurements at 45147 for Storm 143. Top two panels: wind speed, followed by wind and wave direction. Q-Q analyses are based on scalar values, hence a cumulative distribution replaces this test for the wind and wave directions. Statistical test results are given between the plots.

Figure 6-12. Overall maximum wind speed and significant wave height locations for the 140 extreme storm event population.

Figure 6-13. Magnitudes of the maximum wind speed (upper panel) and significant wave height (lower panel) for the 140 extreme storm events.

Figure 6-14. ADCIRC Save point locations for Lake St. Clair.

Figure 6-15. ADCIRC maximum water level envelope for Storm 080 (December 1987) indicating high water levels along northwestern shoreline of Lake St. Clair...

Figure 6-16. ADCIRC maximum water level envelope for Storm 086 (December 1990) indicating high water levels along northwestern shoreline of Lake St. Clair..

Figure 6-17. ADCIRC maximum water level envelope for Storm 108 (February 1998)

indicating high water levels along northwestern shoreline of Lake St. Clair.. 125

Figure 6-18. Time series of water levels for Storm 086 (December 1990) at St. Clair Shores.......... 127

Figure 6-19. Time series of water levels for Storm 086 (December 1990) at Windmill Point............ 127

Figure 6-20. ADCIRC maximum water level envelope for Storm 031 (December 1972)

indicating high water levels along northern and eastern shorelines of Lake St. Clair.

Figure 6-21. Time series of water levels for Storm 031 (December 1972) at St. Clair Shores........... 128

Figure 6-22. Time series of water levels for Storm 031 (December 1972) at Windmill Point.

Figure 6-23. ADCIRC maximum water level envelope for Storm 054 (April 1979) indicating high water levels along eastern shoreline of Lake St. Clair. 129

Figure 6-24. Time series of water levels for Storm 054 (April 1979) at St. Clair Shores.................130

Figure 6-25. Time series of water levels for Storm 054 (April 1979) at Windmill Point. 131

Figure 6-26. ADCIRC maximum water level envelope for Storm 105 (October 1997) indicating high water levels along southern and southeastern shorelines of Lake St. Clair...........131

Figure 6-27. Time series of water levels for Storm105 (October 1997) at St. Clair Shores. ...........132

Figure 6-28. Time series of water levels for Storm105 (October 1997) at Windmill Point. ............132

Figure 6-29. Water level bias at Station 9034052 (St. Clair Shores). ...........................................134

Figure 6-30. Water level bias at Station 9044049 (Windmill Point)..............................................134

Figure 6-31. Water level RMSE at Station 9034052 (St. Clair Shores). ........................................135

Figure 6-32. Water level RMSE at Station 9044049 (Windmill Point). .136

Figure 6-33. Scatter of maximum ADCIRC water levels within 24-hrs (+/-12-hrs) of the peak of the event at Station 9034052 (St. Clair Shores).

Figure 6-34. Bias calculated from the maximum ADCIRC water level within 24-hrs (+/- 12hrs) of the peak of the event and the measured peak of the event at Station 9034052. 
Figure 6-35. Scatter of maximum ADCIRC water levels within 24-hrs (+/- 12-hrs) of the peak of the event at Station 9044049 (Windmill Point).

Figure 6-36. Bias calculated from the maximum ADCIRC water level within 24-hrs (+/- 12hrs) of the peak of the event and the measured peak of the event at Station 9044049 (Windmill Point). 138

Figure 6-37. Maximum wave heights for all post-1970 modeled storm events for NW grid...........140

Figure 6-38. Maximum wave heights for all post-1970 modeled storm events for MW grid..........140

Figure 6-39. Maximum wave heights for all post-1970 modeled storm events for SW grid........... 141

Figure 6-40. Maximum wave heights for all post-1970 modeled storm events for NE grid. ........... 141

Figure 6-41. Time step of maximum wave heights for Storm 059 in SW grid. Contours indicate wave height and vectors indicate wave direction. Note the boundary spectra are traveling parallel to the domain.

Figure 6-42. Maximum wave height field for Storm 080 for NW grid. ............................................142

Figure 6-43. Maximum wave height field for Storm 080 for MW grid............................................143

Figure 6-44. Maximum wave height field for Storm 080 for SW grid...............................................143

Figure 6-45. Maximum wave height field for Storm 080 for NE grid...............................................144

\section{Tables}

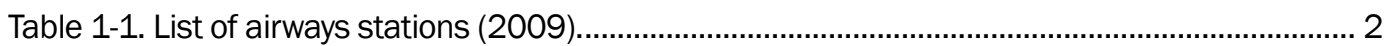

Table 1-2. List of additional meteorological stations (2009)........................................................ 5

Table 3-1. Lake St. Clair direction test runs................................................................................ 18

Table 3-2. Statistical calculations for directional growth rate tests................................................... 21

Table 3-3. List of extreme events from Canadian Buoy 45147..................................................... 24

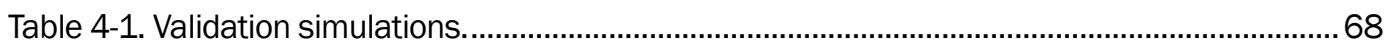

Table 5-1. Geometry of Lake St. Clair STWAVE grids. .......................................................................93

Table 5-2. Location of offshore wave spectra boundary points......................................................... 93

Table 5-3. STWAVE full-plane and parallel in space execution parameters. .....................................98

Table 5-4. Timing between ADCIRC and STWAVE in terms of ADCIRC time steps............................99

Table 6-1. Extreme storm event list. .......................................................................................... 102 


\section{Preface}

The study summarized in this report was conducted at the request of the Detroit District (LRE), USACE. Greg Mausolf was the primary engineering point of contact, and Mary Weidel was the primary project management point of contact at LRE. The study was funded by the Federal Emergency Management Agency (FEMA) through LRE and conducted at the Engineering Research and Development Center (ERDC), Coastal and Hydraulics Laboratory (CHL), Vicksburg, MS, during the period November 2009 September 2010. The FEMA Lead was Ken Hinterlong, Chief, Risk Analysis Branch, Mitigation Division, FEMA Region V. Julie Tochor, Accenture, was the Program Management Lead for FEMA Region V.

The work performed at CHL was under the general supervision of Dr. Ty V. Wamsley, Chief, Coastal Processes Branch and Bruce A. Ebersole, Chief, Coastal Flood and Storm Protection Division. The Director of the Coastal and Hydraulics Laboratory was Dr. William D. Martin.

COL Kevin J. Wilson was Commander of ERDC. Dr. Jeffery P. Holland was Director. 


\section{Unit Conversion Factors}

A sponsor requirement for this study was the use of English Customary units of measurement. Most measurements and calculations were done in SI units and then converted to English Customary. The following table can be used to convert back to SI units.

\begin{tabular}{|l|l|l|}
\hline Multiply & By & To Obtain \\
\hline Feet & 0.3048 & meters \\
\hline cubic feet & 0.02831685 & cubic meters \\
\hline pounds (force) & 4.448222 & newtons \\
\hline square feet & 0.09290304 & square meters \\
\hline
\end{tabular}




\section{Wind and Pressure Field Generation}

\subsection{Introduction}

The development of wind and pressure fields for use in calculations of waves and surge events in Lake St. Clair will follow similar steps to those described in Jensen et al. (2012). It is important to capture the meteorological fields accurately because of the influence of winds and pressure on the lake surge and wave growth. Lake St. Clair is a smaller spatial region than Lake Michigan, so there were slight changes made to the wind generation technique that will be described in this chapter.

The Natural Neighbor Method (NNM) (Schwab 1978; Schwab et al. 1984; Schwab and Beletsky 1998) and National Center for Environmental Prediction (NCEP) Climate Forecast System Reanalysis (CFSR) (Saha et al. 2010) were used in the evaluation tests for Lake St. Clair. The NNM was used for production in all storms before 1979, and CFSR wind fields were used for 1979 to 2009 storms.

\subsection{Mining wind data bases}

The meteorological data for Lake St. Clair was mined in a similar manner to the Lake Michigan FEMA Great Lakes project (Jensen et al. 2012). The longest record of meteorological measurements is the land based Global Surface Airways Hourly records through NOAA's National Climate Data Center. A limited data set of Coastal-Marine Automated Network (CMAN) along with Environment Canada buoy data is available. The shortest record is available through NOAA's National Weather Service (NWS). The NWS, CMAN, and buoy records are valuable due to the location on or near the water surface of Lake St. Clair.

\subsubsection{The Global Integrated Surface Hourly database: ISH}

The Global Integrated Surface Hourly (ISH) data base was mined from NOAA's National Climate Data Center. Each meteorological station was identified using both the US Air Force station number (USAF) and the National Climate Data Center (NCDC) Weather Bureau Army Navy Number (WBAN). Both numerical values are used to identify a station in the hourly data base. Each station with USAF and WBAN identifiers is also associated with the latitude and longitude for the sensor. The latitude and longitude 
are used to identify stations located near Lake St. Clair. The International Civil Aviation Organization (ICAO) designator code along with the state name is provided for United States based stations which are also used to identify stations near Lake St. Clair.

The list of the ISH Airways stations used for Lake St. Clair is provided in Table 1-1. As observed in Lake Michigan, there are some stations listed multiple times. This occurred because the station location, relative elevation, or the sensor (anemometer, barometer) was changed. The station, if older than 1970, may have been referenced by WBAN number only, so a USAF number was added which would create a second listing. All access to the Global and US based Integrated Surface Hourly Data Base was done through File Transfer Protocol. All methods for obtaining data are described in the Lake Michigan report (Jensen et al. 2012).

Table 1-1. List of airways stations (2009).

\begin{tabular}{|c|c|c|c|c|c|c|}
\hline \multirow[b]{2}{*}{ USAF } & \multirow[b]{2}{*}{ WBAN } & \multirow[b]{2}{*}{ LOCATION NAME } & \multirow[b]{2}{*}{ ICAO } & \multicolumn{2}{|c|}{ GEOGRAPHICAL LOCATION } & \multirow[b]{2}{*}{$\operatorname{ELEV}(\mathrm{m})$} \\
\hline & & & & LATITUDE & LONGITUDE & \\
\hline 712980 & 99999 & HARROW CDA AUTO & & 42.033 & -82.900 & 191.0 \\
\hline 713030 & 99999 & POINT PELEE & CXPT & 41.950 & -82.517 & 177.0 \\
\hline 713070 & 99999 & RIDGETOWN RCS & CXRG & 42.450 & -81.883 & 206.0 \\
\hline 714650 & 99999 & ERIEAU & CWAJ & 42.250 & -81.900 & 178.0 \\
\hline 714673 & 99999 & MITCHELLS BAY & WDJ & 42.467 & -82.417 & 186.0 \\
\hline 715380 & 99999 & WINDSOR & CYQG & 42.267 & -82.967 & 190.0 \\
\hline 716341 & 99999 & SARNIA & YZR & 43.000 & -82.300 & 181.0 \\
\hline 716344 & 99999 & SARNIA AIRPORT & & 43.000 & -82.300 & 181.0 \\
\hline 716363 & 99999 & BELLE RIVER & & 42.300 & -82.700 & 184.0 \\
\hline 717040 & 99999 & SARNIA & CYZR & 43.000 & -82.317 & 181.0 \\
\hline 717460 & 99999 & SARNIA CLIMATE & CTZR & 43.000 & -82.300 & 181.0 \\
\hline 718427 & 99999 & HARROW ON & CXHA & 42.033 & -82.900 & 191.0 \\
\hline 720113 & 99999 & OAKLAND TROY & KVLL & 42.550 & -83.183 & 222.0 \\
\hline 725370 & 94847 & DETROIT/METROPOL & KDTW & 42.215 & -83.349 & 202.4 \\
\hline 725373 & 54819 & GROSSE ISLE ARPT & KONZ & 42.099 & -83.161 & 176.0 \\
\hline 725373 & 99999 & GROSSE ISLE ARPT & KONZ & 42.100 & -83.150 & 176.0 \\
\hline 725375 & 14822 & DETROIT CITY & KDET & 42.409 & -83.010 & 190.8 \\
\hline 725376 & 14853 & WILLOW RUN & KYIP & 42.237 & -83.230 & 218.2 \\
\hline 725376 & 99999 & WILLOW RUN & KYIP & 42.233 & -83.517 & 218.0 \\
\hline
\end{tabular}




\begin{tabular}{|l|l|l|l|l|l|l|}
\hline USAF & WBAN & LOCATION NAME & ICAO & \multicolumn{2}{|c|}{ GEOGRAPHICAL LOCATION } & ELEV $(\mathrm{m})$ \\
\hline 725377 & 14804 & SELFRIDGE ANGB & KMTC & 42.613 & -82.832 & 176.8 \\
\hline 725377 & 99999 & SELFRIDGE ANGB & KMTC & 42.600 & -82.833 & 177.0 \\
\hline 725380 & 99999 & WINDSOR AIRPORT & & 42.267 & -82.967 & 190.0 \\
\hline 725384 & 4888 & ST.CLAIR COUNTY & KPHN & 42.911 & -82.518 & 198.1 \\
\hline 725384 & 99999 & ST.CLAIR COUNTY & KPHN & 42.917 & -82.533 & 198.0 \\
\hline 725418 & 54823 & MONROE & KTTF & 41.940 & -83.435 & 188.0 \\
\hline 725418 & 99999 & MONROE & KTTF & 41.933 & -83.433 & 188.0 \\
\hline 726320 & 99999 & WHITE LAKE & & 42.683 & -83.467 & 321.0 \\
\hline 726341 & 99999 & SARNIA & & 43.000 & -82.300 & 181.0 \\
\hline 726375 & 94817 & OAKLAND CO INTL & KPTK & 42.665 & -83.418 & 298.7 \\
\hline 726375 & 99999 & OAKLAND CO INTL & KPTK & 42.667 & -83.417 & 299.0 \\
\hline 998339 & 99999 & MOUTH OF BLACK R & MBRM & 42.975 & -82.419 & 180.0 \\
\hline 999999 & 14822 & DETROIT CITY AIR & KDET & 42.409 & -83.010 & 190.8 \\
\hline 999999 & 14856 & GROSSE ILE NAS & NFB & 42.100 & -83.167 & 180.1 \\
\hline 999999 & 94847 & DETROIT METRO AP & KDTW & 42.215 & -83.349 & 202.4 \\
\hline
\end{tabular}

All ISH data was processed and checked for proper format and consistency. It was assumed all meteorological data had been quality controlled for accuracy. All time series for individual station information applied to the Natural Neighbor Method were visually inspected prior to the generation of the wind and pressure fields. The ISH data was converted into a standard file format for all 50-years (1960 through 2009) of evaluation period.

The number of active meteorological stations varied from year to year and is presented in Figure 1-1. The number of stations shows a decreasing trend from the present to 1960. The first decrease occurred during 2003-2004 from thirteen to fifteen stations down to nine to ten stations. During the mid 1970 s to 1980 there was a drop off of five stations which in Lake St. Clair is sufficient data coverage. For time periods older than 1970, there were only two or three stations available which could potentially limit the accuracy of the wind or pressure fields. However, considering the relative size of Lake St. Clair to the iso-bars (or iso-tacs), the suggestion of spatial uniformity in an extreme storm event would be sufficient to drive the hydrodynamic models. 


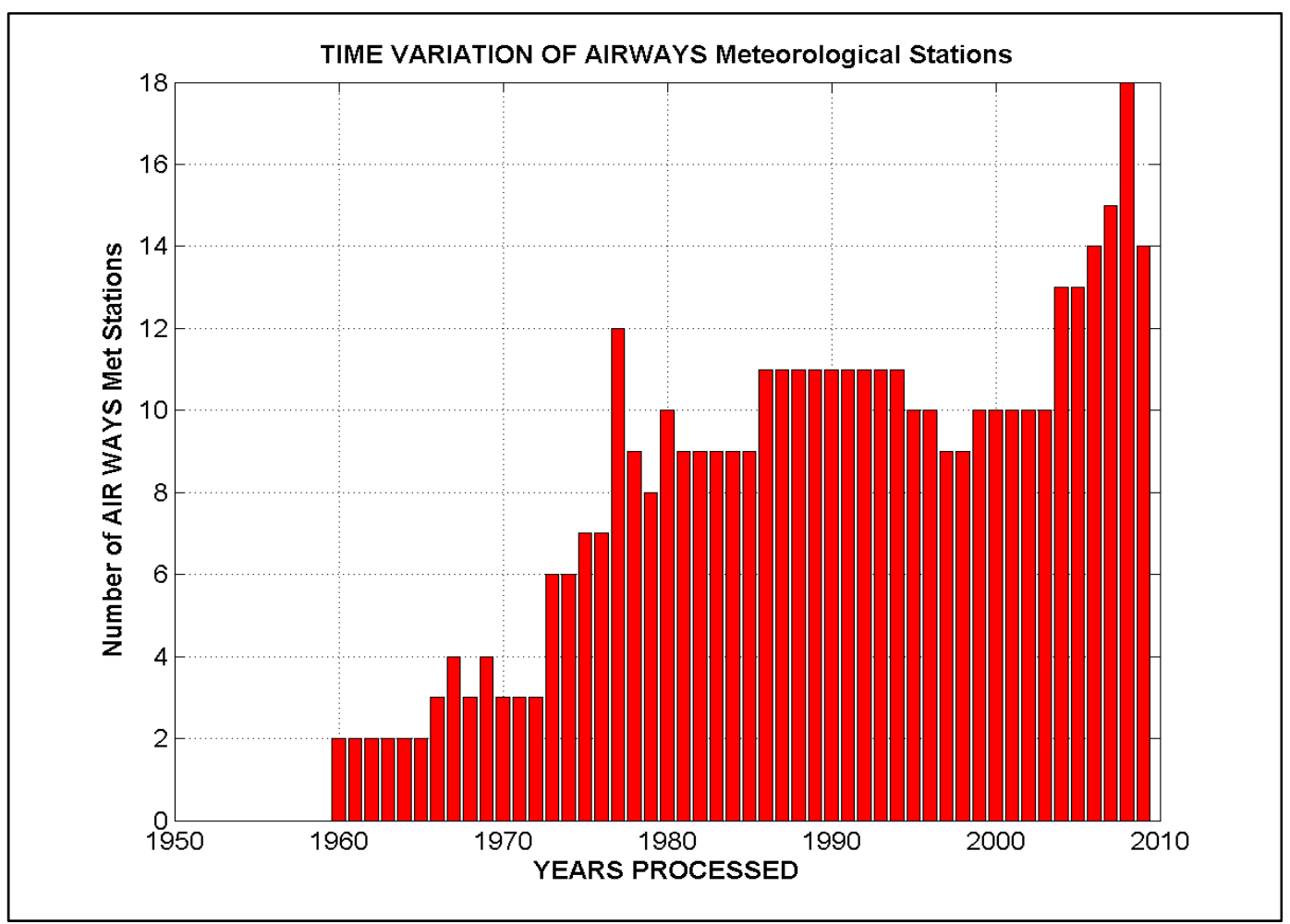

Figure 1-1. Time variation of active airways stations found in the NCDC ISH data archive.

\subsubsection{Additional meteorological stations (NDBC/NOS/NWS/GLERL)}

Data mining for Lake St. Clair meteorological stations found three nonISH stations. These stations were discovered using NOAA's National Data Buoy Center (NDBC, http://www.ndbc.noaa.gov) listing all NDBC, Environment Canada buoys, National Weather Service (NWS), and CMAN stations. The CMAN and NWS measurements were obtained directly from NDBC; the Environment Canada data sets were from the Environment Canada Fisheries and Oceans Canada website (https://www. meds-sdmm.dfo-mpo.gc.ca/isdmgdsi/waves-vagues/index-eng.htm).

The NWS and CMAN stations are located on fixed platforms and operational year-round. The single wave measurement buoy located in Lake St. Clair is routinely recovered every winter to prevent damage due to icing. General operations provide wave data from mid-March to mid-December. Station identification and all information are presented in Table 1-2.

After downloading, the additional meteorological station (three sites) data were converted to the standardized ISH format. All data sets were reviewed for missing data and/or questionable data values. Final quality control (visual inspection of the time series) occurred prior to generation of wind and pressure fields for each individual simulated storm event. 
Table 1-2. List of additional meteorological stations (2009).

\begin{tabular}{|l|l|l|l|l|l|l|l|}
\hline \multirow{2}{*}{ Station } & \multirow{2}{*}{ Operated } & \multicolumn{2}{|c|}{ Location } & \multicolumn{2}{c|}{ Elevations $(\mathrm{m})$} & \multicolumn{2}{c|}{ Time Period } \\
\cline { 3 - 8 } & Longitude & Latitude & Station & Anemometer & Start & End \\
\hline CLSM4 & NWS & 42.470 & -82.880 & 175.0 & 10 & 2007 & Present \\
\hline LSCM4 & CMAN & 42.465 & -82.755 & 178.5 & 6 & 2001 & Present \\
\hline 45147 & EC & 42.430 & -82.680 & 174.6 & 3.3 & 2000 & Present \\
\hline
\end{tabular}

\subsubsection{Data mining summary}

The final outcomes of the data mining were: 1) all point source measurements were obtained; 2) the meta-data (location, and anemometer elevation) were compiled; and 3) all stations were formatted to one unique form and archived locally on a yearly basis. These were vital steps in the procedure, as was assuring that all data sets are properly checked for consistency and quality.

\subsection{Natural Neighbor Method (NNM): wind and pressure fields}

The NNM method for wind and pressure field generation is a construct applying land-based point source meteorological measurements, converting over-land to over-water wind speeds, and adjusting for anemometer elevations. The resulting wind speed estimates are equivalent neutral stable $10-\mathrm{m}$, marine exposure condition. There is also a rotation in the wind direction. Sea level pressure does not change from land to a location over water. The Natural Neighbor Method takes the randomly spaced point source conditions and interpolates to a fixed (in this case the wave model grid, spherical coordinate system) grid of known resolution. The method has been described in detail in Jensen et al. (2012) along with step by step instructions in FEMA Great Lakes Tech Transfer documents ${ }^{1}$ (Vicksburg 2011). The same method described in the report was used for Lake St. Clair; the only changes were in the stations used and the target wave model grid.

As previously noted, the number of active stations varies from year to year, and thus for each extreme storm event simulated. An example of the point source meteorological stations used for the Lake St. Clair simulation is provided in Figure 1-2. Generally, the point source wind speeds were archived on an hourly interval. It was determined that these data were at times noisy and required temporal smoothing. Prior to the generation of the

1 Technology Transfer Meeting, Vicksburg, MS (2011) 


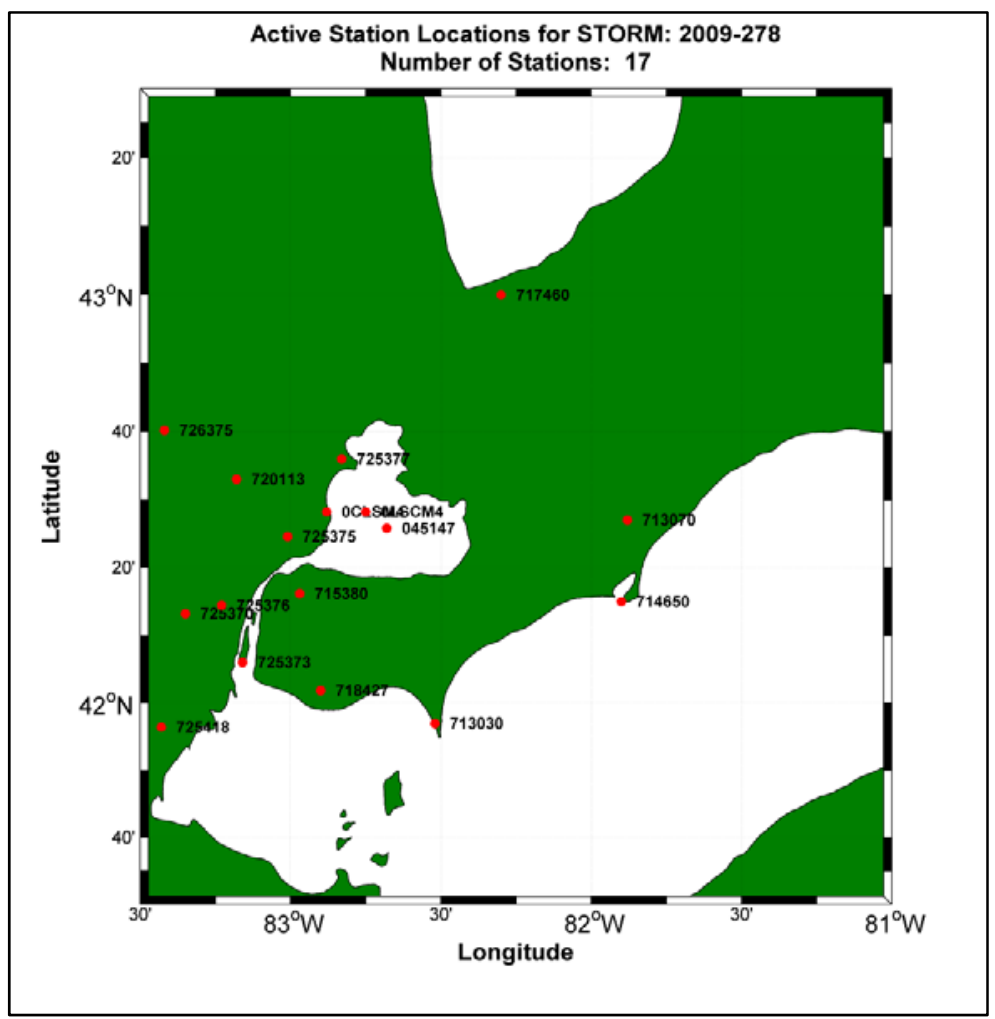

Figure 1-2. Available meteorological station locations accessed and preprocessed for Storm 2009-278.

wind fields, the wind records adopted a three hour box-car filter. As previously mentioned, during the NNM procedure the wind speeds are adjusted to a common anemometer elevation and translated from over-land to over-water conditions. In general, these modifications are multiplicative and result in an increase in magnitude. An example of the evaluation of these adjustments is presented in Figure 1-3. There is a small net increase in speed, and the wind direction is rotated slightly in a clockwise direction. The sea level pressure is not adjusted. The iso-tac color contours for the wind speeds at the peak of the October 2009 extreme storm are shown in Figure 1-4. The contours illustrate clearly the spatial variation in the wind speeds over the Lake St. Clair domain. There is approximately 6-m/sec gradient in the wind speeds from conditions near the center of the lake to the northern shoreline. One would presume because of its structure this snapshot is part of a storm system (cyclogenesis) moving from west to east. This was verified form the NOAA Surface Weather and Station plots (e.g. http://www.hpc.ncep.noaa.gov/dailywxmap/dwm_stnplot_20091006.html). 


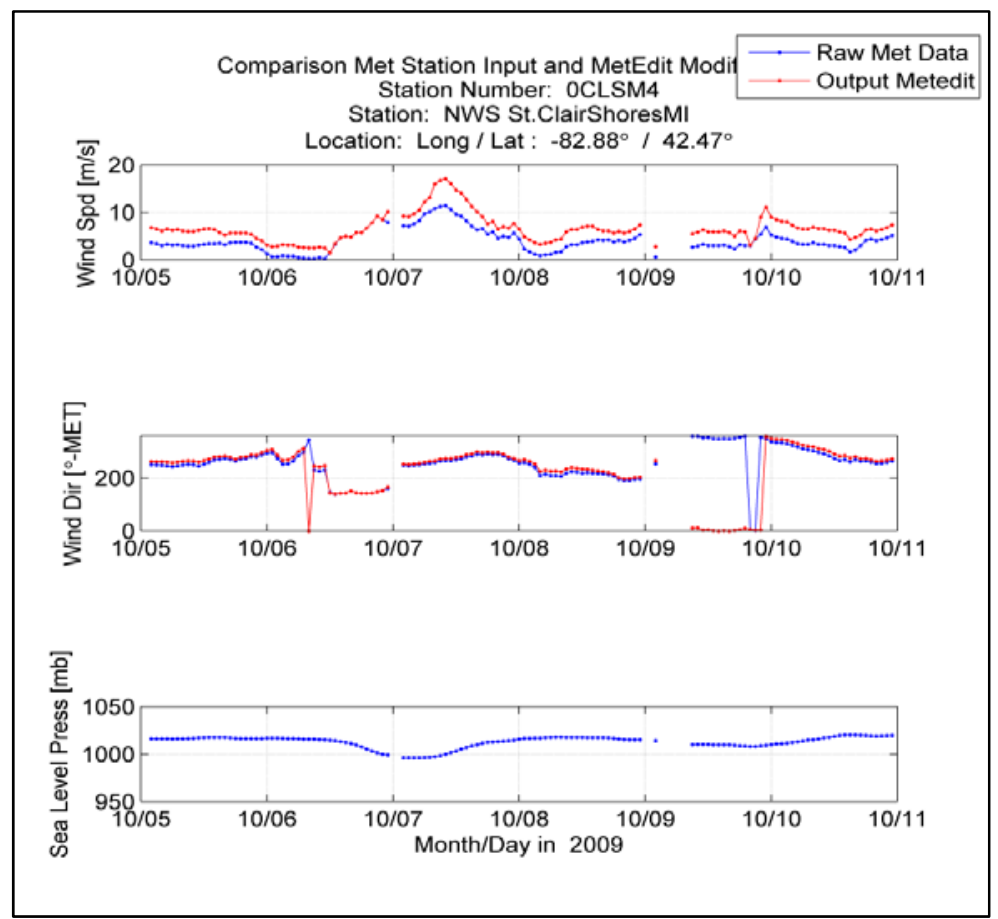

Figure 1-3. Comparison of input wind speed, direction and temporally smoothed (1:1:1) for Storm 2009-278 at NWS Station St. Clair Shores, MI.

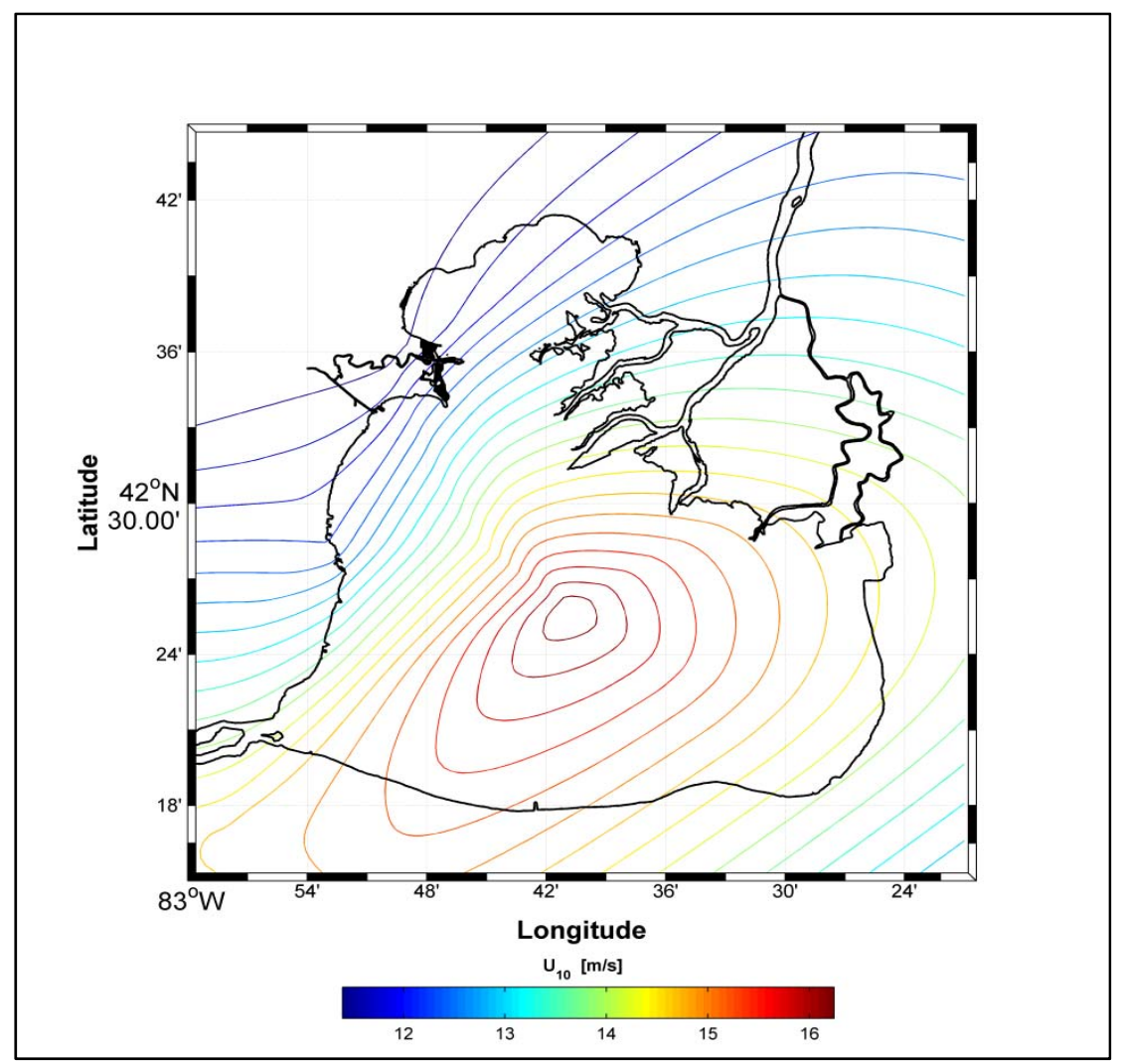

Figure 1-4. Snapshot of wind speed iso-tac color contour $(\mathrm{m} / \mathrm{sec})$ using NNM for the October 2009 validation storm. 
The NNM method is dependent on the number of point source meteorological stations. As the number of stations decrease the spatial variation in the wind (or pressure) fields will diminish. There are many detailed steps required for generation of the NNM wind and pressure fields, so multiple checks have been incorporated into the process. The generation process is dependent on the number of meteorological stations in the vicinity of Lake St. Clair during each storm. This requirement creates variations in the details of each wind and pressure field, but all validation tests showed reasonable results for all time periods in this study.

\subsection{NCEP Climate Forecast System Reanalysis (CFSR): wind and pressure fields}

Recently, the CFSR 31-year data set (Saha et al. 2010) was released to the public. There were many different sets of meteorological parameter fields available, three of which (wind speed, direction, and sea-level pressure) became useful in the Lake Michigan FEMA study and are used for Lake St. Clair. The field files were defined with a spatial resolution of $38-\mathrm{km}$ (globally) at a temporal resolution of one-hour. The original wind and pressure fields were spatially interpolated to a fixed spherical grid at a resolution of 0.02-deg (about 2.2-km). The only consequence of this interpolation was to slightly smear the land-sea boundary. These wind and pressure fields were used extensively in Lake Michigan (Jensen et al. 2012) to drive wave and surge models. Evaluation of the resulting wave and water level estimates to buoy and gauge data revealed these fields were accurate in the depiction of fast moving synoptic, and meso-scale meteorological events as they crossed Lake Michigan.

It was observed at the onset of this study that Lake St. Clair was located in the land portion of the land-water mask for the CFSR winds. Hence, all wind estimates derived from the CFSR fields applicable for Lake St. Clair would be considered as over-land exposure winds. The consequence of this yields lower wind speeds relative to the water surface area. This is shown in Figure 1-5, where the area inside the solid blue line is considered to be marine exposure winds.

Preliminary wave model simulations demonstrated the lack of agreement between the CFSR wind estimates and that of two point source meteorological sites in Lake St. Clair. Based on information contained in Figure 1-5, an adjustment was required to better approximate wind speeds for marine exposure. The analysis focused on time-paired modeled (CFSR) and wind 


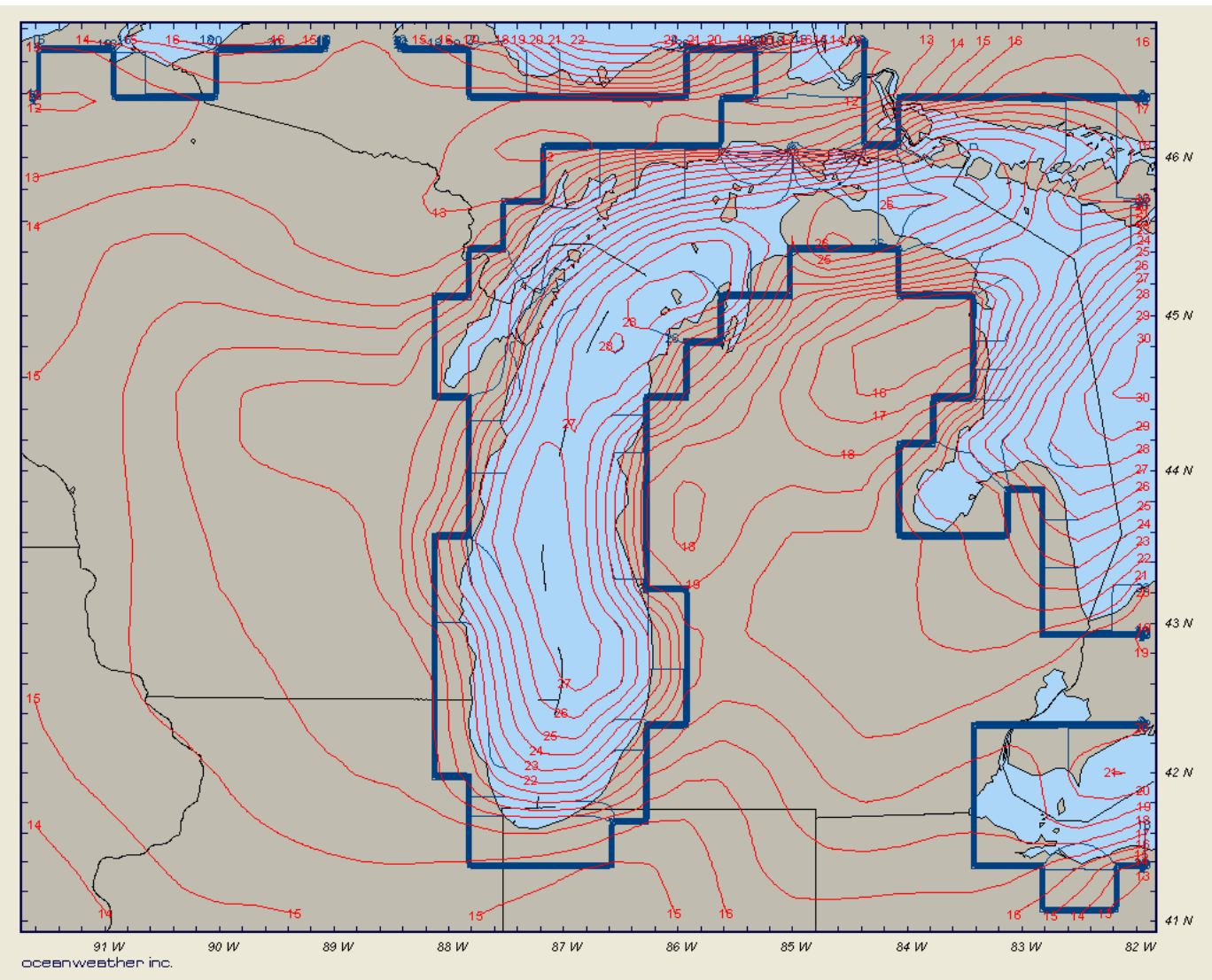

Figure 1-5. Land-water mask for CFSR wind fields. Lake St. Clair is in the land mask inside the green box.

data obtained at a NOAA/National Data Buoy Center (Coastal-Marine Automated Network, CMAN) nearly centrally located in Lake St. Clair, shown in Figure 1-6. The CMAN station is representative of over-water winds, fully exposed in all directions, with no land effects nearby. The only modification made to the wind speeds was to transform the speed to an equivalent neutral stable (air-sea temperature differences) 10-m wind, as in the case of the CFSR winds. The data set spans nearly 10-years (2001 through 2009), and, unlike the wave buoy, was fully operational during the winter months.

Rather than adjust the winds based on a simple bias derived from a mean wind, a Quartile-Quartile analysis method was used to better illustrate any differences in the overall distribution of wind speeds. 


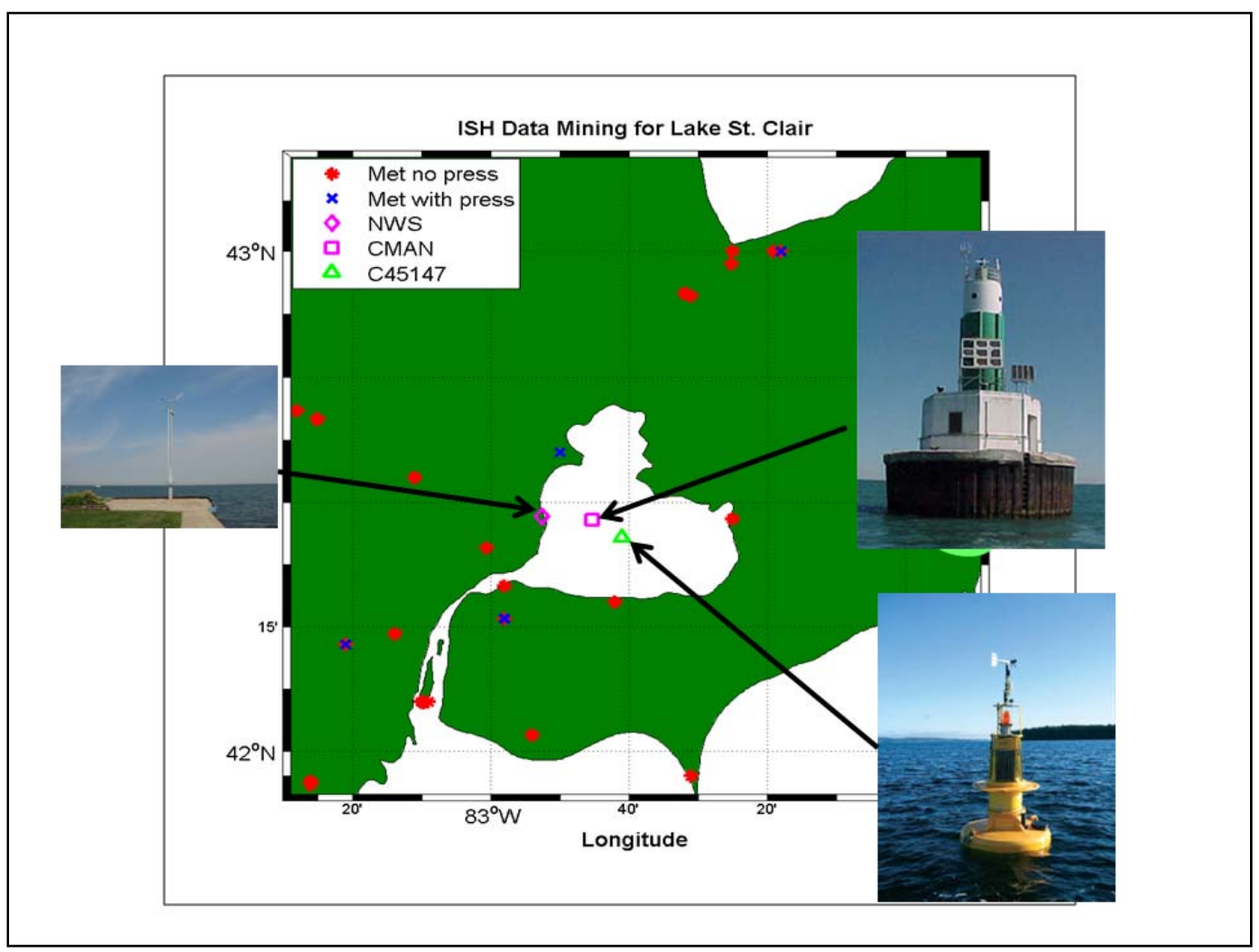

Figure 1-6. Location of meteorological stations used in the CFSR wind speed evaluation. (photographs from NOAA/NDBC).

The results for this technique are displayed in Figure 1-7, where there is a strong tendency for the CFSR to under-estimate the measurements. This negative bias $(6-\mathrm{m} / \mathrm{sec}$ at $18-\mathrm{m} / \mathrm{sec})$ also grows as the wind speed increases. In addition, there are two distinct trends in the data sets with a transition occurring at approximately $3.5-\mathrm{m} / \mathrm{sec}$. Two linear fits were generated to remove the negative biases in the CFSR wind speeds. The two formulations were used to adjust the input CFSR winds. The results are plotted (blue symbols) in Figure 1-7. The fit of the adjusted CFSR wind speed shows excellent agreement to the LSCM4 data set.

The monthly and yearly mean CFSR wind speeds in Figure 1-8 (note the CFSR wind speed is plotted on the ordinate, opposite to that found in Figure 1-7) demonstrate the change in the relationship between CFSR and LSCM4 measurements for the old CFSR and the adjusted CFSR wind speeds. There is a persistent leveling off in the adjusted CFSR wind speeds for high values during some of the monthly/yearly Quartile-Quartile plots that may require further investigation. However, the fit to the time paired adjusted CFSR and LSCM4 data is very good, and provides an increased quality in the wind fields to drive the wave and surge modeling efforts. 


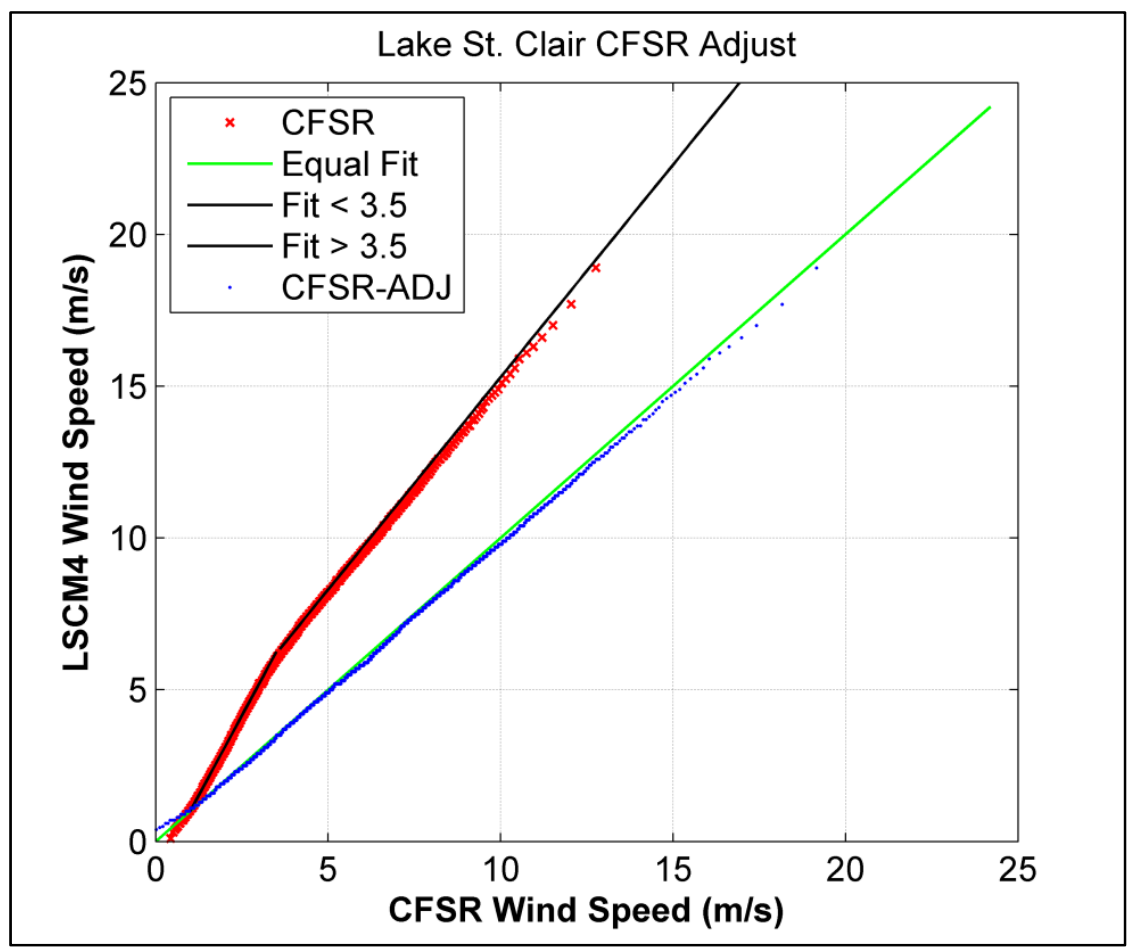

Figure 1-7. Adjustment of CFSR wind speed at station LSCM4 using two linear trend lines.

The results of the Lake Michigan Study (Jensen et al. 2012) using CFSR wind and pressure fields prompted their use in Lake St. Clair. These fields serve as the primary forcing mechanism for the hydrodynamic modeling effort. The forensics study of Lake St. Clair revealed the water body was contained in the land mask used by the CFSR method, and would likely result in low wind speeds. As a preliminary study, the CFSR wind fields were generated and compared with point source measurements to evaluate accuracy in Lake St. Clair. The wind speeds were adjusted to account for land effects, and the resulting wind speeds were much more consistent with the measured values. Based on this study, it was determined that CFSR would be used as the forcing of all extreme storm events occurring from 1979 through 2009, or the CFSR period of record. 


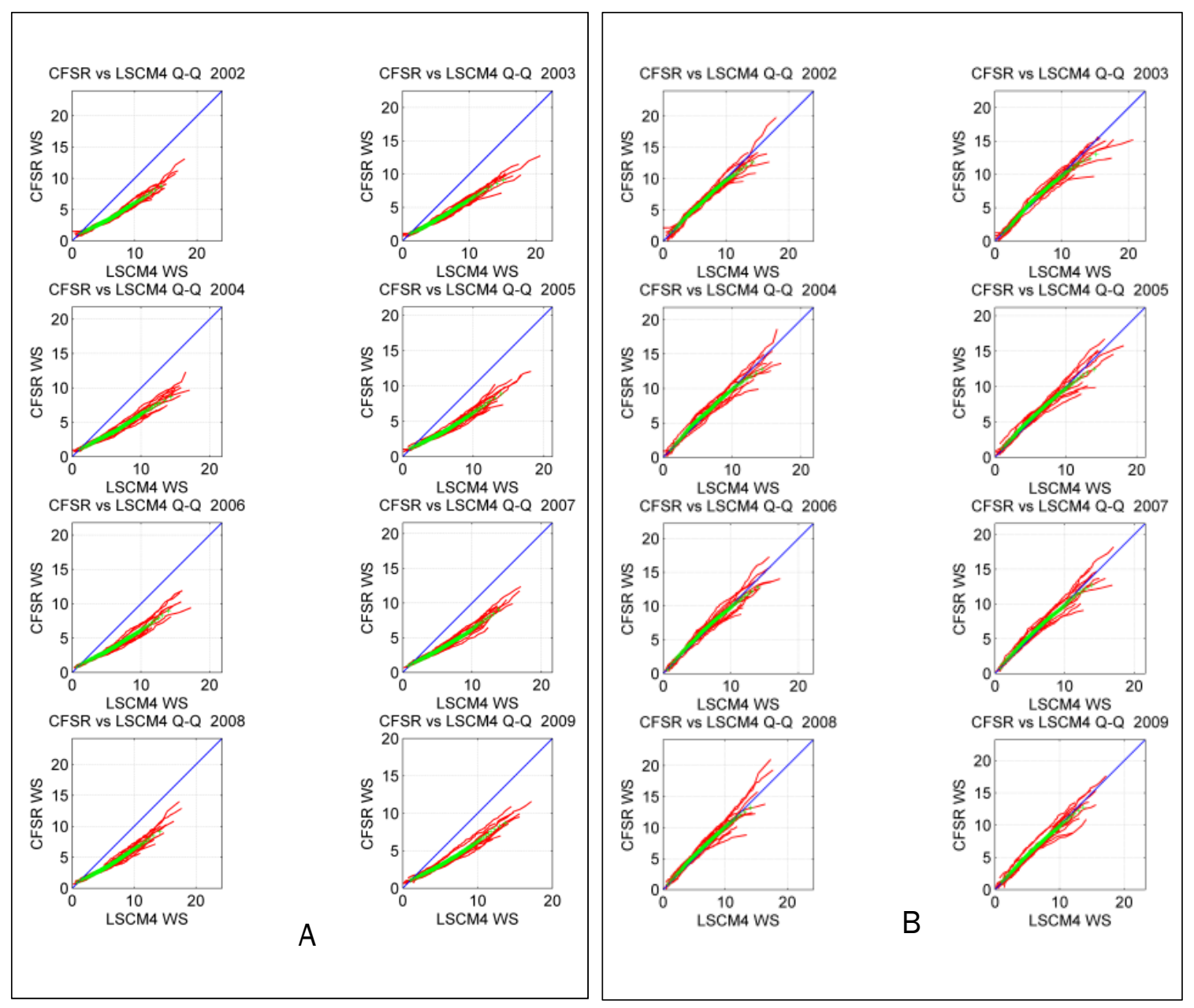

Figure 1-8. Monthly and yearly mean of CFSR wind speed. A) Original CFSR wind speeds.

B) Adjusted CFSR wind speeds. 


\section{Ice Field Generation}

All methodology for ice field generation was described in detail in Jensen et al. 2012). The technique used for generation of the ice field is detailed in the report with only minor adjustments for the Lake St. Clair data set. Lake St. Clair used three ice field archives. The most complete (1973 through 2002) is described in Assel (2003) where daily ice concentration gridded estimates are provided for the entire Great Lakes domain. This archive also includes daily graphical images for evaluation. The second data archive (2003 through 2009) was found at the NOAA/National Ice center (http://www.natice.noaa.gov/products/great_lakes.html). There were variants of grid resolutions for each year and a selection process was used so that a consistency between ice concentration archives was achieved. The final archive spanned the years of 1960 through 1979 (Assel 1983). Only the period of 1960 through 1972 was mined from these records. In addition, the archive data sets were specific to each of the five Great Lakes (Superior, Michigan, Huron, Erie, and Ontario). Lake St. Clair fell in the Lake Erie archive. This later archive (1960 through 1979) for Lake St. Clair was as problematic as in the case identified by Jensen et al. (2012). Individual ice fields were limited, and the data identifying ice concentration levels were sparse. It was determined to use the closest-in-time ice concentration field to the peak storm event date. Lastly, a threshold concentration of 70 percent was used to mask the WAM wave energy at grid locations. This method was used successfully in Lake Michigan and is deemed appropriate for Lake St. Clair.

An example of the ice concentration during a storm in Lake St. Clair is shown in Figure 2-1. What was generally observed for the development of ice fields is that Lake St. Clair is either fully ice covered or not. This occurs rather quickly, or in a matter of weeks. Thus, for storm events in the period of December to the following May, there is a likely potential of Lake St. Clair being completely covered with ice and a concentration level of 100 percent. 


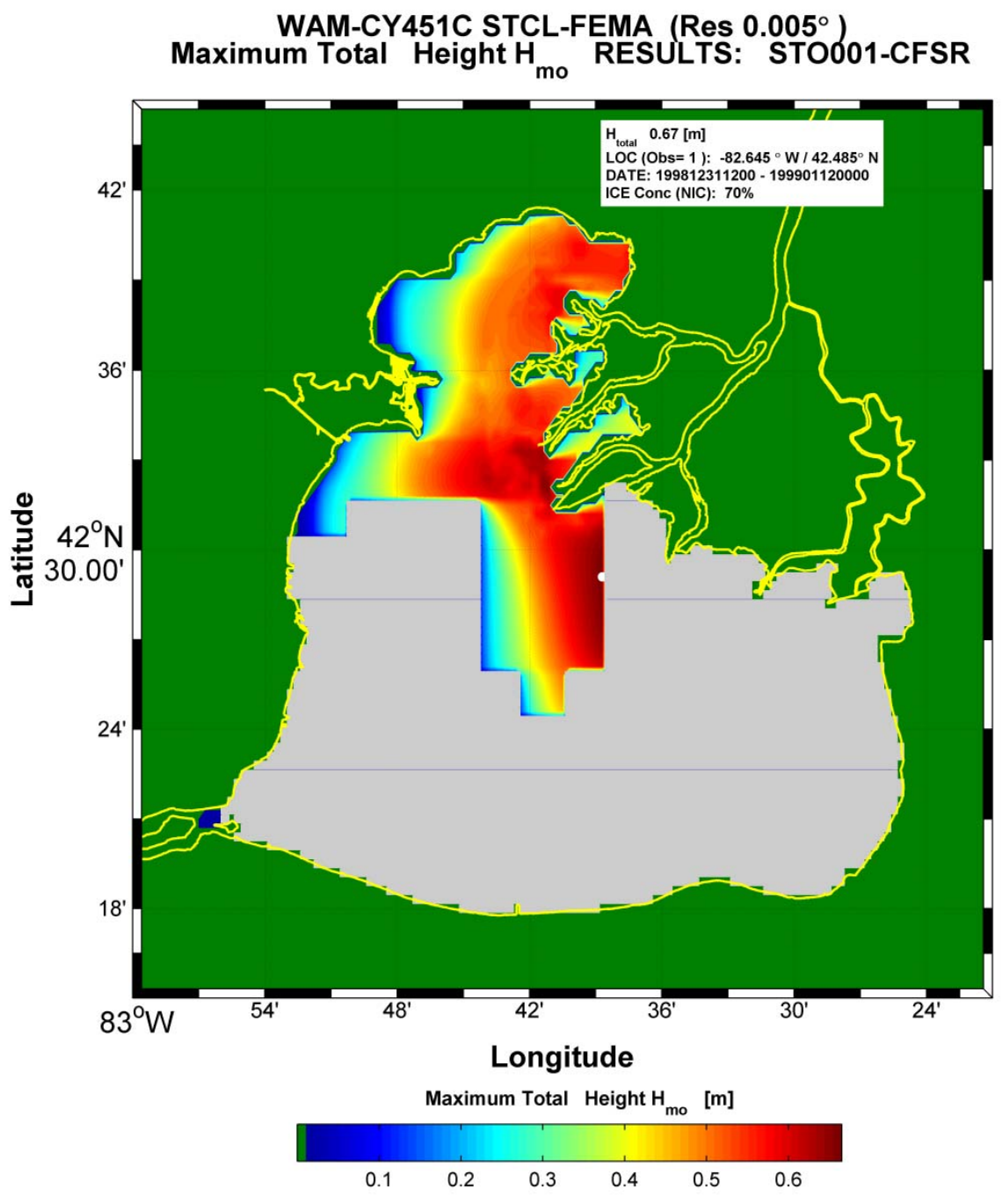

Figure 2-1. Interpolated ice field output for a water-level validation storm. Grey region identifies ice coverage. 


\section{Wave Modeling}

\subsection{Wave modeling approach}

The WAM wave model (Komen et al. 1994) was used to estimate the wind wave growth and propagation in Lake St. Clair. The $3 \mathrm{G}$ WAM model has been used on many wave studies in the past including the recent FEMA Great Lakes: Lake Michigan project (Jensen et al. 2012). Many of the procedures used in this study were described in the Lake Michigan technical report $^{1}$. The WAM model solves the action balance equation to estimate the temporal and spatial evolution of directional wave spectra. The solution is in two parts, solving for the advection of action (e.g. shoaling and refraction) and then changes in the directional wave spectra resulting from the implementation of the source functions. These mechanisms include the atmospheric input (wind forcing), the nonlinear wave-wave interaction (transfer of energy between frequencies, and downshifting), dissipation (e.g. white-capping, or high frequency wave breaking), wave-bottom (bottom friction effects), and depth induced wave breaking. In general, the winds are the forcing mechanism, and are the primary source in error for most discrete spectral wave modeling applications. One must note, the significant wave height $\left(H_{m o}\right.$, or equal to the $\left.4 *\left[\iint E(f, \theta) d f d \theta\right]^{1 / 2}\right)$ is scaled to the wind speed squared. This means if there is a 10-percent error in the wind speed, there is a chance the significant wave height could be in error of 20percent. This is primarily why so much effort is focused on using accurate wind fields in all wave model (and surge) simulations.

\subsubsection{Model domain}

Lake St. Clair is located between Lake Huron and Lake Erie in the Great Lakes region. The lake has a surface area of about 430 square miles and a maximum natural depth of 6-m (Figure 3-1). The city of Detroit is located on the southwest corner of Lake St. Clair which includes both commercial and residential properties on or near the shores of the lake. The greatest depths are located in a shipping channel with a maximum depth of 9-m. The northeastern corner consists of marsh type conditions with depths of less than 3-m. In the center of the lake, the depths allow for deepintermediate wave conditions which are dominated by growth,

\footnotetext{
1 This includes a detailed explanation of the governing equations for the WAM model.
} 


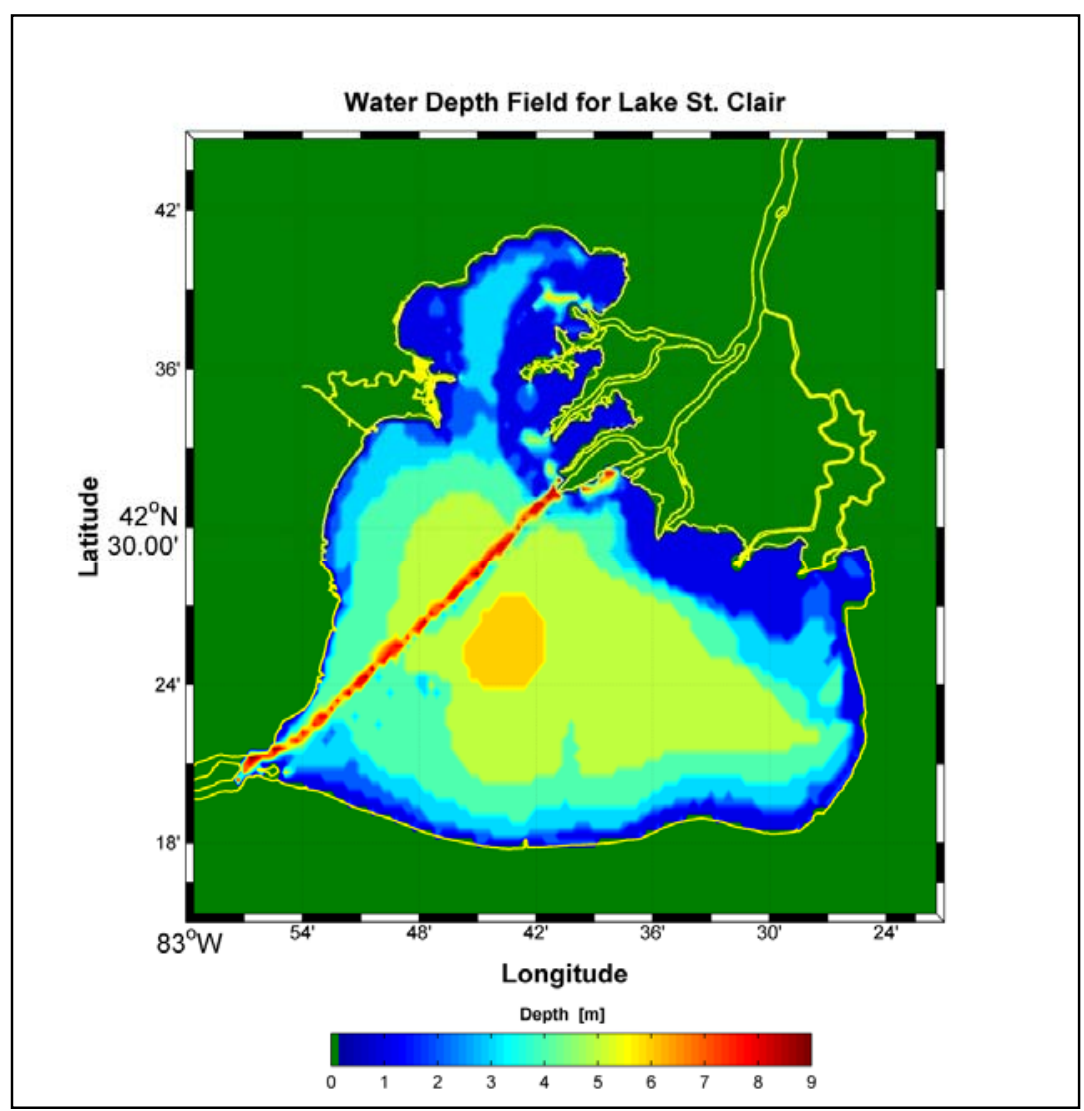

Figure 3-1. Domain and bathymetry for the Lake St. Clair WAM model.

propagation, and source/sink specifications dominating with small inputs from depth dependent processes like friction and refraction. Despite the shallowness of Lake St. Clair, wind-generated wave conditions rarely enter the mathematical representation of shallow water waves.

\subsubsection{Bathymetry and grid resolution}

The bathymetry for Lake St. Clair was derived from the NOAA/NESDIS website (http://www.ngdc.noaa.gov/mgg/greatlakes/erie.html). The gridded bathymetry was in 3-arc-second resolution (about 90-m). The coastline for the lake was interpolated from the unstructured grid used in the circulation modeling of Lake St. Clair to a fixed latitude/longitude spherical grid system used in WAM. This assures spatial consistency between the surge and modeling domains as to where the land/water interface resides. The initial model grid was set to 18 -sec or 0.005-deg. This resolution provides $131 \times 101$ grid points in the domain of Lake St. Clair which allows for high resolution modeling of the features observed in the lake. 


\subsubsection{Frequency resolution}

The frequency and directional resolution used in wave modeling of Lake St. Clair was tested during the Lake Michigan model wave model evaluation (Jensen et al. 2012). The frequency range is dependent on the type of wave growth occurring in the model domain. The wave growth and propagation in Lake St. Clair is similar to Lake Michigan with wind-wave growth dominating the energy spectrum. The frequency distribution validated in Lake Michigan has 28 frequency bands with the first and last bands equal to 0.06116 and $0.8018-\mathrm{Hz}$, respectively ${ }^{1}$. This frequency banding equates to wave periods between 1.2 and 16.5-sec which focuses on the wind-wave portion of the energy spectrum, and spans the range of wave periods that would be observed in the lake.

In Lake Michigan, directional resolutions of 5-deg and 15-deg were evaluated during academic testing of the wave model. The evaluation determined a 5-deg direction resolution resulted in better directional variability, and provided a more consistent set of results. A lower directional resolution showed a persistent trend to misestimate wave measurements in energy and frequency. The 5-deg direction resolution results in 72 directional bins in the wave model.

\subsection{Initial wind-wave growth tests: constant winds}

The initial academic testing of the WAM model in Lake St. Clair was done using constant wind simulations. This process is performed to test grid resolution, refraction, and to evaluate the propagation time step. The wind fields simulated a constant wind speed of $25-\mathrm{m} / \mathrm{sec}$ for 24 hours from the eight primary compass directions. An example of the maximum wave height at all locations given a constant wind from the Northwest shows the maximum wave height variation depending on bathymetry (Figure 3-2). It was found that the largest wave heights occurring in the simulations are always located in the center region of Lake St. Clair at the deepest region of the lake or approximately 6-m. The shipping channel does have an effect on the wave heights in the lake, but did not impact regions closer to the shoreline. In the illustrated test (Figure 3-2), the northeast region of the lake has the lowest wave heights because of the direction of the wind. However, in all tests, the northeast region of the lake has lower wave heights due to the shallow depths. The maximum wave heights modeled

\footnotetext{
1 Where $f(n+1)=1.1 \cdot f(n), n=1$, total number of frequency bands
} 
given a $25-\mathrm{m} / \mathrm{sec}$ wind from all directions was 2.46-m (Table $3-1$ ). The location and magnitude of the maximum wave height in Table 3-1 show the limited ranges in maximum wave height and the small variation in the location given the differing directional winds.

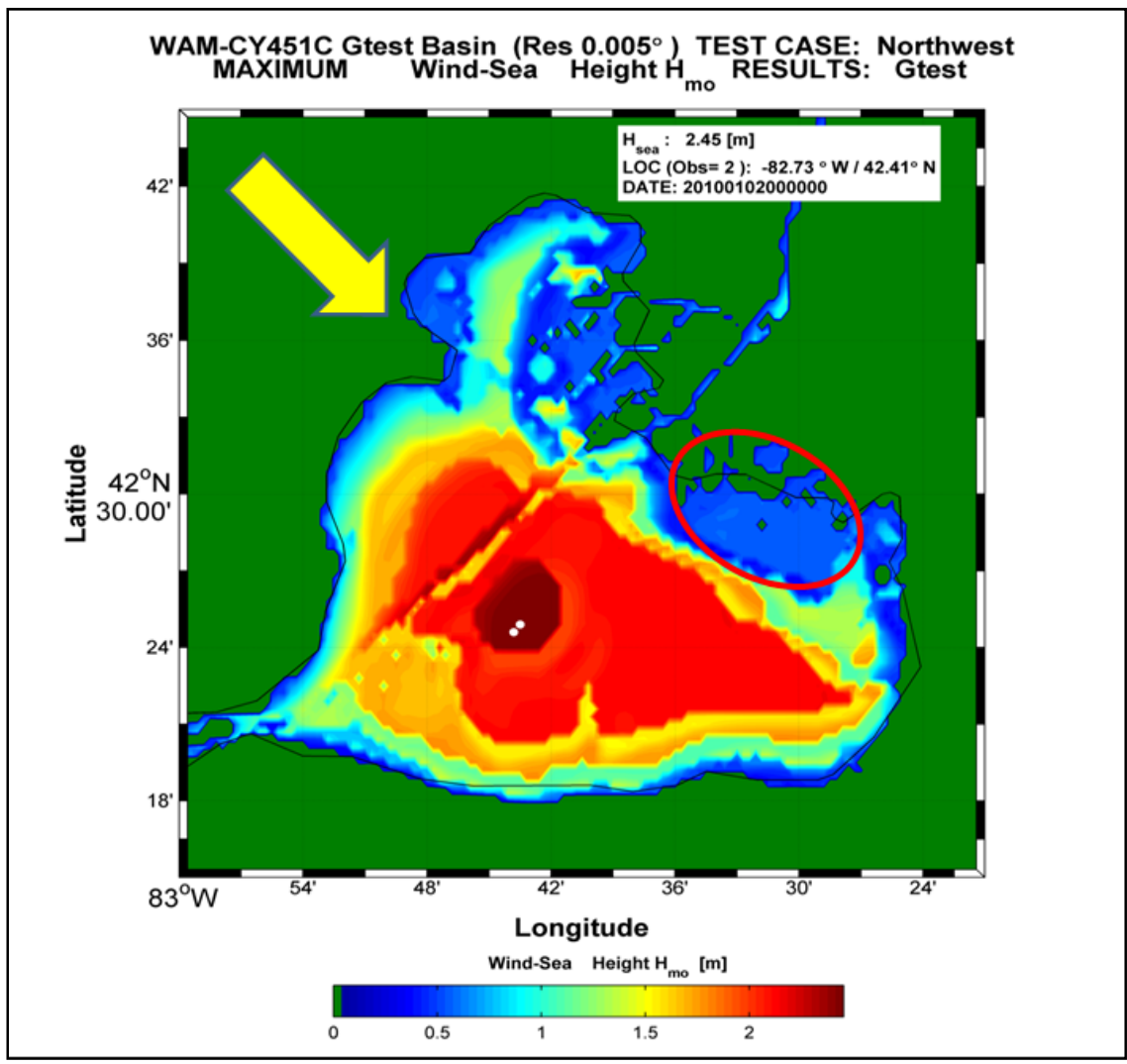

Figure 3-2. Maximum wave height envelope generated from WAM forced with constant $25-\mathrm{m} / \mathrm{sec}$ northwest wind, wind direction yellow arrow, northeast region outlined in red.

Table 3-1. Lake St. Clair direction test runs.

\begin{tabular}{|l|l|l|l|l|l|}
\hline Direction & U-wind $(\mathrm{m} / \mathrm{sec})$ & V-wind $(\mathrm{m} / \mathrm{sec})$ & Latitude & Longitude & Hs max $(\mathrm{m})$ \\
\hline North & 0.00 & -25.00 & 42.400 & -82.745 & 2.46 \\
\hline South & 0.00 & 25.00 & 42.455 & -82.730 & 2.43 \\
\hline East & -25.00 & 0.00 & 42.415 & -82.760 & 2.44 \\
\hline West & 25.00 & 0.00 & 42.415 & -82.695 & 2.42 \\
\hline Northeast & -17.67 & -17.67 & 42.405 & -82.755 & 2.42 \\
\hline Northwest & 17.67 & -17.67 & 42.415 & -82.695 & 2.45 \\
\hline Southeast & -17.67 & 17.67 & 42.455 & -82.730 & 2.43 \\
\hline Southwest & 17.67 & 17.67 & 42.450 & -82.705 & 2.44 \\
\hline
\end{tabular}


Phase II of the academic tests involves the designation of the appropriate grid resolutions to be used in the extreme storm simulation study. It becomes a matter of balancing accuracy versus computational load on the simulations. This study applies the constant wind tests and comparisons to various grid resolutions to results obtained at the coastal special output locations. These locations were numbered 1-through-163 starting in the southwest corner of the lake and proceeding in a clockwise direction (Figure 3-3). The model results were output at all locations so direct comparisons could be made between subsequent model runs at all coastal locations.

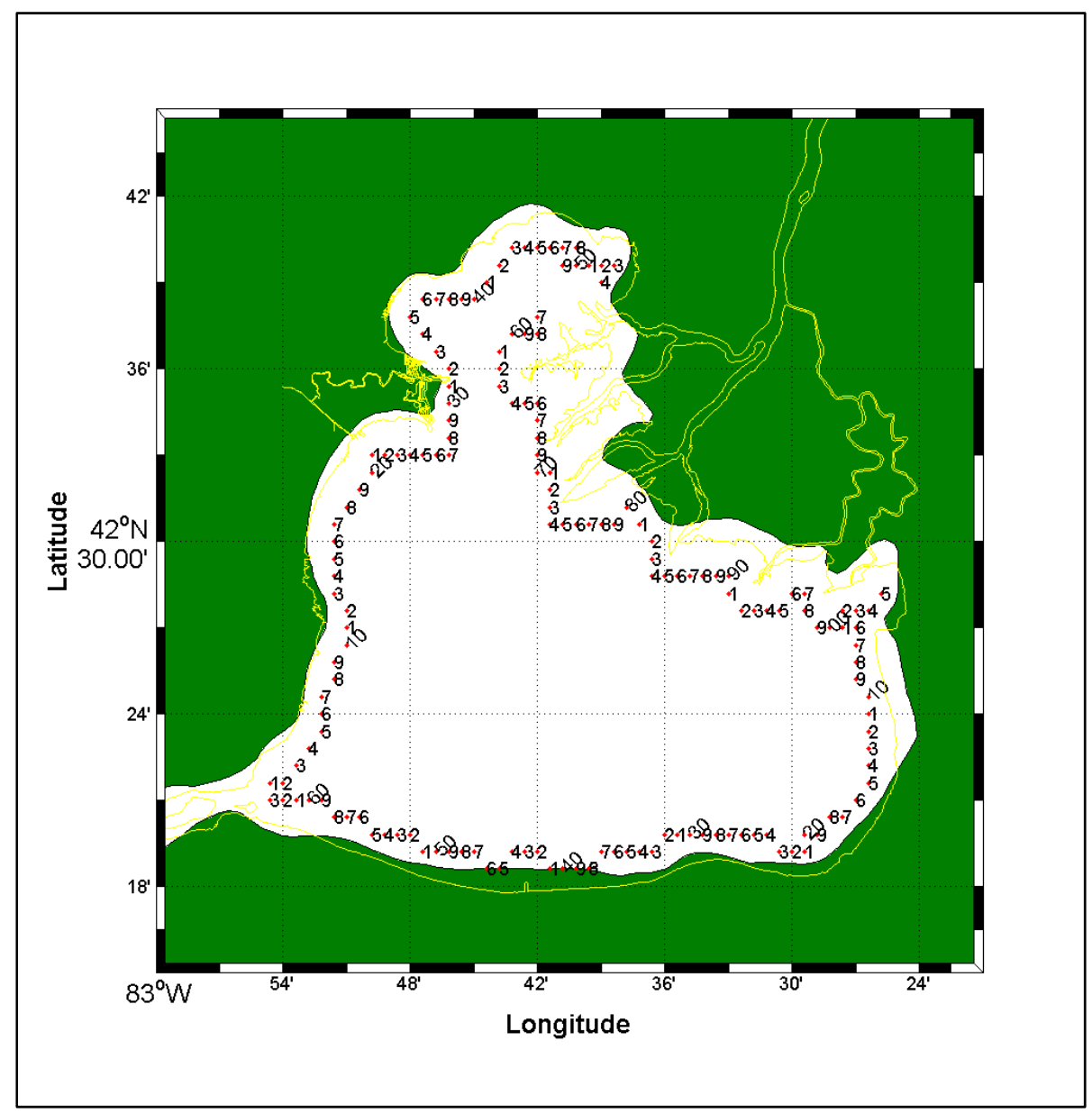

Figure 3-3. Output locations for WAM starting at 1 in the Southwest corner continuing in a clockwise direction.

Various grid resolutions were tested to determine the convergent solution. Computation load on the simulation time varies by a factor of eight just by halving the grid resolution. The initial grid resolution was made at 18 -sec or 0.005-deg. A secondary grid was created with a resolution of 36-sec or o.01-deg. The tests between the two grids were run for all eight constant 
wind directions, and the results were compared at all of the output locations. An example of the comparison for the two grid resolutions with a south wind shows the deviation in the results between stations 50 through 60 and stations 80 through 100 (Figure 3-4). These stations are located in the northeast portion of the lake where the water depths are low. Ideally, changing the grid resolution should produce a Scatter Index (SI) of less than five (5), hence the scatter indices greater than 10 imply that the 18 -sec grid adds value to the results, and would be considered as the best choice for modeling in Lake St. Clair. Note that output points 164 through 170 are located in the middle of the lake co-located to the buoy site and are not part of the focus of this study.

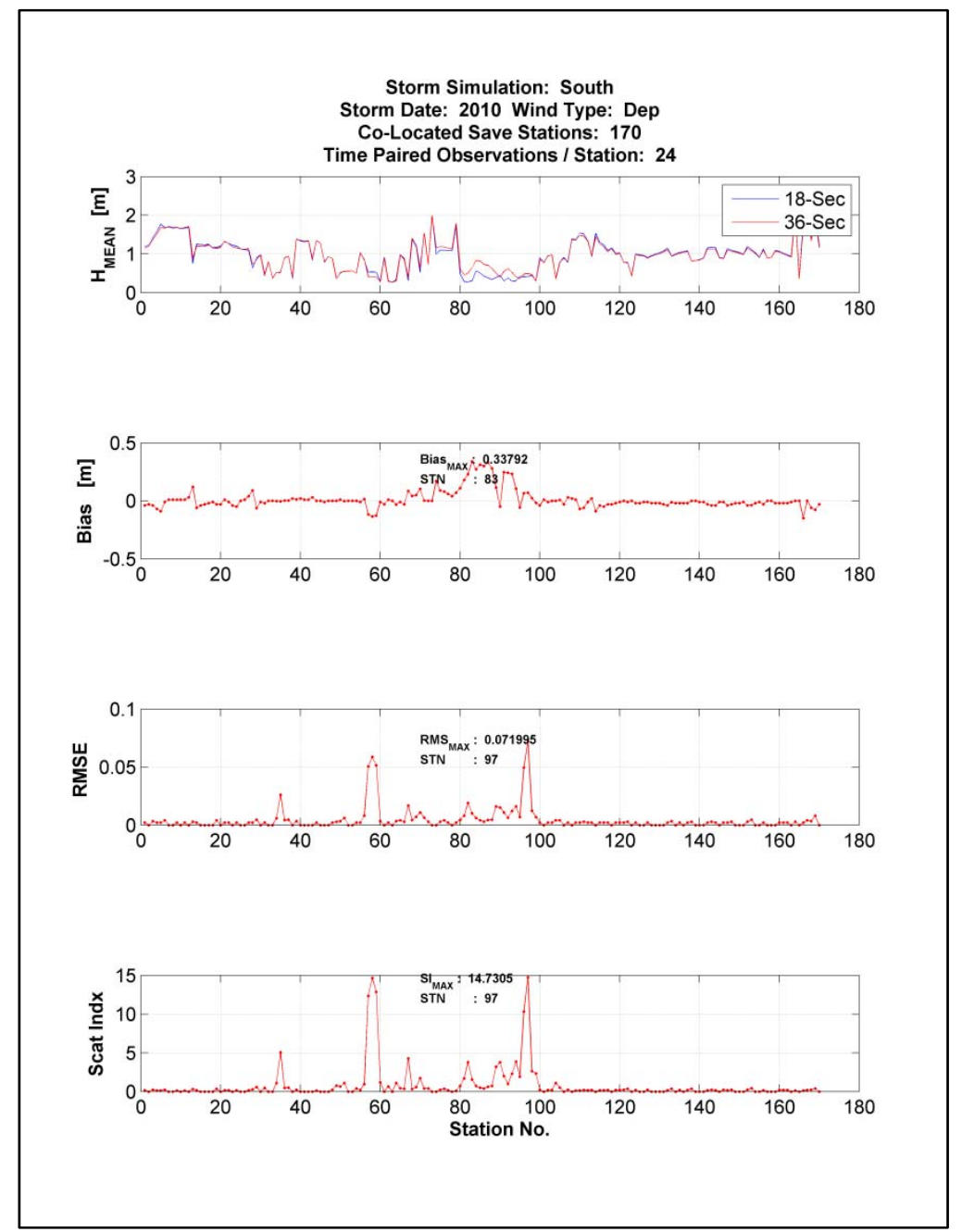

Figure 3-4. Statistical calculations at all output locations around lake for WAM forced with a constant South wind.

There was a wide range of values of the maximum SI for the different wind directions (Table 3-2). The location of the maximum differences in wave 
estimates based on the SI were always in the north to northeast region of the lake which is made up of complex coastlines and shallow depths. It is not unusual to find differences in the wave results based on resolution differences when complexities increase along a coastal reach. Lastly, the locations are generally in Canadian waters (Stations 80 through 100). Based on the results found thus far, there is substantial value added by increasing the grid resolution from 0.01-deg to 0.005-deg.

Table 3-2. Statistical calculations for directional growth rate tests.

\begin{tabular}{|l|l|l|l|l|}
\hline Wind Direction & Max Bias & Max RMSE & $\begin{array}{l}\text { Max Scatter } \\
\text { Index }\end{array}$ & $\begin{array}{l}\text { Location of } \\
\text { Scatter Index }\end{array}$ \\
\hline North & -0.170 & 0.054 & 10 & 35 \\
\hline South & 0.338 & 0.072 & 15 & 97 \\
\hline East & -0.180 & 0.012 & 4 & 84 \\
\hline West & 0.349 & 0.035 & 7 & 97 \\
\hline Northeast & -0.180 & 0.014 & 1 & 58 \\
\hline Northwest & 0.197 & 0.080 & 19 & 88 \\
\hline Southeast & 0.199 & 0.018 & 5 & 88 \\
\hline Southwest & 0.294 & 0.0465 & 10 & 53 \\
\hline
\end{tabular}

\subsection{Point-source wave measurements for model evaluation}

Evaluation of WAM in Lake St. Clair was performed using a single buoy and one short term experiment with multiple point source measurements. Environment Canada buoy 45147 is located in Canadian water near the center of Lake St. Clair (Figure 3-5). The buoy has existed at this location from 2000 to the present, and during the months of late March to early December. The buoy is recovered every winter to prevent damage from ice. Buoy 45147 is a non-directional 1.5-m-Watchkeeper ${ }^{\mathrm{TM}}$ with a $3.3-\mathrm{m}$ anemometer height. The buoy data was mined from the Environment Canada/ Fisheries and Oceans Canada website (http://www.meds-sdmm.dfo-mpo.gc.ca/isdmgdsi/waves-vagues/index-eng.htm). The data is archived in two forms; a spectral output file with the one-dimensional energy density at all frequency bands (*.fb), and a CSV format with integral wave parameters. All the definitions for each file are available off a link from the website listed above.

Initial evaluation of the measured wave heights from buoy 45147 resulted in erroneous data. Significant wave heights were larger than expected; the peak spectral wave period appeared to be longer than what could exist in this small, shallow-water body. 


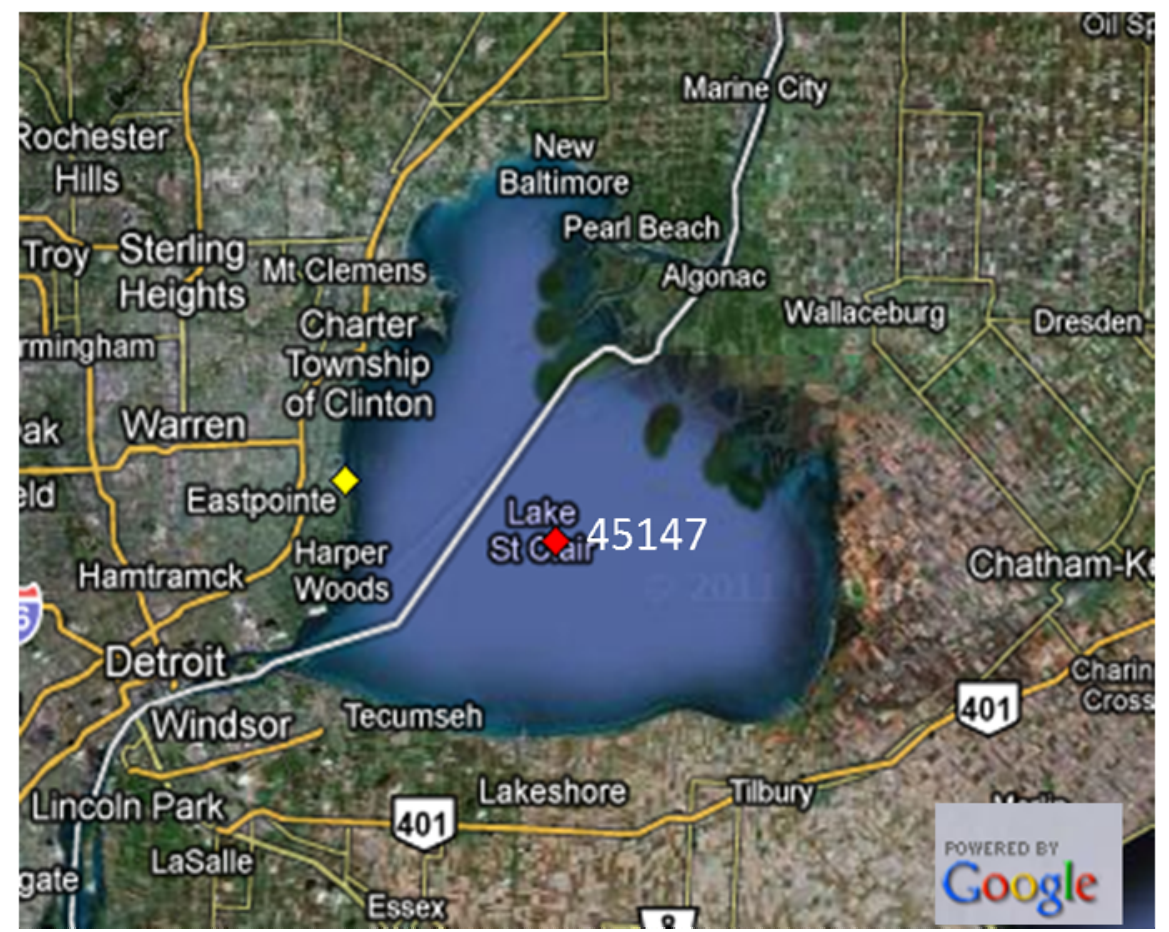

Figure 3-5. Location of Canadian Buoy 45147 in Lake St. Clair.

Further investigations revealed the energy density in the low frequencies had abnormally high values. Integrating the archived energy spectra corroborated the initial thought of contaminated wave estimates yielding very large wave heights. It was concluded that the buoy was measuring low frequency "noise" and then amplifying this signal, to account for the realwave response. A filter was developed and tested at different frequency levels to remove the low frequency noise. A value of $0.2-\mathrm{Hz}$ was determined so that all energy lower than this threshold was zeroed and yielded more realistic significant wave height estimates. The outcome of this analysis is presented in Figure 3-6. A mean wave height was computed for each year using the full unfiltered spectrum. Three obvious results are identified. Prior to 2007, there was a propensity for the Canadian buoy data to carry an appreciable amount of energy in the low frequency range of the spectrum. Second, from 2007 to the present this energy derived from the low frequency noise was removed prior to placing the data in the archive. Third, the records from 2005 obviously appear to be outliers from the other years of data collection. The year 2005 looked promising as a highly active year for storms, but in the midst of further discussion with Environment Canada it was determined the buoy was malfunctioning for much of the year. All data in 2005 was removed from consideration. 


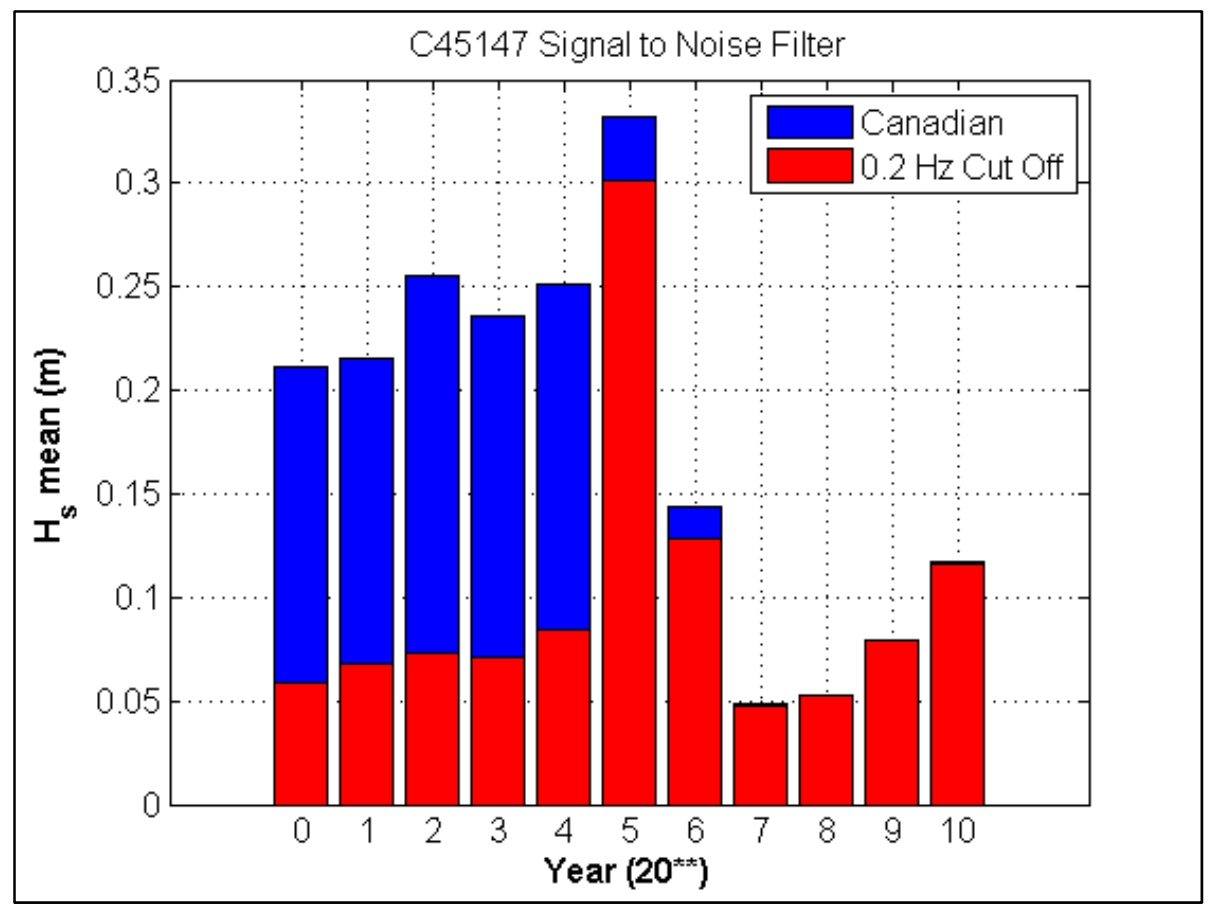

Figure 3-6. Mean zeroth moment wave height for each year at Canadian buoy 45147 without cutoff (blue) and with cutoff (red).

\subsection{Storm event selection and simulations}

An extreme wave event analysis was performed on the complete data record from buoy 45147 to determine the largest events in the buoy deployment history for Lake St. Clair. The top twenty wave height events measured at buoy 45147 are summarized in Table 3-3. The largest wave heights measured in Lake St. Clair were 1.14-m with a peak period of 4.5-sec. These top events demonstrate the small "extreme" wave heights observed in Lake St. Clair. Five storms were selected as wave validation events from Table 3-3. Storms 1, 2, 5 were selected as fall storms as well as the $3^{\text {rd }}$, and the $15^{\text {th }}$ ranked storms. The $3^{\text {rd }}$ and $15^{\text {th }}$ ranked storms were selected because they were the largest recorded spring events.

The five validation storms were run using WAM forced with Natural Neighbor and CFSR wind fields. All CFSR wind speeds were modified as noted in Chapter 1. The simulations were initiated at a time when wave conditions were minimal at least 24 -hrs before the peak of the storm. The simulations lasted until the large wave conditions minimized at least 24-hrs after the peak. All simulations were run with arbitrary water conditions turned on (shoaling, refraction, wave-bottom effects, depth induced wave breaking), using the 18-sec (0.005-deg) grid. Each of the five selected storm simulations is summarized below (highlighted storms in Table 3-3). 
Table 3-3. List of extreme events from Canadian Buoy 45147.

\begin{tabular}{|c|c|c|c|c|c|c|c|c|}
\hline \multicolumn{9}{|c|}{$\begin{array}{l}\text { Extremes for } \mathrm{ST}=45147 \\
\text { Events with } \mathrm{H}>=0.18 \\
\text { Mean and Variance }=0.080 .02 \\
\text { Sorting on Hmo }\end{array}$} \\
\hline Rank & Start & & End & & Peak & & Hmo & TP \\
\hline 1 & $10 / 6 / 2009$ & 23:57 & $10 / 7 / 2009$ & $18: 57$ & $10 / 7 / 2009$ & $8: 57$ & 1.14 & 4.51 \\
\hline 2 & $10 / 11 / 2006$ & $14: 57$ & $10 / 14 / 2006$ & $5: 57$ & $10 / 13 / 2006$ & $15: 57$ & 1.14 & 4.42 \\
\hline 3 & $5 / 20 / 2006$ & 2:57 & $5 / 22 / 2006$ & $21: 57$ & $5 / 21 / 2006$ & $12: 57$ & 1.02 & 3.7 \\
\hline 4 & $5 / 10 / 2006$ & $23: 57$ & $5 / 14 / 2006$ & $15: 57$ & $5 / 11 / 2006$ & $15: 57$ & 1.01 & 3.65 \\
\hline 5 & $12 / 3 / 2007$ & 9:57 & $12 / 4 / 2007$ & $12: 57$ & $12 / 3 / 2007$ & $20: 57$ & 0.96 & 3.99 \\
\hline 6 & $4 / 25 / 2006$ & $7: 57$ & $4 / 26 / 2006$ & $0: 57$ & $4 / 25 / 2006$ & $11: 57$ & 0.93 & 3.65 \\
\hline 7 & $10 / 28 / 2006$ & $6: 57$ & $10 / 29 / 2006$ & $9: 57$ & $10 / 28 / 2006$ & $20: 57$ & 0.89 & 4.15 \\
\hline 8 & $6 / 18 / 2006$ & $2: 57$ & $6 / 19 / 2006$ & $6: 57$ & $6 / 18 / 2006$ & $22: 57$ & 0.88 & 3.35 \\
\hline 9 & $10 / 30 / 2004$ & $13: 24$ & $11 / 1 / 2004$ & $3: 24$ & $10 / 30 / 2004$ & $19: 24$ & 0.88 & 4.21 \\
\hline 10 & $11 / 30 / 2007$ & $10: 57$ & $12 / 1 / 2007$ & 1:57 & $11 / 30 / 2007$ & $14: 57$ & 0.86 & 3.65 \\
\hline 11 & $11 / 15 / 2008$ & $8: 57$ & $11 / 17 / 2008$ & $2: 57$ & $11 / 15 / 2008$ & $14: 57$ & 0.85 & 3.77 \\
\hline 12 & $11 / 29 / 2007$ & $11: 57$ & $11 / 29 / 2007$ & $21: 57$ & $11 / 29 / 2007$ & $16: 57$ & 0.83 & 3.72 \\
\hline 13 & $10 / 19 / 2007$ & $14: 57$ & $10 / 20 / 2007$ & $3: 57$ & $10 / 19 / 2007$ & $16: 57$ & 0.82 & 4.08 \\
\hline 14 & 9/28/2009 & $3: 57$ & 9/29/2009 & $21: 57$ & 9/28/2009 & $22: 57$ & 0.81 & 3.78 \\
\hline 15 & $5 / 13 / 2009$ & $19: 57$ & $5 / 14 / 2009$ & $8: 57$ & $5 / 14 / 2009$ & $7: 57$ & 0.81 & 3.83 \\
\hline 16 & $10 / 31 / 2007$ & $13: 57$ & $10 / 31 / 2007$ & $22: 57$ & $10 / 31 / 2007$ & $18: 57$ & 0.81 & 3.7 \\
\hline 17 & $10 / 27 / 2008$ & $23: 57$ & $10 / 29 / 2008$ & $21: 57$ & $10 / 28 / 2008$ & $9: 57$ & 0.79 & 3.38 \\
\hline 18 & $10 / 30 / 2009$ & 23:57 & $11 / 1 / 2009$ & $2: 57$ & $10 / 31 / 2009$ & $17: 57$ & 0.78 & 4.01 \\
\hline 19 & $4 / 29 / 2009$ & $11: 57$ & $4 / 29 / 2009$ & $20: 57$ & 4/29/2009 & $15: 57$ & 0.78 & 3.64 \\
\hline 20 & $10 / 17 / 2006$ & 06:57 & $10 / 17 / 2006$ & $19: 57$ & $10 / 17 / 2006$ & $12: 57$ & 0.76 & 3.71 \\
\hline
\end{tabular}

\subsubsection{October 2009 storm}

The October 2009 storm was the largest wave event recorded by Canadian buoy 45147. The storm system started as a northern wind and shifted in a clockwise direction as the wind speeds increased. At the peak of the storm, with wind speeds of $17-\mathrm{m} / \mathrm{sec}$, the direction of the wind was approximately westerly. The NNM wind field was generated with fifteen land based stations and two water based stations (Figure 3-7). The east side of Lake St. Clair has no meteorological stations close to the shore, so all stations are from much further away the west side of the lake. 


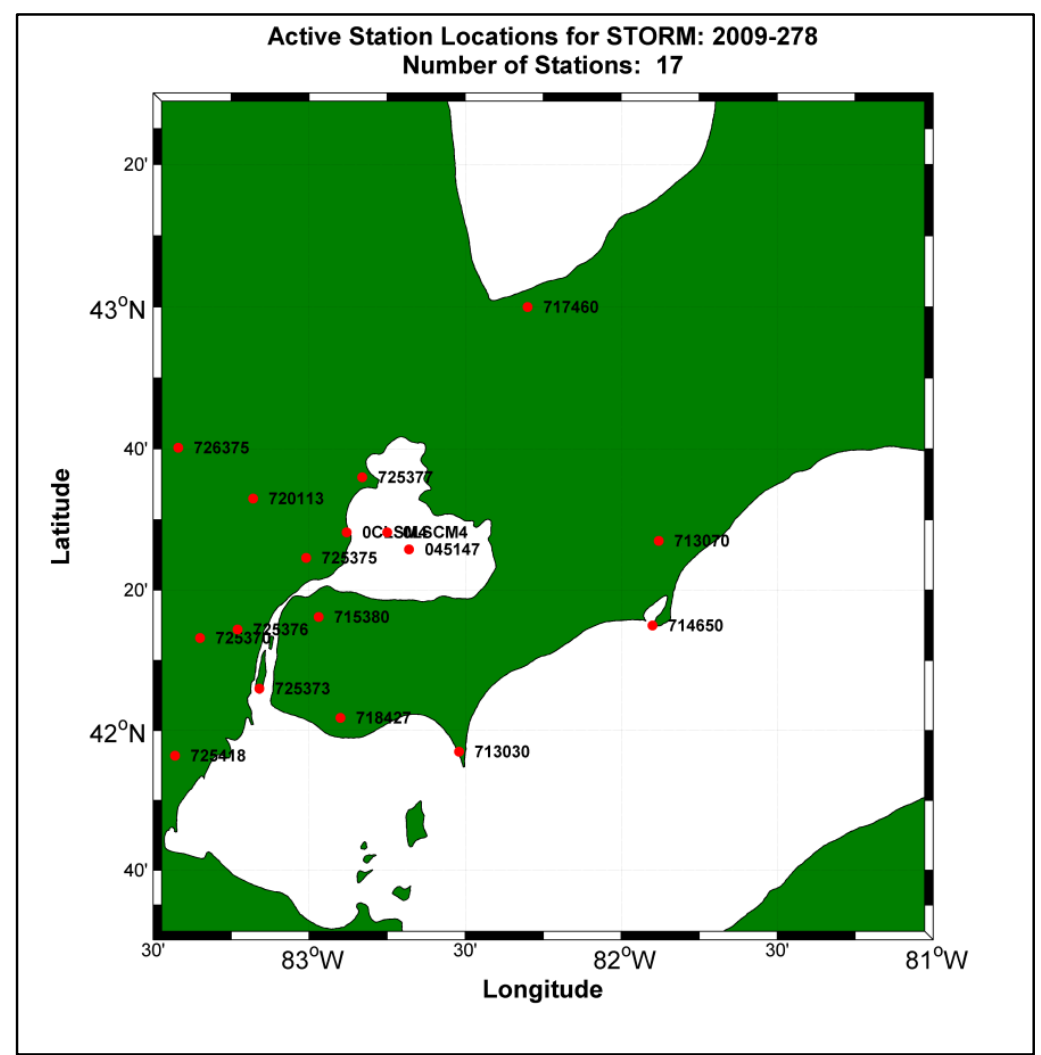

Figure 3-7. Available meteorological station locations accessed and preprocessed for the October 2009 storm.

As described in the Lake Michigan report (Jensen et al. 2012), the maximum wind speed and wave height envelope are graphically generated to provide an assessment of similarities and differences between WAM forced with NNM and CFSR. An initial glance of Figures 3-8 and 3-9 indicates differences between the maximum wind speed contours for NNM and CFSR. The lake wide maximum wind speed only differed by $0.58-\mathrm{m} /$ sec. Both wind fields had the maximum wind speed of approximately $17-\mathrm{m} / \mathrm{sec}$, but the location of the maximum wind speed was different between the two wind fields. The NNM had a maximum wind speed value near the western shore of the lake with circular contours radiating out from the maximum, while CFSR had a maximum near the southeast corner of the lake with almost linear contours to the northwest. The CFSR wind fields, as described in Chapter 1, were interpolated from a 0.5-deg grid down to 0.02-deg for this study. This interpolation means that the wind fields in CFSR have less local variation, such as the contours generated in the NNM method. The winds across Lake St. Clair appear to be almost uniform with variations of less than $14.5-17-\mathrm{m} / \mathrm{sec}$ from the lowest to highest maximum values for both NNM and CFSR. 


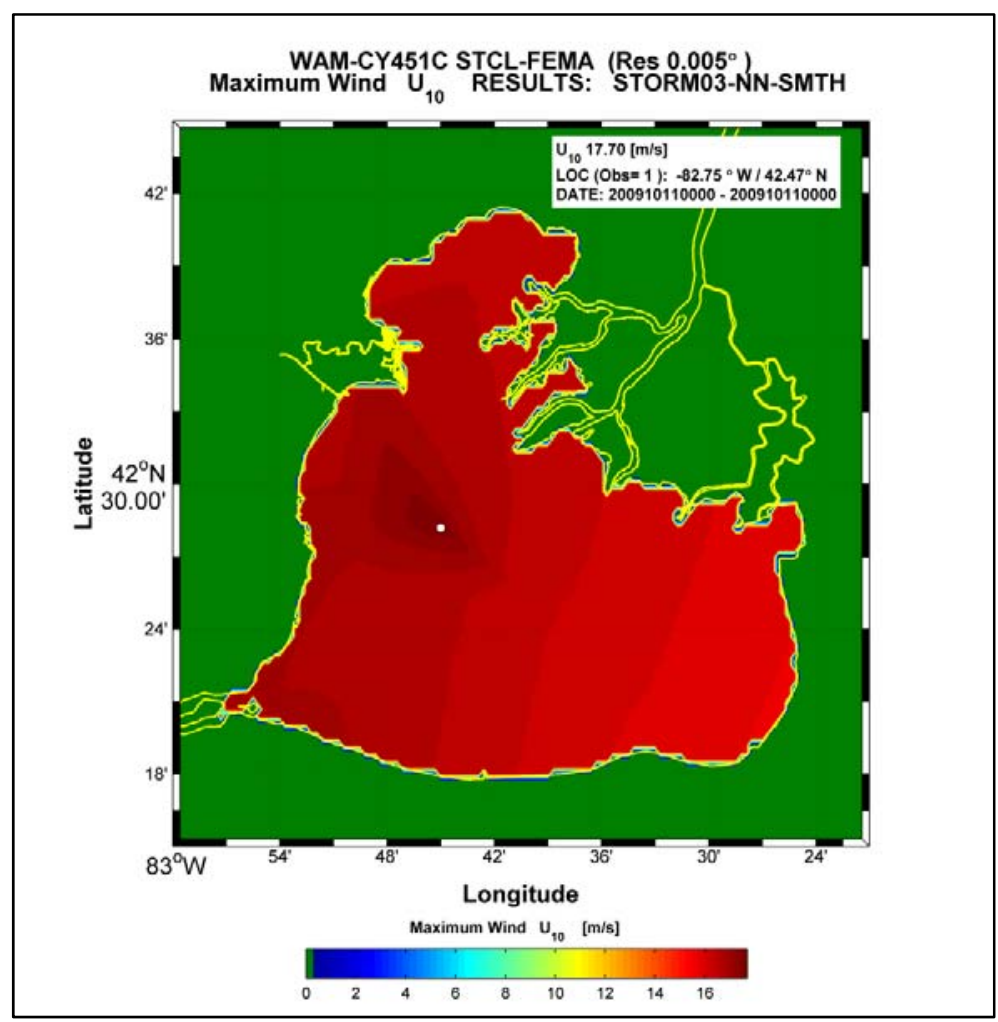

Figure 3-8. Maximum wind speed envelope for the October 2009 storm derived from the NNM wind field generation routine.

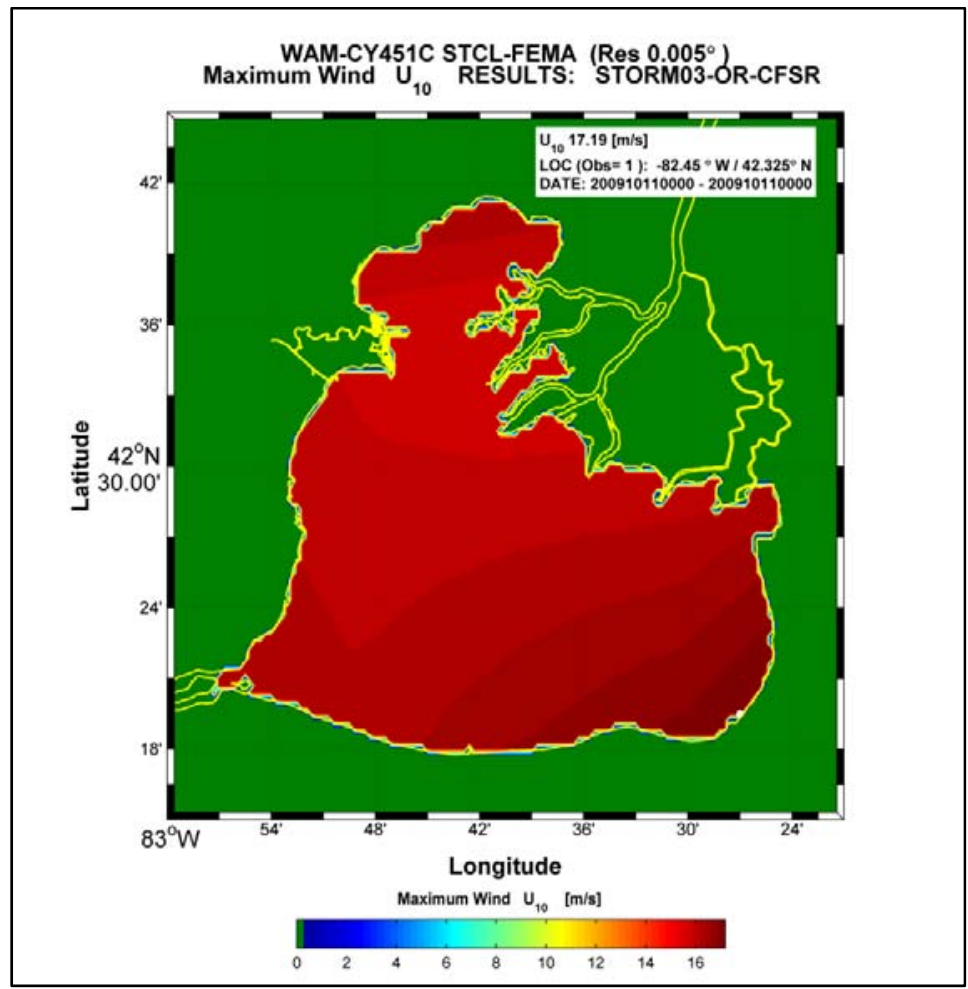

Figure 3-9. Maximum wind speed envelope for the October 2009 storm derived from the CFSR wind field. 
Despite the inconsistencies in the maximum wind speed envelopes between NNM and CFSR, the contours of the maximum significant wave height are very similar (Figures 3-10 and 3-11). The color contours portray consistent trends, and the maximum significant wave heights differ by only 0.01-m. The location of the maximum wave height was in the east region of the lake with the wave height from the CFSR forced model simulation closer to the southeast coast. The lowest maximum wave heights were located in the northern and western region of the lake with minimal fetch for a wind from the west.

The limited evaluation data set leave only comparisons between the wave model results and the Canadian buoy 45147. A time plot of the results from WAM forced with both NNM and CFSR for the storm simulation is shown in Figure 3-12 compared to the measurements. The display is six panels which detail important traits of the time series that are used for comparison. In the order from top to bottom, the figure has significant wave height, $H_{m o}$, parabolic fit to the peak wave period, $T_{p}$, the inverse first moment of the mean wave period, $T_{m}$, the vector mean wave direction, $\theta_{\text {wave }}$, wind speed (WS, adjusted to 10 -m equivalent neutral stable value), and wind direction, $\theta_{\text {wind }}$. The definitions of each of these parameters are listed below. All of the directional parameters are listed in meteorological coordinate system where o-deg is a wind coming from the north and 90-deg is a wind coming from the east.

$$
\begin{gathered}
H_{\text {mo }}=4 *\left[\iint_{00}^{2 \pi} F(f, \theta) d f d \theta\right]^{1 / 2} \\
T_{\text {peak }}=f_{\text {peak }}^{-1}, \text { where } f_{\text {peak }}=\text { parabolic fit to } \frac{d E(f)}{d f}=0 \\
\text { where } E(f)=\int_{0}^{2 \pi} f(f, \theta) d \theta \\
T_{\text {mean }}=f_{\text {mean }}^{-1}, \text { where } f_{\text {mean }}=\left[\frac{\int_{0}^{2 \pi} \int_{0}^{\infty} f^{-1} F(f, \theta) d f d \theta}{\int_{0}^{2 \pi} \int_{0}^{\infty} F(f, \theta) d f d \theta}\right]^{-1} \\
\theta_{\text {mean }}=\text { tan }^{-1}\left[\frac{\int_{0}^{2 \pi} \int_{0}^{\infty} \sin \theta F(f, \theta) d f d \theta}{\int_{0}^{2 \pi} \int_{0}^{\infty} \cos \theta F(f, \theta) d f d \theta}\right]
\end{gathered}
$$




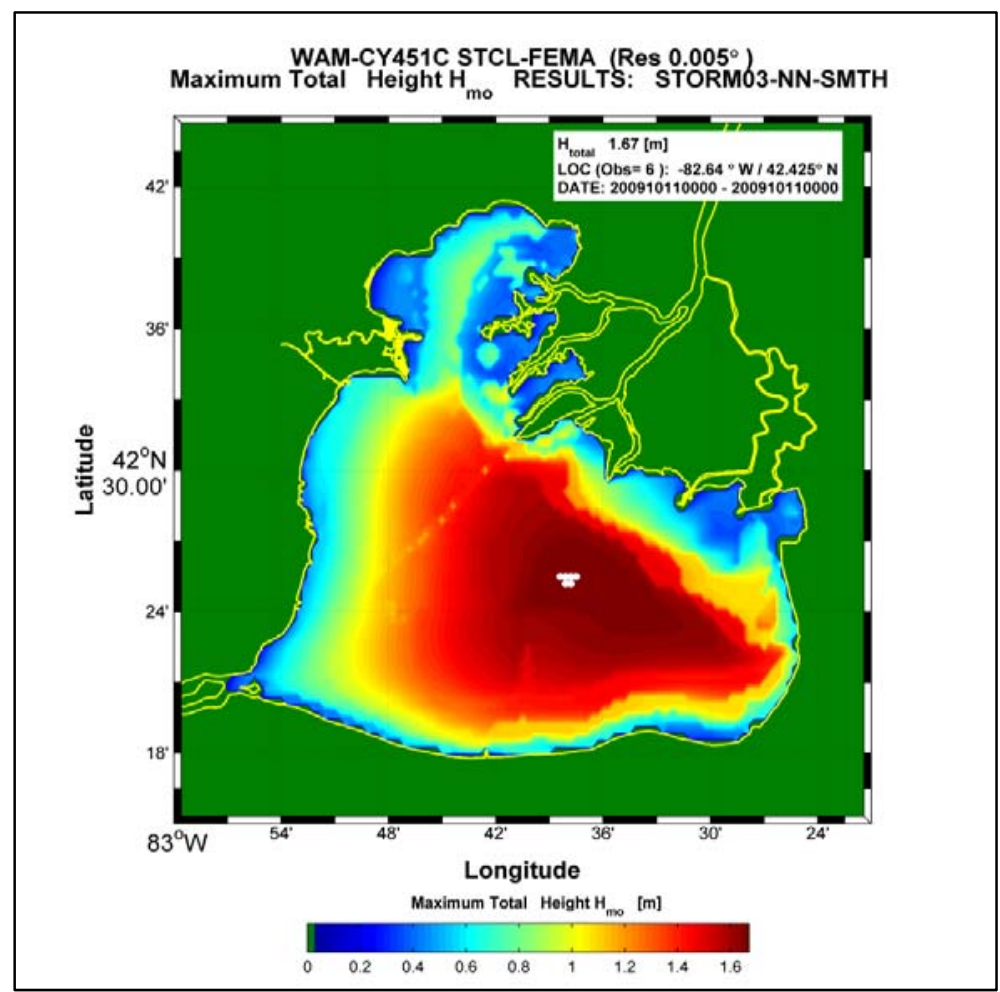

Figure 3-10. Maximum significant wave height envelope for the October 2009 storm derived from the NNM wind field generation routine.

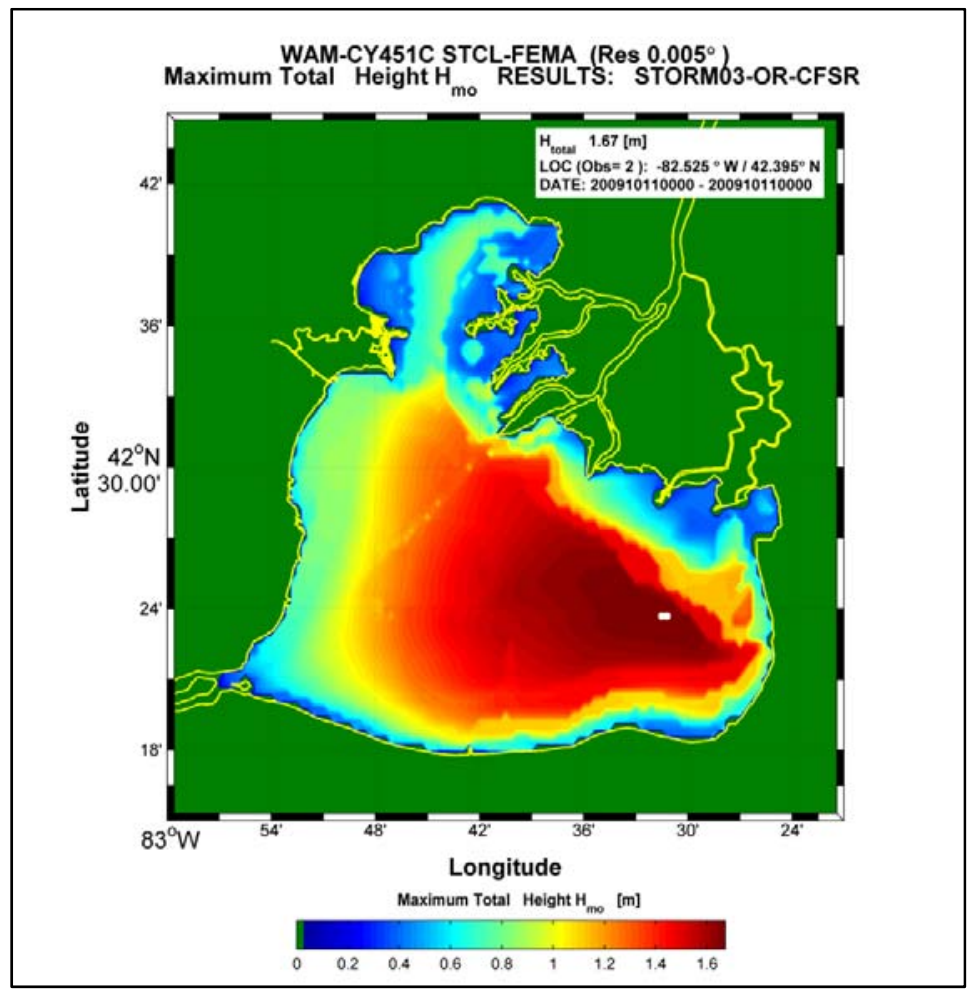

Figure 3-11. Maximum significant wave height envelope for the October 2009 storm derived from the CFSR wind field. 


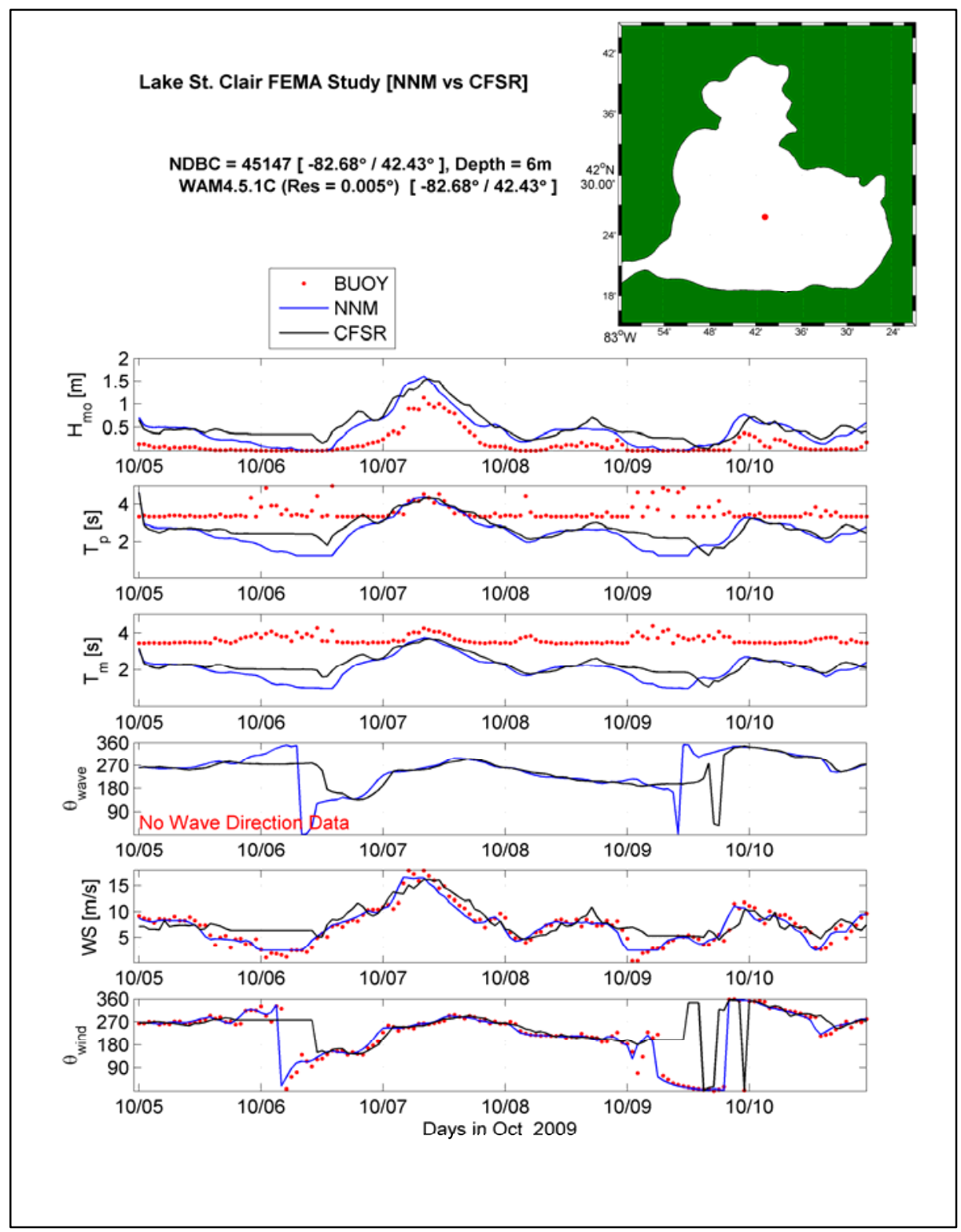

Figure 3-12. Time plots of significant wave height, peak and mean wave period, vector mean wave direction wind speed and direction at Canadian Buoy 45147 for the October 2009 storm.

The initialization for each simulation uses simple fetch laws from the initial wind conditions at each grid point. In general, this presets the water body to a higher value than what exists. The initialization accounts for differences between the model and buoy measurements at the far left (or startup) of the time series.

The shape of significant wave height time series for both the WAM with NNM (blue line) and CFSR (black line) in the top panel showed good agreement with the measured wave heights (red symbols). The model 
results follow the trends of the measurements, temporally increasing and decreasing similar to the case of the measurements. However, the quantitative comparisons show a distinct difference between both of the model results and the measured wave heights. A few variables could cause the overestimation seen in the wave height comparison. The first is the wind components, but in the last two panels, the wind speed and wind direction for both NNM and CFSR seem to match the measured wind speed and direction from the buoy. There was a time period between 09 and 10 October when the CFSR wind direction oscillates randomly. This is caused by the wind direction changing between 5 and 355 degrees. This 10-deg change results in sporadic wind direction results because it crosses over the o-36o degree line. The NNM winds match the measured wind directions (rotating from 180-deg to o-deg in a counter-clockwise direction) through this turning situation, but the CFSR has more fluctuation during this time period, and rotates clockwise. The NNM wind estimate at the buoy location is primarily a result from the fields including the measured winds from buoy 45147 in the NNM wind field estimates.

The second mechanism that could highlight the cause of differences in the wave height between model and measurements is the wave period. The second and third panels from the top in Figure 3-12 show large differences between both model results and the buoy measurements. As described earlier, the buoy measurements had significant low frequency "noise" which was filtered at $0.2-\mathrm{Hz}(5.0-\mathrm{sec})$. For the 2009 season, noise in the measurements are reduced (Figure $3-6$ ). The wave measurements seem to be invariant over time (limit to about 3.5-sec for $T_{p}$ ) until the wave heights increase above one meter, and excluding the extreme low wave heights observed. The model results show similar trends oscillating above and below the measurement threshold. It seems evident the measurement higher frequency range may differ from that of the model.

To determine the reason for differences in the wave period time series, the frequency dependent energy spectrum is analyzed. The energy density spectrum, $S(f)$ at every time step for buoy 45147 (red lines) and WAM forced with NNM (blue lines) is in Figure 3-13. The missing energy less than $0.2-\mathrm{Hz}$ were described earlier as smoothing to remove noise. The energy missing from frequencies greater than $0.3-\mathrm{Hz}$ was unexpected. The data from Environment Canada appeared to be filtered at frequencies greater than $0.3-\mathrm{Hz}$, resulting in a very small frequency range of $0.2-0.3-\mathrm{Hz}$ at 0.01-Hz interval. The WAM model spectra span from 0.06-0.8-Hz which only has a small overlapping region with the measured data. 


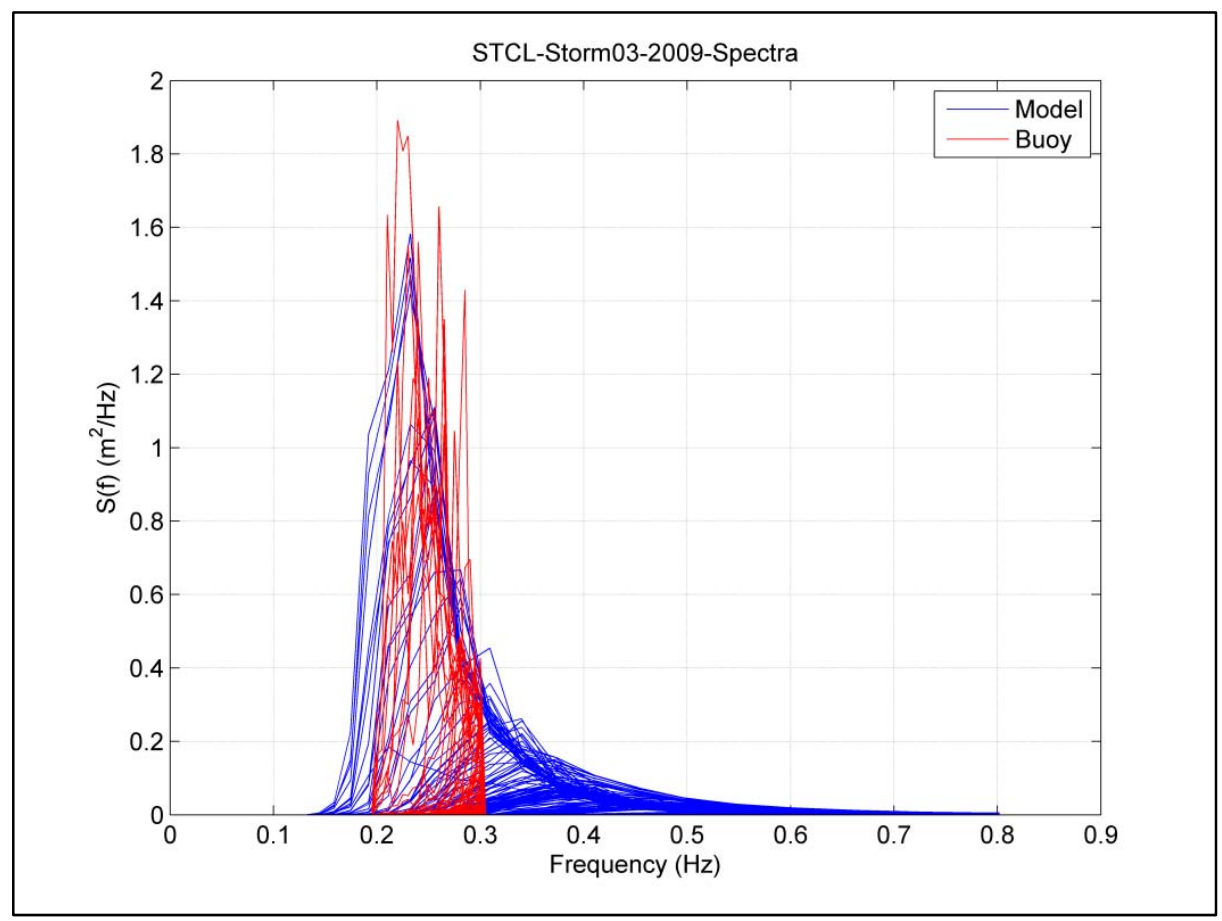

Figure 3-13. Energy density spectrum for Canadian buoy 45147 and WAM output for the October 2009 storm.

In Figure 3-14, the first panel of Figure 3-12 is replotted with the wave heights from the buoy (red symbol) and WAM model forced with NNM winds (blue symbol). The model wave heights were then computed to match the range of the measurements, or from 0.2 to $0.3-\mathrm{Hz}$. The model wave heights calculated consistently with the frequency range of the measurement spectra matching the measurements very well. Reducing the wave model frequency range to that of the measurements corrects the overestimation from the initial model to buoy comparisons.

The results from the evaluation using the October 2009 storm showed similar results between the WAM model forced with NNM and CFSR. The overestimation of wave heights from the two wave model simulations as compared with the measured data was determined to be a function of differences in the frequency banding between the model and the buoy. The use of WAM forced with both NNM and CFSR were shown to produce accurate wave height results during this storm. The model results with the full frequency distribution are a better representation of the real wave heights in Lake St. Clair, as opposed to the erratic wave buoy measurements. 


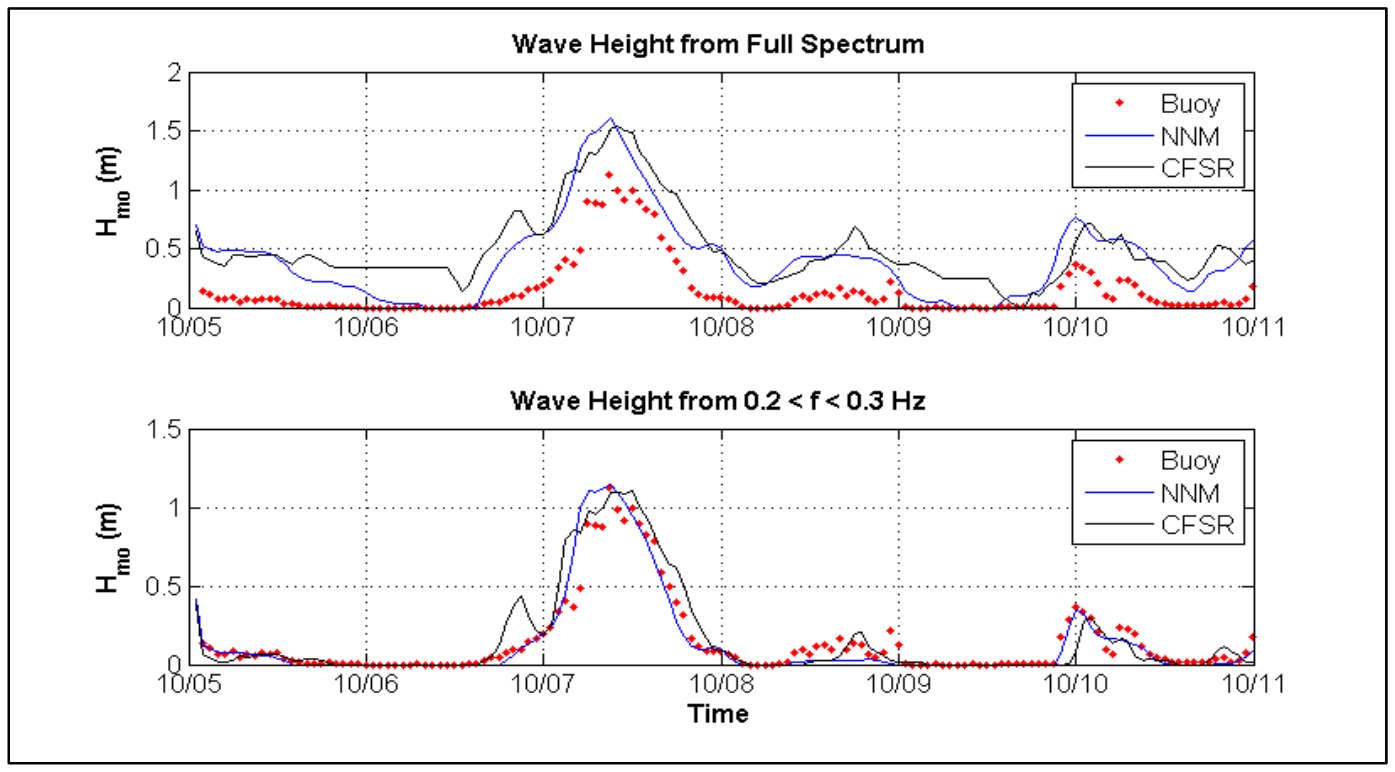

Figure 3-14. Time series of wave heights calculated from full spectrum and reduced frequency range spectrum for the October 2009 storm.

\subsubsection{October 2006 storm}

The October 2006 storm was the second wave event recorded by Canadian buoy 45147. The winds were initially easterly, slowly rotated clockwise to a westerly direction and remained relatively constant for the next three days. The wind speeds oscillated between $10-$ and $15-\mathrm{m} / \mathrm{sec}$ for the first two days, and ultimately decreased slightly on the third day. This storm is very similar to the constant wind academic tests, but with the wind magnitudes a factor of two lower. The NNM wind fields were generated from sixteen sites, fourteen land-based meteorological stations, and two lake based stations (Figure 3-15). The maximum significant wave height measured at buoy 45147 for this event was $1.14-\mathrm{m}$ and wave period of $4.42-\mathrm{sec}$. This storm is very similar to the October 2009 event in terms of the storm characteristics, but this storm persisted for a longer time period with a less defined peak event.

The maximum wind speed envelope from the NNM wind field (Figure 3-16) is nearly $1-\mathrm{m} / \mathrm{sec}$ lower than the CFSR wind field (Figure 3-17) and possess three sub-scale peaks compared to only one (northwest to southeast) in the CFSR wind maxima. The maximum wind speed is greatest in the southwest corner compared with the north region of the lake. The localized effects are very apparent in the different contour formations across the lake with no uniform features. In the CFSR maximum wind speeds, the contours are almost uniform decreasing from the southeast corner to the northwest. There is little influence by localized wind events on the overall wind field. 


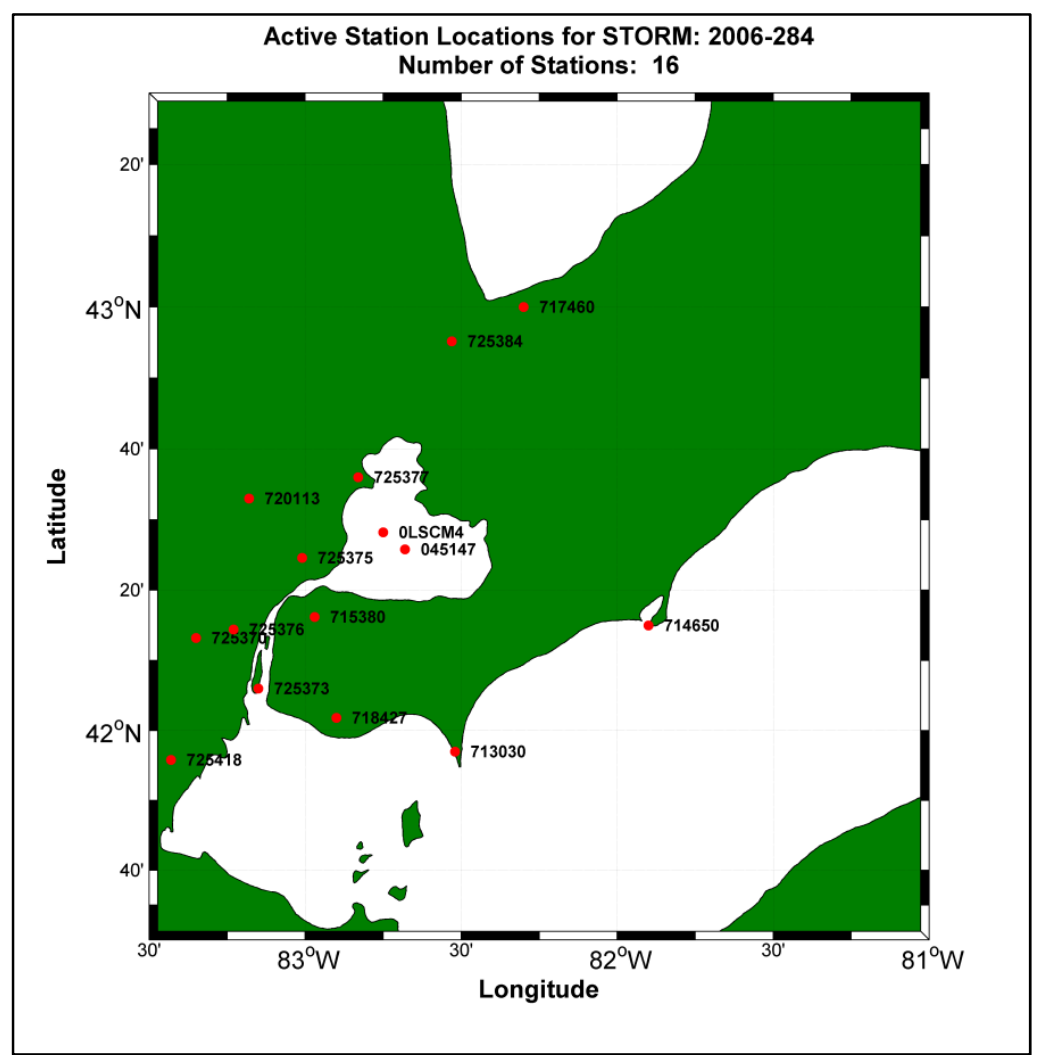

Figure 3-15. Available meteorological station locations accessed and preprocessed for the October 2006 storm.

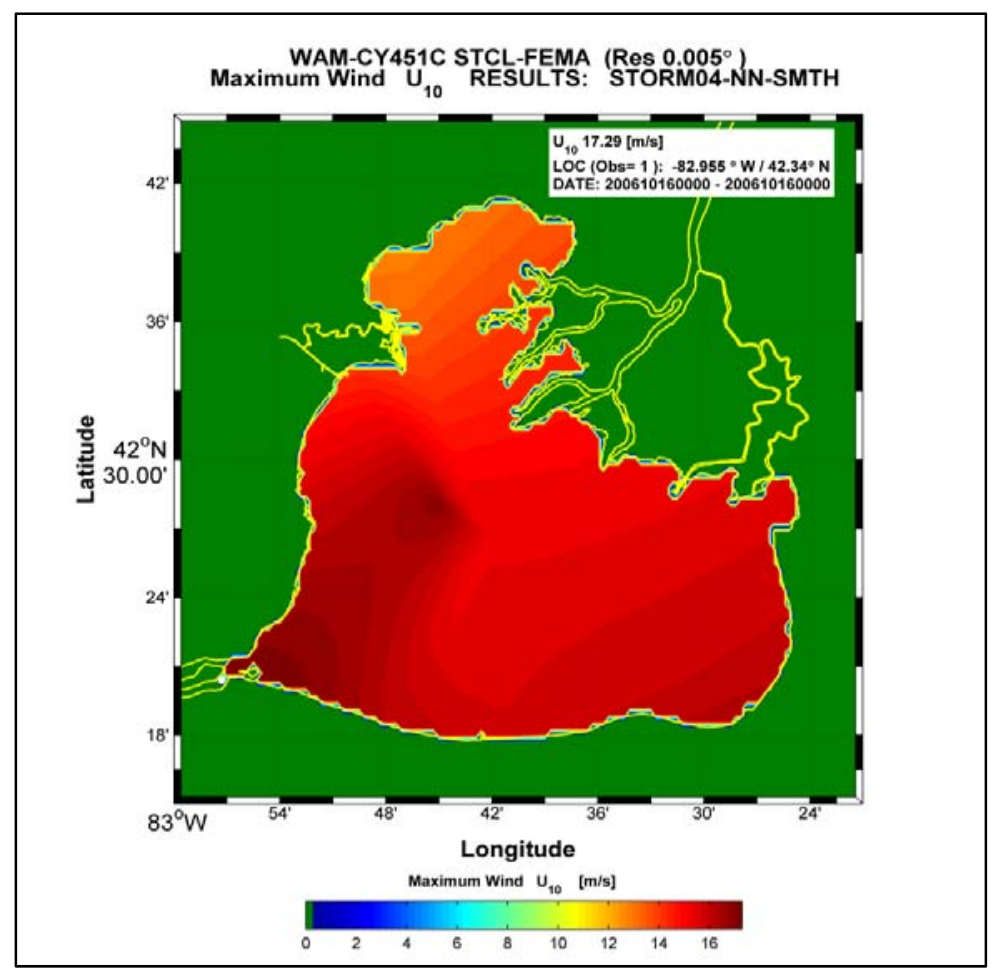

Figure 3-16. Maximum wind speed envelope for the October 2006 storm derived from the NNM wind field generation routine. 


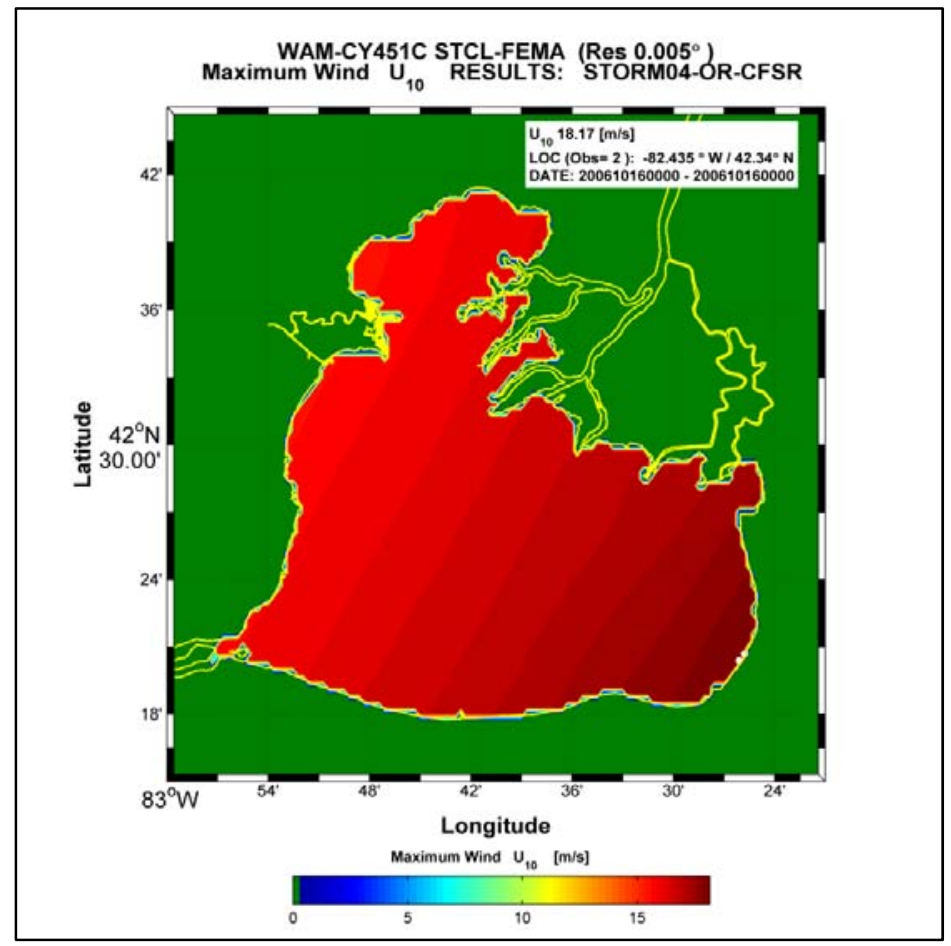

Figure 3-17. Maximum wind speed envelope for the October 2006 storm derived from the CFSR wind fields.

The maximum wave height envelope for the NNM simulation has the maximum wave heights on the west side of the shipping channel as indicated in Figure 3-18. The region occupied by the largest wave heights is nearly identical in location as found in the wind maximum envelope (Figure 3-16). In addition, the lobe of greatest significant wave height is bisected by the shipping channel and attenuating toward the coasts. Wave energy penetrates the northern region (Anchor Bay), and also the shallow water region just southeast of Harsens Island along the Canadian coastline. The maximum wave heights for the CFSR forced simulation were located in the northeast side of the lake. The maximum wave heights decreased from the northeast corner of the lake to the southwest corner, quite different from the wind speed gradients (Figure 3 -17). With a nearly constant westerly direction of the winds, the position of the overall maximum is located along a line of maximum fetch length. The maximum wave heights in the north region of the lake were close to $0.5-\mathrm{m}$ larger in the CFSR simulation (Figure 3-19) compared to NNM. However, the distributions are quite similar. There is an increased wave height lobe around the centerline of Anchor Bay and small-scale wave height peak conditions (about 0.75-m) to the east and west of the central lobe. These similarities are true for almost all of the offshore area in Lake St. Clair, despite the two wind forcing differences. 


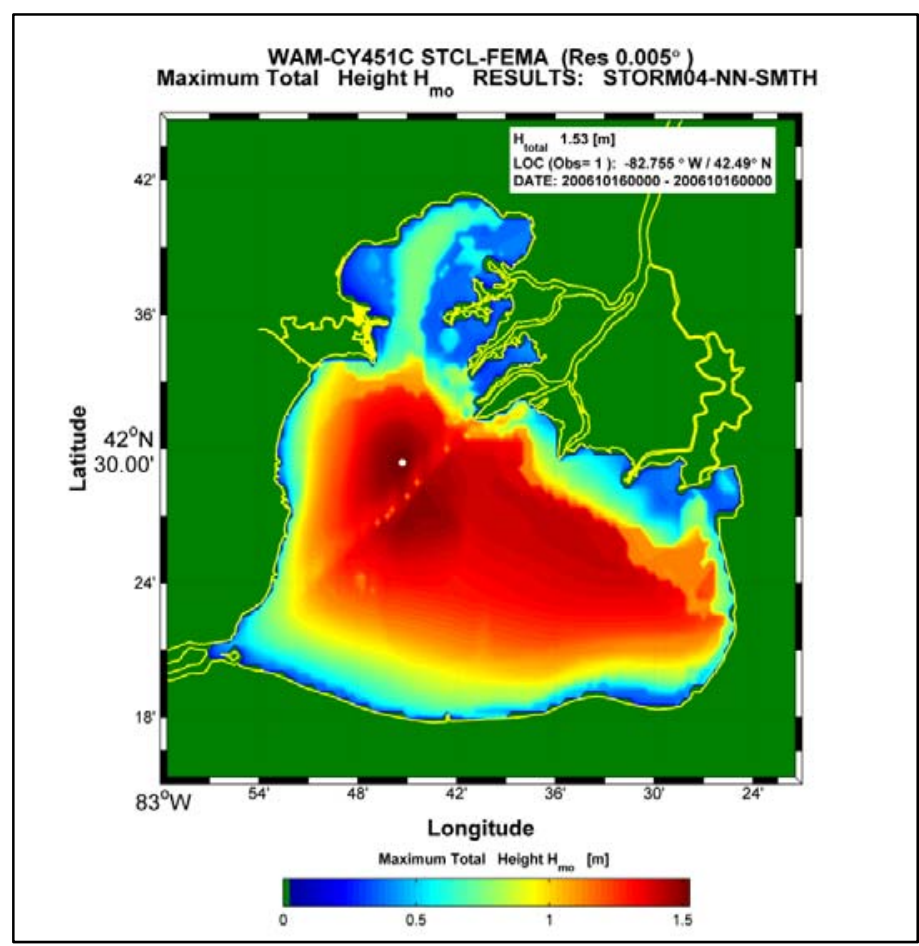

Figure 3-18. Maximum wave height envelope for the October 2006 storm derived from the NNM wind fields.

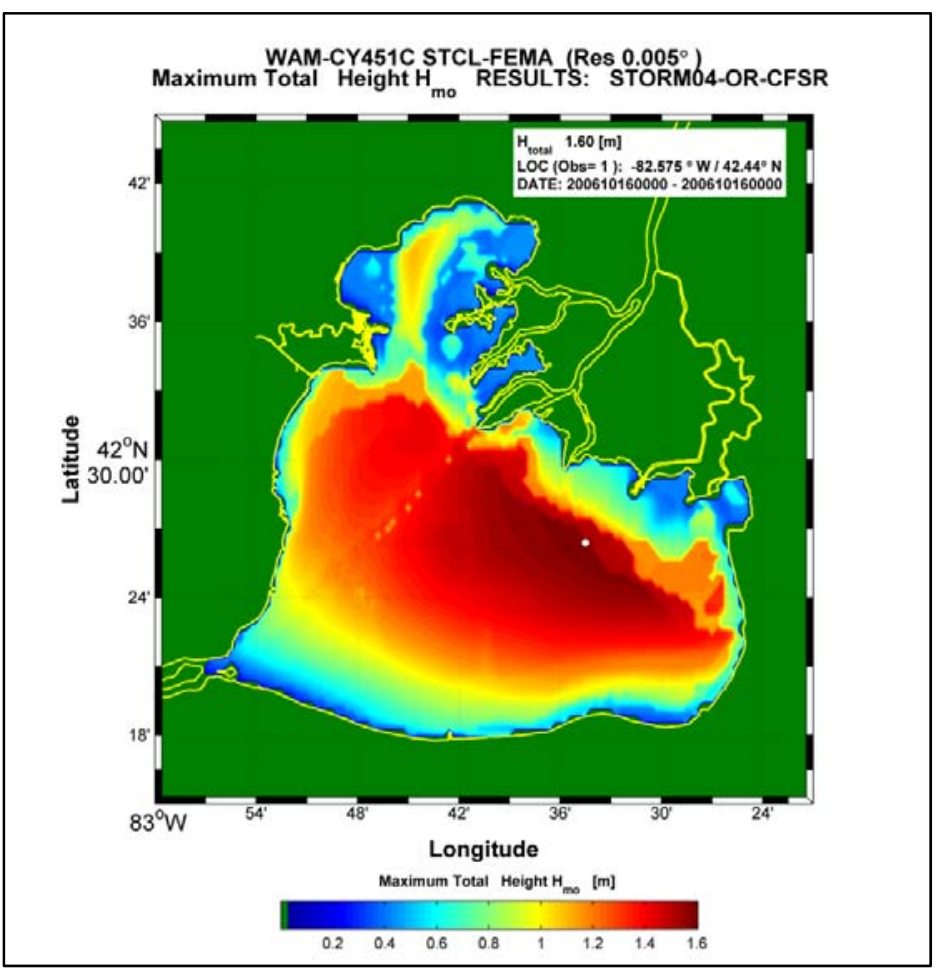

Figure 3-19. Maximum wave height envelope for the October 2006 storm derived from the CFSR wind fields. 
The evaluation of WAM results (NNM and CFSR forcing) are presented in Figure 3-20. The buoy data does show many drop-outs (either no data or the filtering method removed all energy) in the data record for this storm simulation. In the top panel of the time series plot (Figure 3-20) both the measurements and model results identify three peak events during the fiveday simulation. In all cases WAM over-estimates the wave heights. The CFSR wind forcing biases the wave heights slightly more than the NNM wind forcing. However, during the decay cycle between storm peaks two and three, the CFSR wind forcing matches the data better than NNM. What is striking to see is that during this sequence, the NNM winds follow the buoy data records (NNM uses the buoy data as input), and the wave height estimates derived from WAM do not decay according to the data. This storm is unique in that the wind direction remains virtually constant (after the initial directional shift). Wave heights scale to the wind speed squared, hence deviations in the wind magnitudes will directly affect, and prompt similar results in the model's wave height estimates. The only complicating factor in this scenario is that growth characteristics are also dictated by fetch length, and the shoreline reach of Lake St. Clair is not uniform. In addition, localized wind gusts (not found in the hourly wind records) and depth dependent mechanisms can offset the simple scaling of wind speeds to wave height estimates. One is not always certain the buoy data are correct, and this includes the wind speeds. Despite NNM matching the wind speeds at 45147, the outcome in the wave estimates using NNM wind fields only follow the trends, and miss peak and decay cycles found in the measurements. On the other hand, the CFSR winds tend to diverge higher and lower than the buoy data yet compare more favorably to the wave height estimates. This seems to be the general trend in the first two storm simulations evaluating WAM and the two wind field methodologies.

The archived frequency spectra $(S(f))$ derived from 45147 had a similar trait as in the previous storm simulation. It appears again the energy above 0.3-Hz was zeroed as evident in Figure 3-21. The frequency spectra from WAM, forced with NNM, extend from 0.06 to $0.8-\mathrm{Hz}$ (identified as the blue lines in Figure 3-21). Similar to the previous storm, the difference in the range of frequencies with energy would cause the positive wave height bias found in Figure 3-20. The top panel in Figure 3-22 is a replication of the top panel in Figure 3-20. The bottom panel compares the buoy wave heights and the model wave heights integrated from $S(f)$ in the range of frequencies from 0.2 to $0.3-\mathrm{Hz}$. The NNM forced WAM results has some underestimation of the three peaks when using the filtered spectra. The CFSR 


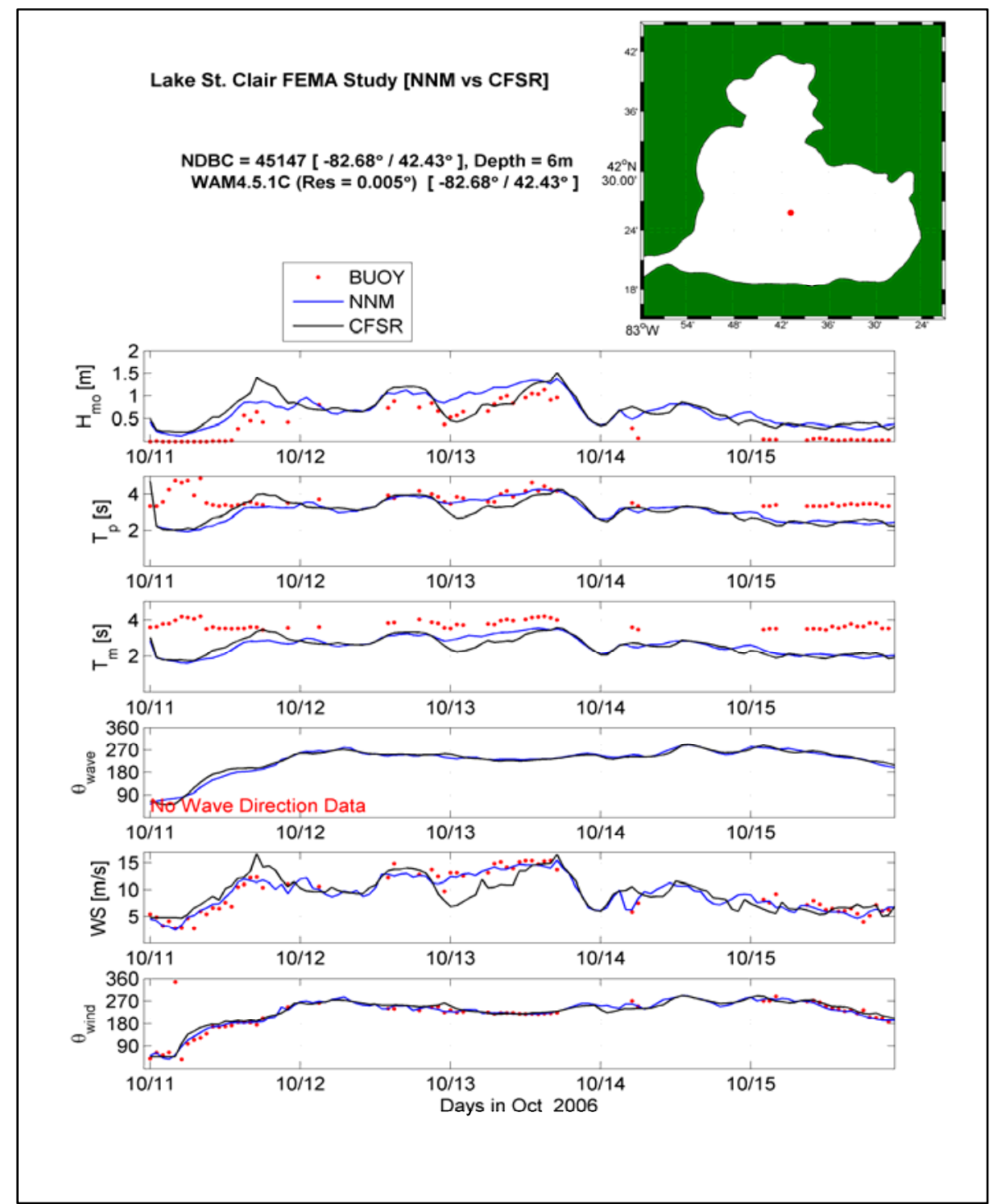

Figure 3-20. Time plots of significant wave height, peak and mean wave period, vector mean wave direction wind speed and direction at Canadian Buoy 45147 for the October 2006 storm.

results appear to fit the peaks much better in the filtered spectrum results than in the full spectrum results. The NNM forced filtered model results show much better agreement on 13 October during the initial decay of the first storm event, followed by growth of the second event, compared to the non-filtered results. However, the CFSR forced filtered model wave heights under-estimate the buoy wave heights on 13 October more than in the full spectrum. This agrees with the previous discussion concerning the underestimation of the CFSR wind field at different points in time (Figure 3-20). The results show the importance of analyzing all aspects of the model results when determining the accuracy of a model, including frequency spectra and wind speeds. 


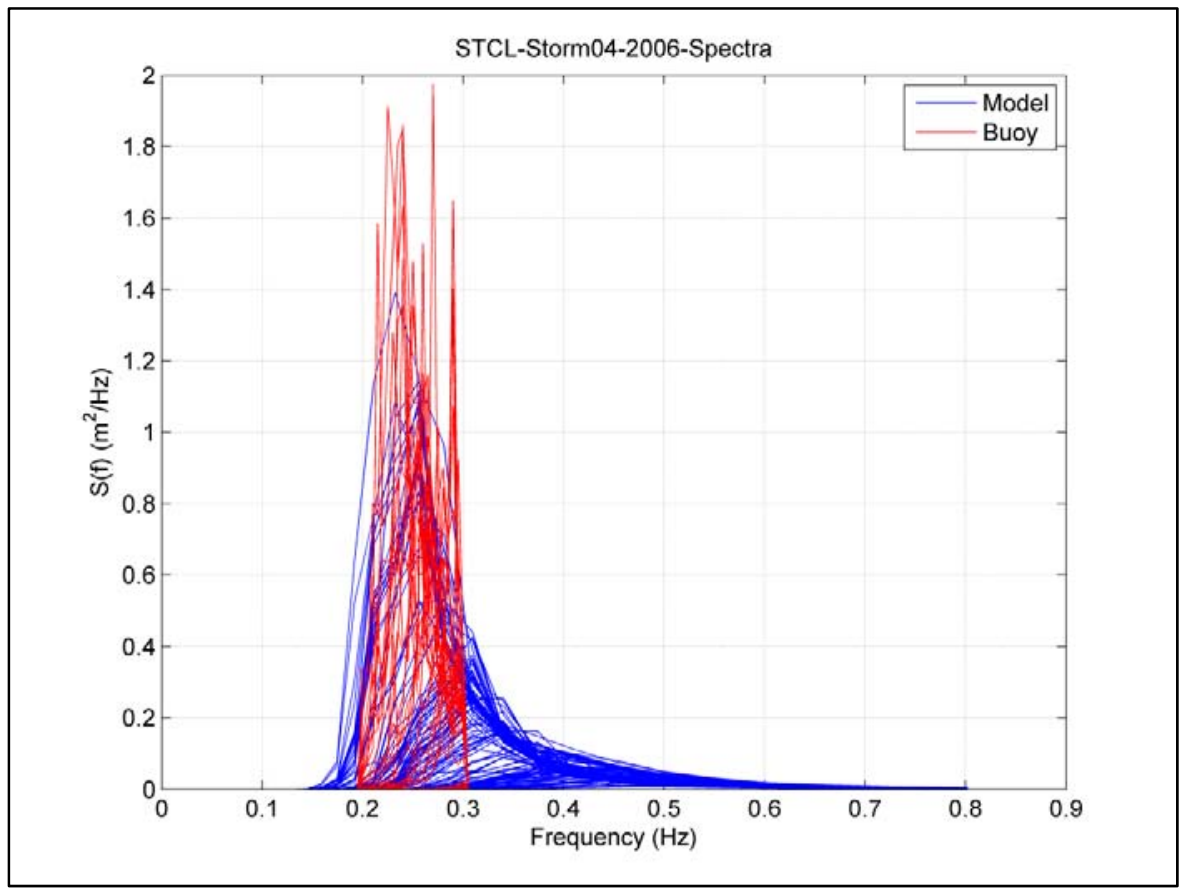

Figure 3-21. Energy density spectrum for Canadian buoy 45147 and WAM output for the October 2006 storm.

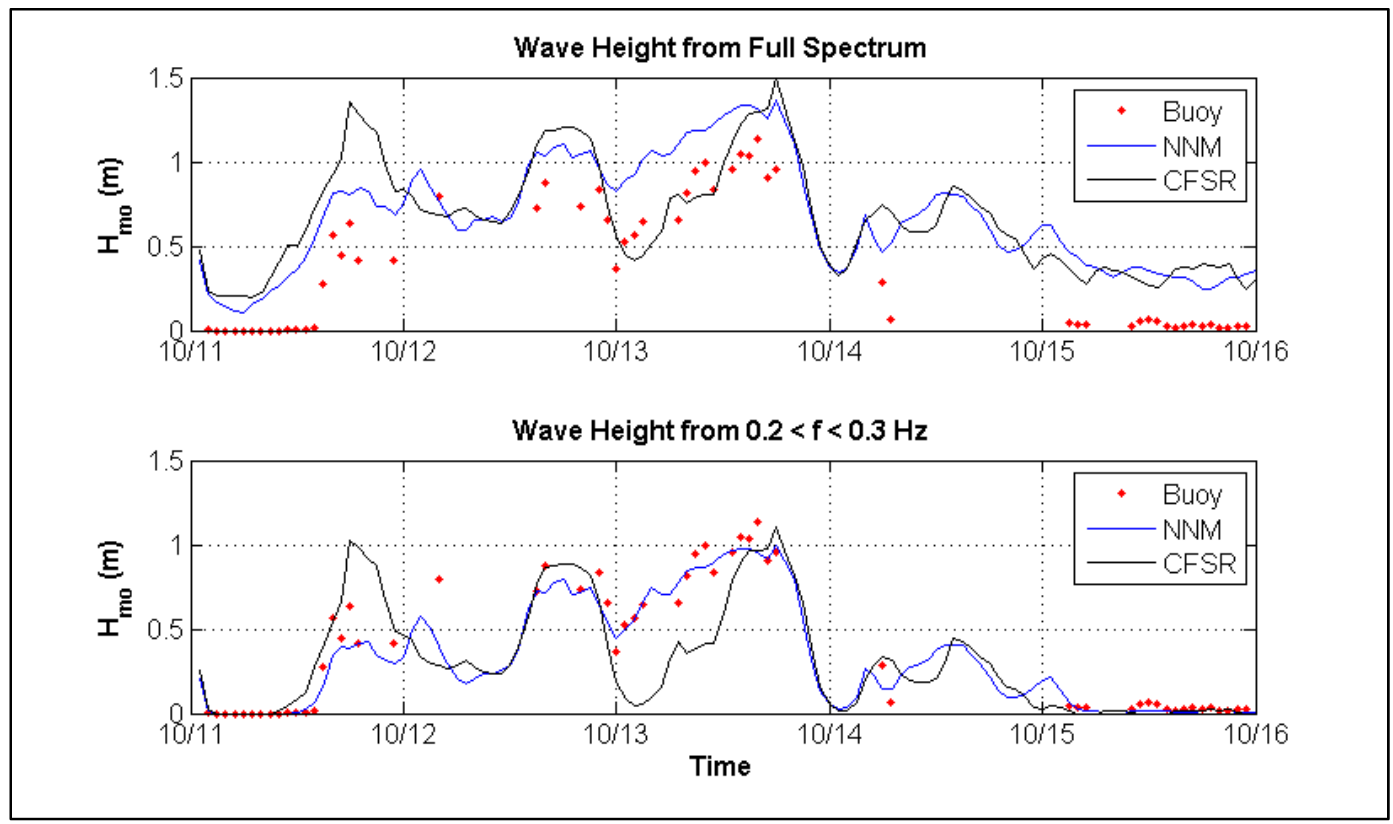

Figure 3-22. Time series of wave heights for calculated from full spectrum and cut spectrum for the October 2006 storm.

\subsubsection{May 2006 storm}

The May 2006 storm was selected because it was the largest storm in the spring measured by Canadian buoy 45147. The winds during this storm were out of the west for nearly the entire simulation period, but more 
importantly at the storm peak. The NNM method used sixteen land based stations along with a CMAN station, LSCM4, and the Canadian buoy 45147 (Figure 3-23).

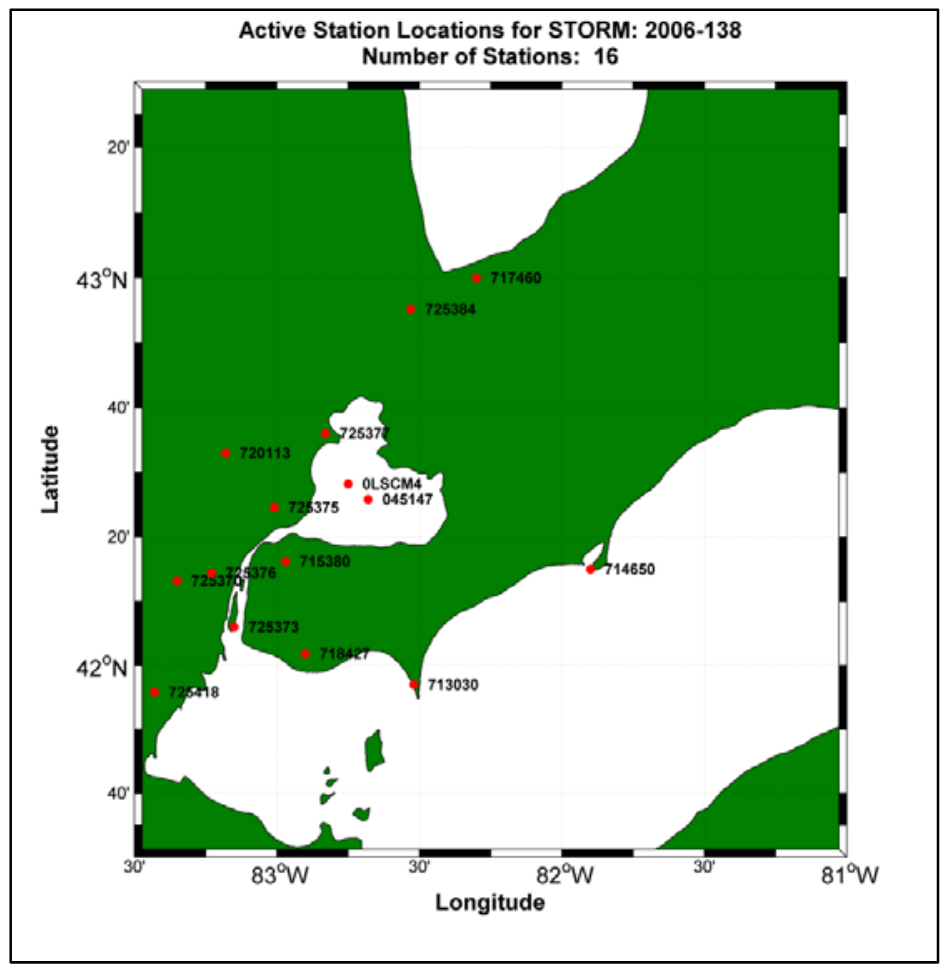

Figure 3-23. Available meteorological station locations accessed and preprocessed for the May 2006 storm.

The maximum wind speeds from the NNM wind field in Figure 3-24 have a maximum of $11.4-\mathrm{m} / \mathrm{sec}$ located in the middle of the lake on the west side of the shipping channel. The contours of maximum wind speed radiate out from this center with the lowest maximum wind speeds located in the north and southeast parts of the lake. However, the difference in the lowest maximum wind speed and the highest is only 2 - to $3-\mathrm{m} / \mathrm{sec}$. The maximum wind speeds from the CFSR wind field in Figure 3-25 have no contours across Lake St. Clair. The maximum wind speed is $12.99-\mathrm{m} / \mathrm{sec}$, and that wind speed was estimated at all locations across the lake. This does not imply that the wind speed was the same at all times across the lake, but at all grid points the maximum wind speed was $12.99-\mathrm{m} / \mathrm{sec}$.

The maximum wave height envelope from WAM forced with NNM is displayed in Figure 3-26. The overall maximum wave height $(0.81-\mathrm{m})$ is centrally located in Lake St. Clair with peak conditions uniformly distributed throughout the domain. There are shadow zones that seem to emulate 


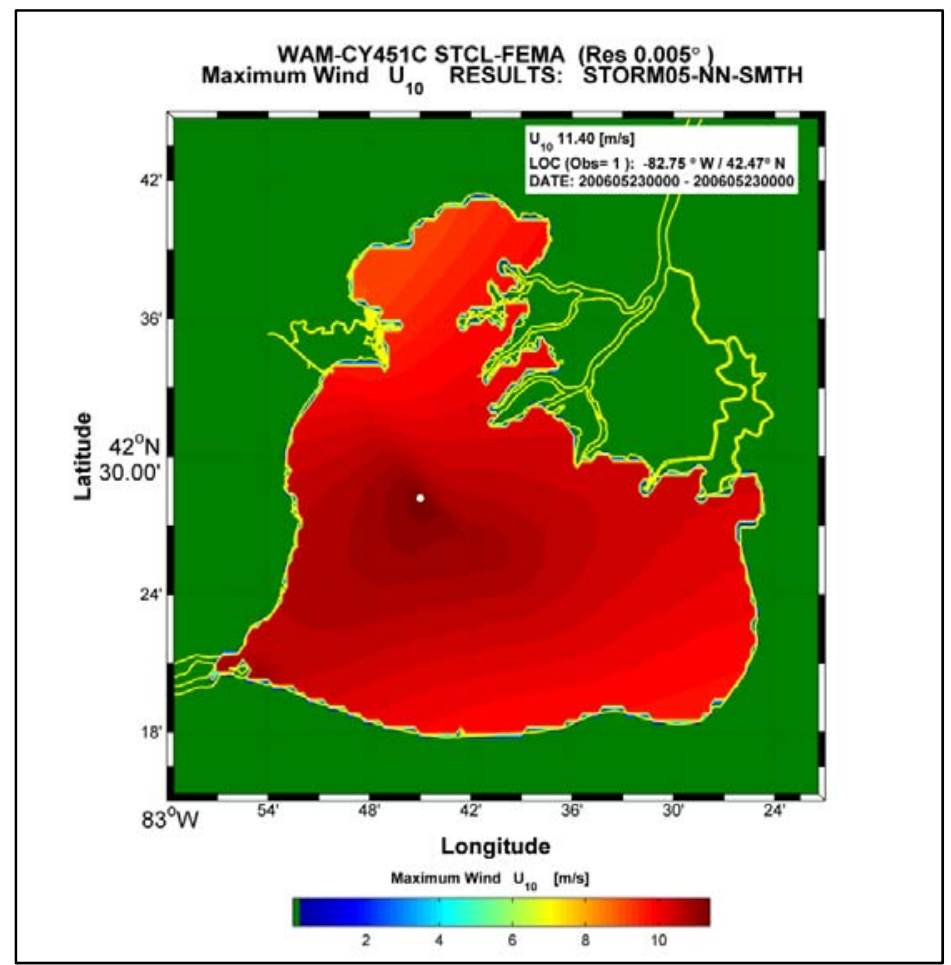

Figure 3-24. Maximum wind speed envelope for the May 2006 storm derived from the NNM wind fields.

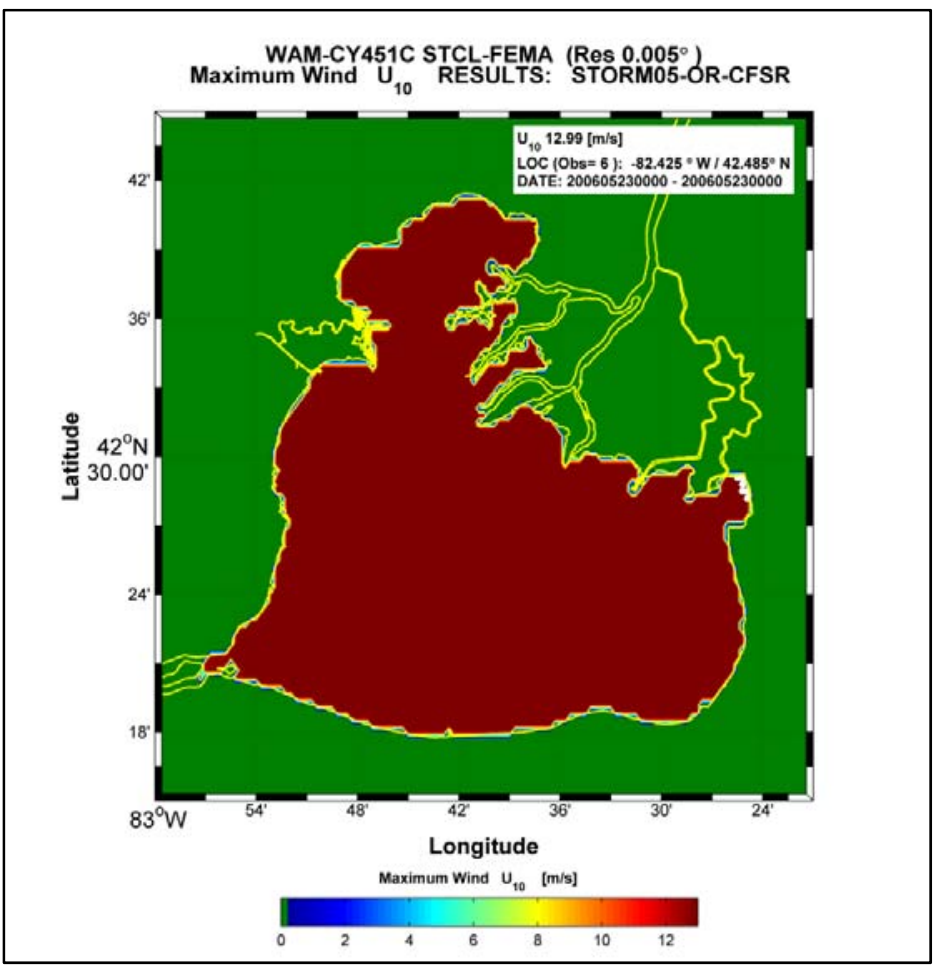

Figure 3-25. Maximum wind speed envelope for the May 2006 storm derived from the CFSR wind fields. 


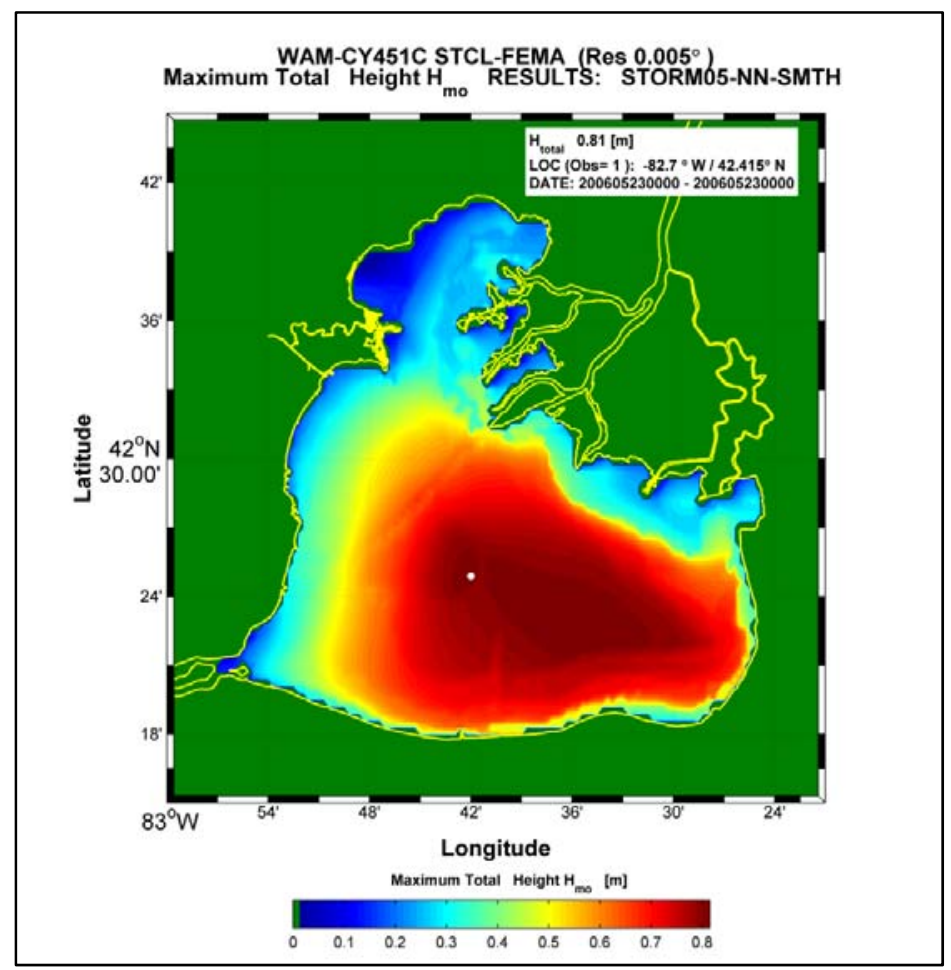

Figure 3-26. Maximum wave height envelope for the May 2006 storm derived from the NNM wind fields.

the bathymetry, such as the ship channel, and the small-scale submarine canyon along the southern portion of the high wave lobe (Figure 3-1). The lowest maximum wave heights were in the northern and western region of the lake which is the result of westerly winds during the peak of the storm.

The maximum wave height envelope from the WAM forced CFSR simulation is provided in Figure 3-27. Despite differences in the NNM and CFSR wind speed maximum envelopes, the resulting wave height distributions are quite similar. The maximum significant wave height region is located in the southeast corner of Lake St. Clair; the lowest maximum wave heights are in the north and west regions. The CFSR forced WAM runs produce an overall maximum wave height of $1.07-\mathrm{m}$ or $0.26-\mathrm{m}$ higher than the results from the NNM simulation. This difference is largely due to greater wind speeds in the CFSR wind field.

The basis of all wave model evaluations centers on the comparisons of results to measurements. As in the previous two-storm event analyses, the May 2006 storm model to measurement evaluation is presented in Figure 3-28. Despite the differences in the NNM and CFSR maximum wind speed envelope analysis, the speed and direction model results compare 


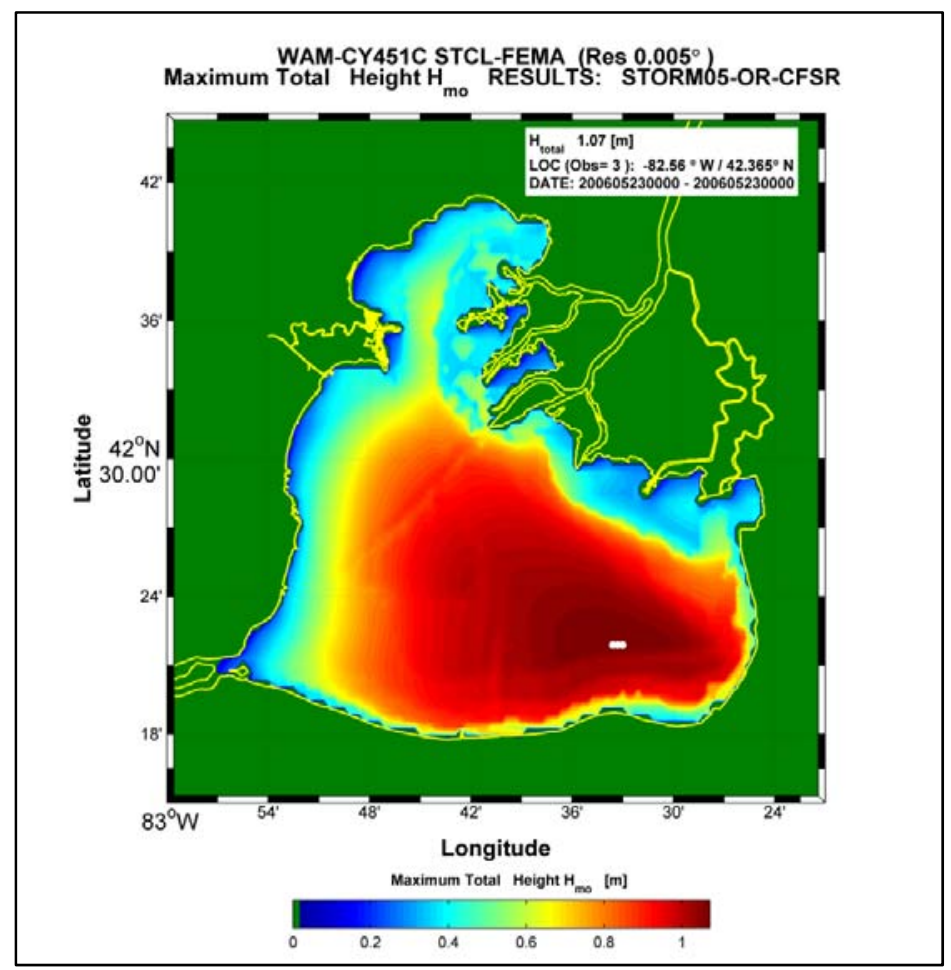

Figure 3-27. Maximum wave height envelope for the May 2006 storm derived from the CFSR wind fields.

well to the buoy measurements as found in the lower two panels of Figure 3-28. It is not surprising NNM results follow the measurements because they are used in the generation of the wind fields; however the CFSR also follow the general trend in the data, with some exceptions. Those exceptions occur around 20 May 1200 UTC where the data suggest a net decrease in the wind magnitude while the CFSR wind speed remains relatively constant. The difference at its maximum is about 4-m/sec. Small scale local oscillations in the lee of the storm peak (after 22 May oooo UTC) are not captured in the CFSR wind fields. They are evident in the NNM. The resulting WAM wave height estimates for wind field forcing show good agreement to the measurements. This result is in contrast to the previous two storms, which indicated a persistent positive bias in the significant wave height, and a negative bias in the wave period estimates. All of these results present a different picture than the previous tests.

As in the previous two cases, a spectral analysis is performed on this data set to determine the cause of the differences in results. The frequency spectrum for each time step of the model and buoy are plotted and displayed in Figure 3-29. The frequency range of the buoy is much larger in this test than in previous tests. The archived frequency spectra for this 
storm are from 0.2 to $0.5-\mathrm{Hz}$. This is a much larger range of frequencies where there is energy in the buoy data records, and is consistent with the model. It is obvious that the buoy data spectra are more sharply peaked, and noisy in the higher frequencies (greater than $0.3-\mathrm{Hz}$ ) compared to model estimates. There does appear to be a few times when the buoy spectral peak energy becomes nearly three times greater than the model results. These peaks correspond to the measurements on the 21 May 1200 UTC (Figure 3-28) where the significant wave height data were close to 0.25 -m greater than the model estimates.

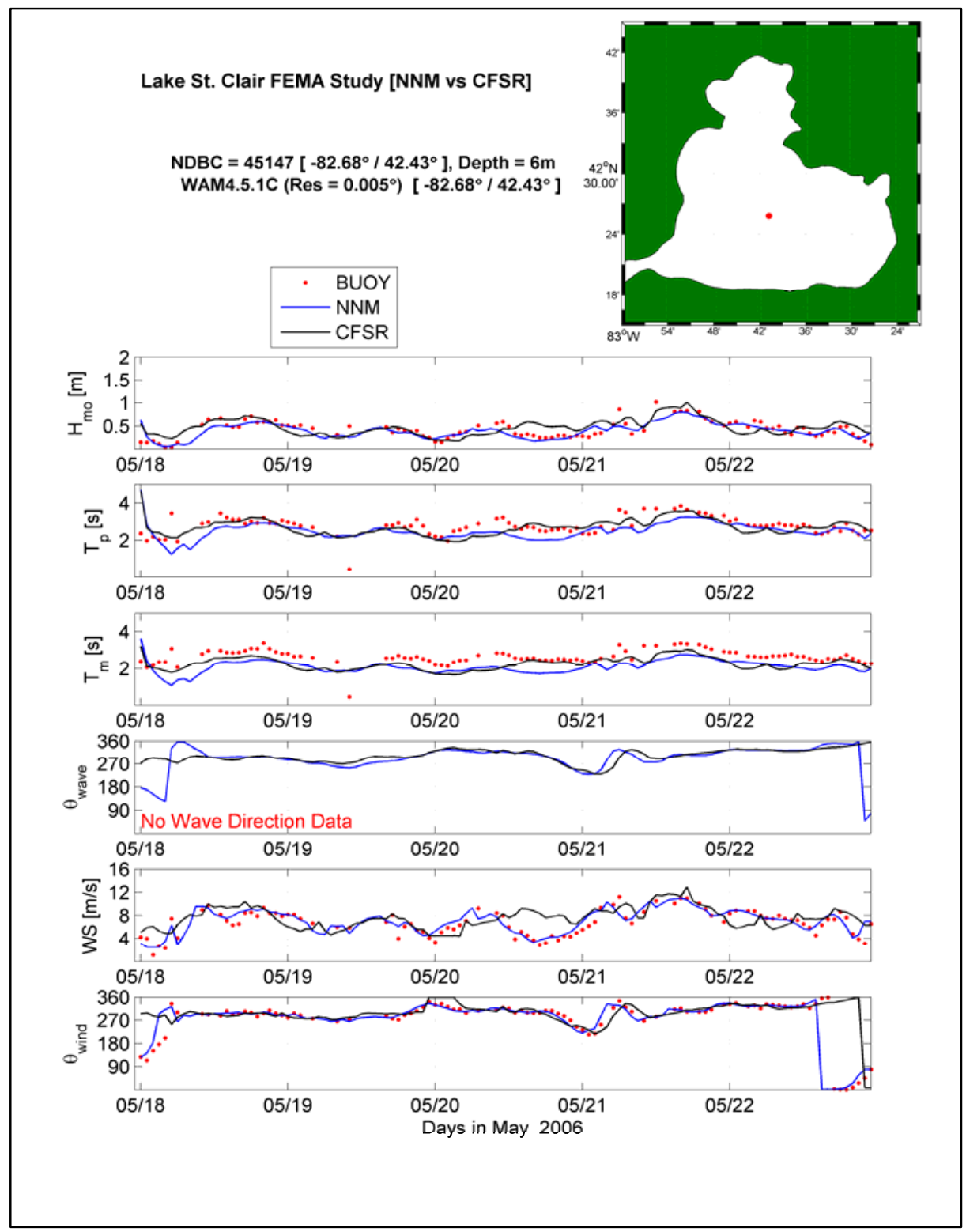

Figure 3-28. Time plots of significant wave height, peak and mean wave period, vector mean wave direction wind speed and direction at Canadian Buoy 45147 for the May 2006 storm. 


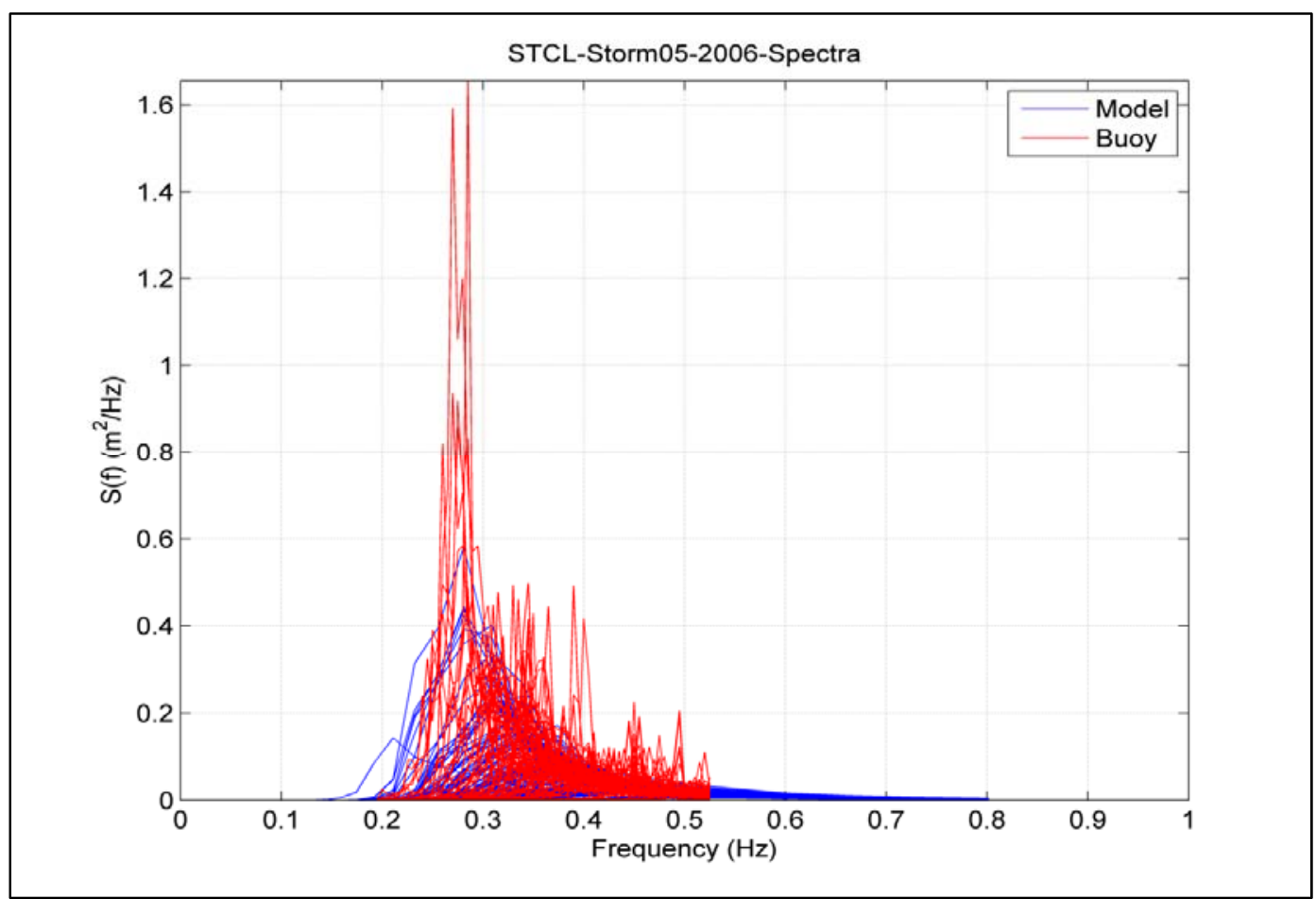

Figure 3-29. Energy density spectrum for Canadian buoy 45147 and WAM output for the May 2006 storm.

The larger frequency range of the measured data, more consistent with WAM's range, can be reinforced by performing the same frequency dependent time series analysis of wave heights described in the previous tests. The wave heights calculated using the full spectrum seem to match the measured wave heights very well (Figure 3-30). In the bottom panel, the wave heights for both models are calculated using energy only from frequency bins greater than 0.2 and less than o.3. The wave heights from the model greatly under-estimate the measured wave heights in this case. This result reinforces the importance of understanding the data set that is being used for model validation.

\subsubsection{May 2009 storm}

The May 2009 event is not in the top ten extreme storm events found in the buoy data archive; however, it contained meteorological characteristics that differed from the previous three storms. Gleaning from the buoy data (45147), the storm initially contained southerly winds at a magnitude of 5 -m/sec. Over the next 24-hrs the wind speed increased to a maximum of $10-\mathrm{m} / \mathrm{sec}$, and remained near that speed for an additional 12-hr. Unfortunately there was an 18-hr data gap after the peak wind condition. From the data records after that gap, one can assume the winds were in a 
decaying mode, ultimately becoming light and variable. The wind speeds ranged between 8 and 12-m/sec during the peak of the storm. The NNM wind fields were developed using fifteen land based stations, the CMAN station, (LSCM4) and Canadian buoy 45147, all considered as marine exposure wind conditions (Figure 3-31).

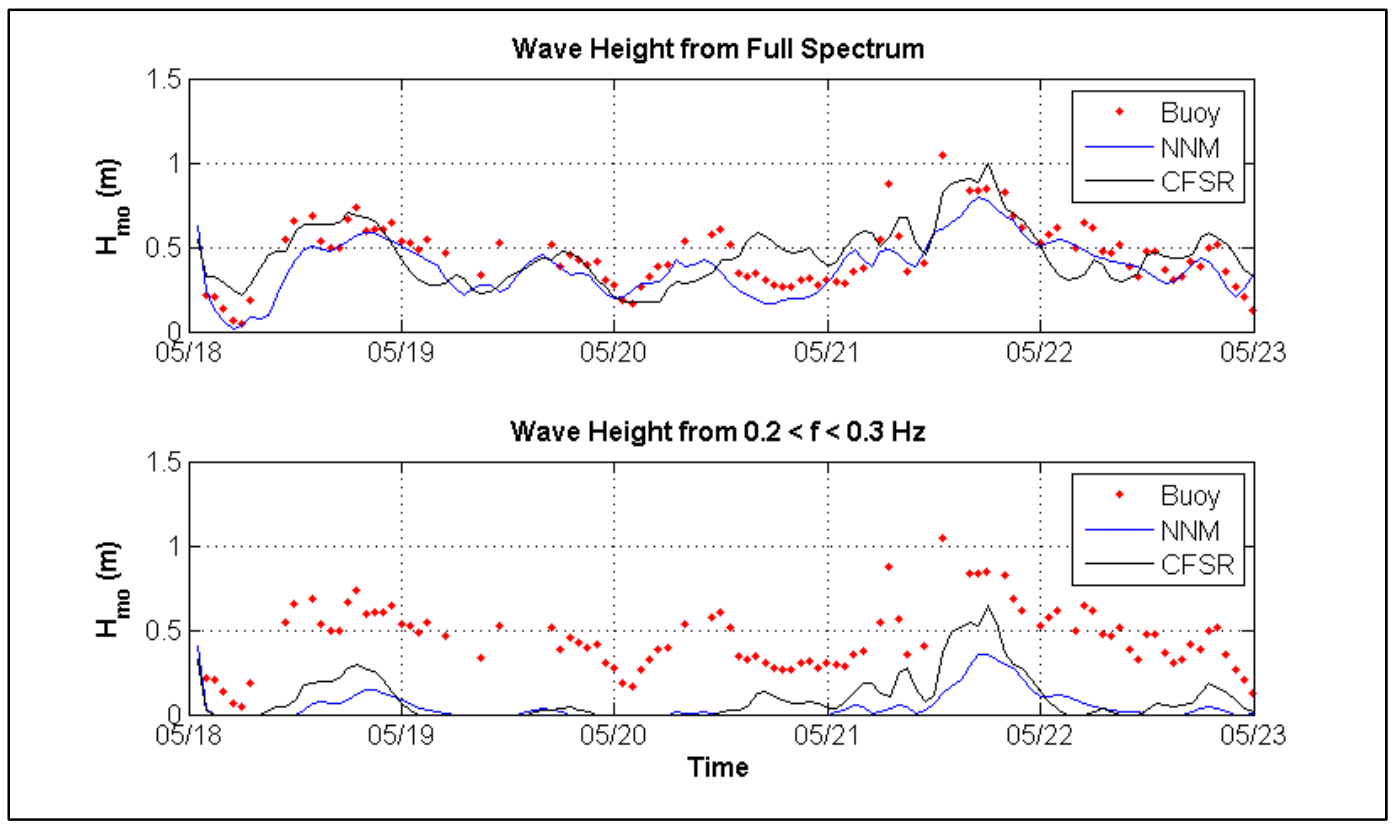

Figure 3-30. Time series of wave heights for calculated from full spectrum and cut spectrum for the May 2006 storm.

The maximum wind speed envelope generated from the NNM wind field has a peak value of $12.28-\mathrm{m} / \mathrm{sec}$ located in the extreme southwestern corner of Lake St. Clair (Figure 3-32). There is a localized high wind speed area co-located to the overall maximum and is of the same magnitude for a secondary peak. This secondary peak of the higher wind speed is contained in the central region of the lake and decaying toward the shore. The CFSR wind speed envelope (Figure 3-33) seems to be controlled by a larger-scale event, where the overall maximum of $16.3-\mathrm{m} / \mathrm{sec}$ is located in the southeastern corner of Lake St. Clair, and a smooth gradient heading in a northwesterly direction. There is a minimum in Anchor Bay, then a slight increase in speed at the coastline.

Given the vast differences in the spatial coverage of the wind speed maxima, one would expect to find a similar variation in the maximum significant wave height envelope. The maximum wave height for WAM forced with $\mathrm{NNM}$ was $0.9-\mathrm{m}$, with the largest maximum along the eastern region of the lake (Figure 3-34), consistent with the abrupt change in water depth 


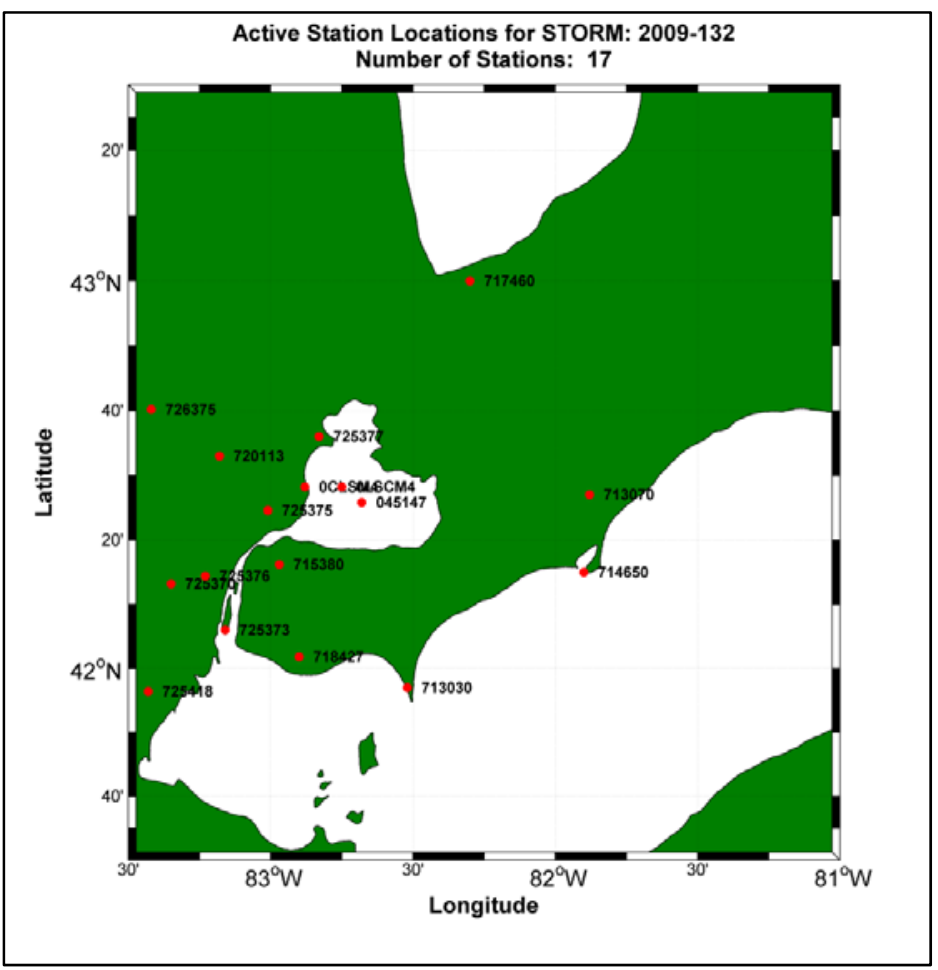

Figure 3-31. Available meteorological station locations accessed and preprocessed for the May 2009 storm.

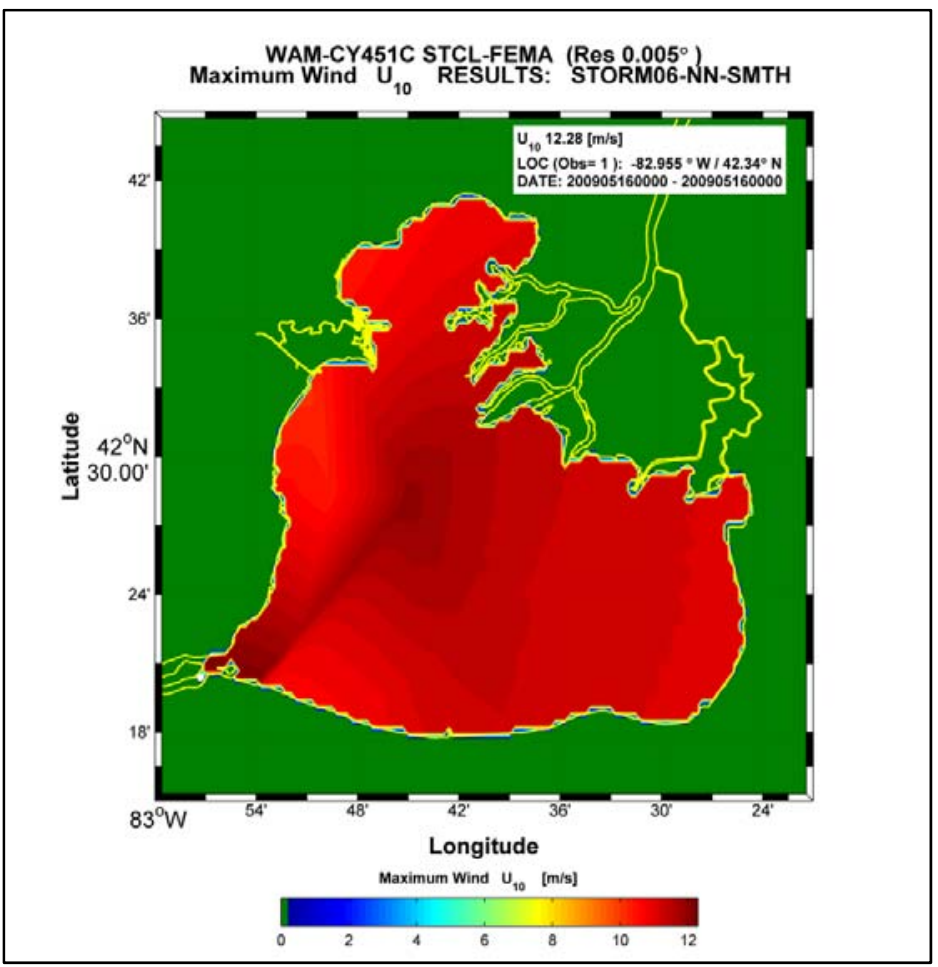

Figure 3-32. Maximum wind speed envelope for the May 2009 storm derived from the NNM wind field generation routine. 


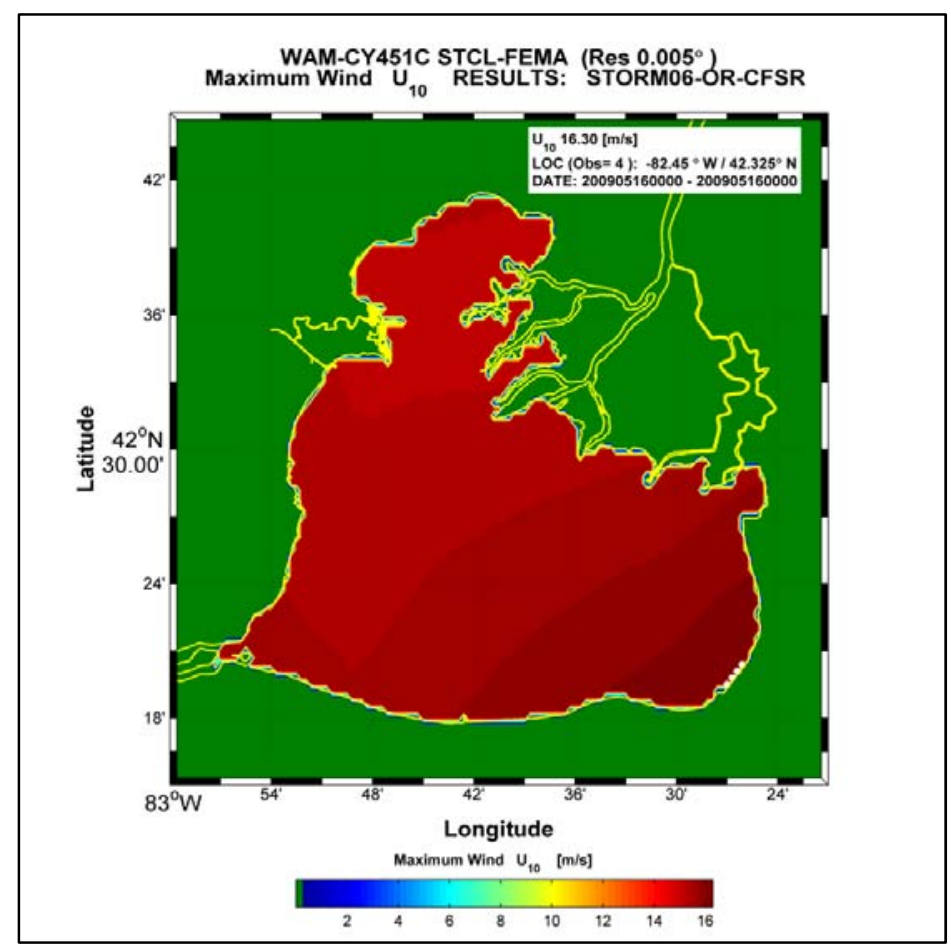

Figure 3-33. Maximum wind speed envelope for the May 2009 storm derived from the CFSR wind field generation routine.

(Figure 3-1). Despite a complex wind speed envelope, the wave envelope generally emulates the changes in bathymetry; turning and focusing energy based on refractive effects, penetrating areas when permitted by slightly deeper water depths, as in the central portion of Anchor Bay, just south of Harsens Island, and along the Canadian coastline near the Thames River. Corresponding with the higher maximum wind speeds in the CFSR wind field, the peak maximum wave height for WAM forced with CFSR is 1.42-m (Figure 3-35). This overall maximum is $0.52-\mathrm{m}$ greater than what was found in the NNM results. The distribution of wave heights derived from CFSR forcing are similar to the NNM results, emulating the bathymetric changes, aligning with the 5 -m contour, and focusing wave energy in water depths along the southern shore of Harsens Island. One difference in the CFSR forced wave conditions is south of the entrance to Anchor Bay; the distribution is detached from the lake proper. This location is at a shoal and the potential for depth induced wave breaking is anticipated. It is highly likely the predominant wind direction dictates the wave climate and the speed only influences the relative magnitude of the wave heights. The maximum wave heights estimated by CFSR forcing of WAM occurred during a more southerly wind than in the estimated wave heights from WAM forced with NNM. The difference in the local affects in NNM would cause slight differences in directions that were observed in this validation case. 


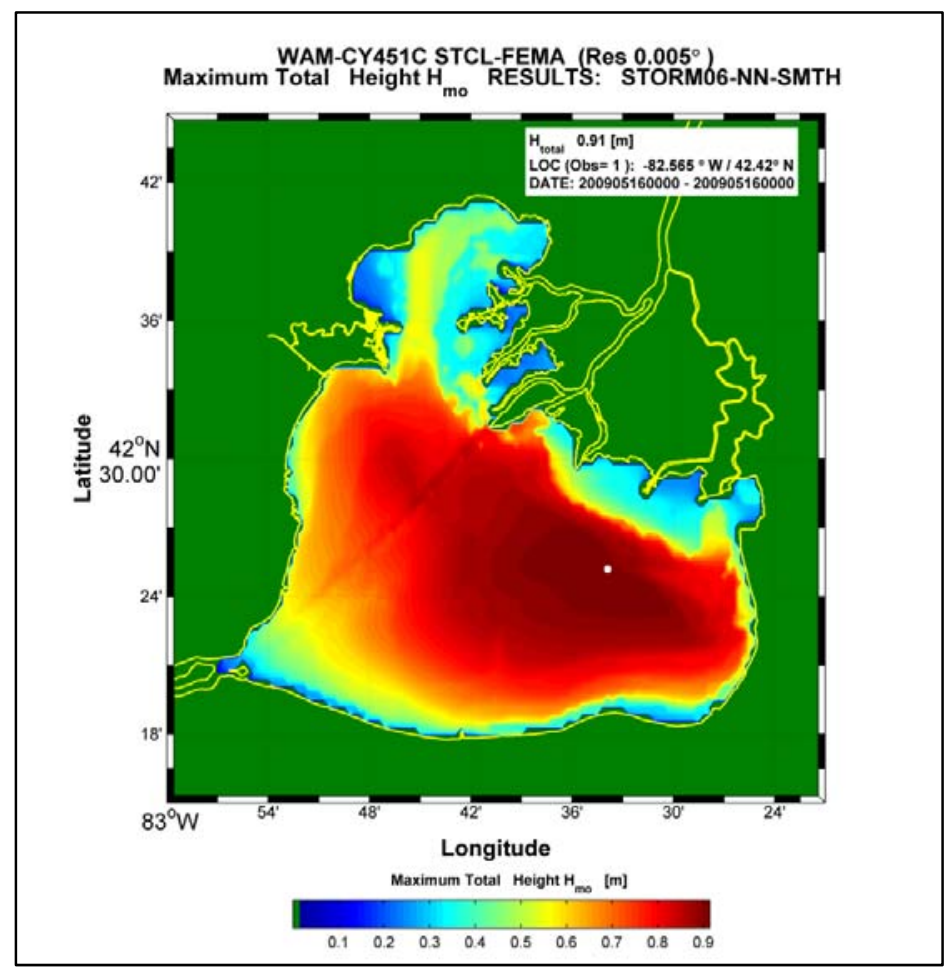

Figure 3-34. Maximum wind speed envelope for the May 2009 storm derived from the NNM wind field generation routine.

The time series of the wave height in Figure 3-36 shows the peak wave height measured by the buoy occurs on 14 May 0700 UTC. The two model results show peaks in wave heights during a similar time frame; however, the CFSR forced WAM simulation leads the measurements by about $2 \mathrm{hr}$ at the storm peak. The NNM forcing lags behind the buoy data by about four hours. Both model simulations are biased high (about 0.25- to 0.5-m), despite NNM matching the winds, and CFSR being slightly higher than the observations. The model results for the peak wave period is good only during the time at which the measured wave height exceeds about 0.5-m and near the storm peak. The WAM mean wave period results are negatively biased compared to the data by at least 1-sec. However, the buoy data wave periods seem to be independent of any wind forcing or change in the wave climate over time. Overall, both NNM and CFSR forced WAM results are a poor representation of the measured conditions during the extent of this simulation. In general, the NNM results appear to be slightly better compared to CFSR.

Examining frequency spectra at 45147 found in the Environment Canada archive reveals the reasoning why the measured wave period estimates are invariant to the wind forcing. The spectra measured by the buoy were cut off 


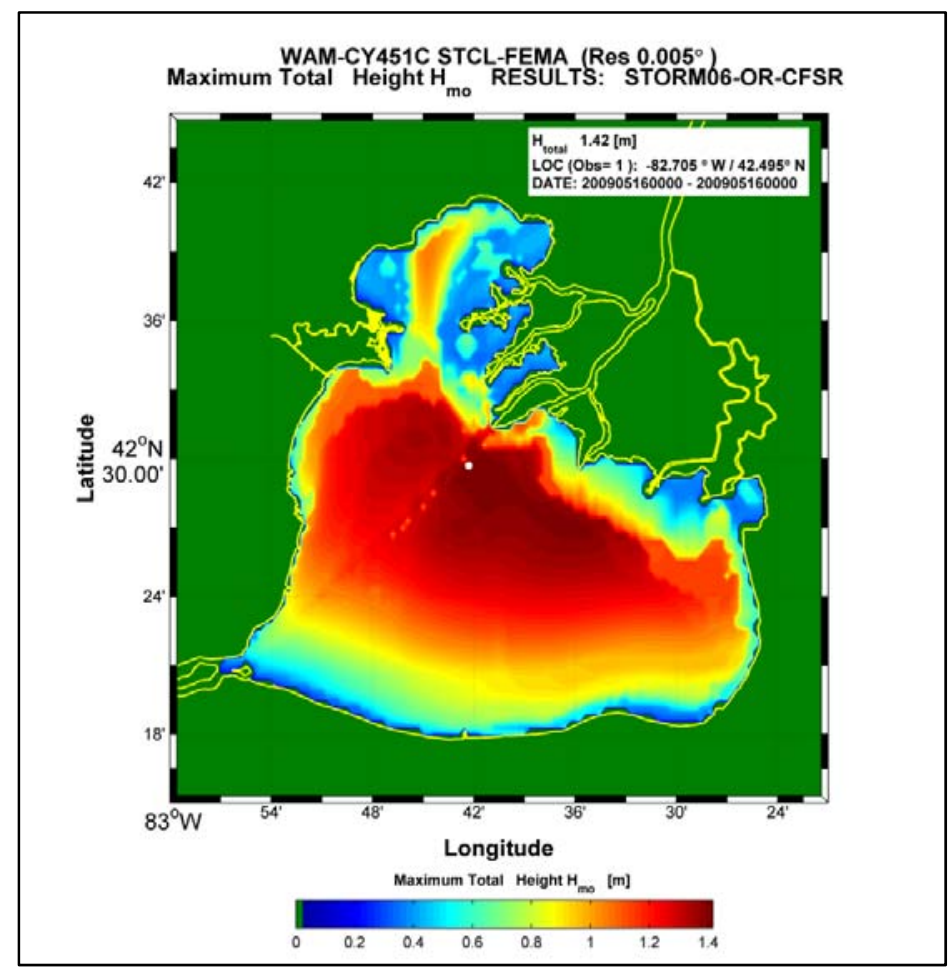

Figure 3-35. Maximum wind speed envelope for the May 2009 storm derived from the CFSR wind field generation routine.

at frequencies greater than $0.3-\mathrm{Hz}$, and less than $0.2-\mathrm{Hz}$ (Figure 3-37). The latter was to eliminate low frequency noise. The resulting spectra occupy a limited range of frequencies (0.2- to $0.3-\mathrm{Hz}$ ) in a wave climate generally dominated by very short period waves (2- to 4-s). Comparing this with the WAM frequency range (blue lines Figure 3-37), there is substantial energy existing above $0.3-\mathrm{Hz}$. The peak frequencies in the WAM result are closer to $0.2-\mathrm{Hz}$ while the peak frequency measured by the buoy is closer to $0.3-\mathrm{Hz}$. The larger frequency range in WAM contributes to the over-estimation of the wave height seen in Figure 3-36. The result of filtering the WAM spectra to match the measured spectra frequency range in Figure 3-38 show good agreement in the WAM forced with CFSR results leading up to the peak. The peak of the storm is still over-estimated by WAM forced with CFSR, but the results are improved.

\subsubsection{November 2007 storm}

The November storm from 2007 is the fifth ranked extreme wave event measured at buoy 45147. The maximum wave height measured at the peak of the storm is $0.98-\mathrm{m}$. The NNM wind field was generated using eighteen meteorological stations, sixteen land based stations and two marine exposure sites (Figure 3-39). The storm consisted of multiple peaks in wind 
speed with speeds near $15-\mathrm{m} / \mathrm{sec}$ at the peaks and six wind directional shifts of 90-deg or larger over a nine-day simulation period. During the peak storm event (2 December 120oUTC) the wind speed reached about $15-\mathrm{m} / \mathrm{sec}$ and the wind directions reached a constant 270-deg (westerly) for about 12-hr. In one of the minor events (2 December 0200UTC), the wind speed increased to $10-\mathrm{m} / \mathrm{sec}$ over a 12-hr period while the direction shifted from the north to the east. Of all of the storms selected, this nine-day cycle contained the most complex meteorological forcing. With all of the meteorological events moving through the Lake St. Clair domain, the maximum wind speed envelope graphic is expected to reflect some of these conditions.

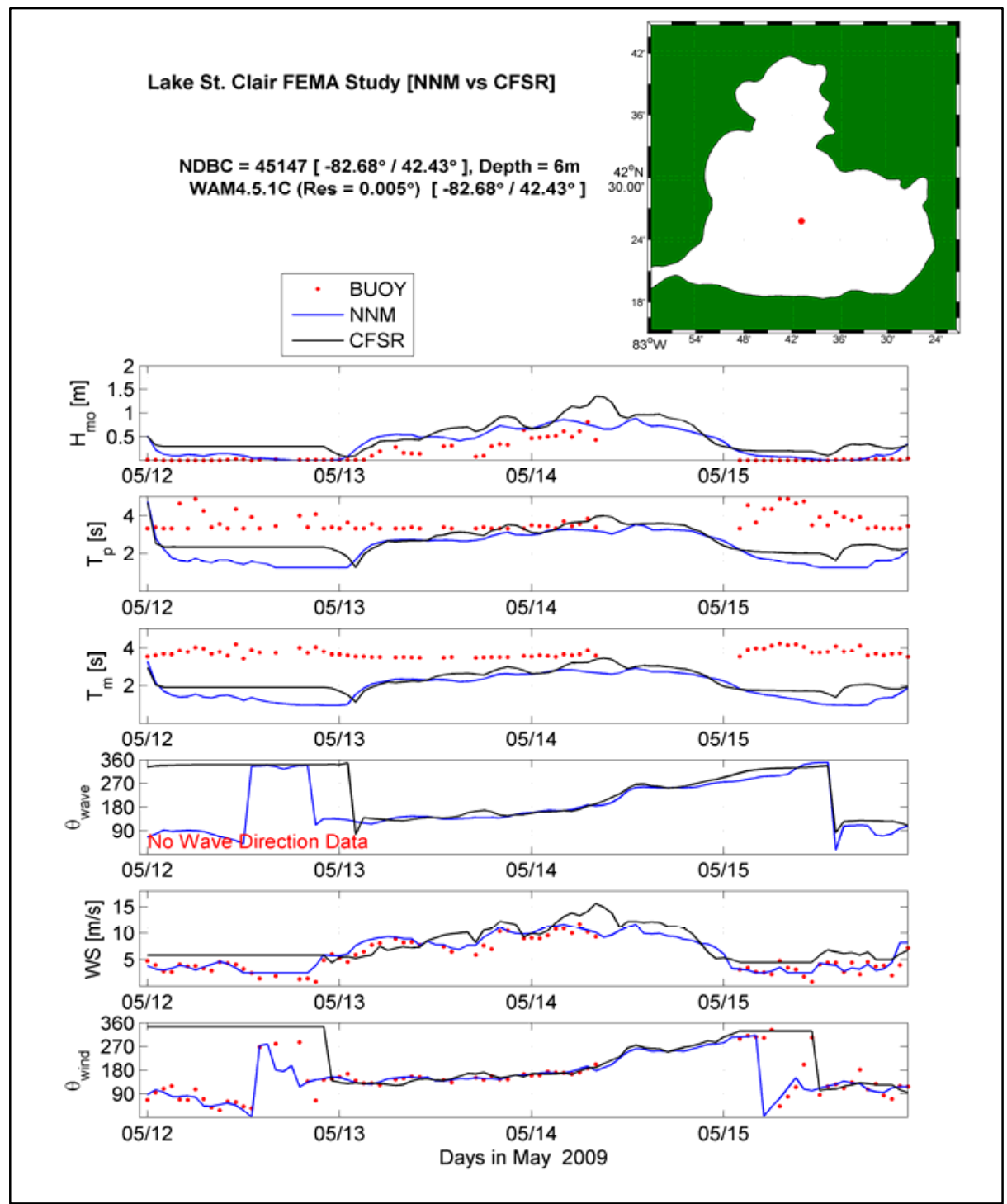

Figure 3-36. Time plots of significant wave height, peak and mean wave period, vector mean wave direction wind speed and direction at Canadian Buoy 45147 for the May 2009 storm. 


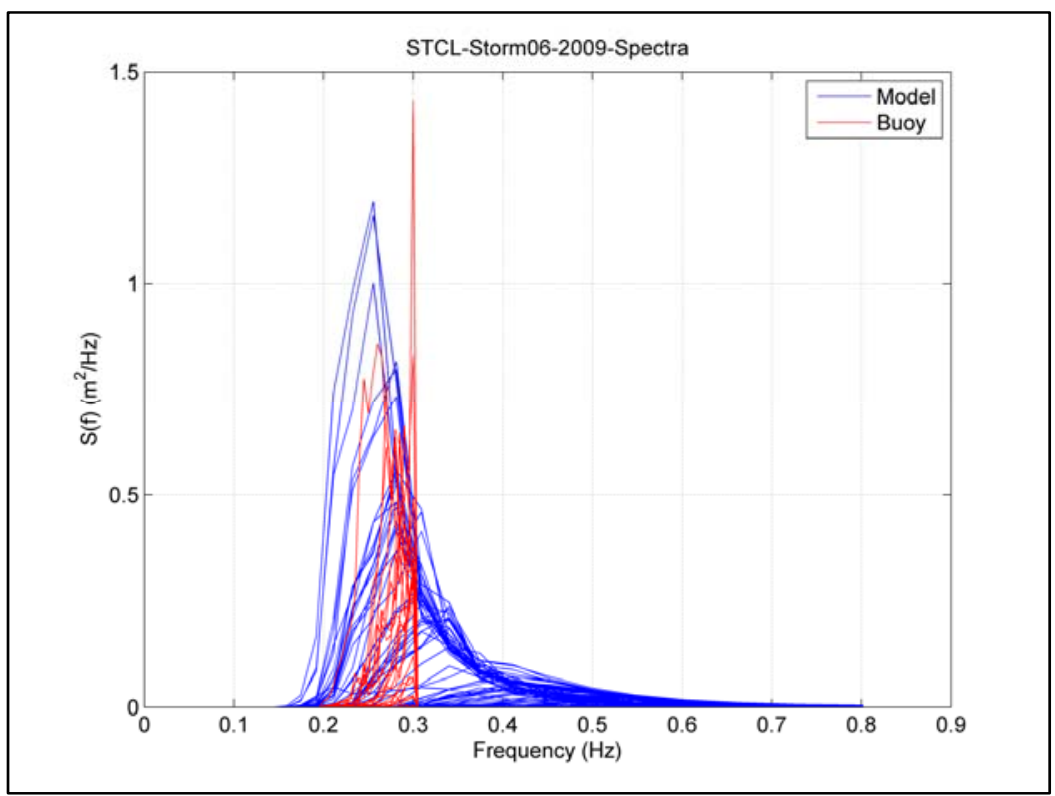

Figure 3-37. Energy density spectrum for Canadian buoy 45147 and WAM output for the May 2009 storm.

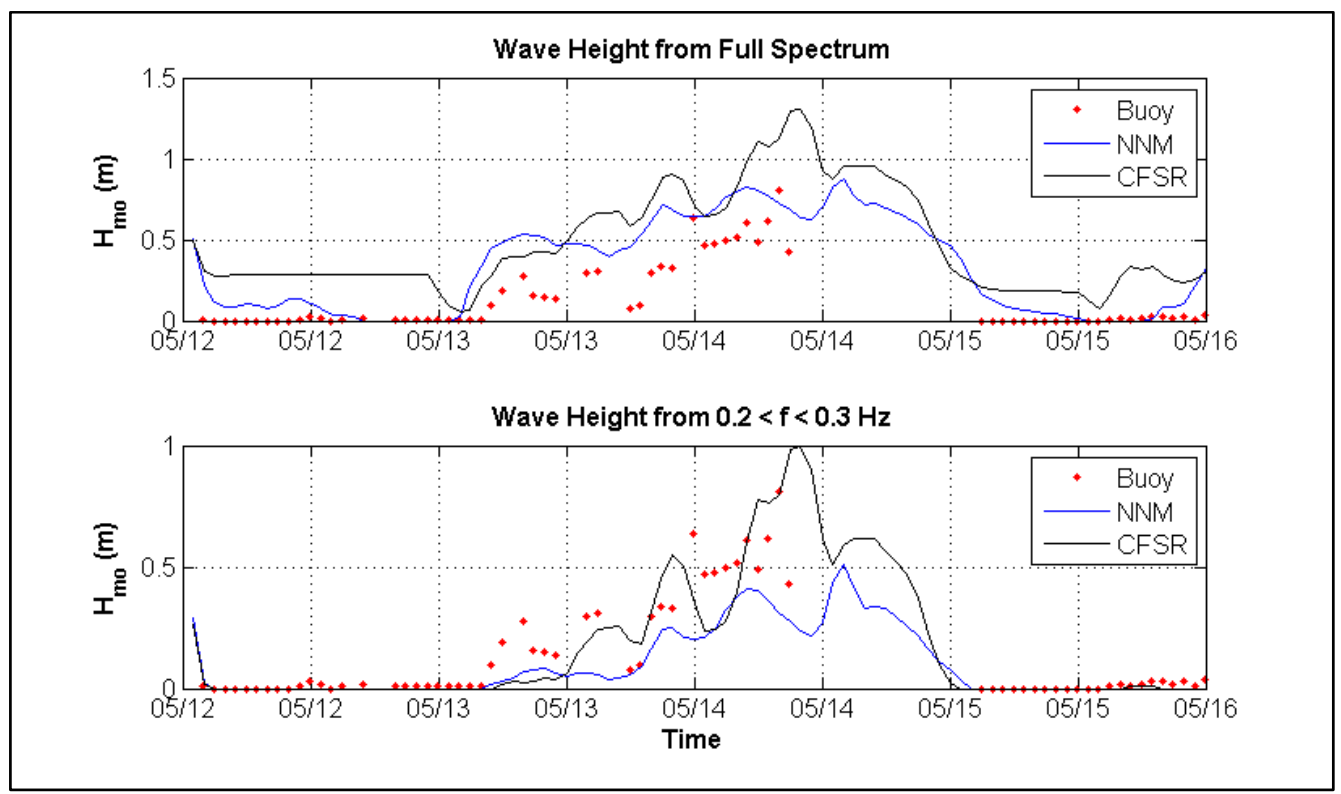

Figure 3-38. Time series of wave heights for calculated from full spectrum and cut spectrum for the May 2009 storm.

However, this is not the case. The NNM results are found in Figure 3-40 where the magnitude is fairly uniform over the lake. The maximum wind speeds in the NNM wind field in Figure 3-40 are greatest along the western side of the lake. Specifically, the highest wind speeds of $17.47-\mathrm{m} / \mathrm{sec}$ are located in the northwest region of the lake. The maximum wind speeds decreased to approximately $14-\mathrm{m} / \mathrm{sec}$ on the eastern region of the lake. The maximum wind speeds in the CFSR wind field in Figure 3-41 are located on 


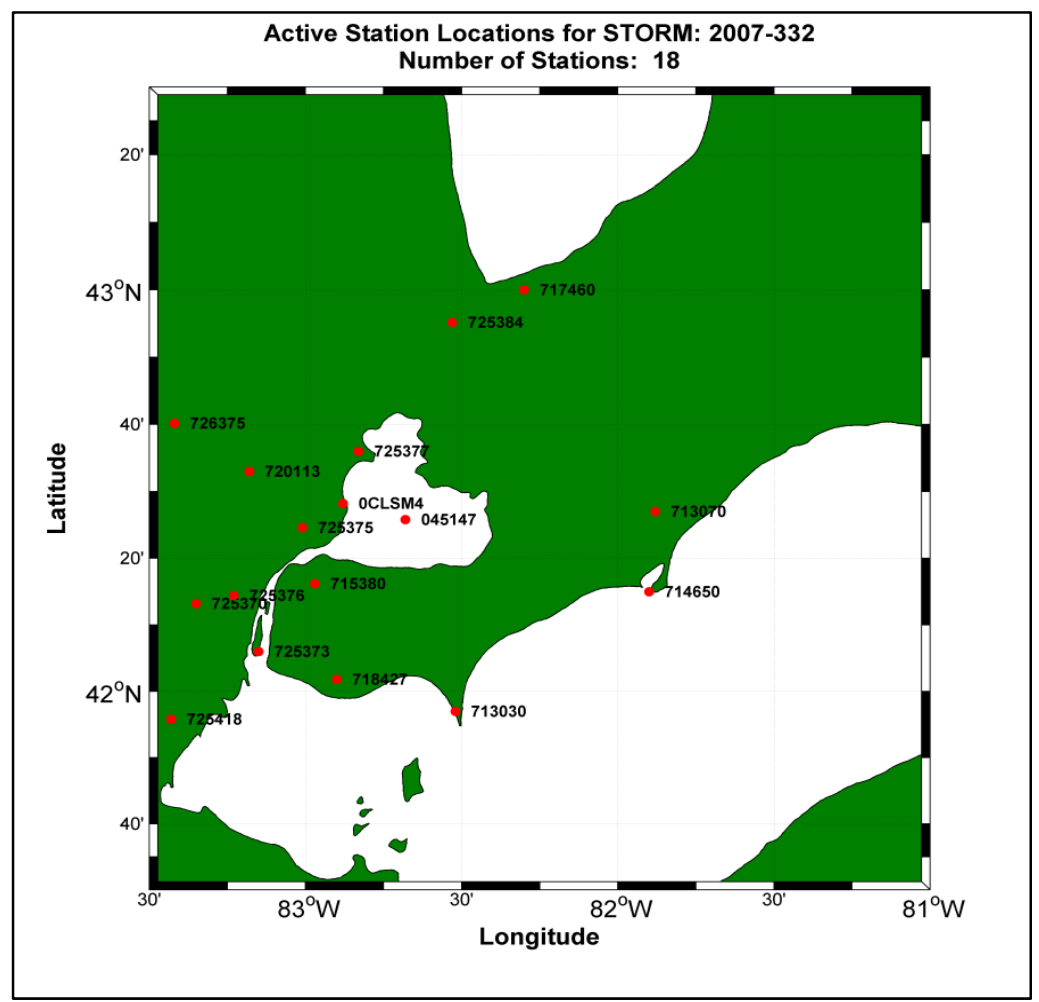

Figure 3-39. Available meteorological station locations accessed and preprocessed for the November 2007 storm.

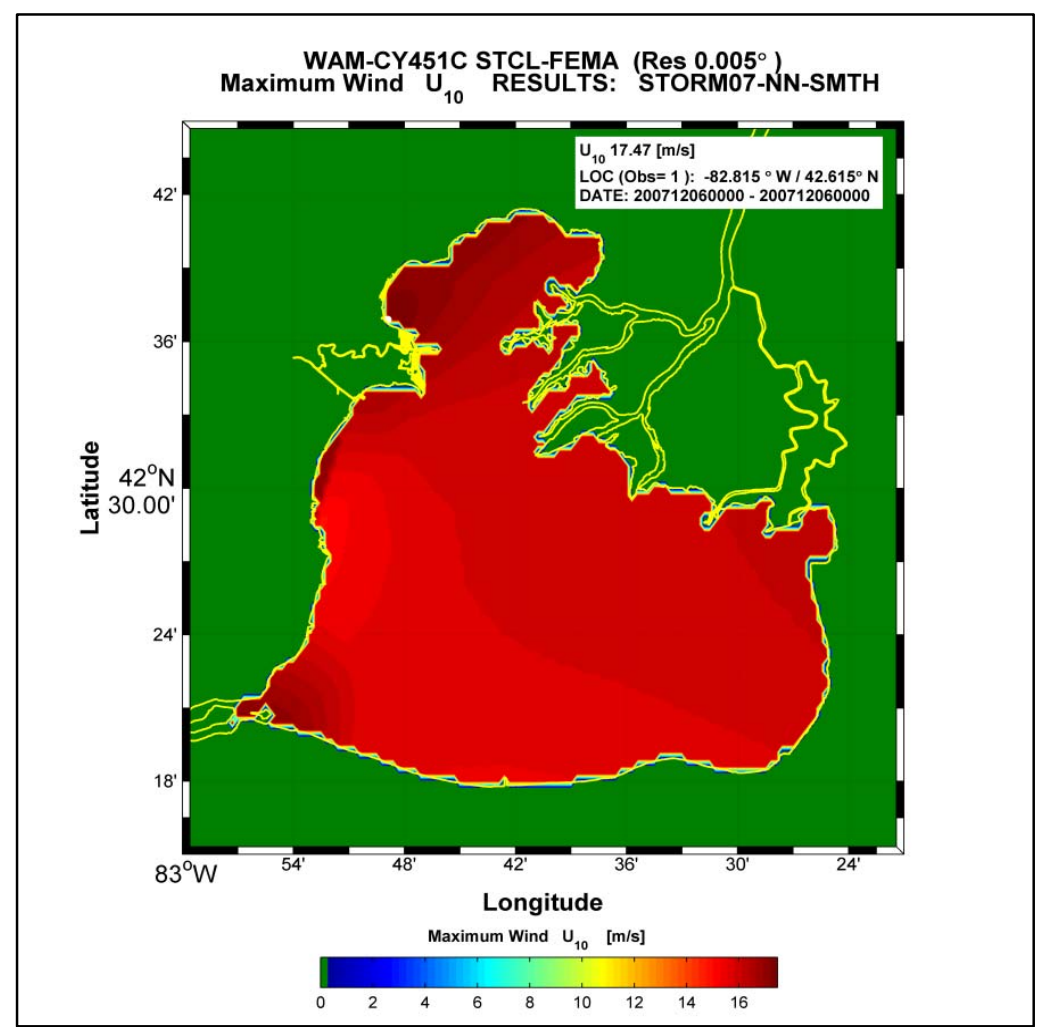

Figure 3-40. Maximum wind speed envelope for the November 2007 storm derived from the NNM wind field generation routine. 


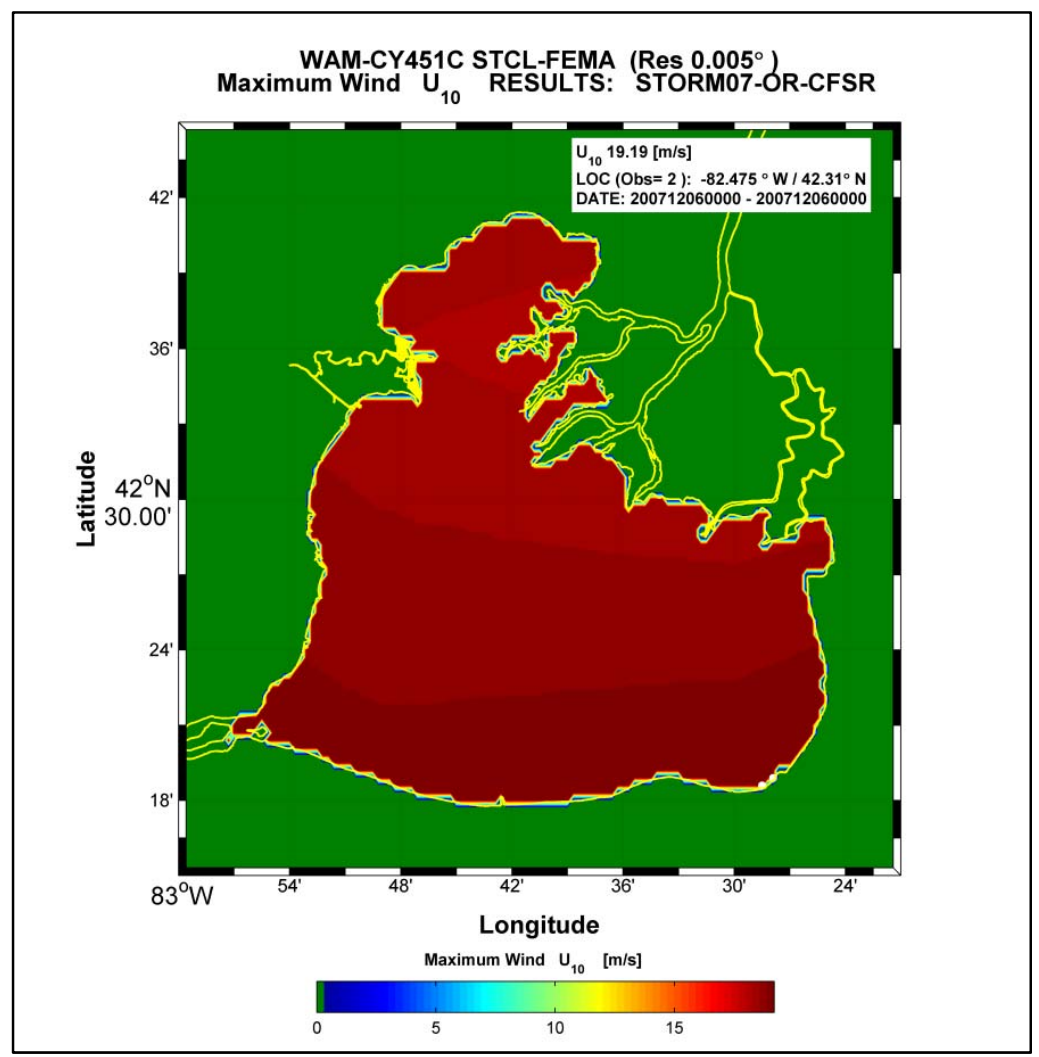

Figure 3-41. Maximum wind speed envelope for the November 2007 storm derived from the CFSR wind field generation routine.

the southern portion of the lake and the gradient is north to south, in direct contrast to NNM. The maximum wind speed of $19.19-\mathrm{m} / \mathrm{sec}$ is located in the southeast corner of the lake. There is also little or no variation in the magnitudes found in this wind speed envelope throughout the lake.

The maximum wave heights in Figure 3-42 from WAM forced with NNM have the largest wave heights in the southeast region of the lake. The largest maximum wave height is $1.59-\mathrm{m}$. The maximum wave height decreased to the west with the smallest maximum wave heights in the north region of the lake. The maximum wave heights from WAM forced with CSFR, in Figure 3-43, show a similar contour shape as the NNM results. The largest maximum wave heights are located in the southeast corner of the lake. The largest wave height in the CFSR is $1.89-\mathrm{m}$ or $0.3-\mathrm{m}$ greater than the NNM results. Larger maximum wave heights persist in the western region of the lake in the WAM forced with CFSR tests than in the NNM tests. 


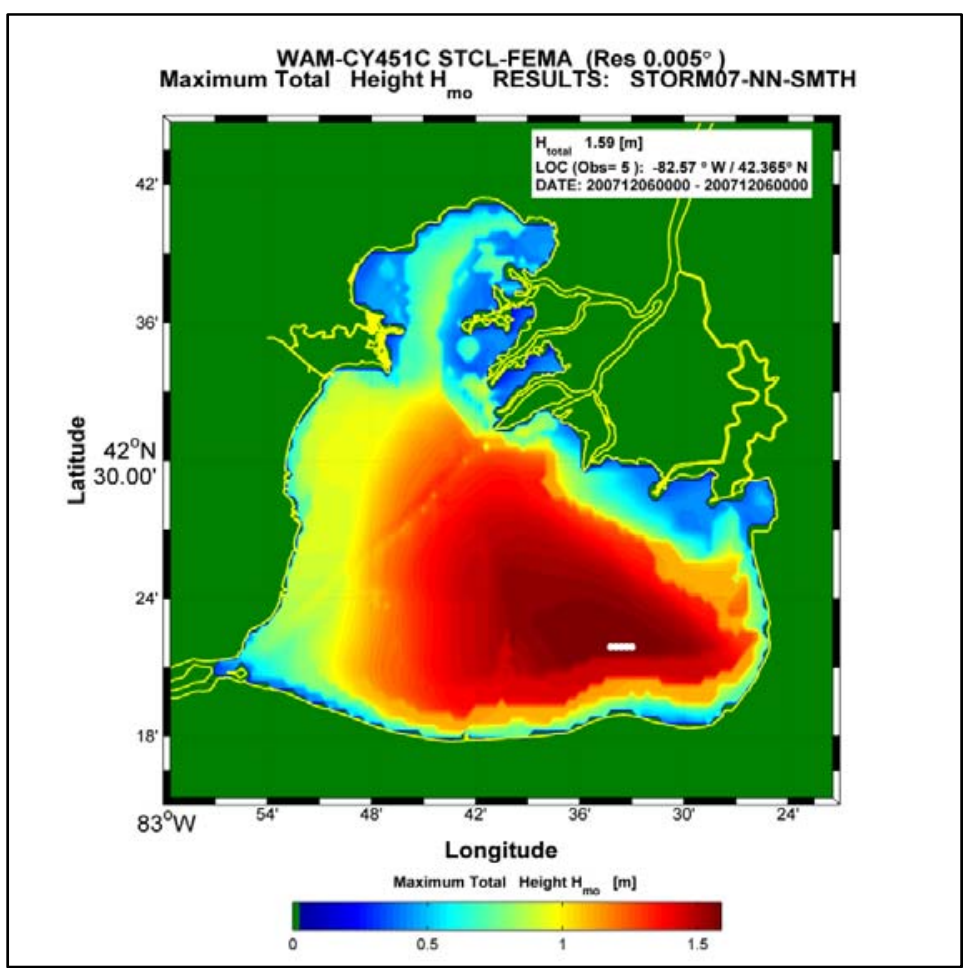

Figure 3-42. Maximum wind speed envelope for the November 2007 storm derived from the NNM wind field generation routine.

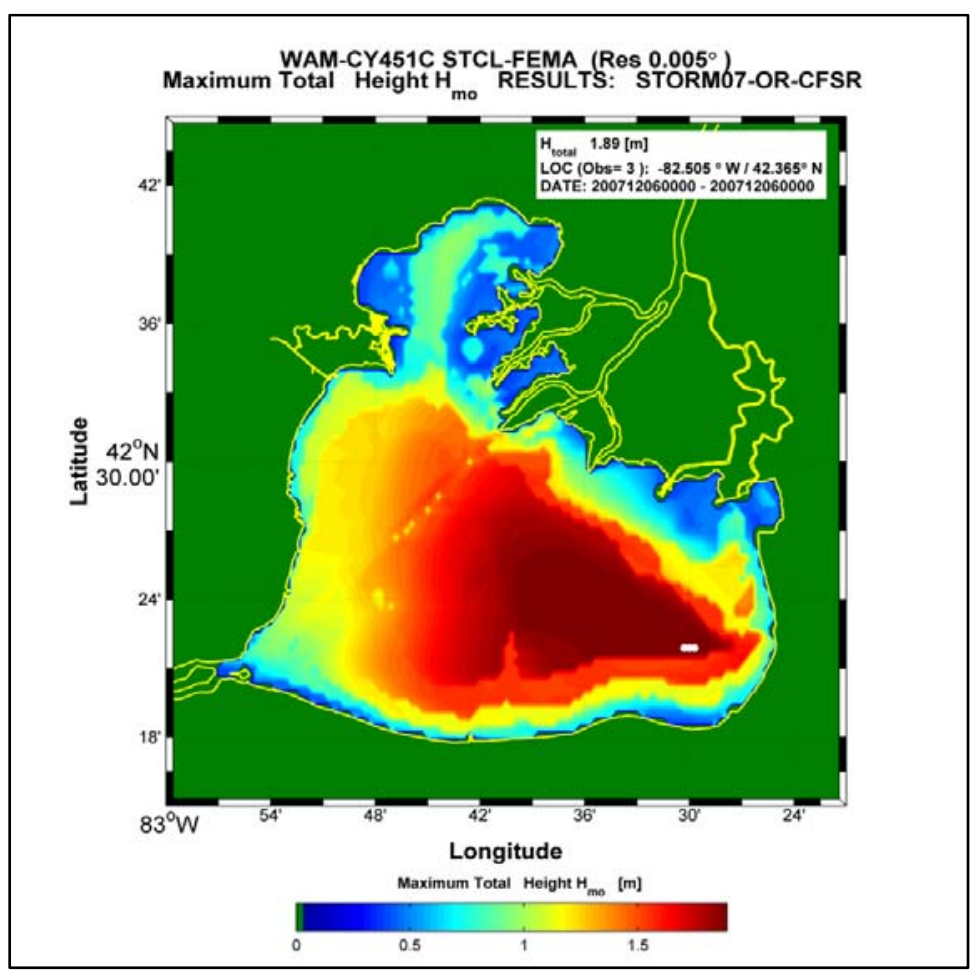

Figure 3-43. Maximum wind speed envelope for the November 2007 storm derived from the CFSR wind field generation routine. 
The time series of wave heights in Figure 3-44 show the multiple peaks during the storm time frame. There are four storm event peaks that occur over a five day period. The WAM model wave height results forced by NNM and CFSR follow the trend in the buoy data; however, they contain a persistent positive bias over the entire simulation compared to the measured wave heights. The WAM forced with NNM wave heights compare better to the existing data set, while the CFSR simulation results possess slightly more energy at the storm peaks. These results emulate the wind speed evaluation, where CFSR estimates fall generally above the measurements, while the NNM track the data. This is true especially during the lulls between storm peaks. There also appears to be little or no change in the buoy data wave period estimates for the entire simulation. Despite the wind speed variation, and the six wind directional shifts, the buoy measurements suggest the dominant wave period found in Lake St. Clair is about 3.5 -sec. The WAM results indicate a stronger variation in the wave period climate ranging from $2.0-$ to $4.5-\mathrm{sec}$.

The filtering of the frequency range used in processing the WAM results (Figure 3-45) shows that the agreement in the integral wave height can be attained. If the WAM frequency spectral range is set to that of the measurements, the strong positive bias is significantly reduced. Both model simulation results were still slightly higher than the measured wave heights; however the bulk of the positive bias has been removed. This suggests WAM spectral estimates contain approximately one-quarter of the total energy in the high frequency range. Given the size of Lake St. Clair, and the applied forcing (wind input), this is reasonable. The WAM forced with NNM compares more favorably to the measured wave heights than WAM forced with CFSR. The differences however, can be assumed to be small because of buoy measurements seemingly missing a majority of the record, especially at the storm peaks.

\subsubsection{Donelan et al. study}

The study in Lake St. Clair by Donelan et al. (1992) was conducted in 1985 to measure the growth rate of wind-generated waves. The study provided multiple wave measurement sites in Lake St. Clair during three month duration. From the previous storm cases, the evaluation of WAM (and indirectly the two wind field methods), there was only one point-source measurement site to validate the model's performance. In this study, six wave towers were deployed on the southeast corner of the lake. The measurement devices consisted of three towers from Great Lakes 


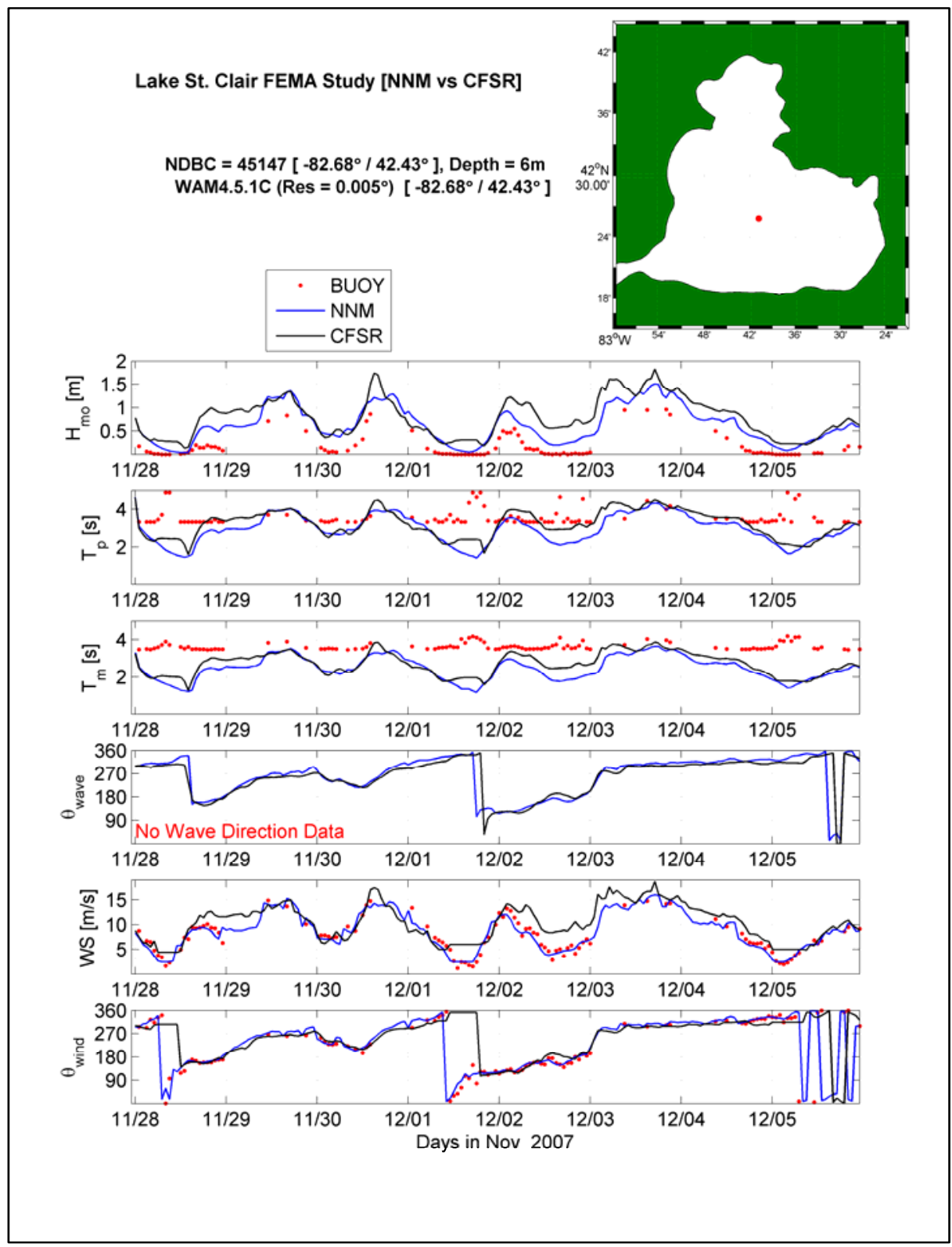

Figure 3-44. Time plots of significant wave height, peak and mean wave period, vector mean wave direction wind speed and direction at Canadian Buoy 45147 for the November 2007 storm.

Environmental Research Laboratory (GLERL), and three towers from the National Water Research Institute (NWRI) of Environment Canada. Five of the towers were aligned at 295-deg from north with the sixth tower off to the south of the linear array (Figure 3-46). The towers numbered 85001, 85003 , and 85005 are from NWRI. Towers 85002,85004 , and 85006 are from GLERL. The contours in Figure 3-46 are an example of the maximum wave height from WAM forced with CFSR during a segment of the experiment. 


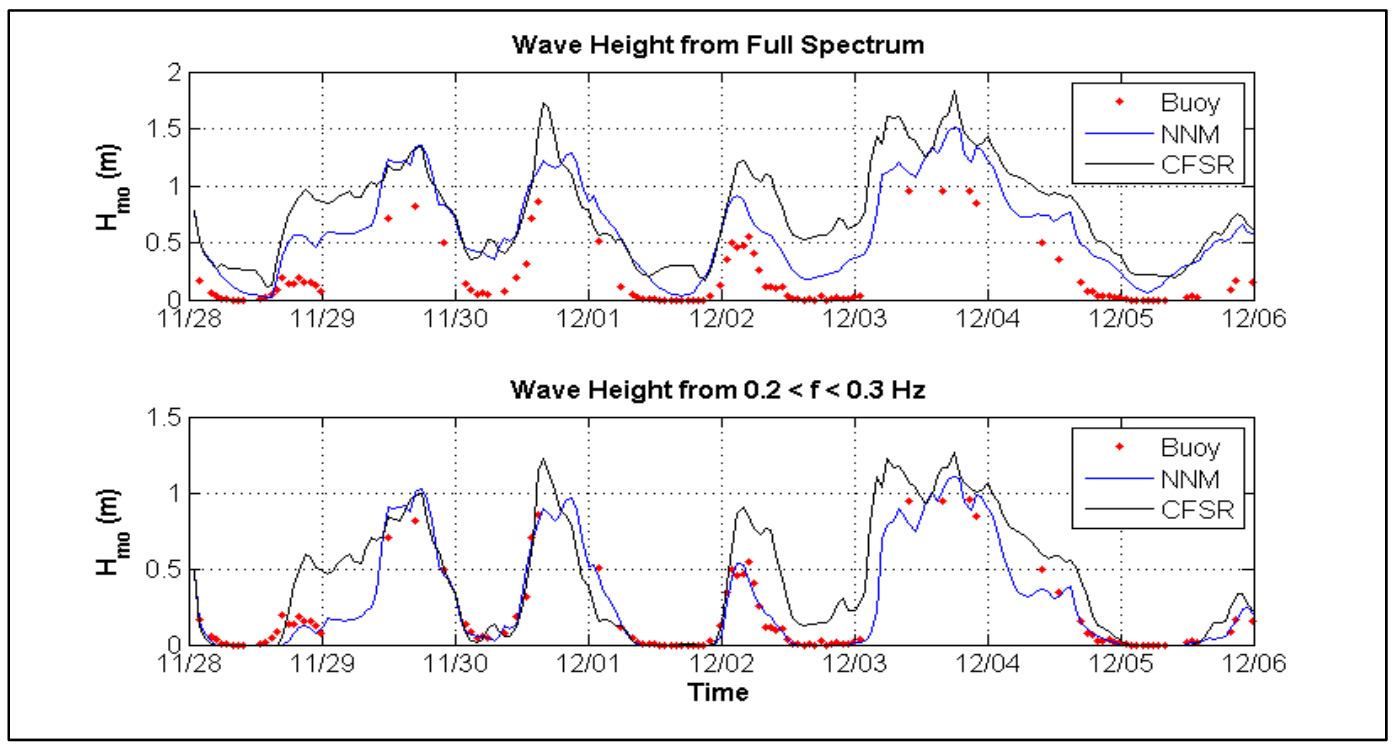

Figure 3-45. Time series of wave heights for calculated from full spectrum and cut spectrum for the May 2009 storm.

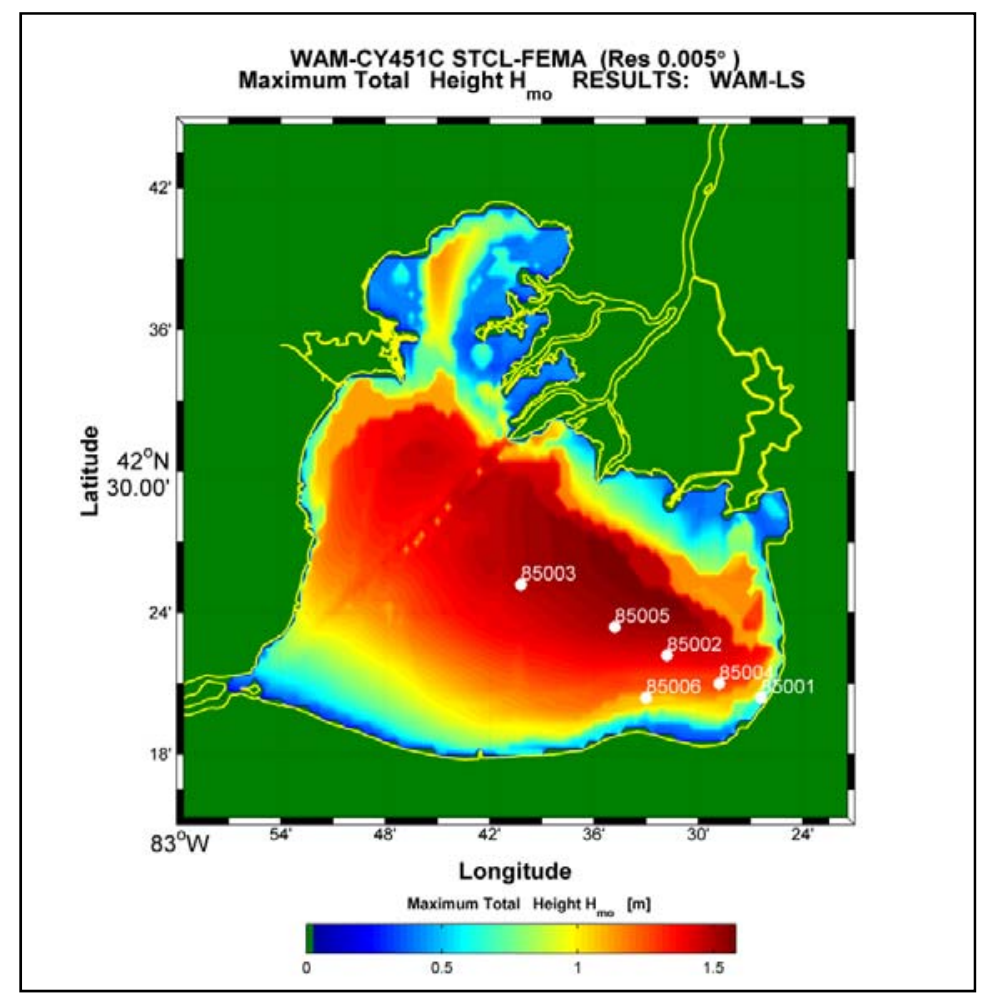

Figure 3-46. Location of wave towers during the 1985 Donelan et al. (1992) study.

The measured results were received in integral parameter form, $\left(H_{m o}, T_{p}\right.$, and $\theta_{\text {wave }}$ only for the NWRI data) so no spectral information is available to conduct the advanced calculations that were described in the previous tests. The wind speed and direction data was based on an average of multiple 
measurements around the lake. There was no in-situ measurement of wind speed and wind direction. The time series was split into three segments to focus on the peaks during the three-month data collection period. The first segment is from 3 October to 10 October with a maximum measured wind speed of $10-\mathrm{m} / \mathrm{sec}$. The second segment is from 18 November to 23 November containing a maximum measured wind speed of $13-\mathrm{m} / \mathrm{sec}$; and the final segment is from 30 November to 04 December with a maximum measured wind speed of $18-\mathrm{m} / \mathrm{sec}$. The three segments were run as if they are unrelated storms to focus the calculated statistics on the peak events instead of the low wave energy episodes. The NWRI data records were discontinuous, identifying wave conditions only during moderate wind events.

The wave height compendium time series for the first segment in Figure 3-47, displays the limited data set available. The peak for this segment occurred during the 5 October with an initial smaller peak occurring at the end of the day on the 4 October. The time series of wave heights from NNM and CFSR forced WAM model runs generally follow the trends in the measurements, except at the storm peak. The initial peak was estimated well by both model runs at all of the wave towers. However, both wind fields (NNM and CFSR) over-estimate the peak by $0.2-\mathrm{m}$ at all sites.

Further analysis was needed to determine the cause of the over estimation at the peak of the storm, so the six parameter plots (wave height, peak, mean wave period, wave direction wind speed and direction) were used. An example from station 85005 in Figure 3-48 identifies the difficulty encountered in the evaluation of this validation data set. The wind speeds are much lower in the reported data set because they are the averaged wind speed measured at a number of sites around the lake. The exact locations are not reported, and the data analysis performed was not described. The peak period in Panel 2 and the wind direction in Panel 6 show very good agreement between the measured data and the model results. The disagreement between the measured and model data in this experiment, combined with the lack of information and availability of the data, make this data set unsupportive of the present evaluation. The results show interesting trends, but no further understanding of the wave heights in Lake St. Clair can be drawn from comparisons between the wave model and the 1985 study data set. 


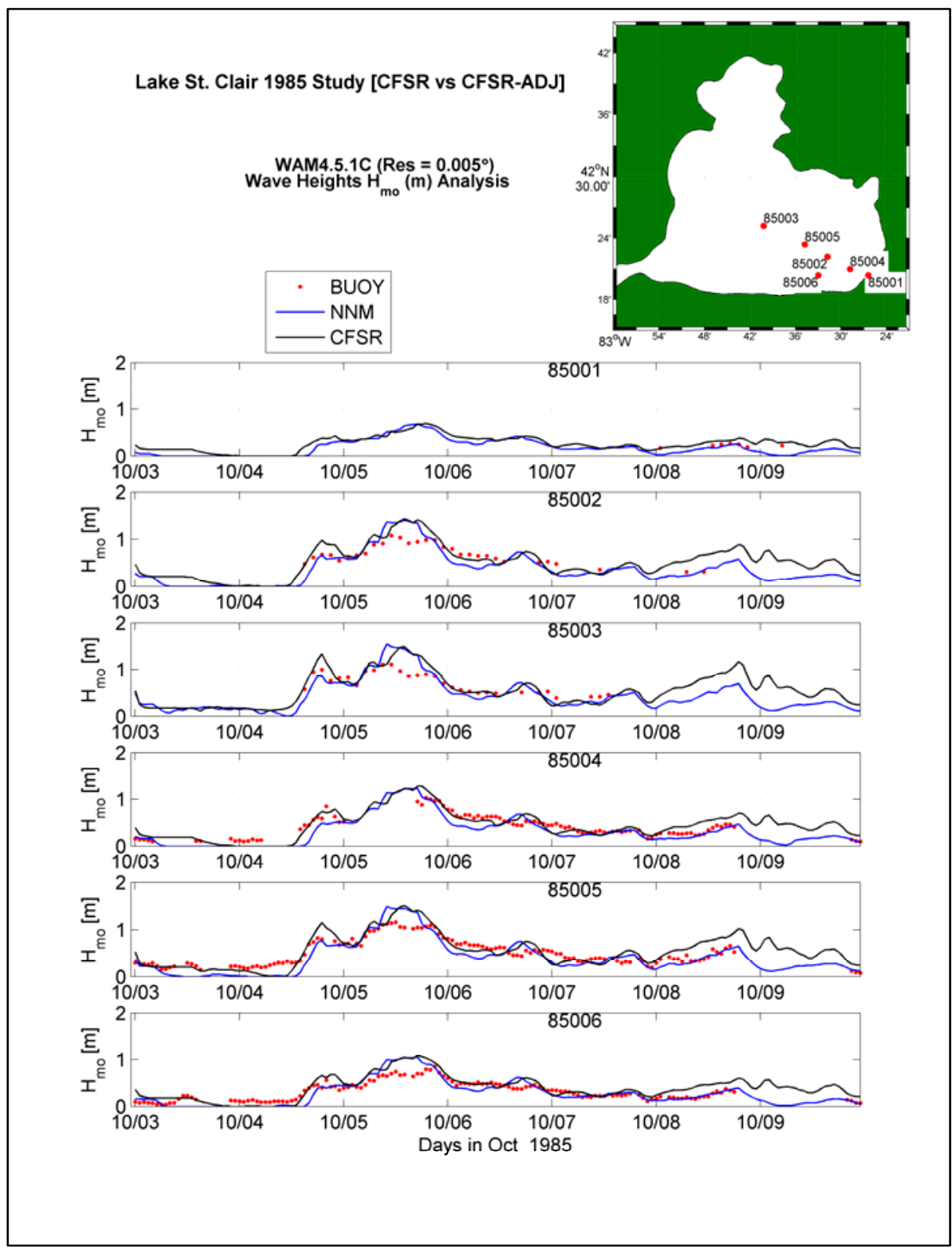

Figure 3-47. Compendium time plots of significant wave height at all six stations for segment 1 of 1985 Donelan et al. (1992) study.

\subsection{Summary of observations and recommendations}

The following summarizes OBSERVATIONS, defined here as findings that occurred during the processing of winds, ice and/or wave modeling tasks. The OBSERVATIONS can be further pursued in the future and have modest bearing on the outcome of the study. The RECOMMENDATIONS should be specifically pursued to assure overall success of the study. 


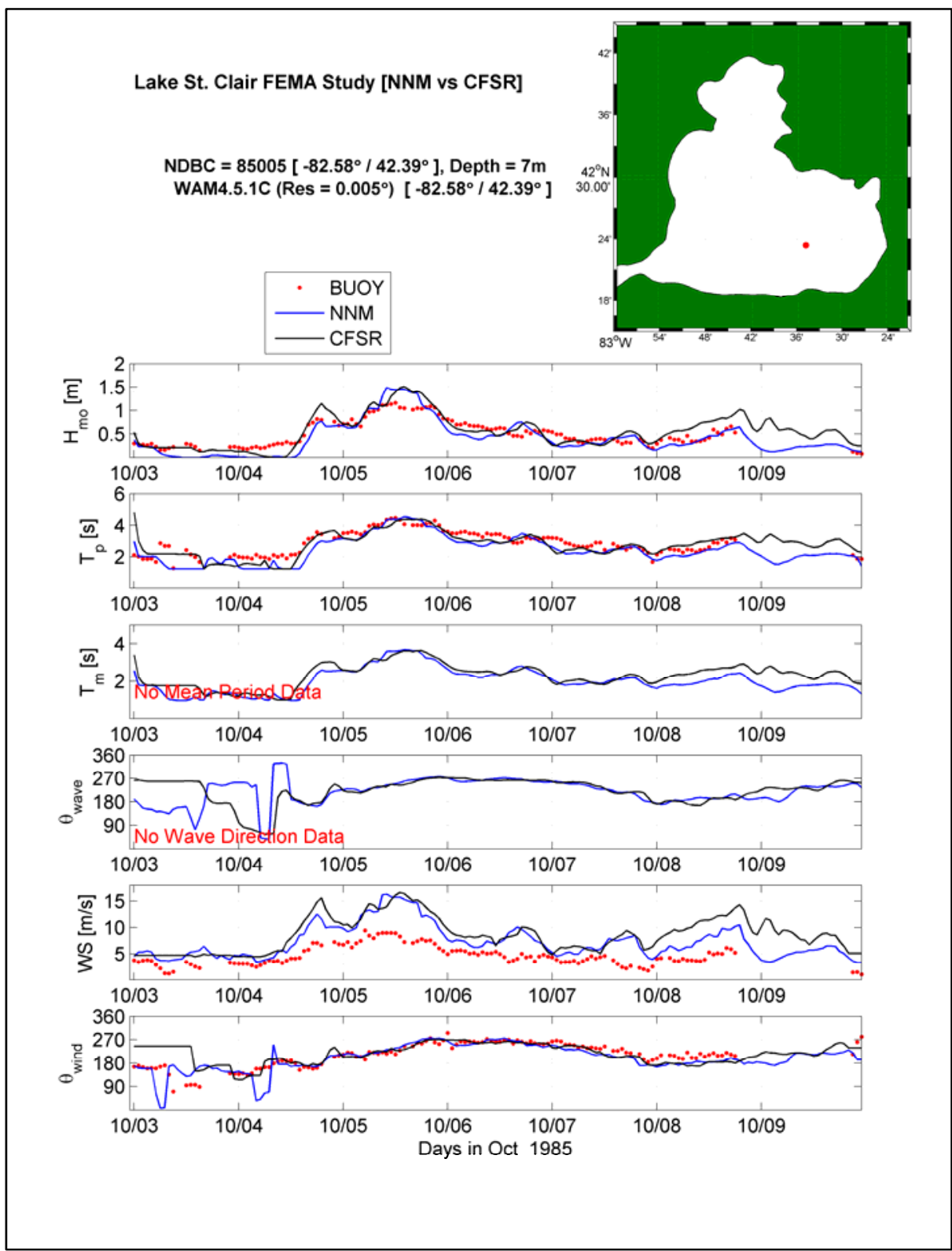

Figure 3-48. Time plots of significant wave height, peak and mean wave period, vector mean wave direction wind speed and direction at Station 85005 for segment 1 of 1985 Donelan et al. (1992) study.

\subsubsection{Observations: winds}

- The NNM and CFSR wind fields showed good agreement with each other and in-situ wind speeds.

- Most of the differences occur on the eastern side of the lake where NNM has fewer measurement locations in the older data sets.

- The original CFSR wind fields were consistently biased low because Lake St. Clair was in the land mask suggesting non-marine exposure wind speeds. 
- Adjustments were required to enhance CFSR wind fields from over land to over water.

\subsubsection{Observations: ice fields}

- All ice field information was similar to Jensen et al. (2012). Only slight changes in lake files were performed to generate Lake St. Clair ice fields.

\subsubsection{Observations: wave measurements}

- The Canadian Buoy 45147 provided difficulties in initial evaluation of data quality.

- A filter was applied to remove low frequency energy that does not exist in Lake St. Clair.

\subsubsection{Observations: wave model and modeling effort}

- There are a number of different $3^{\text {rd }}$ Generation Discrete Spectral Wave Models available to estimate the time and spatial change of directional wave spectra.

- The majority of errors manifested from a wave model can be attributed to errors in the wind estimation.

- Grid and model resolution (frequency and direction) selection can play an important role in the quality of the wave estimates.

\subsubsection{Recommendations: winds}

- CFSR winds with the defined adjustment algorithm should be used any time available (1979-2009).

- NNM should be used when CFSR winds are not available.

\subsubsection{Recommendations: ice fields}

- Follow similar techniques as described in Jensen et al. (2012).

\subsubsection{Recommendations: wave measurements}

- All comparisons should include an analysis of energy density spectrum along with the bulk wave parameters.

- In Lake St. Clair, the frequency range of the energy density spectrum is important when performing validation tests. 


\subsubsection{Recommendations: wave model and modeling effort}

- WAM should be the modeling technology used for estimating wave conditions in the Great Lakes.

- Proper preliminary investigations must be preformed to examine optimal setting all of the model's frequency (preferably based on longterm wave measurements) and direction resolutions.

- The grid used by WAM should be consistent with the surge model, coastline, (e.g. o.o water depth).

- Extensive testing and evaluation must be performed. This includes graphic products, time, scatter, Quartile-Quartile plots, and statistical testing. 


\section{Water Level Modeling}

\subsection{Introduction}

This chapter describes the process to develop and apply the ADCIRC storm surge simulation model (Luettich et al. 1992) for estimating storm eventdriven water levels in Lake St. Clair. This system is characterized by 2-6 $\mathrm{m}$ depths, a dredged $(9.1 \mathrm{~m})$ north-to-south navigation channel, and numerous flats and shoals along the northern shoreline. The Lake St. Clair model mesh development was for the lake complex as a single system, including connectivity between Lake St. Clair and Lake Huron through the St. Clair River and between Lake St. Clair and Lake Erie through the Detroit River. All other river tributaries and inflow sources were not included in the model domain. The St. Clair River boundary to the north was forced with monthly mean river flow rates provided by the Detroit District, and the Detroit River boundary was forced with hourly water level time series data from a NOAA NOS water level gauge. This chapter will describe the ADCIRC mesh development, boundary condition development, and meteorological forcing. The evaluations of these various forcing conditions are described by the sensitivity of water levels to capture the hydrodynamic interactions that occur in Lake St. Clair.

\subsection{The ADCIRC model}

\subsubsection{Model description}

The ADCIRC model has been applied extensively to simulate extreme levels of storm surge which are forced by winds, pressures, and waves; most recently in support of FEMA flood risk map updates in the northern Gulf of Mexico region, in support of USACE projects in Louisiana and Mississippi (see Bunya et al. 2010), as well as in the Lake Michigan FEMA modeling study (Jensen et al. 2012). A detailed description for the general application of ADCIRC is available at http://www.adcirc.org. The specific application of the model to this system including a procedure to account for the effects of ice cover in the simulation of water levels as applied by Chapman et al. (2005) on the western coast of Alaska, is described in this chapter. ADCIRC employs an unstructured mesh that is particularly well suited to resolving and representing the complex and irregular shoreline features of Lake St. Clair. 


\subsubsection{Storm surge modeling approach}

The modeling approach for Lake St. Clair consisted of the following steps:

- Developing the bathymetric dataset and model grid mesh for the system;

- Assembling input files for atmospheric forcing (wind and pressure fields) from both the NNM and CFSR input sources and surface ice fields;

- Developing flow rate boundary conditions for the St. Clair River, water level boundary conditions for the Detroit River;

- Testing the initial model setup; validating the model for several time periods; and

- Assessing model sensitivity to bottom friction, presence of ice, wind speed, and in-flow rates.

The model validation effort consisted of simulating several of the highlyranked water level events that were measured at the St. Clair Shores and Windmill Point NOAA NOS gauges. In addition, the October 2008 time period was simulated because the New Baltimore NOAA NOS gauge was operational during that time period. The validation simulations will be discussed in the section entitled "Validation of Lake St. Clair ADCIRC Mesh for Storm Simulations"

\subsubsection{Treatment of ice cover - method for specifying the coefficient of drag}

The ADCIRC model ordinarily uses the wind drag coefficient formulation of Garratt (1977) in the calculation of surface wind stresses. It is a widelyapplied formulation and has worked well for storm surge applications. The influence of sea ice as an aerodynamic roughness element affecting the wind drag was examined in this study. Macklin (1983) and Pease et al. (1983) found that measurements of wind drag coefficients over first year sea ice typically yielded values that were significantly larger and varied less with wind speed than those predicted for open water. More recent work (Birnbaum and Lupkes 2002) and (Garbrecht et al. 2002) has formalized the effect of form drag on the specification of wind drag coefficients within marginal ice zones. From their work, Chapman et al. (2005 and 2009) developed an empirical fit to the range of field data for the air-ice-water wind drag coefficient, $C_{D F}$, and suggested: 


$$
C_{D F}=\left(0.075+0.75 * I C-0.9 * I C^{2}+0.2 * I C^{3}\right) * 10^{-3}
$$

where

$$
I C=\text { Percent Ice }{ }^{*} 10^{-3}
$$

in which $I C$ is the ice concentration varying from 0.0 to 1.0 for open water and complete ice cover conditions, respectively. Inspection of the air-icewater-wind drag coefficient formula shows that a maximum value of 0.0025 occurs with 50-percent ice coverage. This value is very close to the Macklin (1983) measurement of 0.0028 for first year ice. Furthermore, it is seen that the value of the drag coefficient is symmetrical at about 50 -percent ice coverage, suggesting that the drag coefficient needed to represent 75-percent ice coverage is similar to that of 25-percent ice coverage. An alternative method using linear fit dependence on ice concentration has been applied by Danard et al. (1989). The hypothesis of varying the wind drag coefficient with ice cover have been supported by a number of Chukchi and Beaufort Sea storm surge simulations (Henry and Heaps 1976; Kowalik 1984; and Schafer 1966) in which, wind drag coefficients greater than or equal to 0.0025 where utilized.

The approach developed by Chapman et al. (2005) involving a variation in wind drag due to the presence of ice was used in this study. This method requires reading ice field concentration files into ADCIRC and calculating the wind drag coefficient values (variable over the model domain) from Equation 4-1. If ice cover is present and the increased drag coefficient exceeds the value calculated using the standard Garratt (1977) formulation, the standard Garratt drag coefficient is replaced with the increased value associated with ice cover.

\subsubsection{ADCIRC mesh development}

The NOAA Electronic Navigation Charts (ENC), together with published 3and 9-arc-sec data files from NOAA's National Environmental Satellite Data and Information Service Lake St Clair digital bathymetry data base were used to develop the ADCIRC grid bathymetry. The bathymetry data sets were processed and merged with ArcView to a consistent IGLD 1985 vertical water level datum. In addition, the NOAA's IGLD 1985 zero-depth coastline file was incorporated into the data set. Geo-rectified photography and images were used to establish a higher resolution shoreline. 
The model mesh was developed with the Surface-water Modeling System (SMS). SMS and user documentation is commercially available at http://www.aquaveo.com/sms. SMS contains linkages with the Environmental Science and Research Institute's ArcView and ArcEditor software for displaying GIS layers and shape files. The US National Ocean Service has published and released its navigational charts in electronic form. GIS layers composing these NOS Electronic Nautical Charts (ENC) were input to the SMS, as were the other data sources.

A SMS "feature map" file that allows grid generation and modification was built as an initial step. Intersecting arcs generated from this initial step are joined to form polygons. Sub-grids are generated for each polygon, using the vertices that lie along the arc and a paving algorithm. The sub-grids are then merged forming a cursory ADCIRC grid.

After generating the initial grid, the grid is refined, which includes smoothing skewed element shapes so that each is roughly an equilateral triangle, optimizing agreement between the grid and the shoreline and adding coastal features, such as breakwaters and jetties. Arc spacing between vertices was about 50-m along the shoreline of Lake St. Clair. Grid resolution was on the order of 300-m in the central region of Lake St. Clair. The bathymetric database, XYZ file, was imported and interpolated onto the grid mesh in SMS. Note that the Lake St. Clair low water datum of $174.4 \mathrm{~m}$ IGLD 1985 was applied to the main lake portion of the ADCIRC mesh. Bathymetry for the St. Clair River was adjusted linearly between the lower water datums of Lake St. Clair and Lake Huron and applied to the St Clair River portion of the ADCIRC mesh. Similarly, bathymetry for the Detroit River was adjusted linearly between the low water datums of Lake St. Clair and Lake Erie.

The ADCIRC mesh for Lake St. Clair is shown in Figure 4-1 and the bathymetry is shown in Figure 4-2. A few assumptions were made during grid development including:

- The effect of Lake Huron was incorporated in the flow boundary at the St. Clair River;

- The effect of Lake Erie was incorporated in the water level boundary at the Detroit river; and

- Overland flooding or wetting and drying was turned off along the lake periphery. 


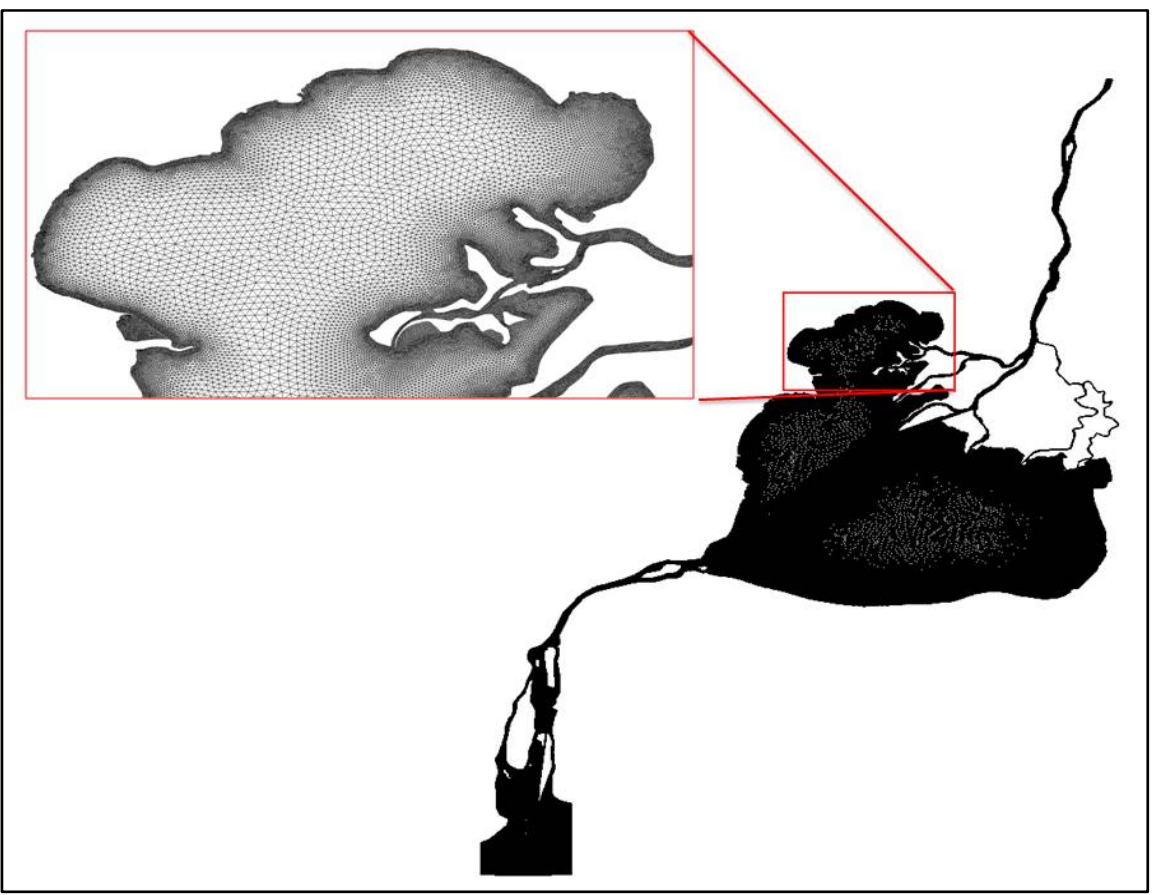

Figure 4-1. ADCIRC mesh for Lake St. Clair and a detailed mesh inset.

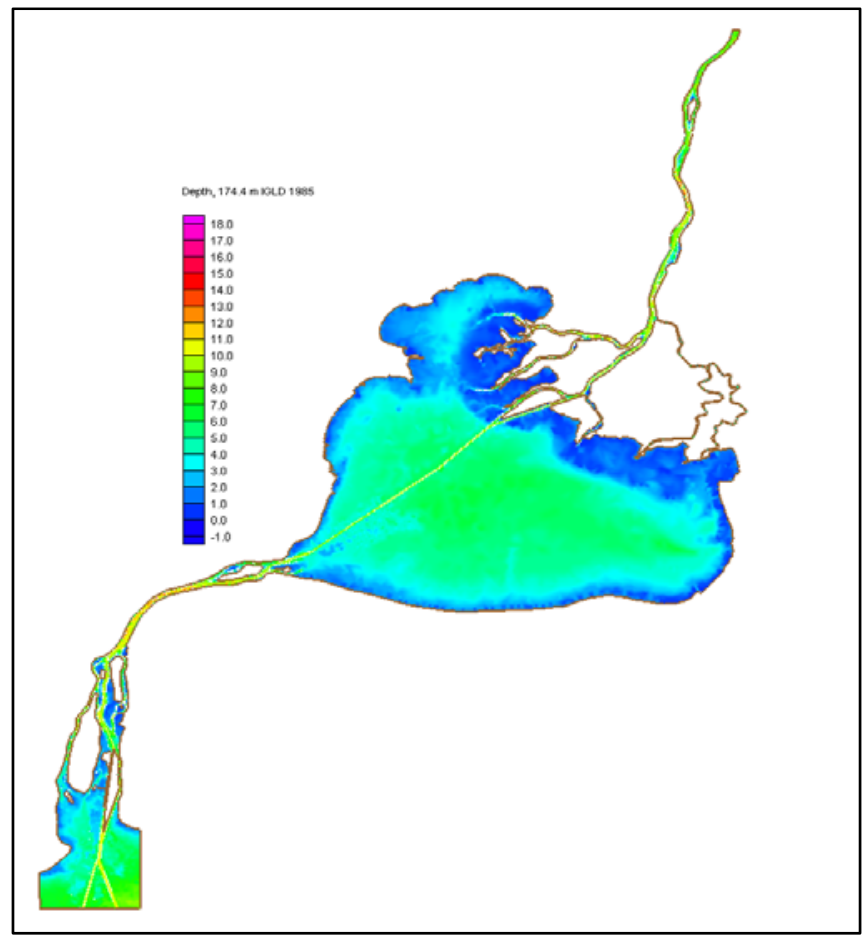

Figure 4-2. Lake St. Clair bathymetry.

Local flooding will be addressed in work to develop flood risk maps, so the wetting and drying was turned off, resulting in specification of vertical walls and no-flow boundary conditions at the shoreline. The unstructured grid mesh contains a total of over 400,000 elements and over 200,000 nodes. 


\subsection{Validation of Lake St. Clair ADCIRC mesh for storm simulations}

\subsubsection{Selection of validation storms}

A set of 10 validation simulations (Table 4-1) were selected because they are the top-ranked water levels measured at St. Clair Shores and Windmill Point NOAA NOS water level stations for the period 1960-2009 (Figure 43 ). These storms included ice and non-ice events that occurred in the October through March time period. For comparison purposes, model simulations initially applied atmospheric forcing from both the NNM and the CFSR wind products that were described previously. The final validation storms applied CFSR winds if available, based on the comparative analysis of wind fields. Storms 1, 2, 3, 4, 6, 9, and 10 apply CFSR winds and Storms 5 , 7, and 8 apply NNM wind fields. Monthly mean water levels were applied to the model mesh as an initial condition for each simulation and the St. Clair River monthly mean flow rate estimate (Fay and Noorbakhsh 2010) was applied at a constant rate at the northern (St. Clair River) boundary. Hourly water levels from the NOAA NOS Gibraltar gauge (9044020) were applied at the southern (Detroit River) boundary of the mesh. For each simulated storm event, the model was run for 12 days with the storm peak occurring during the $10^{\text {th }}$ day of the simulation (nine days prior and two days after the peak day). For discussion purpose, Storms 001 through 004 will be shown herein. Comparisons to water level data for additional storms are provided in Chapter 6.

Table 4-1. Validation simulations.

\begin{tabular}{|l|l|l|l|l|l|l|}
\hline \multirow{2}{*}{$\begin{array}{l}\text { Storm } \\
\text { No. }\end{array}$} & \multicolumn{2}{|l|}{ Time of Peak Water Level } & Mean Water Level & $\begin{array}{l}\text { St. Clair River } \\
\text { Monthly Mean Flow } \\
\text { Rate }\end{array}$ & Ice Coverage \\
\cline { 2 - 8 } & Year & Month & Day & m IGLD 1985 & $\mathrm{m} / \mathrm{sec}$ & \\
\hline 1 & 1999 & 01 & 09 & 175.10 & 4700 & Yes \\
\hline 2 & 1990 & 12 & 03 & 175.10 & 5380 & No \\
\hline 3 & 1987 & 12 & 15 & 175.32 & 5710 & No \\
\hline 4 & 1994 & 01 & 05 & 175.06 & 5215 & Yes \\
\hline 5 & 1977 & 03 & 18 & 175.15 & 5150 & Yes \\
\hline 6 & 1984 & 03 & 29 & 175.50 & 5210 & Yes \\
\hline 7 & 1972 & 11 & 14 & 175.51 & 6120 & No \\
\hline 8 & 1973 & 03 & 17 & 175.68 & 5690 & Yes \\
\hline 9 & 1995 & 10 & 06 & 175.08 & 5565 & No \\
\hline 10 & 1999 & 01 & 14 & 175.10 & 4700 & Yes \\
\hline
\end{tabular}




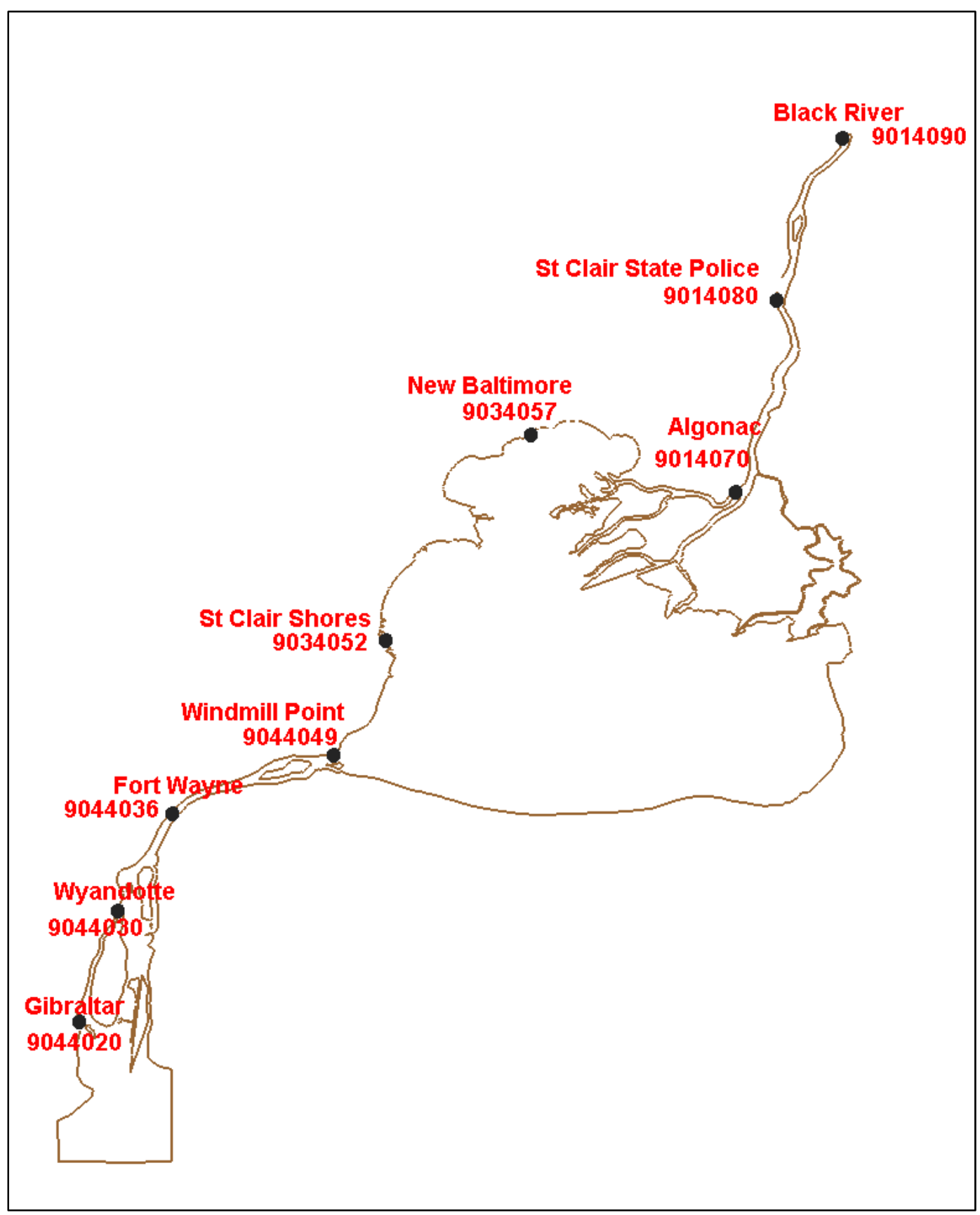

Figure 4-3. NOAA NOS water level stations in Lake St. Clair and adjoining rivers.

\subsubsection{Storm 001 event for January 1999}

Figure 4-4 shows a comparison between a time series of measured (denoted as "Observed") and ADCIRC-computed (denoted "ADCIRC") water surface elevations at NOS Station 9034052 (St. Clair Shores) for Validation Storm o01 with CFSR winds applied. Storm o01 occurred in January 1999 and was the Number 1 ranked event at St. Clair Shores. Ice was present for the simulation. Simulated water levels do not compare well with the measured 
water levels for this event. The measured water levels indicate a response to the storm winds for the first three days of the event when the water levels are meteorologically driven and then the measurements increase steadily as the ice becomes more prevalent. The initial water level in ADCIRC was higher than the measured water level because the modeled value was adjusted to the monthly mean water level for the 12-day modeled time period, rather than the water level at the start of the simulation. Ice coverage for this event was extensive and the response at the gauge indicates a pattern that differs from what is observed during periods of open water. It is unclear whether the steady increase indicated at the gauge is due to ice at the gauge location, ice blocking flow along the Detroit River, a variation in the St. Clair River flow rate from the mean value, or a combination of all three.

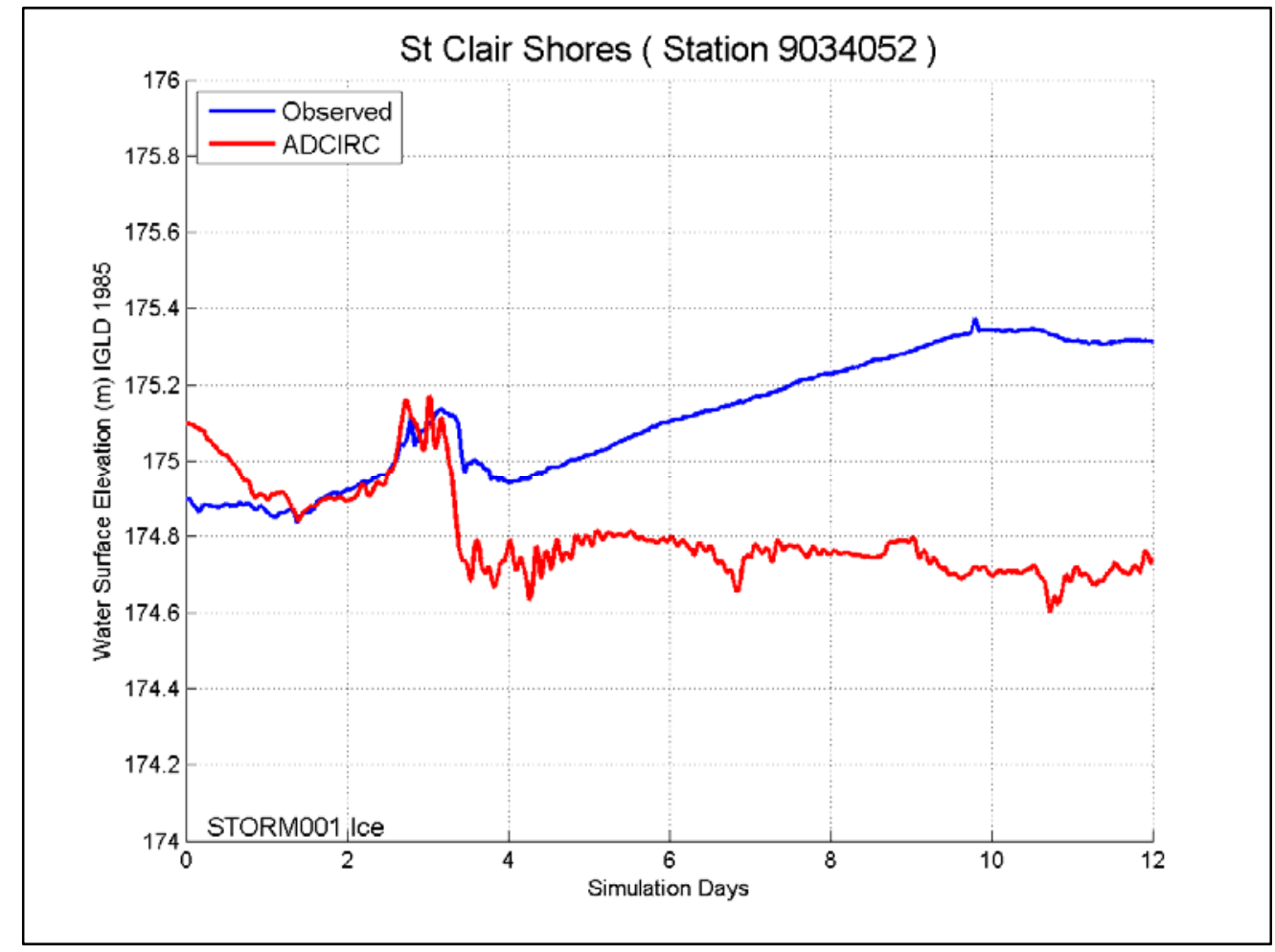

Figure 4-4. Comparison of Storm 001 observed and modeled water levels at St. Clair Shores.

\subsubsection{Storm 002 event for December 1990}

Figure 4-5 shows a comparison between observed and ADCIRC-computed water surface elevation at NOS Station 9034052 (St. Clair Shores) for Validation Storm 002 with CFSR winds applied. Storm 002 occurred in December 1990 and was the \#2 ranked event at St. Clair Shores. There was 


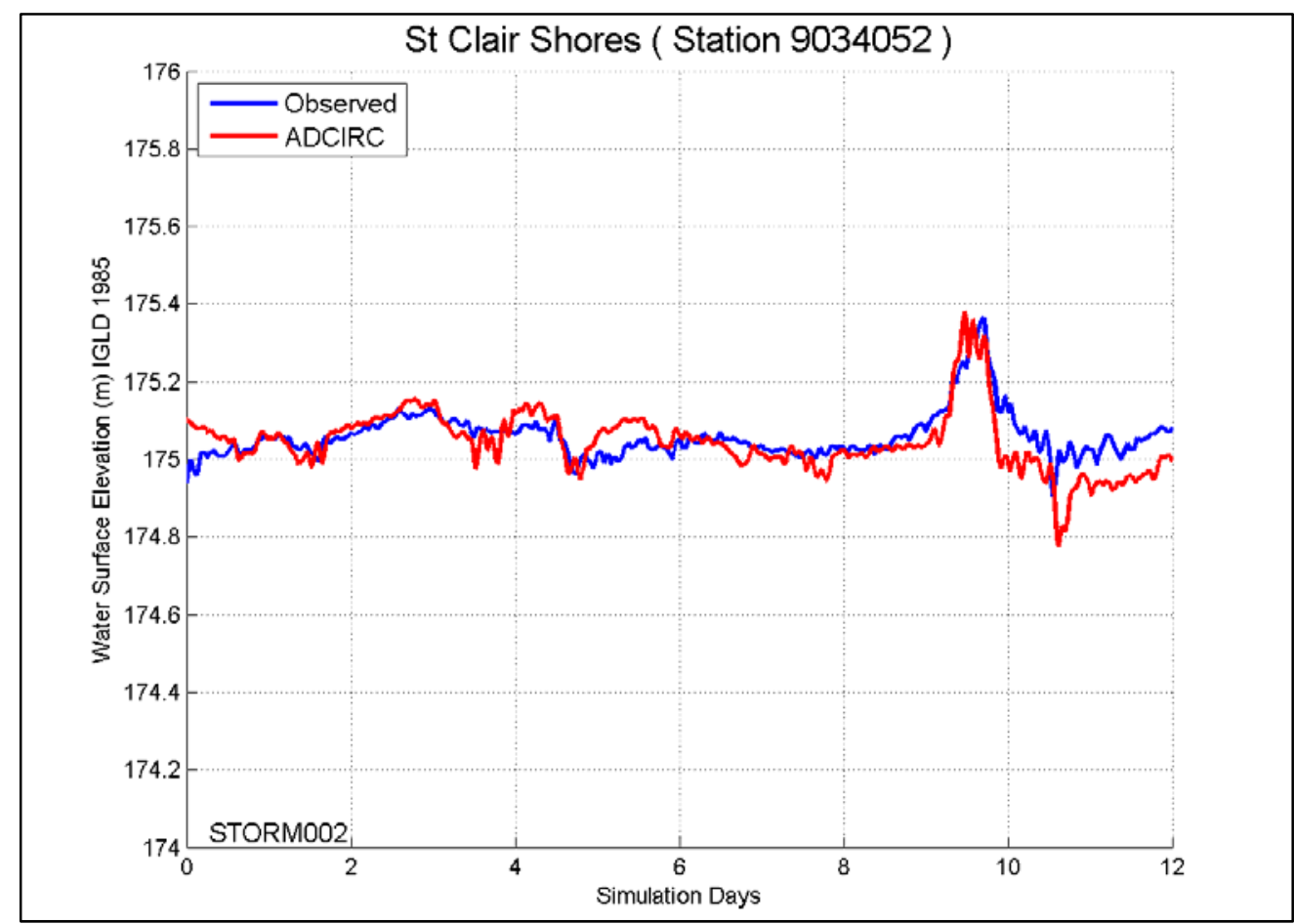

Figure 4-5. Comparison of Storm 002 observed and modeled water levels at St. Clair Shores.

no ice present for this storm event. Simulated water levels compare well with the measured water levels for this event. The measured water levels indicate a response to the storm winds that replicate the measured water levels in both magnitude and duration of the surge event with the exception of a small ( $0.2 \mathrm{~m})$ post-surge seiche discrepancy. Similarly, Figure 4-6 shows that the comparison between measured and ADCIRC-computed water surface elevation at NOS Station 9044049 (Windmill Point) for Storm 002 indicate good agreement. The simulated peak water level is within $0.1 \mathrm{~m}$ of the measured peak water level at Station 9044049. These water level time-series comparisons of simulated and observed pre-storm oscillations, as well as the storm surge magnitude and duration, demonstrate the ability of ADCIRC to simulate storm surge hydrodynamics in Lake St. Clair for this storm time period. Small scale oscillations that are finer than the temporal and spatial scales of the forcing conditions were not captured in the simulated responses.

\subsubsection{Storm 003 event for December 1987}

Figure 4-7 shows a comparison between measured and ADCIRC-computed water surface elevation at NOS Station 9034052 (St. Clair Shores) for validation Storm 003 with CFSR winds applied. Storm 003 occurred in 


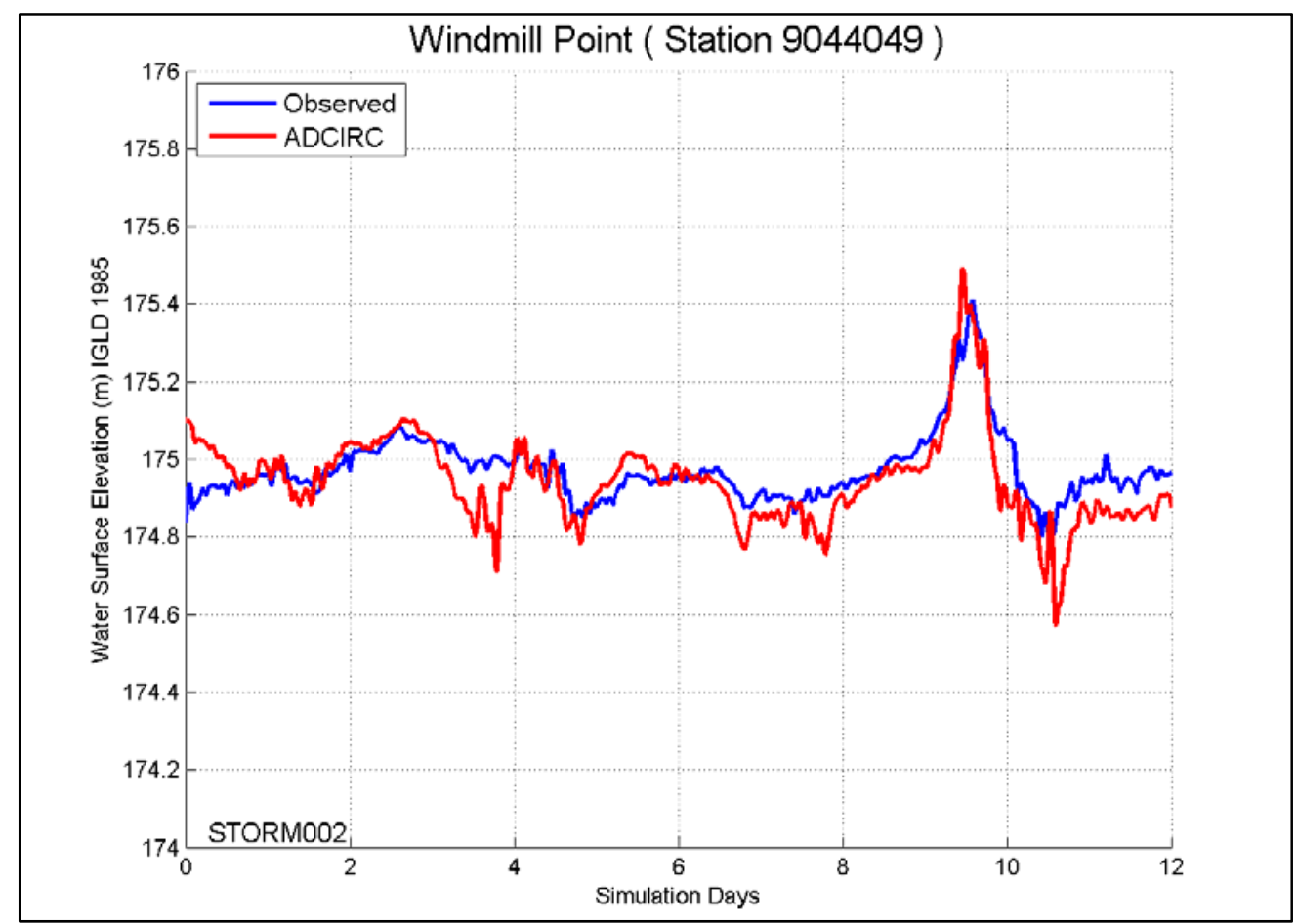

Figure 4-6. Comparison of Storm 002 observed and modeled water levels at Windmill Point.

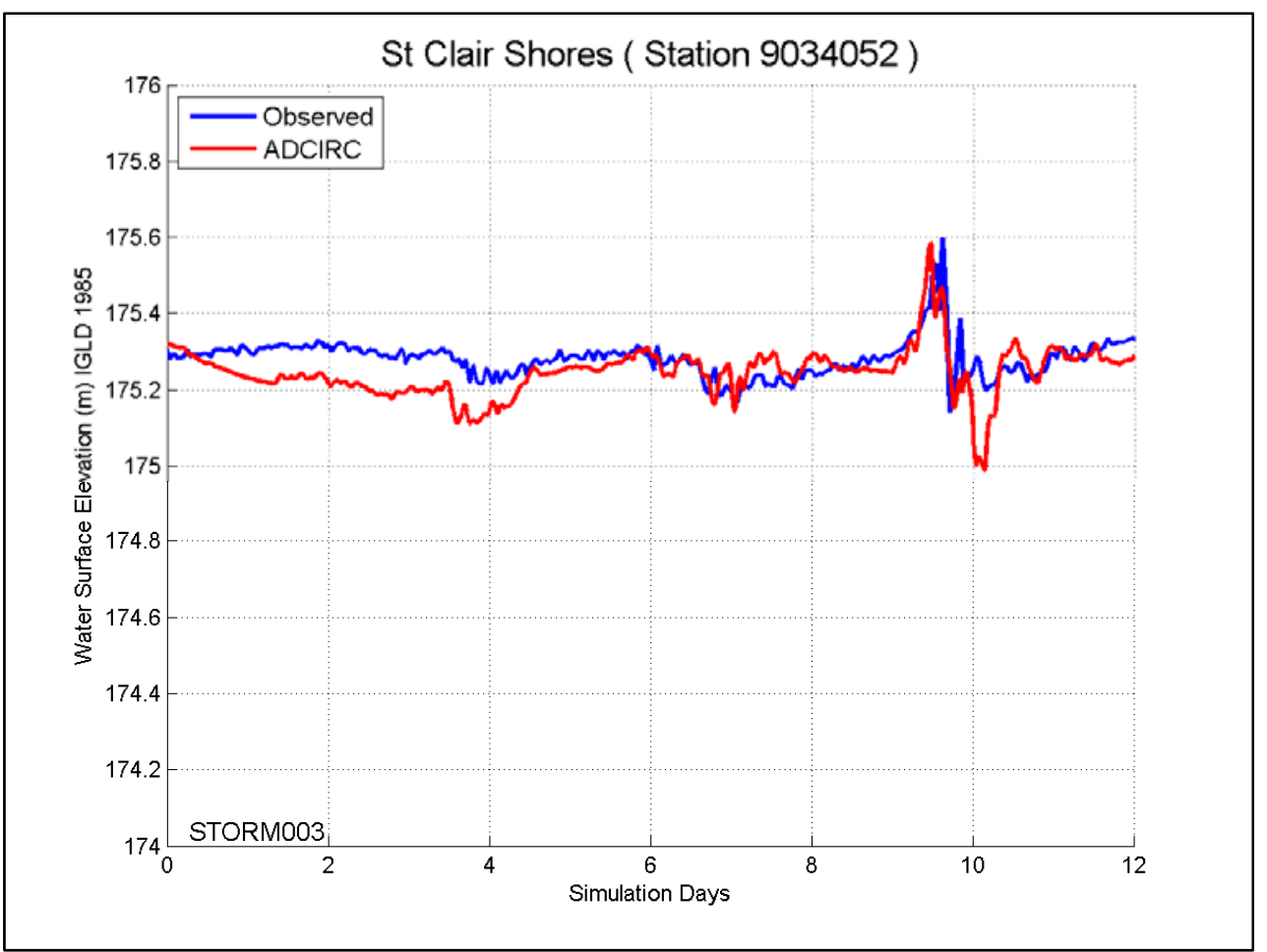

Figure 4-7. Comparison of Storm 003 observed and modeled water levels at St. Clair Shores. 
December 1987 and was the Number 3 ranked event at St. Clair Shores. There was no ice present for this storm event. Simulated water levels compare fairly well with the measured water levels for this event with the exception of the post-surge seiche which again shows a $0.2 \mathrm{~m}$ drop that is not indicated in the observations. The model under-estimates water levels following the storm peak at approximately Day 10. The ADCIRC water levels indicate a response to the storm winds that replicate the measured water levels in both magnitude and duration for the peak of the storm. Figure 4-8 shows a comparison between measured and ADCIRC-computed water surface elevation at NOS Station 9044049 (Windmill Point) for Storm 003. This comparison indicates very good agreement for the pre-storm oscillation and the storm peak water level, but also indicates an exaggerated poststorm seiching of approximately $0.4 \mathrm{~m}$. Despite the over-estimation of post storm seiching, these water level time-series comparisons of simulated and observed pre-storm oscillations as well as the storm surge magnitude and duration, display the ability of ADCIRC to simulate storm surge hydrodynamics in Lake St. Clair.

\subsubsection{Storm 004 event for January 1994}

Figure 4-9 shows a comparison between measured and ADCIRC-computed water surface elevation at NOS Station 9034052 (St. Clair Shores) for validation Storm 004 with CFSR winds applied. Storm 004 occurred in January 1994 and was the fouth ranked event at St. Clair Shores and was an ice event. As with the previously discussed ice event (Storm 1), simulated water levels do not compare well with the measured water levels for this event. The measured water level time series shows a muted response that steadily increases through the storm time period. The initial water level in ADCIRC was lower than the measured water level because the modeled value was adjusted to the monthly mean water level for the 12-day modeled time period, rather than the water level at the start of the simulation. Ice coverage for this event was extensive and the response at the NOS gauge indicates a pattern that differs from what is observed during periods of open water. Further examination of NOS Station 9034052 (St. Clair Shores) data for time periods that include the ice storms (Storms 001, 004, and 010) shows a 0.2-0.4 $\mathrm{m}$ rise in water level during the ice event time periods, whereas the water level measurements at this location generally oscillate 0.1-0.2 m during open water time periods. It is unclear whether the steady increase indicated at the gauge is due to ice at the gauge location, ice blocking flow along the Detroit River, a variation in the St. Clair River flow rate from the mean value, or a combination of all three. 


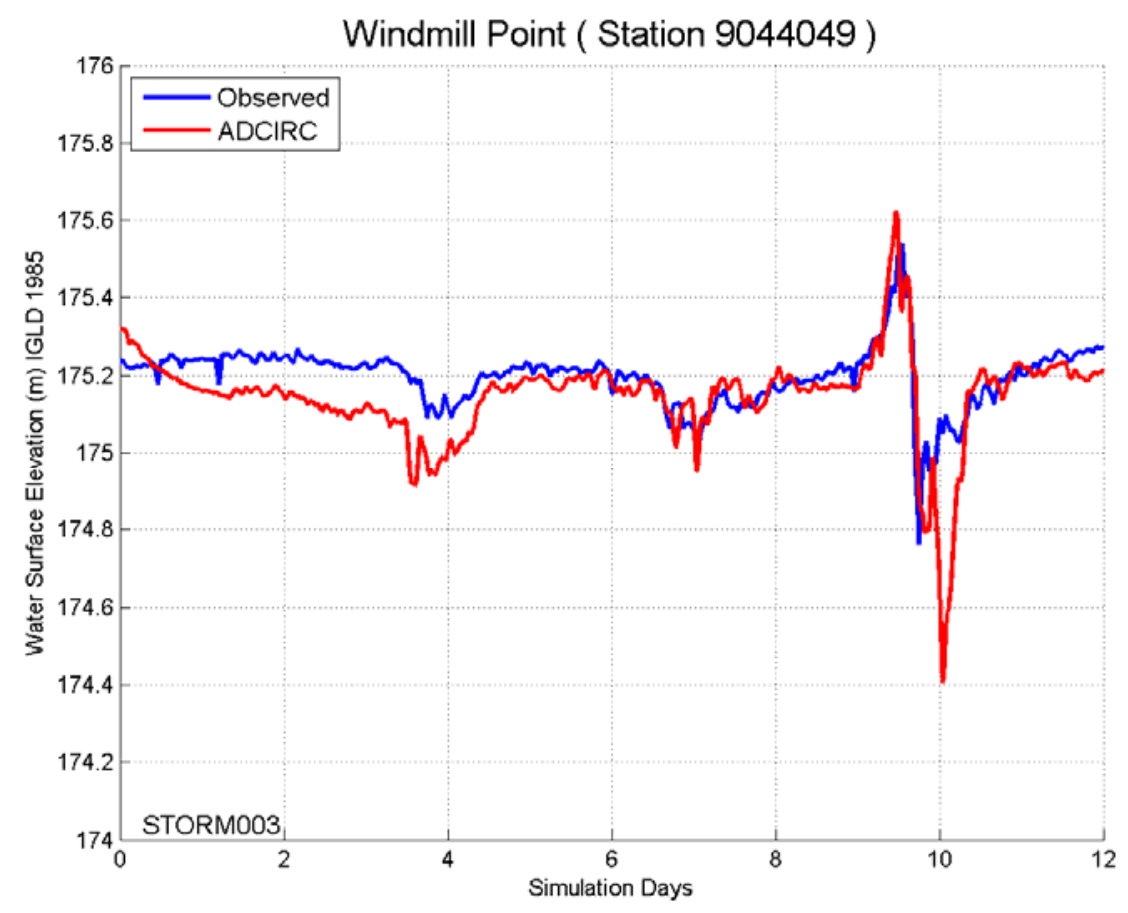

Figure 4-8. Comparison of Storm 003 observed and modeled water levels at Windmill Point.

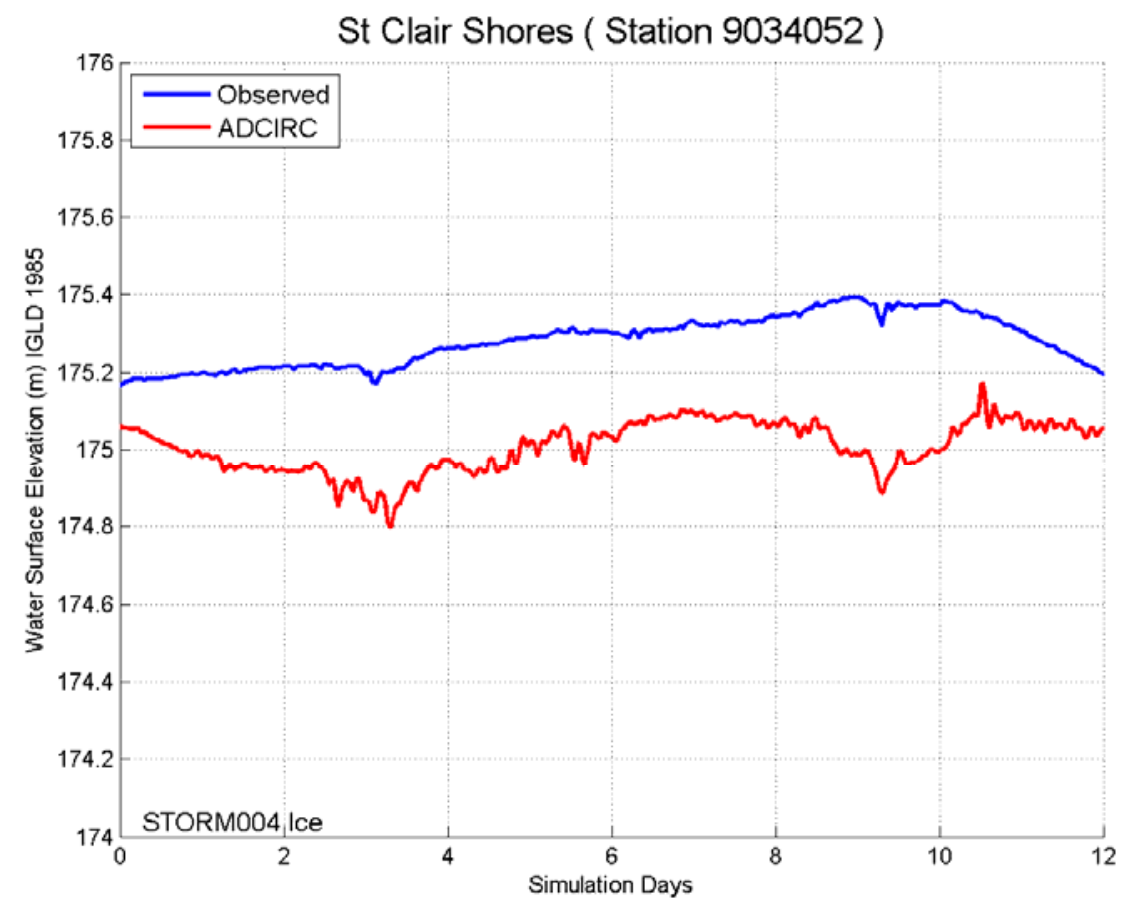

Figure 4-9. Comparison of Storm 004 observed and modeled water levels at St. Clair Shores. 


\subsubsection{October 2008 simulation}

The last storm in the validation process was selected because water level measurements were available at the New Baltimore gauge (Figure 4-3) during the October 2008 time period. Figure 4-10 through 4-12 show comparisons between measured and ADCIRC-computed water surface elevation at NOS Station 9034057 (New Baltimore), 9034052 (St. Clair Shores), and NOS Station 9044049 (Windmill Point) for validation Storm o04 with CFSR winds applied. The response to wind and pressure variation over Lake St. Clair shows a small $(0.1 \mathrm{~m})$ increase in water level at new Baltimore around Day-8 whereas the other two gauges show little water level fluctuation. The model replicates a surge pulse at New Baltimore, but it overpredicts the peak by approximately $0.1 \mathrm{~m}$. The model also replicates the minor fluctuations at the other two gauges. The ability to model the spatial variability in water level response demonstrated in this simulation as well as the other validation simulations without any adjustments to model parameters provides a degree of confidence in the models ability to simulate any other storm time periods selected in the production process.

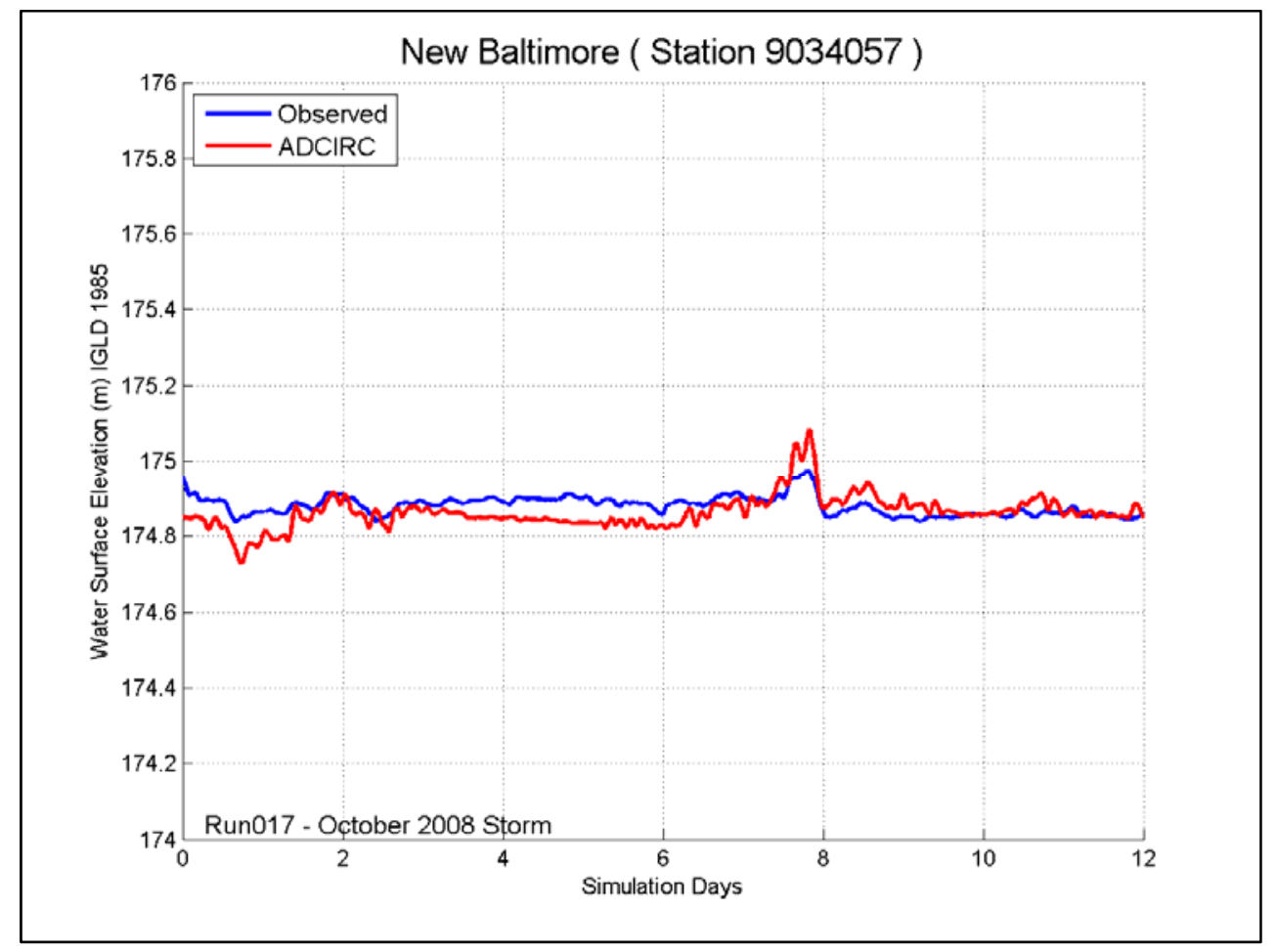

Figure 4-10. Comparison of October 2008 observed and modeled water levels at New Baltimore. 


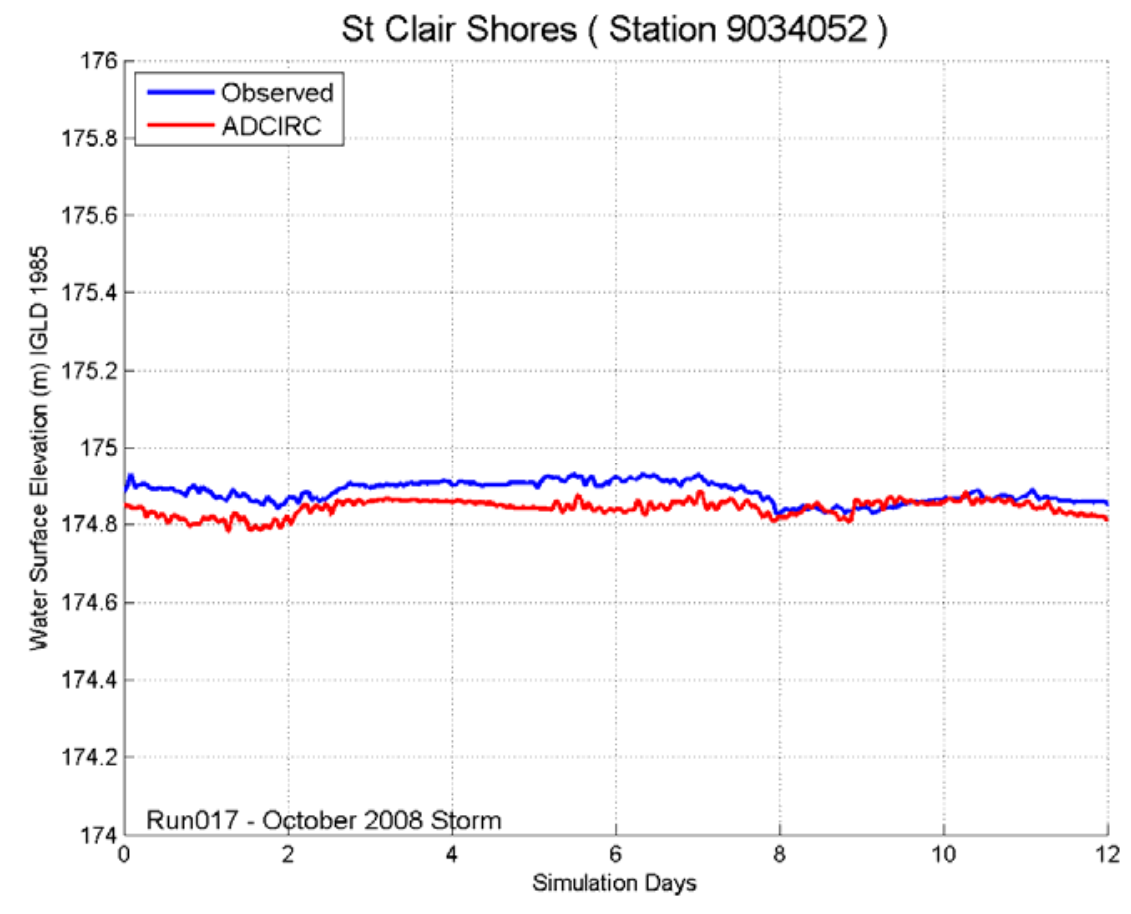

Figure 4-11. Comparison of October 2008 observed and modeled water levels at St. Clair Shores.

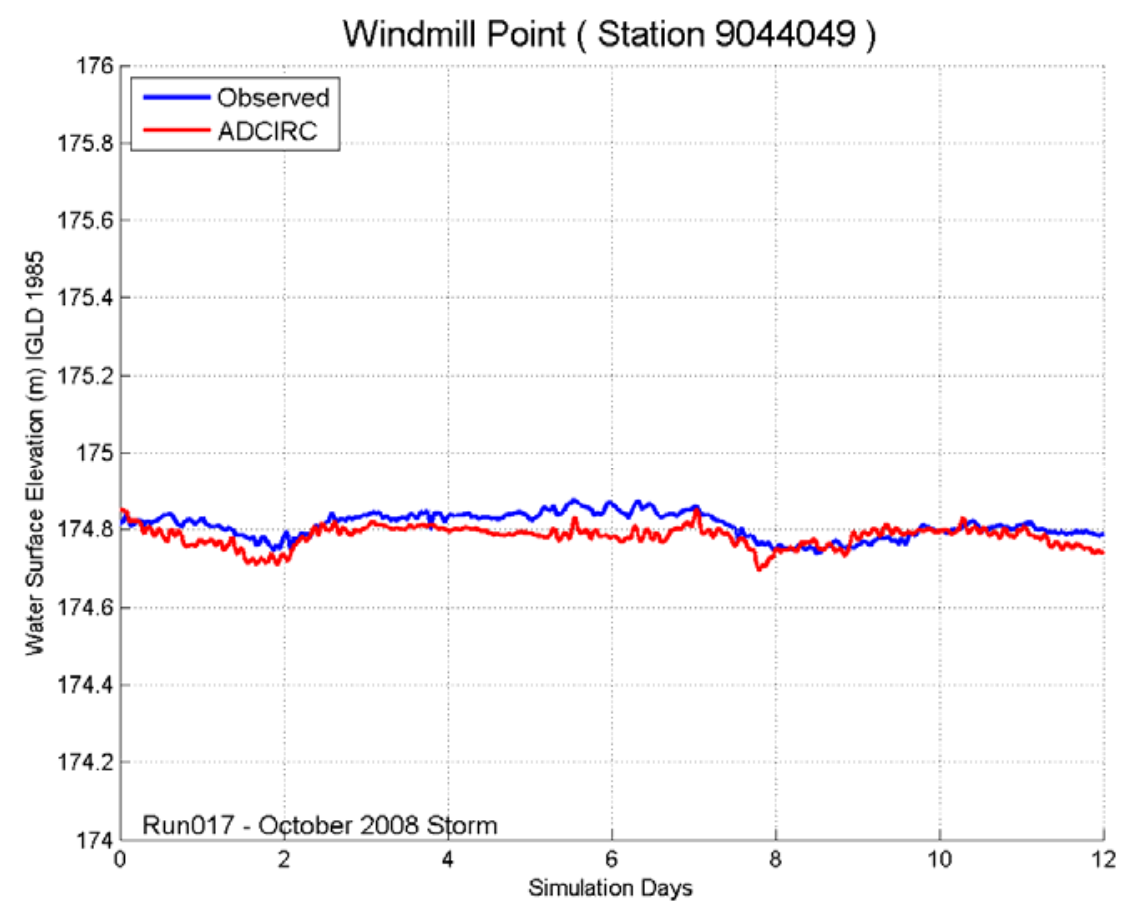

Figure 4-12. Comparison of October 2008 observed and modeled water levels at Windmill Point. 


\subsection{Model sensitivity testing}

The main thrust of this study is to estimate extreme water levels in Lake St. Clair properly for a large set of storm events. Sensitivity of simulated water levels to forcing conditions and model parameters provides insight into the significance of correctly representing physical parameters to reproduce the hydrodynamic response to those parameters. In this study, variability in water level response to changes in wind type, wind magnitude, ice coverage, inflow/outflow, and bottom friction were examined and will be described herein.

\subsubsection{Sensitivity to wind type}

Part of the validation model simulations involved applying atmospheric forcing from both the NNM and the CFSR product that were described previously. Figures 4-13 and 4-14 show a comparison between measured and CFSR- and NNM-computed water surface elevation time series for Storm 002 at St. Clair Shores and Windmill Point, respectively. In the time period leading up to the primary wind-driven surge event, the model results forced with both the NNM and CFSR winds qualitatively reproduce the observed trends and patterns in water level variability, including the discrete oscillations that are evident in the observations, but with a slight $(0.1 \mathrm{~m})$ bias. In the day preceding the surge event, both sets of wind forcing produce a similar response, but the CFSR winds result in a delayed response relative to the observed water surface fluctuations followed by a quicker rise to the peak water level (Day-9). Water level oscillations that occur just prior to the main wind forcing can contribute to both the timing and magnitude of peak surge created by the event (Jensen et al. 2012).

The peak storm surge value of $0.4 \mathrm{~m}$ associated with the main surge event is reasonably well simulated with both wind sources. However, the overall shape and duration is under estimated with the NNM. The seiche-induced oscillations that are observed after the main surge peak are under-estimated by both wind sources. Overall, the primary water level features comprising the main surge event are simulated better with the CFSR winds. In general, considering all of the extreme events that were simulated, the CFSR winds yielded a better match with observed waves and water levels. The CFSR winds show a slightly better representation of the spatial and temporal coherence in storm wind fields. The CFSR winds were adopted as the preferred source for wind input when they are available to follow the precedence set by the Lake Michigan modeling effort (Jensen et al. 2012). Comparisons shown throughout the rest of this chapter reflect model results using the CFSR winds only. 


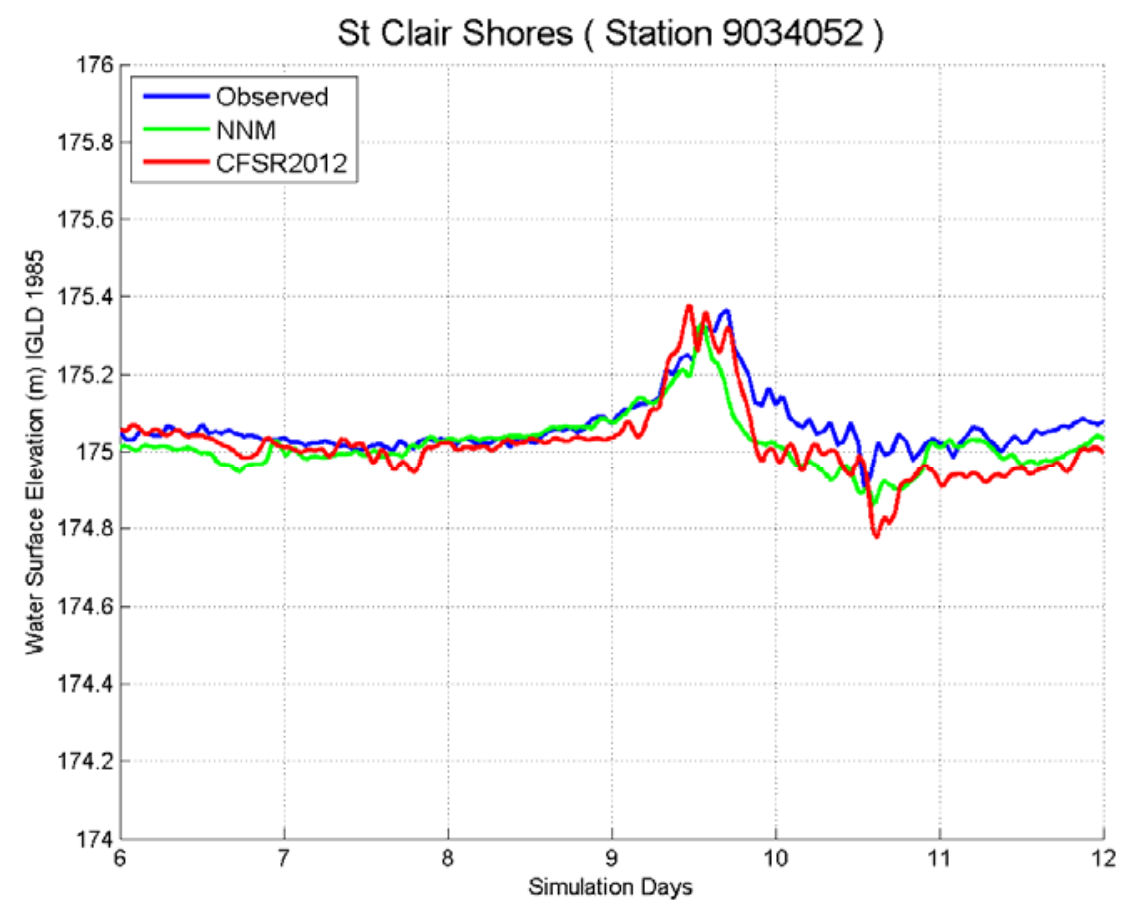

Figure 4-13. Comparison of Storm 002 water level response at St. Clair Shores when $A D C I R C$ is forced with CFSR and NNM winds.

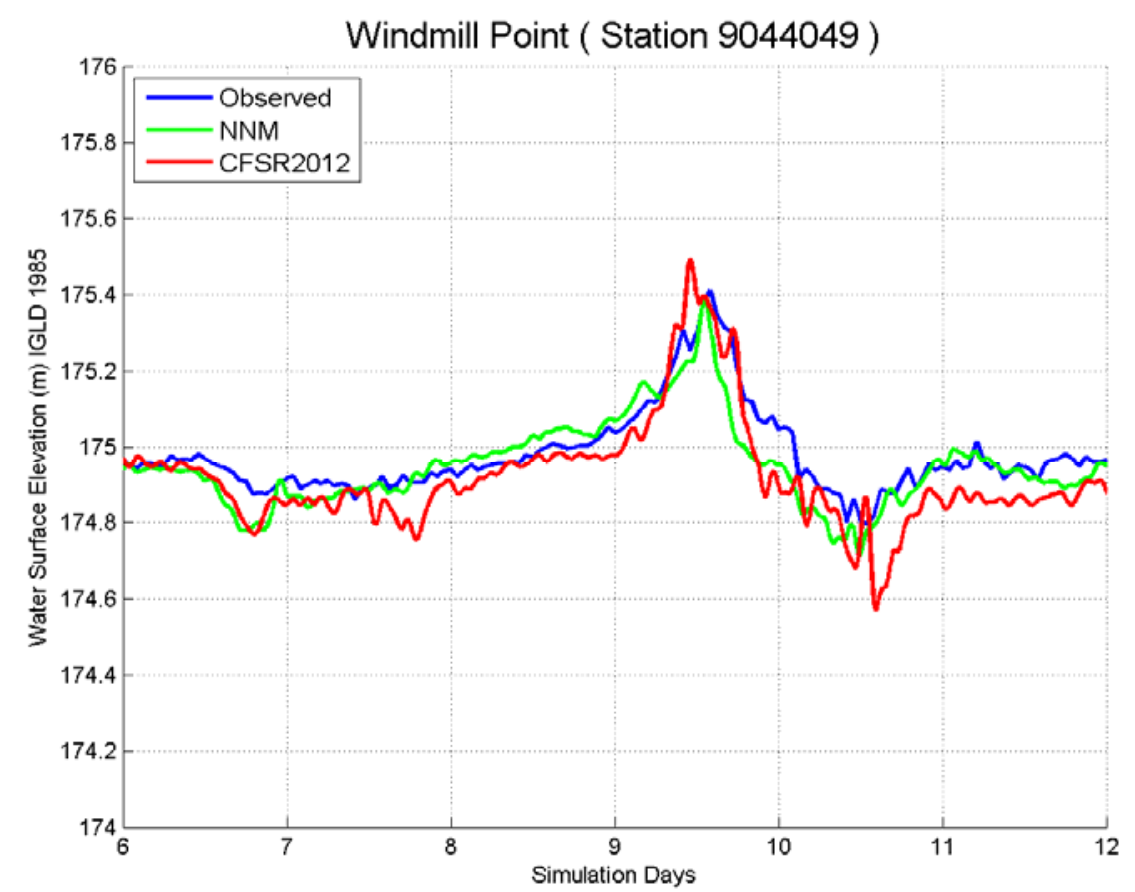

Figure 4-14. Comparison of Storm 002 water level response at Windmill Point when $A D C I R C$ is forced with CFSR and NNM winds. 


\subsubsection{Sensitivity to wind forcing}

To examine the effect that a positive bias in wind speed may have on calculated water levels. Four events were selected based on availability of winds from the North, Northeast, and East with maximum wind speeds ranging from 18 to $20 \mathrm{~m} / \mathrm{sec}$. These storms were simulated with CFSR winds and with a nine percent change in wind speed applied to the CFSR winds throughout the model domain for the entire storm duration. The percent change in wind speed selected in this sensitivity analysis is a standard conversion from 30-min CFSR winds to 10-min winds applied in ADCIRC (IPET 2007). The sensitivity of water levels to this percent change was examined herein. Figure 4-15a compares 1) simulated water levels applying CFSR winds, 2) simulated water levels applying CFSR winds with a 1.09 multiplier, and 3) observed water-surface elevations at St. Clair Shores. The nine percent change in wind speed had a very slight effect on water level for this storm event as well as the other storm events that were examined in the sensitivity testing process. Based on previous work and this sensitivity analysis, all Great Lakes ADCIRC applications applied a wind multiplier of 1.09 to change the $30-\mathrm{min}$ averaged winds to 10-min winds required by ADCIRC.

As an extreme test, another simulation (validation Storm 010) was repeated with wind speeds reduced to zero (Figure 4-15b). The original simulation with CFSR winds and pressures applied shows oscillations in the free surface at St. Clair Shores; but with winds reduced to zero, the response in water level is a smooth response to the inflows and outflow at the river boundaries. The observed water level response is smooth, which is similar to simulated water levels with no wind. It is possible that the ice on the free surface may serve to block the wind stress on the water surface thus responding as if there was no wind at all.

\subsubsection{Sensitivity to presence of ice cover}

A sensitivity test was conducted to examine the effect of the presence of ice on simulated water levels in Lake St. Clair. Figure 4-16 compares simulated water-surface elevations during the Storm 004, January 1994 event, with and without ice coverage applied to the entire lake. A 50-percent ice concentration produces the maximum surface shear stress, using the drag coefficient formulation discussed previously. (This example illustrates the maximum influence ice cover can have on calculated water levels, and the relative role of surface stress changes associated with ice compared to water level changes induced by other factors). For this example the change was less than $0.1 \mathrm{~m}$. 

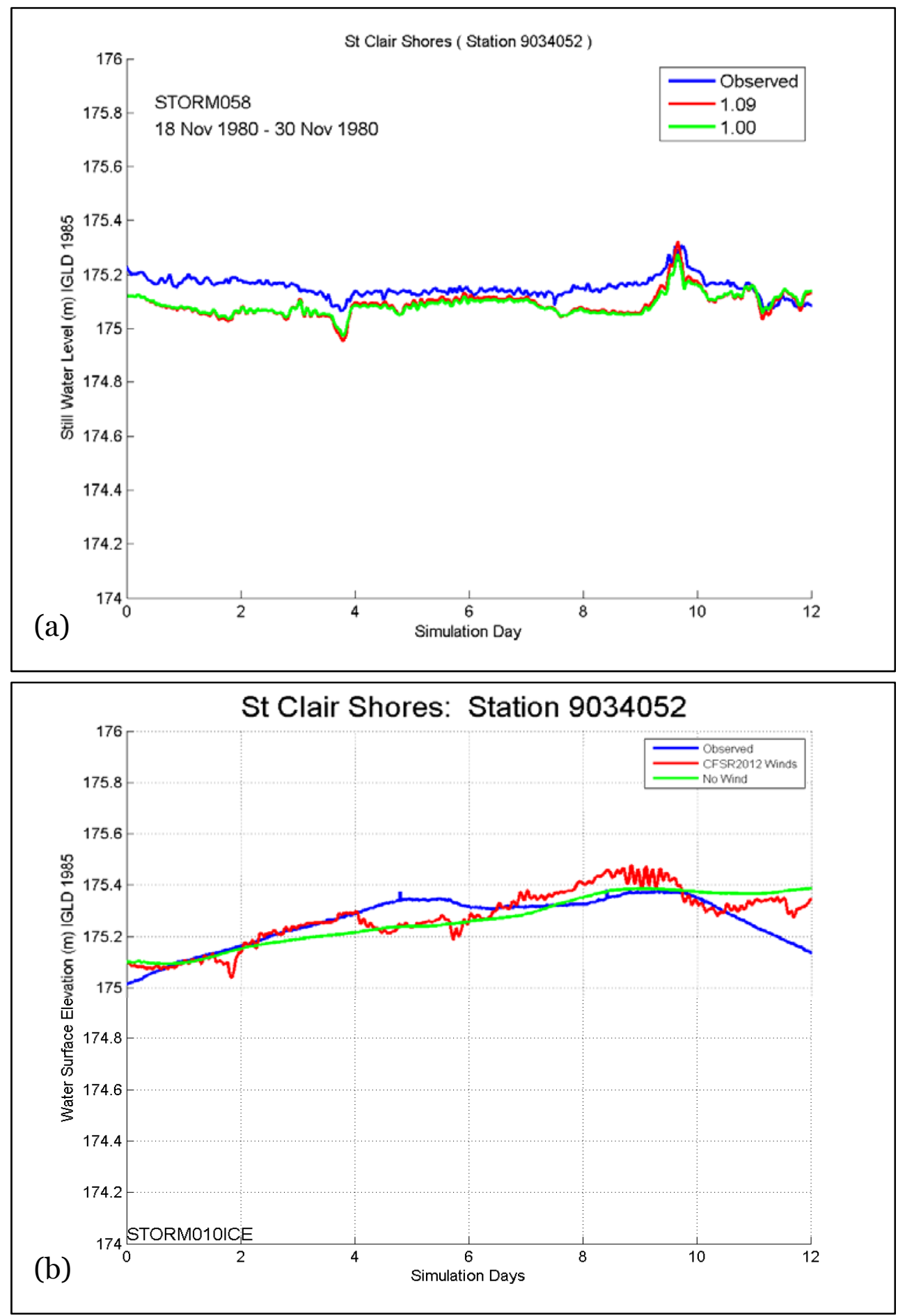

Figure 4-15. (a) Comparison of water level response to a nine percent change in wind speeds, (b) Comparison of water level response to elimination of wind forcing. 


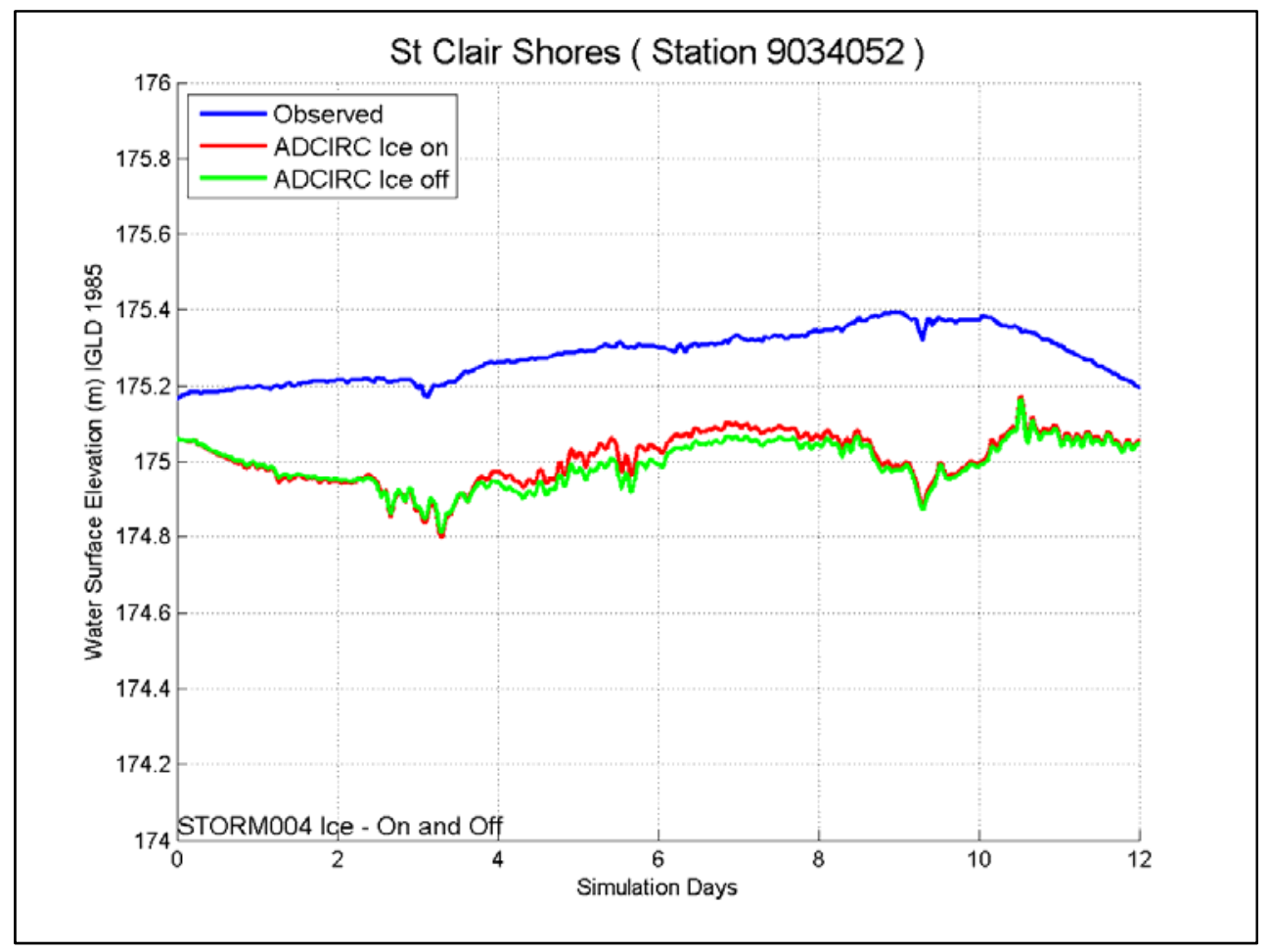

Figure 4-16. St. Clair Shores water level time series with and without ice coverage.

\subsubsection{Sensitivity to river inflow}

The sensitivity of the ADCIRC simulated water levels to river inflow was also investigated. In these preliminary tests, a Manning's n values of 0.02 was applied for a bottom friction coefficient and a constant inflow rate estimated for October 2008 of $5170 \mathrm{~m} 3 / \mathrm{sec}$ was applied at the upstream (St. Clair River) boundary (Fay and Noorbakhsh 2010). Historically, the estimated flow rates in the St. Clair River have been based on a combination of stage-fall-rating equations and one-dimensional hydraulic models. Due to low Great Lakes water levels in the 1990-2005 time-frame, an investigation was conducted into the methodology used to estimate flow rates. From those efforts, the historic monthly mean flows and rating equations were revised (Fay and Noorbakhsh 2010). The monthly mean flow rates from this latest effort were applied in this project.

In the sensitivity analysis, three simulations were made to examine the change in Lake St. Clair water levels in response to variation in river inflow. Simulations were made for the October 2008 time period with the full $5170 \mathrm{~m}^{3} / \mathrm{sec}$ inflow rate, 85 percent of the full inflow, and 62 percent of the full inflow (Figures 4-17 and 4-18). At both the St. Clair Shores and Windmill Point NOS NOAA station locations, water levels with the lowest 
(62 percent) inflow were approximately $0.4 \mathrm{~m}$ lower than the water levels with the full monthly river inflows. Although flow rates can vary considerably over the monthly time period, sometimes by as much as 25 percent (Fay and Noorbakhsh 2010), applying the flow rate reduced by 38 percent (62 percent of full monthly inflow) is not a reasonable solution for improving water level estimates. Note that production simulations applied the monthly mean river inflow values at the St. Clair River boundary. Some of the production simulations were also made with five percent, $+/-10$ percent, and 15 percent changes to the inflow rate. Forty percent of the storms required no adjustment to the inflow rate, 21 percent required 5-10 percent changes to the inflow rate, 29 percent required a 15 percent change to the inflow rate, and 10 percent of the storms had no adjustments because of lack of observation data to compare with model results. These minor adjustments to the river inflow are justified because they are well within the range of the monthly flow variability and for some production storms they improved water level comparisons.

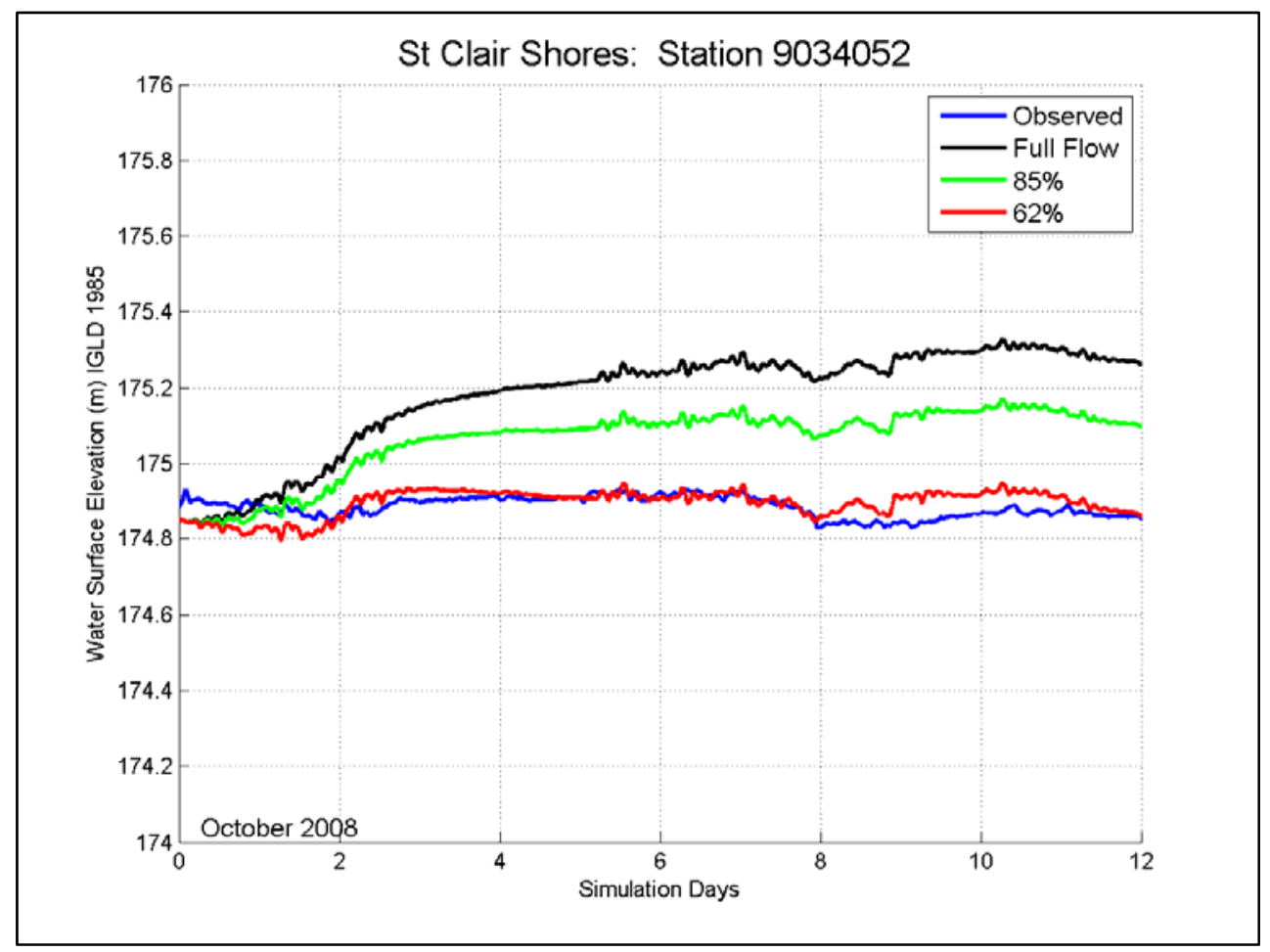

Figure 4-17. St. Clair Shores water level time series for October 2008 with full river inflow, 85 percent river inflow, and 62 percent river inflow. 


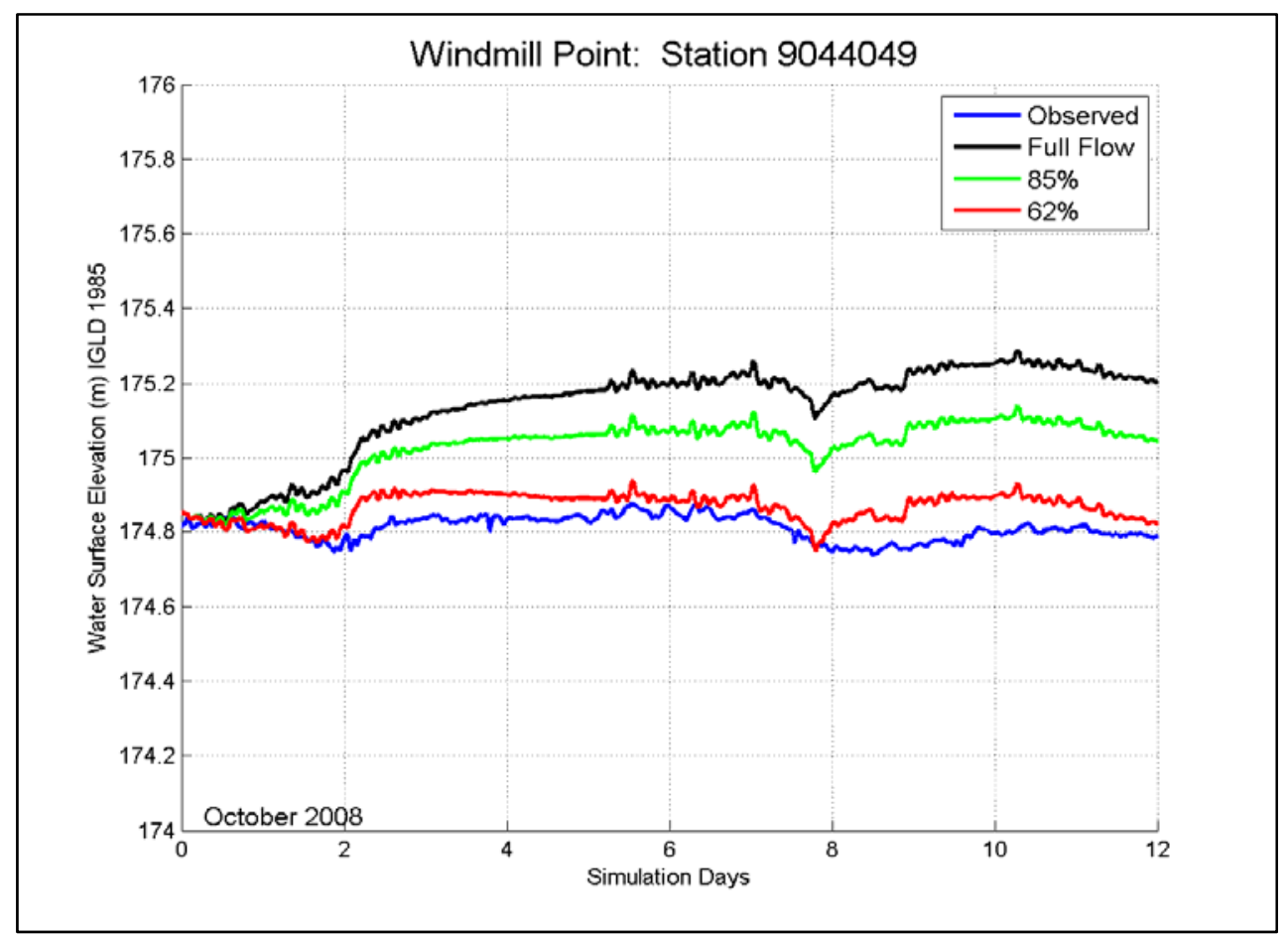

Figure 4-18. Windmill Point water level time series for October 2008 with full river inflow, 85 percent river inflow, and 62 percent river inflow.

\subsubsection{Sensitivity to bottom friction}

The sensitivity of the ADCIRC simulated water levels to bottom friction was also investigated. In ADCIRC, the bottom friction is a quadratic function of depth-averaged velocity and the model applies a quadratic friction coefficient. In the sensitivity analysis, Manning's n values of 0.018 to 0.02 and Chezy friction coefficients of 0.0012 to 0.0020 were simulated and results were compared to measured water levels. From this validation process, a Chezy friction coefficient of 0.0019 compared well with the observed data and was therefore selected as the recommended value to be used for Lake St. Clair. Figures 4-19 and 4-20 compare simulated storm surge levels generated with a Manning's n value of 0.02 and Chezy coefficients of 0.0012 and 0.0019. Results show that the range of friction coefficients produces a fairly large range $(0.6 \mathrm{~m})$ of ADCIRC water level responses. Shallow regions are most sensitive to changes in friction values. Effects are greater for the low amplitude oscillations than for the wind-driven surge events.

\subsection{Summary of findings from Lake St. Clair storm surge validation}

The construction of the wind, atmospheric pressure and ice fields as well as appropriate specification of boundary conditions and friction parameters is critical to reasonable prediction of storm surge. In general, water level 


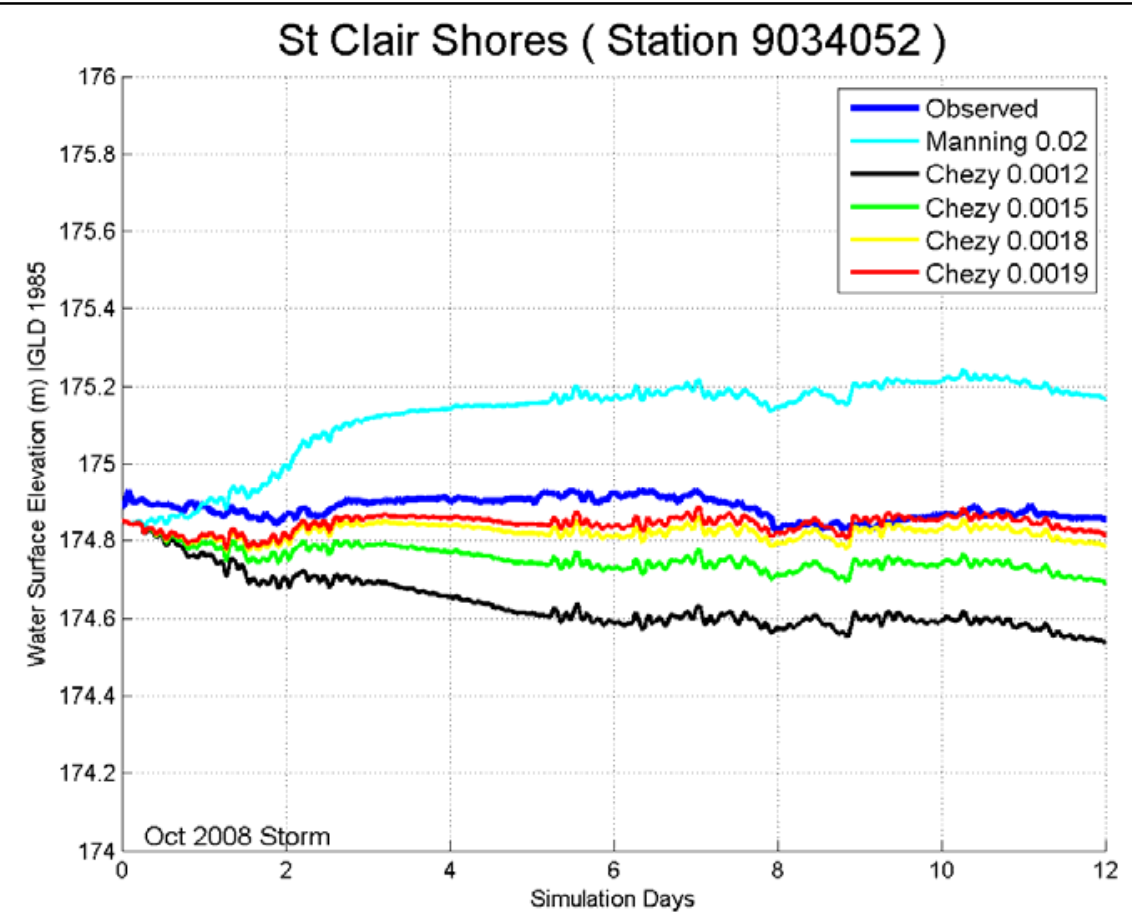

Figure 4-19. St. Clair Shores water level time series for October 2008 with variation in friction coefficient.

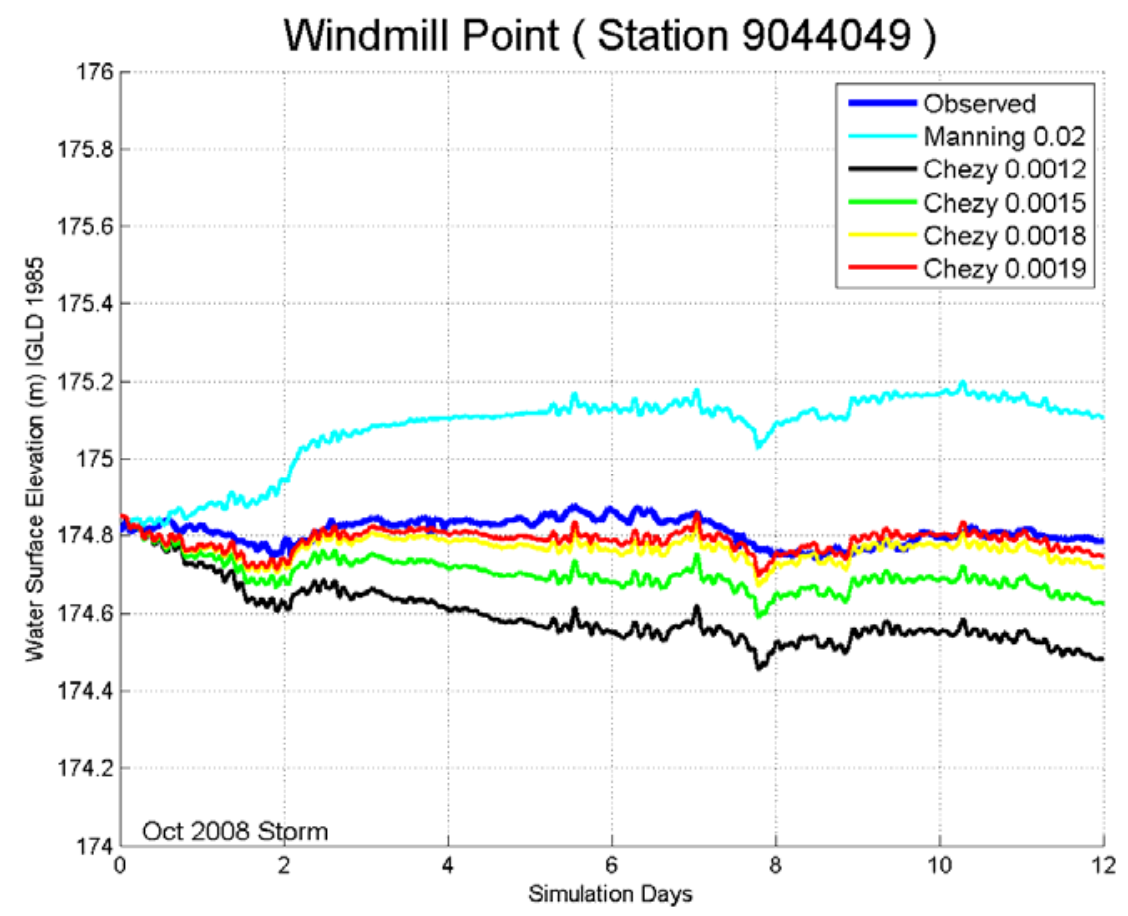

Figure 4-20. Windmill Point water level time series for October 2008 with variation in friction coefficient. 
response was most sensitive to the inflow rate at the St. Clair River boundary and to the friction parameter applied to the model domain. A fairly large range in water level response was associated with the value of the mean flow applied at the river inflow boundary. Because monthly mean flow rates were applied at the boundary (rather than hourly or daily rates) and because flow rates can vary by as much as 25 percent in a given month, the effect of flow rate on water levels in Lake St. Clair was investigated in this study by varying the inflow rate by 5,10 , and 15 percent. Water level response in the lake to these changes in flow rate was 0.3-0.4 $\mathrm{m}$. The sensitivity of the simulated water levels to bottom friction was also investigated. Manning's $\mathrm{n}$ values of 0.018 to 0.02 and Chezy friction coefficients of 0.0012 to 0.0020 were simulated and produced a fairly large range $(0.6 \mathrm{~m})$ of water level responses. The simulated water levels with the range of friction parameters were compared to measured water levels, resulting in the recommendation of a Chezy friction coefficient of 0.0019 to be used for Lake St. Clair.

The temporal frequency and spatial resolution of the available wind and pressure data needed to develop the forcing conditions limits the ability to capture events that quickly traverse the lake. High frequency oscillations associated with rapid events cannot be captured with the spatial and temporal resolution applied in the model simulations.

A methodology for including the presence of free-floating ice has been presented and applied to Lake St. Clair. It has been validated in prior applications of the modeling approach in Alaska and has been demonstrated and validated for Lake Michigan as well.

Given that the selection of the starting date for each event should represent a near initial undisturbed still water depth or elevation, care must be taken in selecting a starting date and duration so that the simulation is not unduly influenced by the initial zero water level assumption of ADCIRC. In cases where the primary storm event was preceded by smaller forcing events, sufficient lead time should be simulated so that the local seiche frequency is correct with respect to timing of the peak wind setup. In these simulations, the storm event occurred on the $10^{\text {th }}$ day of the simulation with 2 days following the main surge or wave event.

The examination of the sensitivity of Lake St. Clair water levels to wind source, wind magnitude, ice coverage, river inflow, and friction coefficient that was presented in this chapter, demonstrates the importance of 
providing appropriate representations of the physical properties and processes effecting a given water body. Although the simulated water levels compared very well to measured water levels, potential sources of error include the surface wind stresses applied to the model, either the applied over-water wind fields or the method for computing wind stress from wind speed. Errors can be associated with either the wind speed and/or wind direction.

Wind stress, which is directly related to water surface slope and therefore water surface elevation, is proportional to wind speed squared (in the wave modeling) or cubed (in the surge modeling) using the drag coefficient formulations adopted in this study. So any error in wind speed input is amplified considerably in terms of error in water level prediction. Errors in wind field products of $5^{-}$to 10-percent are not considered extreme or uncommon, and for a cubic relationship between wind speed and surface shear stress, this magnitude of error translates into 15- to 35-percent error in water surface gradient and water surface elevation.

Another potential source of error is the river inflow applied at the St. Clair River boundary. For Lake St. Clair simulations, a constant monthly mean inflow is applied at the upstream (St. Clair River) boundary. These monthly mean flow rate estimates are based on a combination of stage-fall-rating equations and one-dimensional hydraulic models and have recently been revised in response to noticeably lower lake levels. The monthly mean flow rate estimates from this latest effort were applied in this project. However, flow rates can vary considerably over a one month time period, sometimes by as much as 25 percent, resulting in 0.3-0.4 $\mathrm{m}$ differences in water level response. Applying a monthly mean water level for a 12-day period is likely within 25 percent of the actual daily flow rate, therefore some of the production simulations were also made with five percent, +/-10 percent, and 15 percent changes to the inflow rate. These minor adjustments to the river inflow are justified because they are well within the range of the monthly flow variability and for some production storms they improved water level comparisons.

Other factors that contribute to water levels, such as the friction coefficient show that the range of friction coefficients produce a fairly large range $(0.6 \mathrm{~m})$ of water level responses. Shallow regions are most sensitive to changes in friction values. Effects are greater for the low amplitude oscillations than for the wind-driven surge event. 


\section{Nearshore Wave Modeling}

\subsection{Introduction}

The purpose of applying nearshore wave transformation models is to describe quantitatively the change in wave parameters (wave height, period, direction, and spectral shape) of waves propagating from offshore to the shoreline. Offshore wave information obtained from wave gauges or globalor regional-scale wave hindcasts and forecasts is transformed through the coastal region using these models.

STWAVE has been recently used in the numerical modeling study of storm events for Lake Michigan in support of the FEMA Great Lakes Flood Mapping Study, and was again employed for the modeling effort in Lake St. Clair. Four STWAVE grids (encompassing the northwest, midwest, southwest, and northeast coasts of Lake St. Clair) were interpolated from the ADCIRC mesh with spectral boundary information provided by WAM. As in Jensen et al. (2012), water cells matching or exceeding a 70-percent ice concentration level were set to land to model ice coverage.

Tight two-way coupling between ADCIRC and STWAVE was facilitated with CSTORM-MS. During two-way coupling, a single instance of ADCIRC passes water elevations, wind fields, and ice coverage to multiple instances of STWAVE, which then pass non-zero radiation wave stress gradients to ADCIRC to force wave-driven currents and water level changes.

This chapter documents the theoretical description of STWAVE as well as grid development and simulation parameters for application in Lake St. Clair.

\subsection{STWAVE Version 6.0}

\subsubsection{Governing equations and description}

STWAVE simulates nearshore wave transformation including depthinduced refraction and shoaling, current-induced refraction and shoaling, depth- and steepness-induced wave breaking, wind-wave growth, and wave-wave interaction and whitecapping. 
Refraction and shoaling are implemented in STWAVE by applying the conservation of wave action along backward traced wave rays. Rays are traced in piecewise manner, from the previous grid column or row, and the length of ray segment $D R$ is calculated.

The energy is calculated as a weighted average of energy between two adjacent grid points in the column and direction bins. The energy density is corrected by a factor that is the ratio of the 5 -deg standard angle band width to the width of the back-traced band to account for the different angle increment in the back-traced ray. The governing equation for steadystate conservation of spectral wave action along a wave ray is given by Jonsson (1990).

Source and sink mechanisms include the flux of input energy due to wind (Resio 1988), surf-zone breaking in the form of the Miche criterion (1951), energy distribution through wave-wave interactions (Resio and Perrie 1989), whitecapping (Resio 1987; Resio 1988), and energy losses due to bottom friction (Hasselmann et al. 1973; Padilla-Hernandez and Monbaliu 2001; Holthuijsen 2007).

The assumptions made in STWAVE v6.0 as they apply to this study are the following:

- Phase-averaged. STWAVE is based on the assumption that relative phases of the spectral components are random, and phase information is not tracked;

- Mild bottom slope and negligible wave reflection. Waves reflected from the shoreline or from steep bottom features are neglected;

- Steady-state waves, currents, and winds. STWAVE is formulated as a steady-state model, which reduced computation time and is appropriate for wave conditions that vary more slowly than the time it takes for waves to transit the domain;

- Linear refraction and shoaling. STWAVE incorporates linear wave refraction, shoaling, and propagation, and does not represent wave asymmetry or other nonlinear wave features;

- Linear radiation stress. Radiation stress is calculated based on linear wave theory. 
Readers are referred to STWAVE documentation (Massey et al. 2011; Smith 2007; Smith et al. 2001) for additional model features and technical details.

\subsubsection{Grid geometry and bathymetry}

STWAVE is formulated on a Cartesian grid and operates in a local coordinate system with the $x$-axis oriented in the cross-shore direction and the $y$-axis oriented alongshore, forming a right-handed coordinate system. The $y$-axis is aligned with the offshore contours. Orientation and wave angles are defined in a mathematical sense, measured counterclockwise from the $x$-axis.

Four STWAVE grids were interpolated from the ADCIRC mesh to UTM NAD 83 Zone 17 for this project. These grids cover the northwest, midwest, southwest, and the northeast coasts of Lake St. Clair, and are hereafter referred to as the NW, MW, SW, and NE grids, respectively. Figure 5-1 shows the location of the grids with respect to the ADCIRC mesh. The grids' offshore boundaries were extended sufficiently offshore of wave breaking. As in Jensen et al. (2012), the cell size of the grid was 200-m, which allowed

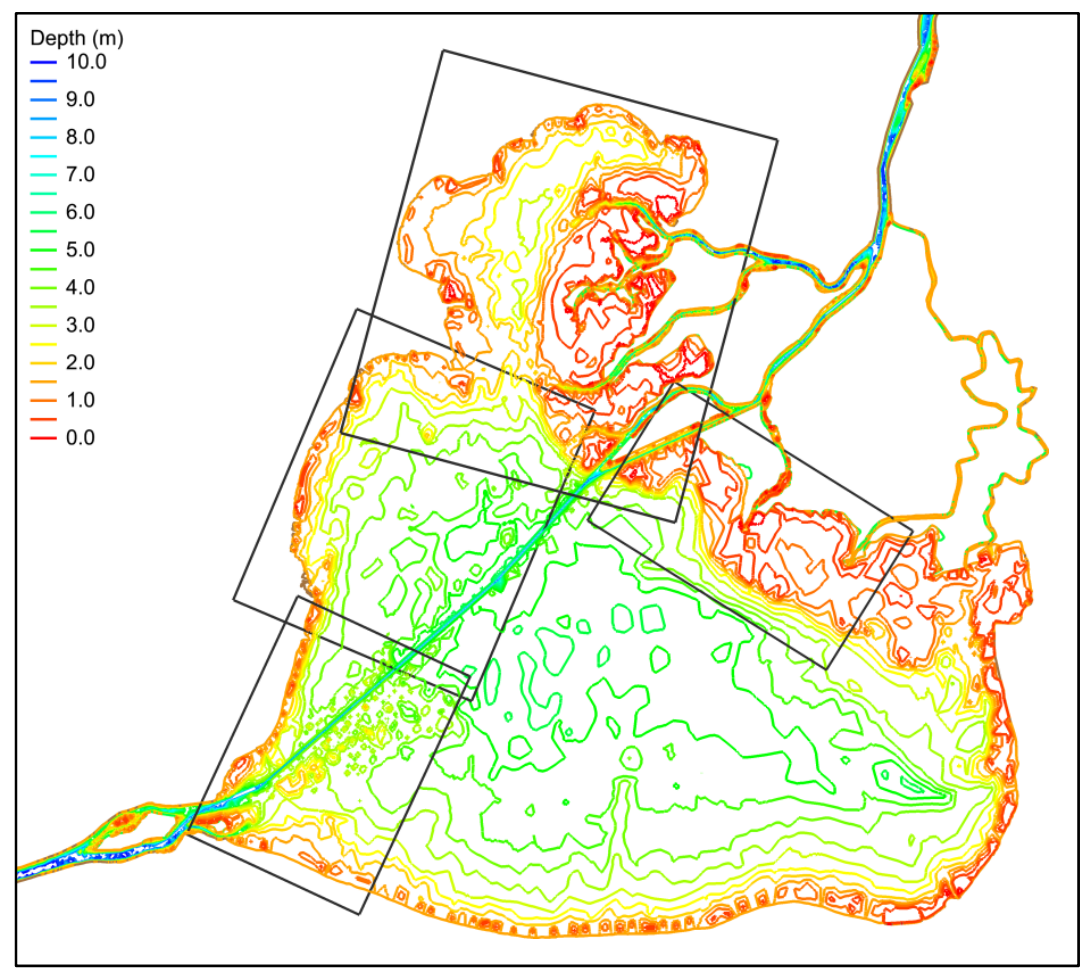

Figure 5-1. Location of the Lake St. Clair northwest (NW), midwest (MW), southwest (SW), and northeast (NE) STWAVE grids. 
fast execution times while retaining high resolution and good representation of bottom features and shipping channels. Detailed bathymetry of the NW, MW, SW, and NE grids is shown in Figures 5-2 to 5-5, respectively, with grid geometries presented in Table 5-1.

\subsubsection{Boundary spectra}

Spectral wave energy saved from WAM is transformed to STWAVE coordinates and applied as offshore boundary conditions for the STWAVE domains. The longitude/latitude of these boundary points are found in Table 5-2 with their locations shown in Figures 5-6 to 5-9. Linear interpolation of the two-dimensional spectra was performed between these boundary points. Land boundaries were assigned zero spectra, and one-dimensional transformed spectra were set on the lateral boundaries. Boundary conditions were assigned for each STWAVE time step.

The number and values of the discrete frequency bands, as well as the starting and ending bands, were the same as those defined in WAM. The number and value of the frequency bands were defined as:

$$
f(n+1)=1.1^{*} f(n) \text { wheren }=1,28
$$

where the starting and ending starting bands were $0.0612 \mathrm{~Hz}$ ( $T=16.3 \mathrm{sec}$ ) and $0.8018 \mathrm{~Hz}(T=1.2 \mathrm{sec})$, respectively. The angular resolution was set to 5 -deg (seventy-two direction bins).

\subsubsection{Save points}

The zero-moment wave height $\left(H_{m o}\right)$, mean wave period $\left(T_{m}\right)$, mean wave direction $\left(\alpha_{m}\right)$, and 2-D spectra at special save points are exported each time step. Save points were selected along the 2-m contour at an alongshore space of $1.5 \mathrm{~km}$ for all grids. The number of save points for the NW, MW, SW, and NE grid was 53, 28, 31, and 21, respectively, for a total of 133 points. Locations of the STWAVE save points for each grid is shown below in Figures 5-10 to 5-13.

\subsubsection{Model parameters}

Based on the methodologies in Jensen et al. (2012), STWAVE was executed in full-plane mode, allowing wave generation and transformation on the full 360-deg plane. The solution process for the full-plane version of STWAVE is 


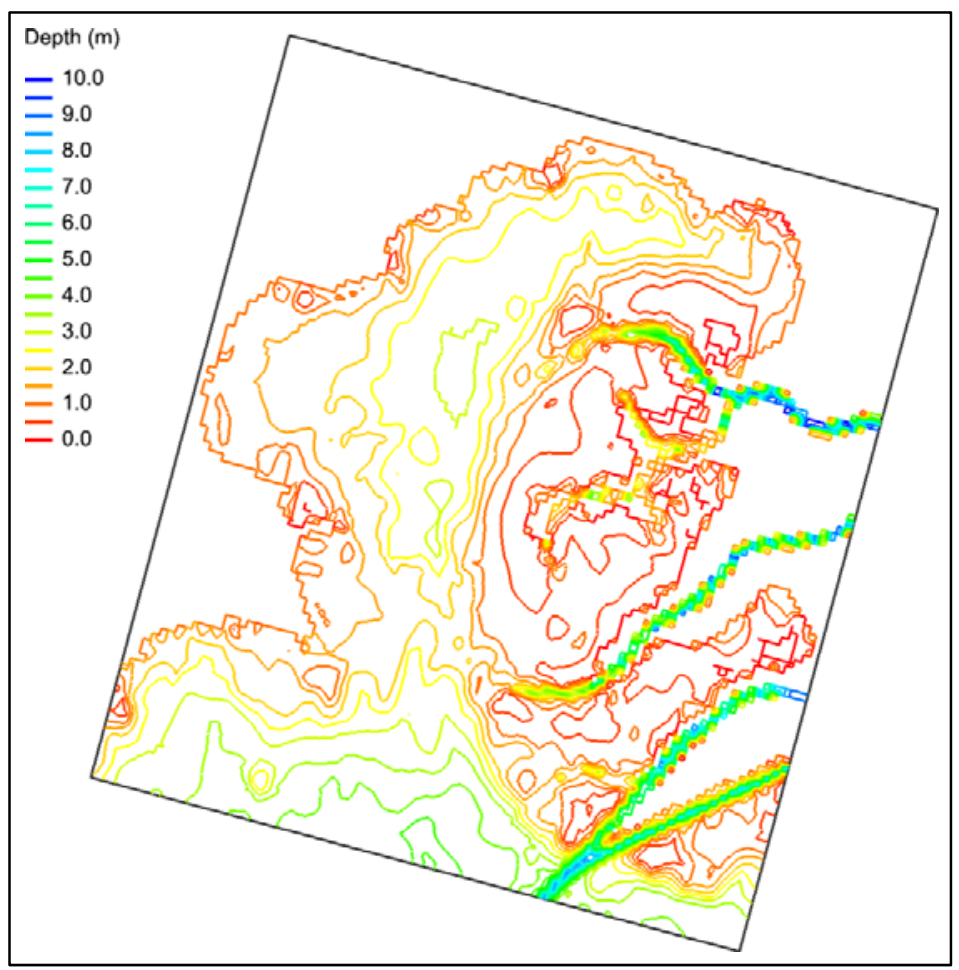

Figure 5-2. STWAVE NW grid bathymetry.

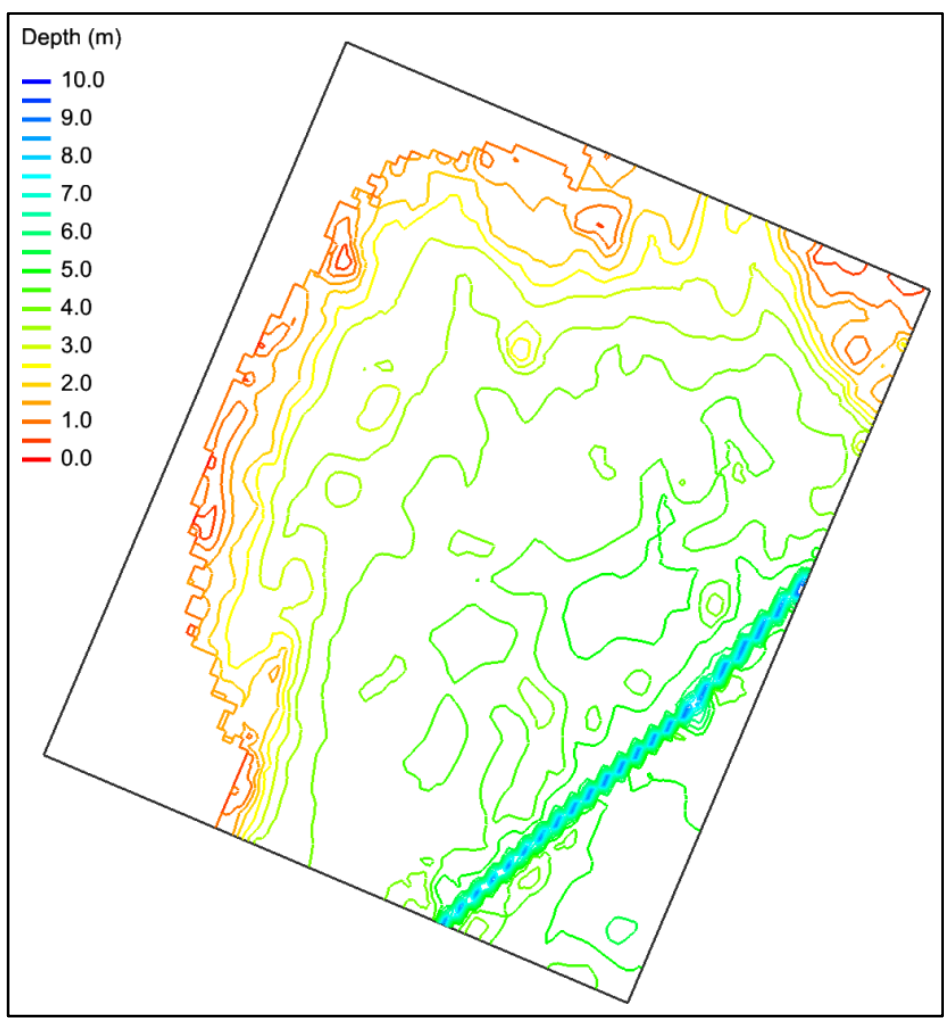

Figure 5-3. STWAVE MW grid bathymetry. 


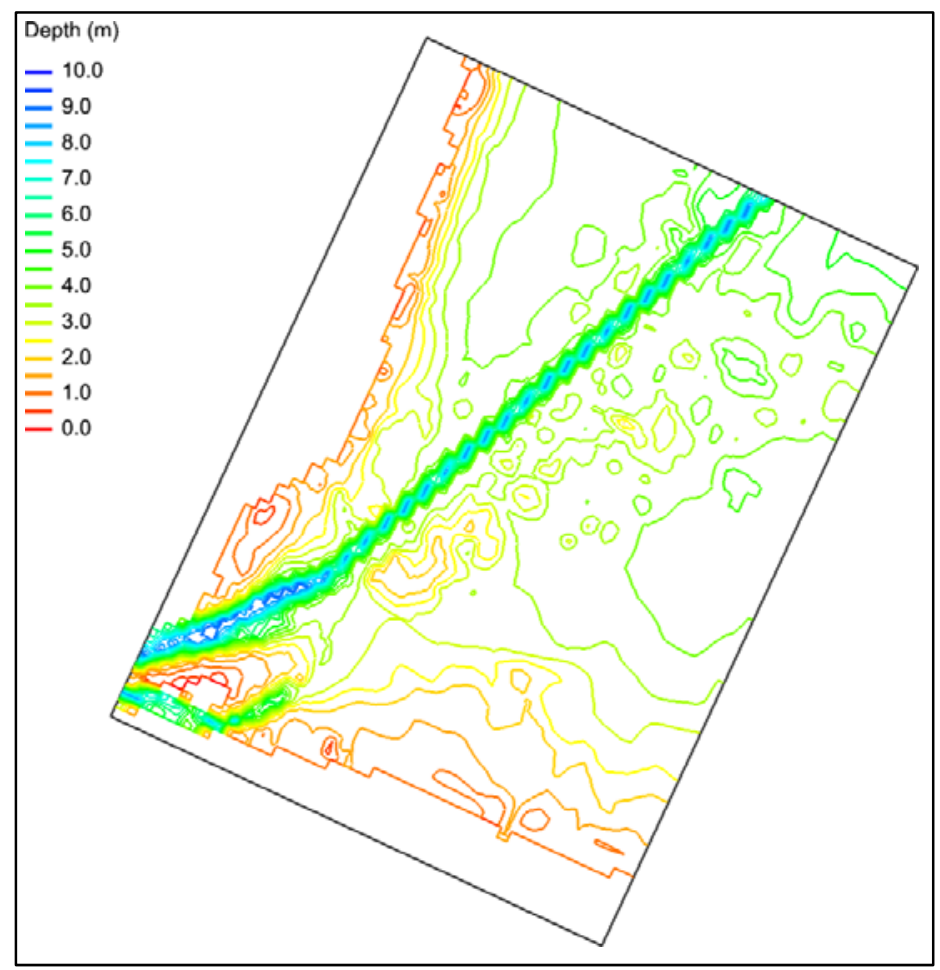

Figure 5-4. STWAVE SW grid bathymetry.

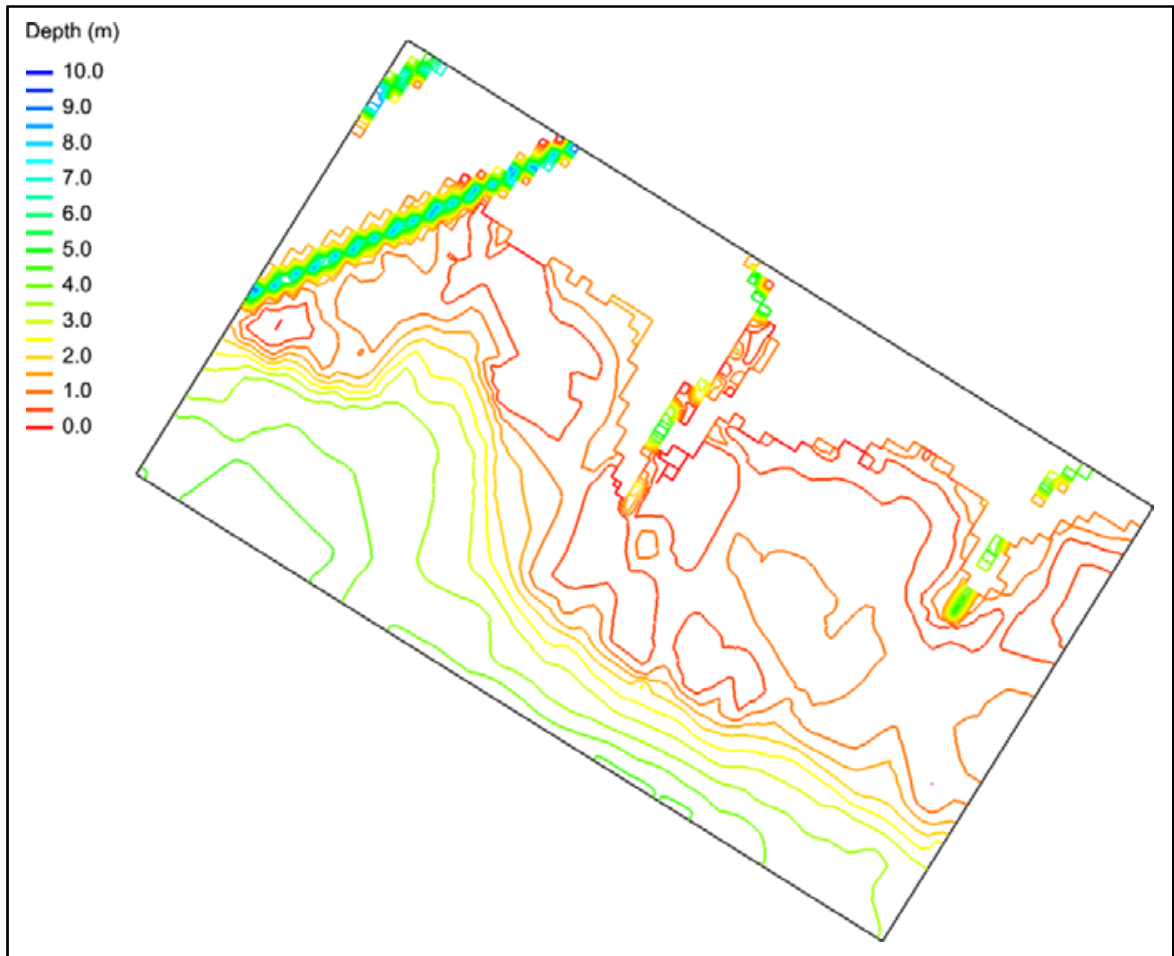

Figure 5-5. STWAVE NE grid bathymetry. 
Table 5-1. Geometry of Lake St. Clair STWAVE grids.

\begin{tabular}{|c|c|c|c|c|c|c|}
\hline \multirow[b]{2}{*}{ Grid Name } & \multirow[b]{2}{*}{$\begin{array}{l}\text { Grid Origin } \\
(x, y)(m)\end{array}$} & \multirow[b]{2}{*}{$\begin{array}{l}\text { Grid Angle } \\
\text { (deg) }\end{array}$} & \multicolumn{2}{|c|}{ Extent $(\mathrm{m})$} & \multicolumn{2}{|c|}{ Number of cells } \\
\hline & & & Cross-shore (I) & Alongshore $(J)$ & $\begin{array}{l}\text { Cross-shore } \\
\text { (NI) }\end{array}$ & $\begin{array}{l}\text { Alongshore } \\
\text { (NJ) }\end{array}$ \\
\hline Northwest (NW) & $\begin{array}{l}(365310.0 \\
4705886.0)\end{array}$ & 75.0 & 20800.0 & 18200.0 & 104 & 91 \\
\hline Midwest (MW) & $\begin{array}{l}(361096.0 \\
4711793.0)\end{array}$ & 157.0 & 13600.0 & 16600.0 & 68 & 83 \\
\hline Southwest (SW) & $\begin{array}{l}(354540.0 \\
4697812.0)\end{array}$ & 155.0 & 10000.0 & 13800.0 & 50 & 69 \\
\hline Northeast (NE) & $\begin{array}{l}(373246.0 \\
4698157.0)\end{array}$ & 58.0 & 8600.0 & 14800.0 & 43 & 74 \\
\hline
\end{tabular}

Table 5-2. Location of offshore wave spectra boundary points.

\begin{tabular}{|c|c|c|c|}
\hline \multicolumn{4}{|c|}{ Longitude/Latitude of Boundary Points (deg) } \\
\hline \multicolumn{4}{|l|}{ Grid Name } \\
\hline NW & MW & SW & $\mathrm{NE}$ \\
\hline $\begin{array}{l}(-82.850,42.530) \\
(-82.840,42.530) \\
(-82.830,42.530) \\
(-82.820,42.530) \\
(-82.810,42.530) \\
(-82.800,42.530) \\
(-82.790,42.520) \\
(-82.780,42.520) \\
(-82.770,42.520) \\
(-82.765,42.515) \\
(-82.760,42.520) \\
(-82.750,42.520) \\
(-82.740,42.510) \\
(-82.730,42.510) \\
(-82.710,42.510) \\
(-82.700,42.510) \\
(-82.690,42.510) \\
(-82.670,42.500) \\
(-82.660,42.500) \\
(-82.655,42.495) \\
(-82.650,42.500)\end{array}$ & $\begin{array}{l}(-82.770,42.410) \\
(-82.765,42.415) \\
(-82.760,42.430) \\
(-82.760,42.440) \\
(-82.750,42.440) \\
(-82.750,42.450) \\
(-82.750,42.460) \\
(-82.740,42.460) \\
(-82.740,42.470) \\
(-82.730,42.480) \\
(-82.730,42.490) \\
(-82.720,42.490) \\
(-82.720,42.500) \\
(-82.710,42.510) \\
(-82.710,42.520) \\
(-82.710,42.530) \\
(-82.700,42.510) \\
(-82.700,42.540) \\
(-82.700,42.550)\end{array}$ & \begin{tabular}{|l}
$(-82.830,42.320)$ \\
$(-82.830,42.330)$ \\
$(-82.820,42.330)$ \\
$(-82.820,42.340)$ \\
$(-82.820,42.350)$ \\
$(-82.810,42.355)$ \\
$(-82.805,42.360)$ \\
$(-82.800,42.365)$ \\
$(-82.795,42.370)$ \\
$(-82.800,42.380)$ \\
$(-82.790,42.390)$ \\
$(-82.790,42.400)$ \\
$(-82.780,42.400)$ \\
$(-82.780,42.410)$ \\
$(-82.780,42.420)$ \\
$(-82.770,42.420)$
\end{tabular} & $\begin{array}{l}(-82.700,42.500) \\
(-82.690,42.490) \\
(-82.680,42.490) \\
(-82.670,42.490) \\
(-82.660,42.480) \\
(-82.655,42.475) \\
(-82.650,42.480) \\
(-82.640,42.470) \\
(-82.635,42.465) \\
(-82.630,42.470) \\
(-82.620,42.460) \\
(-82.610,42.460) \\
(-82.600,42.460) \\
(-82.600,42.450) \\
(-82.590,42.450) \\
(-82.580,42.440) \\
(-82.570,42.440) \\
(-82.560,42.440) \\
(-82.560,42.430) \\
(-82.550,42.430)\end{array}$ \\
\hline
\end{tabular}




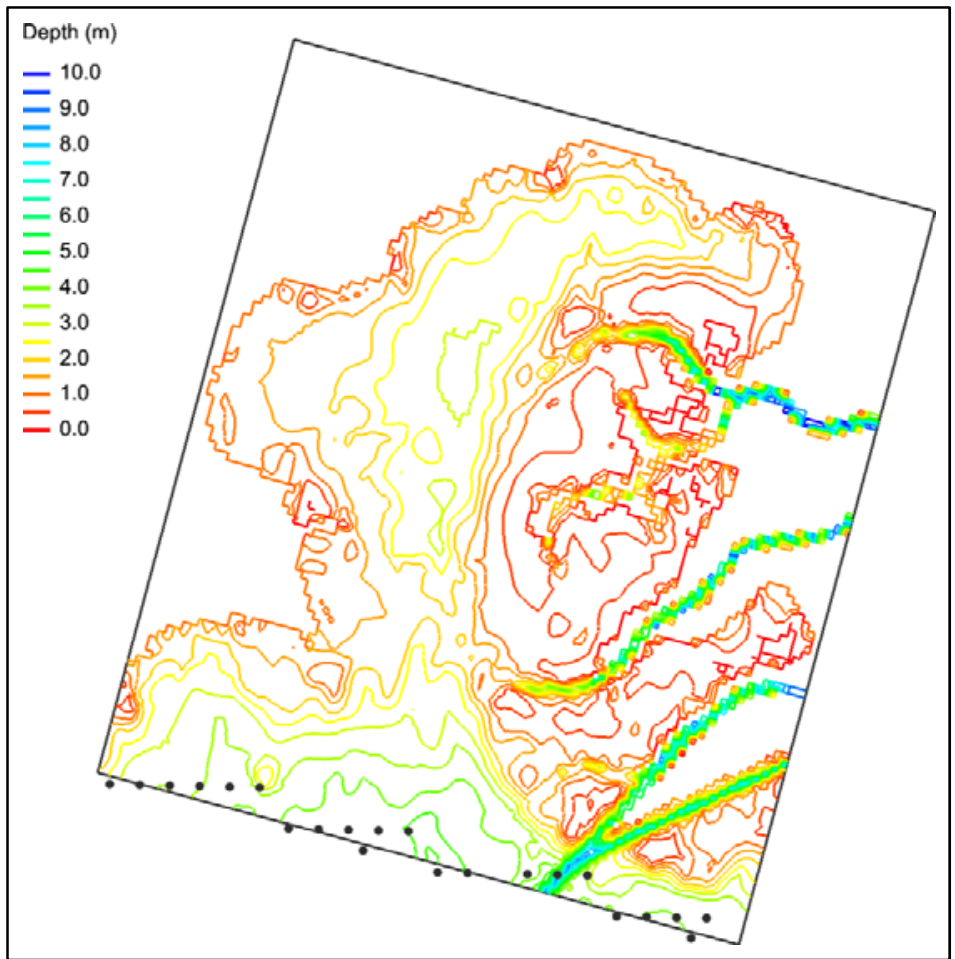

Figure 5-6. WAM spectra save points for NW grid.

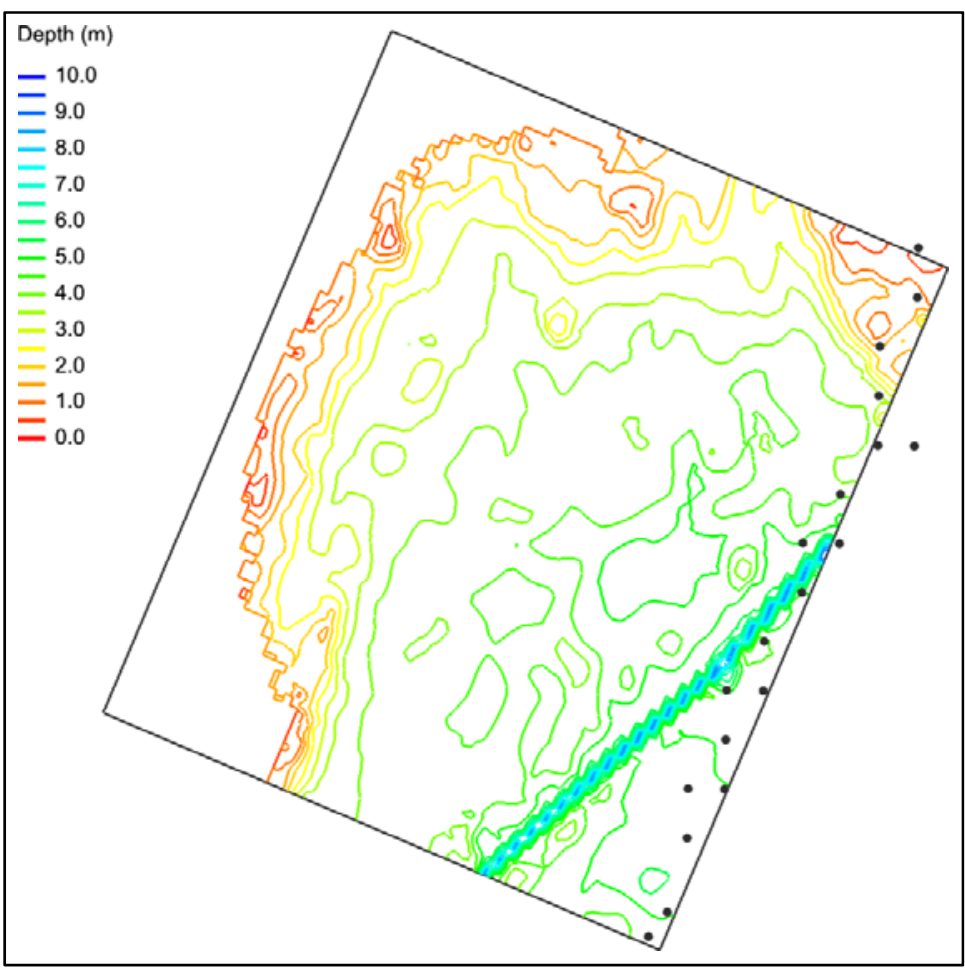

Figure 5-7. WAM spectra save points for MW grid. 


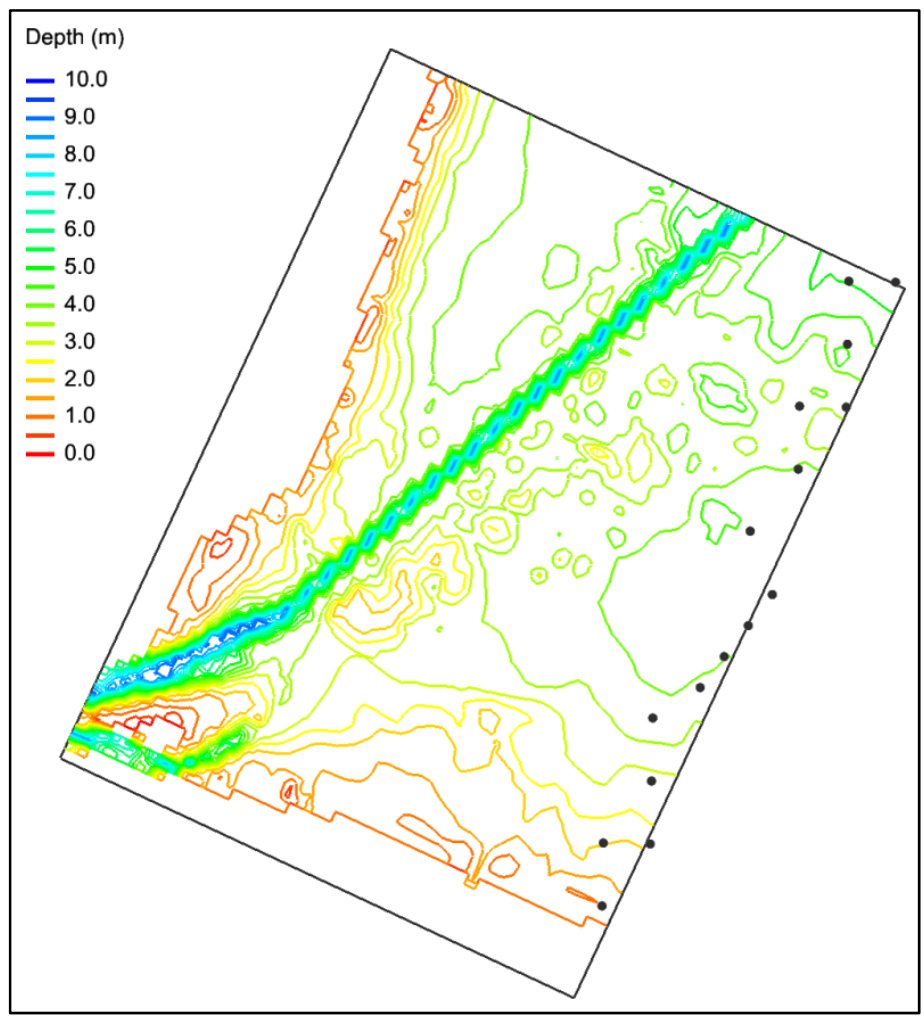

Figure 5-8. WAM spectra save points for SW grid.

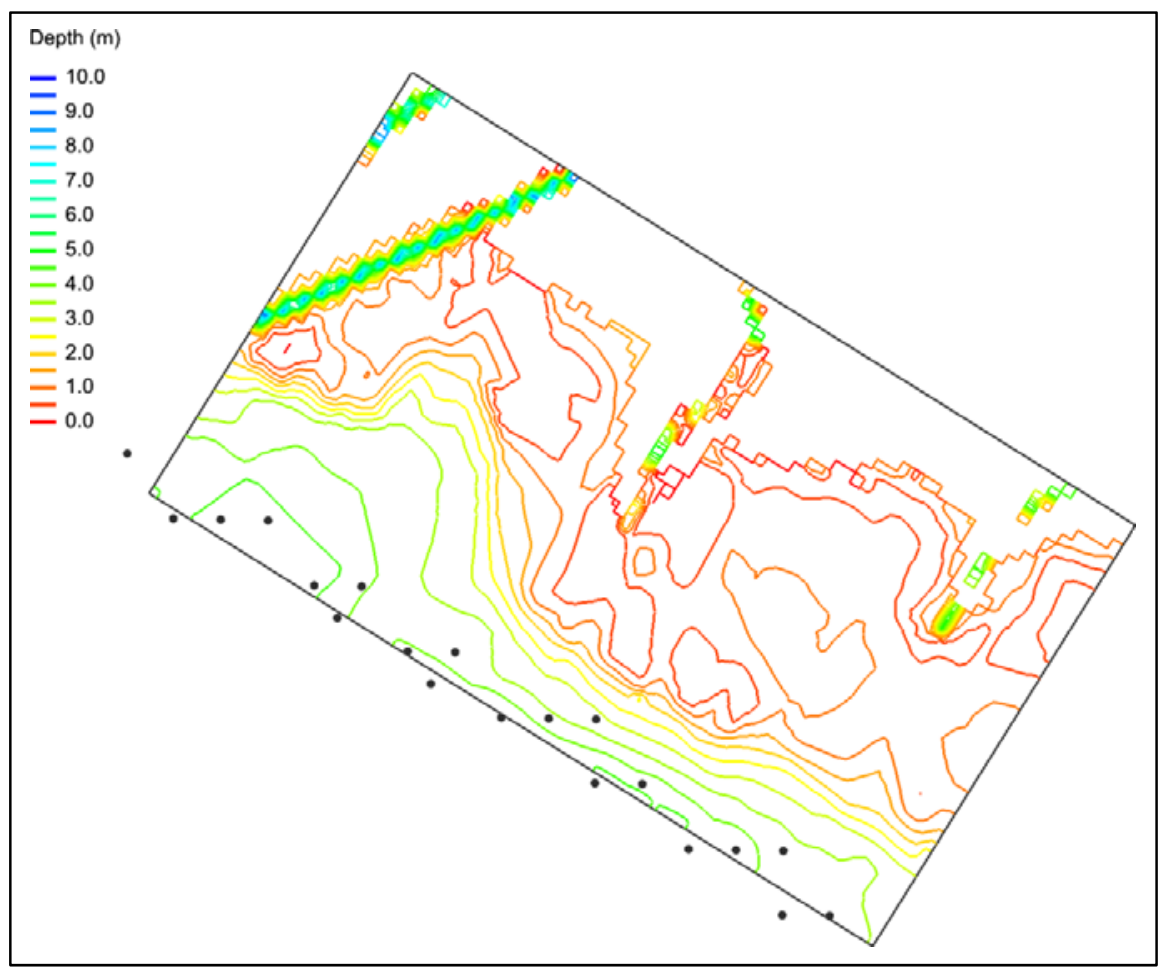

Figure 5-9. WAM spectra boundary points for NE grid. 


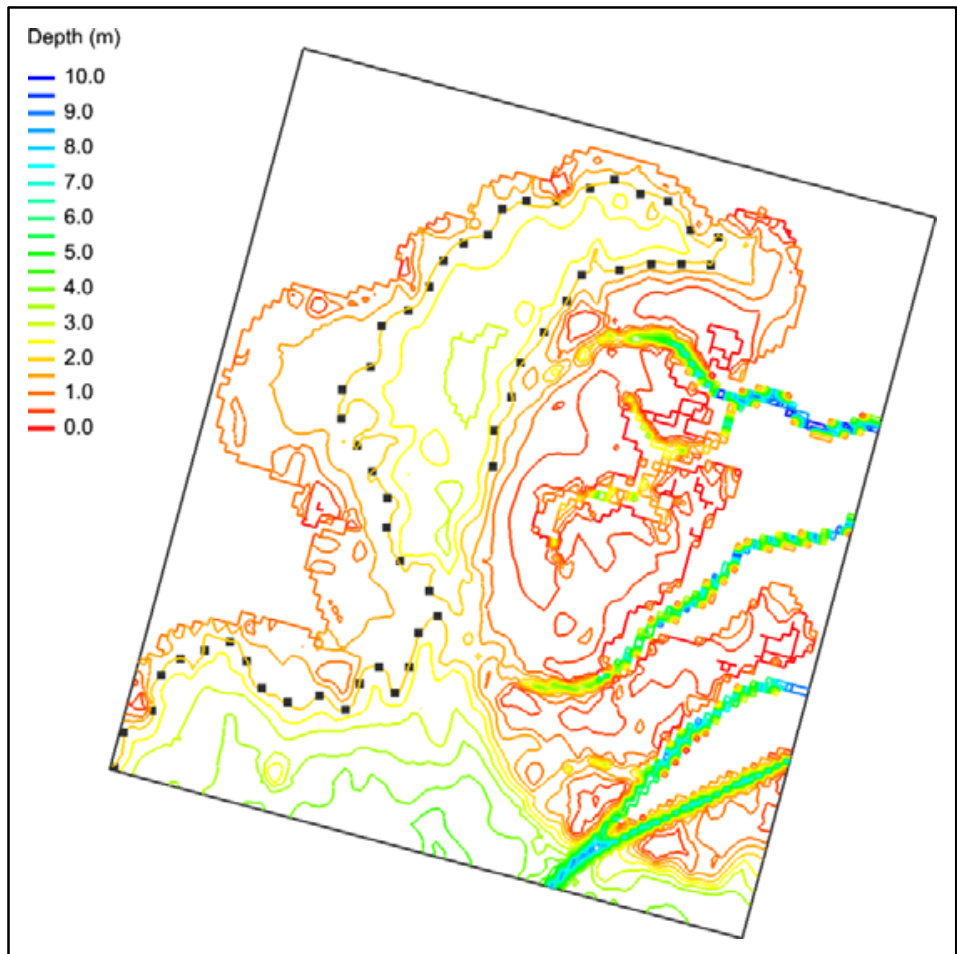

Figure 5-10. STWAVE save points for NW grid.

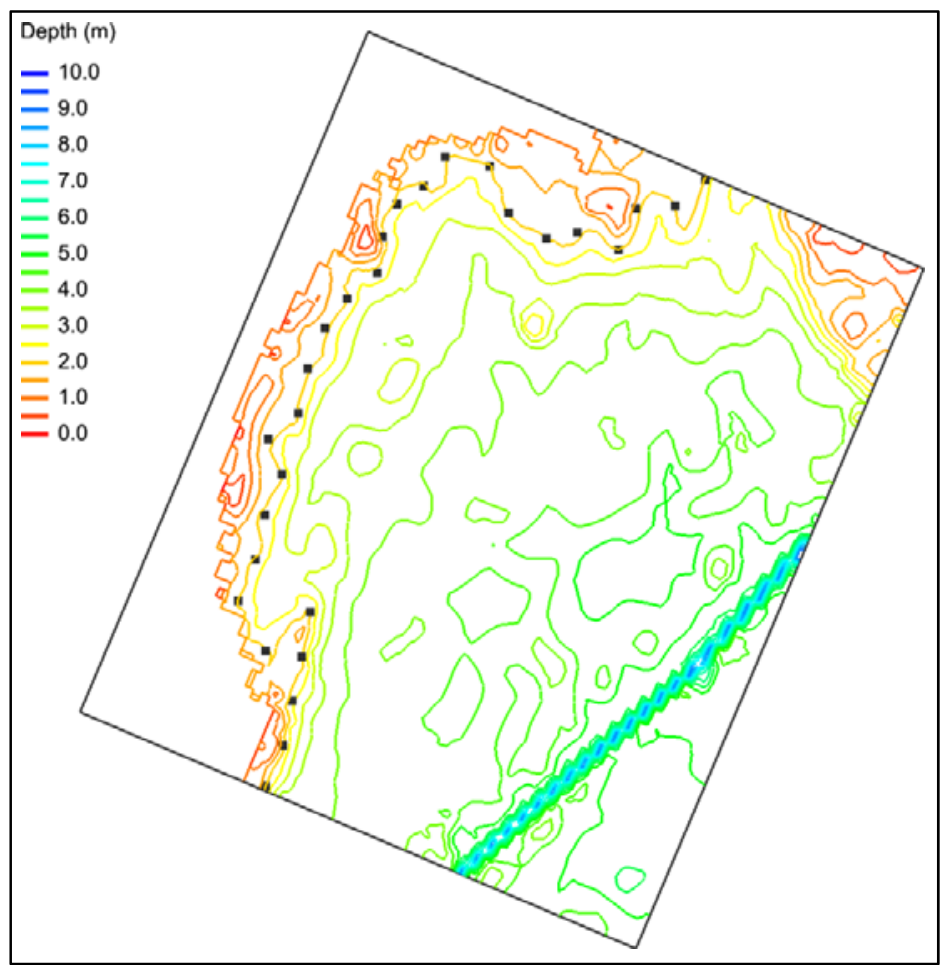

Figure 5-11. STWAVE save points for MW grid. 


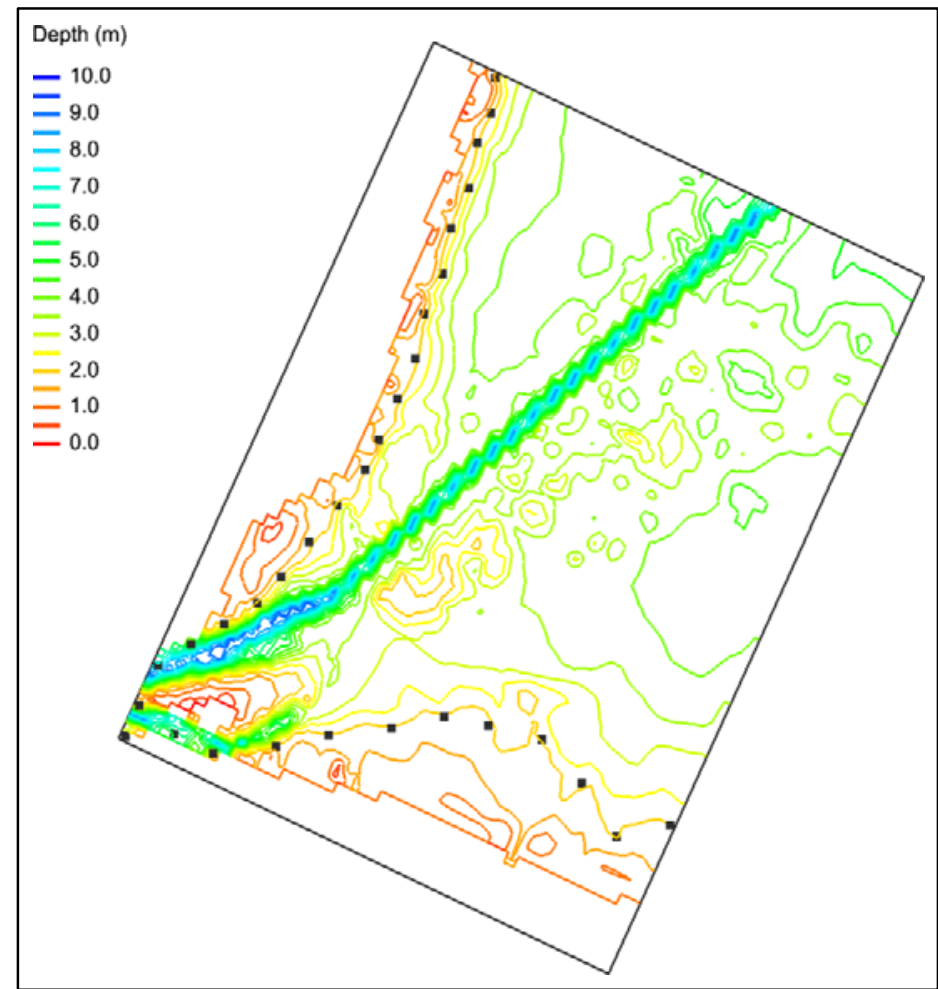

Figure 5-12. STWAVE save points for SW grid.

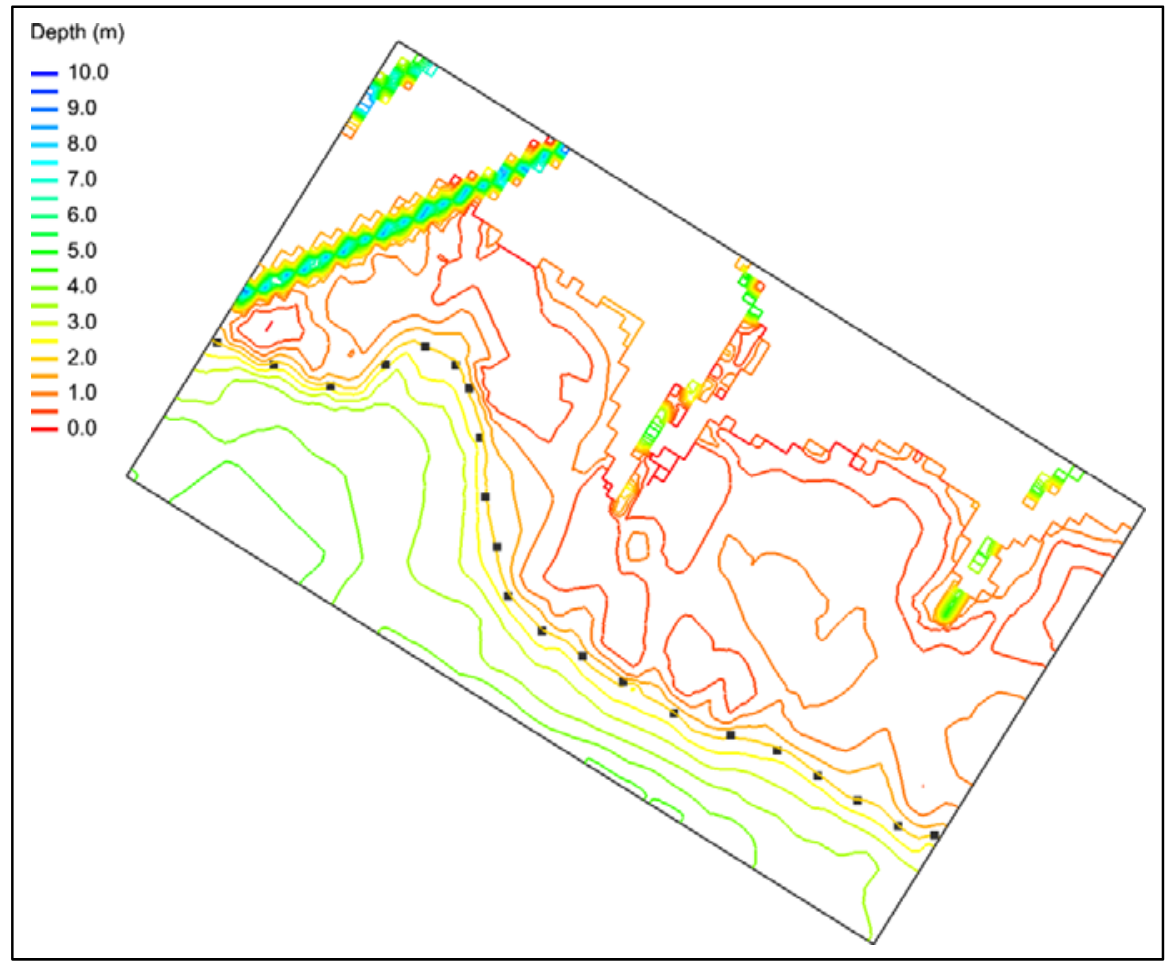

Figure 5-13. STWAVE save points for NE grid. 
an iterative process that requires user-defined convergence criteria to signal a suitable solution. Boundary spectra information is propagated from the boundary throughout the domain during the initial iterations. Once this stage converges, winds and surges are added to the forcing and this final stage iteratively executes until it also reaches a convergent state. The convergence criteria for both stages include the maximum number of iterations to perform (per time step), the relative difference in average wave height between iterations, and the minimum percent of cells that must satisfy the stop criteria (i.e., have values less than the relative difference). Convergence parameters remained the same as those in Jensen et al. (2012).

STWAVE was setup with parallel in space execution whereby the computational grid is broken into different partitions with each partition residing on a different computer processor. This allows for the modeling of larger domains with finer resolution as a full-plane grid can be separated in both the $x$ - and $y$-direction. As energy can only cross one grid partition at a time during a single iteration, the maximum number of initial/final iterations was set to a value at least 15 higher than the largest grid partition while maintaining at least 20 cells in each partition. The convergence criteria and partitions for each grid are shown in Table 5-3. Comparisons of STWAVE results to wave observations were unable to be completed as there were no wave gauges available within any of the four domains.

Table 5-3. STWAVE full-plane and parallel in space execution parameters.

\begin{tabular}{|l|l|l|l|l|l|l|l|l|l|}
\hline \multirow{2}{*}{ Grid } & \multicolumn{2}{|c|}{ Maximum Iterations } & Relative Difference & \multicolumn{2}{c|}{$\begin{array}{c}\text { Minimum Cell } \\
\text { Percentage }\end{array}$} & \multicolumn{2}{|c|}{ Partitions } \\
\cline { 2 - 10 } & Initial & Final & Initial & Final & Initial & Final & x & y \\
\hline NW & 20 & 25 & 0.1 & 0.05 & 100.0 & 99.8 & 5 & 4 \\
\hline MW & 20 & 25 & 0.1 & 0.05 & 100.0 & 99.8 & 3 & 4 \\
\hline SW & 20 & 25 & 0.1 & 0.05 & 100.0 & 99.8 & 2 & 3 \\
\hline NE & 20 & 25 & 0.1 & 0.05 & 100.0 & 99.8 & 2 & 3 \\
\hline
\end{tabular}

\subsubsection{CSTORM-MS coupler}

CSTORM-MS is a physics-based modeling capability for simulating storm winds, waves, and water levels. The wave-circulation coupling is completed with one unstructured ADCIRC mesh and one or more structured STWAVE grids. One-way and two-way coupling is available in CSTORM-MS. One-way coupling passes information in one direction from one model to the other 
(i.e. ADCIRC $\rightarrow$ STWAVE or STWAVE $\rightarrow$ ADCIRC) while information is exchanged between models during two-way coupling (ADCIRC $\leftrightarrow$ STWAVE). Two-way coupling (ADCIRC $\leftrightarrow$ STWAVE) was selected for application to Lake St. Clair where the shared information is ADCIRC's surge, wind, and ice fields and STWAVE's wave radiation stresses.

ADCIRC and STWAVE run sequentially during the coupling process. ADCIRC executes first using a zero valued wave radiation stress field and passes its surge, wind, and ice information (if applicable) to STWAVE at the desired time step. STWAVE then executes, using the surge, wind, and ice fields along with boundary forcing to compute the wave field and passes non-zero wave stress gradients to ADCIRC. These gradients are used by ADCIRC to force wave-driven currents and water level changes, and the process is repeated.

All time values must be provided relative to ADCIRC to synchronize ADCIRC and STWAVE. Timing is performed via an external control file that specifies the ADCIRC starting and ending times in terms of the ADCIRC time step, the starting and ending of all STWAVE simulations in terms of the ADCIRC time step, and the number of ADCIRC time steps that occur between STWAVE time steps or snaps.

ADCIRC is run for 12 days using a 0.5 sec time step, which corresponds to 1036800 sec or 2073600 time steps. STWAVE starts on Day 6 of the coupled simulation ( $518400 \mathrm{sec}$ or 1036800 time steps) and is run for 6 days ( 3 days prior to the storm peak, the peak day, and 2 days following the storm peak). STWAVE is run every $30 \mathrm{~min}(1800 \mathrm{sec})$, which corresponds to 3600 time steps. ADCIRC and STWAVE terminate on Day 12. The timing for this scenario in terms of ADCIRC time steps is shown below in Table 5-4 and illustrated in Figure 5-14.

Table 5-4. Timing between ADCIRC and STWAVE in terms of ADCIRC time steps.

\begin{tabular}{|l|l|l|l|l|}
\hline $\begin{array}{l}\text { ADIRC } \\
\text { Start }\end{array}$ & $\begin{array}{l}\text { ADCIRC } \\
\text { End }\end{array}$ & $\begin{array}{l}\text { Number of ADCIRC time steps between } \\
\text { STWAVE snaps }\end{array}$ & $\begin{array}{l}\text { STWAVE } \\
\text { Start }\end{array}$ & $\begin{array}{l}\text { STWAVE } \\
\text { End }\end{array}$ \\
\hline 0 & 2073600 & 3600 & 1036800 & 2073600 \\
\hline
\end{tabular}




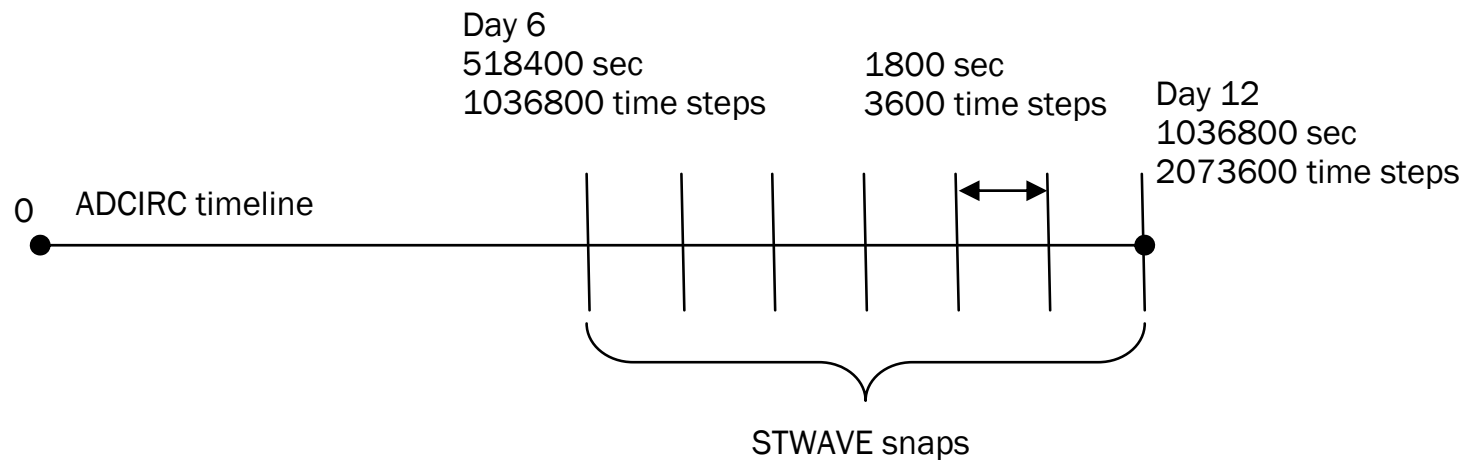

Figure 5-14. Diagram of timing between ADCIRC and STWAVE.

CSTORM-MS required 80 processors for each Lake St. Clair storm simulation. One cpu is always reserved to serve as the controller, and one coupler ( $1 \mathrm{cpu} /$ coupler) is required for each STWAVE grid. ADCIRC's efficiency is highest with 2000-4000 nodes per processor, and three writers were used for this application (one for each global file written). The number of processors required by STWAVE is determined by multiplying the number of partitions in the $x$-direction by the number of partitions in the $y$-direction. The processors break down according to the following:

- Controller - $1 \mathrm{cpu}$

- Writers - 3cpu ( $1 \mathrm{cpu} /$ writer)

- ADCIRC - $72 \mathrm{cpu}$

- Couplers - 4 cpu (1 coupler/STWAVE grid)

- STWAVE NW - 20 (5 x 4)

- STWAVE MW - 12 (3 x 4)

- STWAVE SW - $6(2 \times 3)$

- STWAVE NE - 6 ( $2 \times 3)$

All instances of STWAVE run simultaneously, and ADCIRC and STWAVE share cpus so the number of processors in this study was dictated by ADCIRC. The total number of processors required by CSTORM-MS is the sum of the controller, the couplers, and the processors required by the dominant model (in this study, ADCIRC).

All coupled simulations were run on the ERDC DSRC high performance Cray XE6 computer known as Garnet. Garnet contains 1,260 computer nodes (20,160 computer cores). Each compute node contains a $2.4-\mathrm{GHz}$ AMD Opteron 64-bit quad-core processor and 32 GBytes of dedicated memory. The nodes are connected together using a Cray Gemini communications engine (http://www.erdc.hpc.mil/). The majority of the storm simulations finished within 5 -hrs. 


\section{Storm Production}

\subsection{Introduction}

The selection of extreme water level, wave and wind events was performed for the two long-term water level stations and one wave measurement buoy in Lake St. Clair (Figure 6-1). The analysis and subsequent synthesis to define the top 150-events for simulations followed the procedure defined in Melby et al. (2012) and Nadal-Caraballo et al. (2012). The list was further edited based on ice coverage for a given storm to 145 storm events. The final list of production storms is presented in Table 6-1. The table lists the starting, ending and storm peak date, the water level site defined, the presence of ice in any part of Lake St. Clair, and the type of wind field generation (i.e. Natural Neighbor Method or CFSR). The storms highlighted in red were either outside the top 20 peak events at the gauges and completely iced over or duplication storms that were removed from the list. The reduction of storms to 145 was deemed acceptable because of the diminishing intensity of the events as the selection method approached 150 .

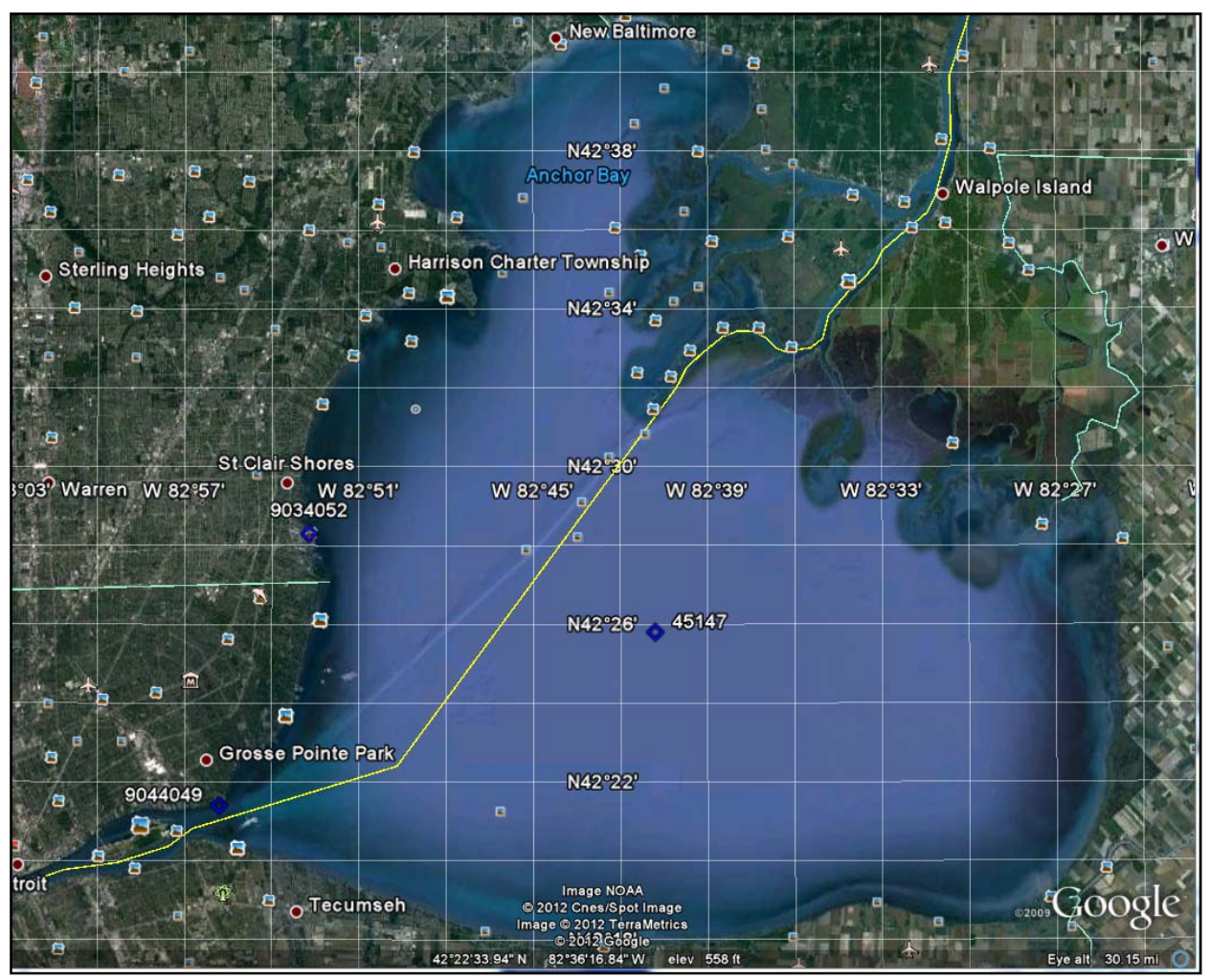

Figure 6-1. Location of wave measurements and water level sites. 
Table 6-1. Extreme storm event list.

\begin{tabular}{|c|c|c|c|c|c|c|c|}
\hline \multirow[b]{2}{*}{$\begin{array}{l}\text { STORM } \\
\text { No. }\end{array}$} & \multicolumn{3}{|c|}{ STORM DATES (YYYMMDDHH) } & \multirow[b]{2}{*}{ ICE } & \multirow[b]{2}{*}{ WIND } & \multirow{2}{*}{$\begin{array}{l}\text { Water } \\
\text { Level } \\
\text { Adj. (m) }\end{array}$} & \multirow[b]{2}{*}{$\begin{array}{l}\text { Mon. Flow } \\
\text { Rate }(\mathrm{m} 3 / \mathrm{s}\end{array}$} \\
\hline & START DATE & $\begin{array}{l}\text { STORM PEAK } \\
\text { DATE }\end{array}$ & END DATE & & & & \\
\hline ST0001 & 1986092700 & 1986100600 & 1986100900 & NO & CFSR & 1.48 & 6740 \\
\hline STO002 & 1960110700 & 1960111612 & 1960111900 & NO & NNM & 0.34 & 5610 \\
\hline STO003 & 1961022800 & 1961030920 & 1961031200 & YES & NNM & 0.26 & 5180 \\
\hline STO004 & 1961040700 & 1961041617 & 1961041900 & NO & NNM & 0.19 & 5150 \\
\hline ST0005 & 1962122000 & 1962122920 & 1963010100 & NO & NNM & 0.13 & 4640 \\
\hline ST0006 & 1963030800 & 1963031715 & 1963032000 & YES & NNM & 0.04 & 4300 \\
\hline STO007 & 1963032600 & 1963040406 & 1963040700 & YES & NNM & 0.18 & 4445 \\
\hline ST0008 & 1963092400 & 1963100304 & 1963100600 & NO & NNM & 0.05 & 4785 \\
\hline STO009 & 1964011600 & 1964012517 & 1964012800 & YES & NNM & -0.35 & 3770 \\
\hline ST0010 & 1964022500 & 1964030518 & 1964030800 & YES & NNM & -0.19 & 3865 \\
\hline ST0011 & 196501500 & 1965012410 & 1965012700 & Drop & & & \\
\hline ST0012 & 1977042900 & 1977050821 & 1977051100 & NO & NNM & 0.83 & 5350 \\
\hline ST0013 & 1990021500 & 1990022416 & 1990022700 & YES & CFSR & 0.53 & 4950 \\
\hline ST0014 & 1965122500 & 1966010317 & 1966010600 & NO & NNM & 0.02 & 4885 \\
\hline ST0015 & 1966031500 & 1966032402 & 1966032700 & NO & NNM & 0.13 & 4810 \\
\hline ST0016 & 1966123000 & 1967010800 & 1967011100 & Drop & & & 4730 \\
\hline ST0017 & 1968050700 & 1968051618 & 1968051900 & NO & NNM & 0.57 & 5180 \\
\hline ST0018 & 1968111100 & 1968112000 & 1968112300 & NO & NNM & 0.44 & 5580 \\
\hline ST0019 & 1968112600 & 1968120518 & 1968120800 & NO & NNM & 0.46 & 5465 \\
\hline STO020 & 1978111800 & 1978112710 & 1978113000 & NO & NNM & 0.59 & 5660 \\
\hline ST0021 & 2003040800 & 2003041708 & 2003042000 & NO & CFSR & 0.26 & 4710 \\
\hline ST0022 & 1970031700 & 1970032614 & 1970032900 & YES & NNM & 0.52 & 5410 \\
\hline ST0023 & 1970032400 & 1970040211 & 1970040500 & NO & NNM & 0.55 & 5425 \\
\hline ST0024 & 1970041000 & 1970041920 & 1970042200 & NO & NNM & 0.61 & 5440 \\
\hline ST0025 & 1970111100 & 1970112011 & 1970112300 & NO & NNM & 0.63 & 5780 \\
\hline ST0026 & 2004030700 & 2004031620 & 2004031900 & NO & CFSR & 0.27 & 4780 \\
\hline STO027 & 1971031000 & 1971031912 & 1971032200 & YES & NNM & 0.69 & 5550 \\
\hline ST0028 & 1971122100 & 1971123014 & 1972010200 & NO & NNM & 0.63 & 5750 \\
\hline STO029 & 1972041300 & 1972042208 & 1972042500 & YES & NNM & 0.81 & 5490 \\
\hline ST0030 & 1972110500 & 1972111410 & 1972111700 & NO & NNM & 0.94 & 6120 \\
\hline ST0031 & 1972122600 & 1973010403 & 1973010700 & YES & NNM & & \\
\hline ST0032 & 1973012800 & 1973020611 & 1973020900 & YES & NNM & 0.98 & 5905 \\
\hline ST0033 & 1973030800 & 1973031714 & 1973032000 & NO & NNM & 0.98 & 5614 \\
\hline ST0034 & 1973033100 & 1973040920 & 1973041200 & NO & NNM & 1.09 & 5690 \\
\hline
\end{tabular}




\begin{tabular}{|c|c|c|c|c|c|c|c|}
\hline \multirow[b]{2}{*}{$\begin{array}{l}\text { STORM } \\
\text { No. }\end{array}$} & \multicolumn{3}{|c|}{ STORM DATES (YYYMMDDHH) } & \multirow[b]{2}{*}{ ICE } & \multirow[b]{2}{*}{ WIND } & \multirow{2}{*}{$\begin{array}{l}\text { Water } \\
\text { Level } \\
\text { Adj. (m) }\end{array}$} & \multirow[b]{2}{*}{$\begin{array}{l}\text { Mon. Flow } \\
\text { Rate (m3/s }\end{array}$} \\
\hline & START DATE & $\begin{array}{l}\text { STORM PEAK } \\
\text { DATE }\end{array}$ & END DATE & & & & \\
\hline ST0035 & 1973101900 & 1973102806 & 1973103100 & NO & NNM & 1.18 & 6060 \\
\hline ST0036 & 1974022800 & 1974030908 & 1974031200 & YES & NNM & 1.04 & 6370 \\
\hline ST0037 & 1974033000 & 1974040814 & 1974041100 & NO & NNM & 1.12 & 5830 \\
\hline ST0038 & 1974112300 & 1974120209 & 1974120500 & NO & NNM & 1.17 & 5950 \\
\hline ST0039 & 1975031900 & 1975032806 & 1975033100 & YES & NNM & 0.92 & 6098 \\
\hline ST0040 & 1975082200 & 1975083107 & 1975090300 & NO & NNM & 1.03 & 5440 \\
\hline ST0041 & 1975100900 & 1975101809 & 1975102100 & NO & NNM & 1.18 & 6221 \\
\hline STO042 & 1990042500 & 1990050421 & 1990050700 & NO & CFSR & 1.03 & 6000 \\
\hline ST0043 & 1976022500 & 1976030512 & 1976030800 & YES & NNM & 0.61 & 5215 \\
\hline ST0044 & 1976030300 & 1976031207 & 1976031500 & NO & NNM & 1.07 & 5320 \\
\hline ST0045 & 1976041600 & 1976042517 & 1976042800 & NO & NNM & 1.10 & 5490 \\
\hline ST0046 & 1977030900 & 1977031812 & 1977032100 & YES & NNM & 1.18 & 6000 \\
\hline ST0047 & 1977032600 & 1977040423 & 1977040700 & NO & NNM & 0.69 & 5150 \\
\hline ST0048 & 1977041800 & 1977042700 & 1977043000 & NO & NNM & 0.74 & 5235 \\
\hline ST0049 & 1977112600 & 1977120520 & 1977120800 & NO & NNM & 0.81 & 5320 \\
\hline ST0050 & 1977121100 & 1977122015 & 1977122300 & NO & NNM & 0.68 & 5295 \\
\hline ST0051 & 1975032500 & 1975040300 & 1975040600 & NO & NNM & 0.77 & 5150 \\
\hline ST0052 & 1999041400 & 1999042319 & 1999042600 & NO & CFSR & 1.05 & 5635 \\
\hline ST0053 & 1978032800 & 1978040619 & 1978040900 & YES & NNM & 0.60 & 5210 \\
\hline ST0054 & 1979040300 & 1979041211 & 1979041500 & NO & CFSR & 0.86 & 5014 \\
\hline ST0055 & 1979040800 & 1979041709 & 1979042000 & NO & CFSR & 0.83 & 5550 \\
\hline ST0056 & 1979121800 & 1979122722 & 1979123000 & NO & CFSR & 0.86 & 5550 \\
\hline ST0057 & 1980040500 & 1980041414 & 1980041700 & NO & CFSR & 0.84 & 5800 \\
\hline ST0058 & 1980111800 & 1980112718 & 1980113000 & NO & CFSR & 0.97 & 5610 \\
\hline ST0059 & 1987032600 & 1987040422 & 1987040700 & NO & CFSR & 0.72 & 5830 \\
\hline ST0060 & 1981112200 & 1981120109 & 1981120400 & NO & CFSR & 1.13 & 6025 \\
\hline ST0061 & 1982032800 & 1982040608 & 1982040900 & YES & CFSR & 0.77 & 5633 \\
\hline ST0062 & 1982100100 & 1982101007 & 1982101300 & NO & CFSR & 0.89 & 5108 \\
\hline ST0063 & 1983033100 & 1983040918 & 1983041200 & NO & CFSR & 0.79 & 5640 \\
\hline ST0064 & 1983040800 & 1983041708 & 1983042000 & NO & CFSR & 0.91 & 5610 \\
\hline ST0065 & 1985111900 & 1985112810 & 1985120100 & NO & CFSR & 0.94 & 5610 \\
\hline ST0066 & 1984021900 & 1984022813 & 1984030200 & YES & CFSR & 1.26 & 6260 \\
\hline ST0067 & 1984032000 & 1984032902 & 1984040100 & YES & CFSR & 0.98 & 5410 \\
\hline ST0068 & 1984032700 & 1984040501 & 1984040800 & YES & CFSR & 0.96 & 5210 \\
\hline ST0069 & 1984051900 & 1984052822 & 1984053100 & NO & CFSR & 0.89 & 4445 \\
\hline
\end{tabular}




\begin{tabular}{|c|c|c|c|c|c|c|c|}
\hline \multirow[b]{2}{*}{$\begin{array}{l}\text { STORM } \\
\text { No. }\end{array}$} & \multicolumn{3}{|c|}{ STORM DATES (YYYMMMDDHH) } & \multirow[b]{2}{*}{ ICE } & \multirow[b]{2}{*}{ WIND } & \multirow{2}{*}{$\begin{array}{l}\text { Water } \\
\text { Level } \\
\text { Adj. (m) }\end{array}$} & \multirow[b]{2}{*}{$\begin{array}{l}\text { Mon. Flow } \\
\text { Rate (m3/s }\end{array}$} \\
\hline & START DATE & $\begin{array}{l}\text { STORM PEAK } \\
\text { DATE }\end{array}$ & END DATE & & & & \\
\hline ST0070 & 1984122500 & 1985010318 & 1985010600 & YES & CFSR & 1.04 & 6000 \\
\hline ST0071 & 1983111900 & 1983112811 & 1983120100 & NO & CFSR & 0.95 & 5805 \\
\hline ST0072 & 1984042400 & 1984050321 & 1984050600 & YES & CFSR & 0.87 & 5800 \\
\hline ST0073 & 1985032200 & 1985033112 & 1985040300 & NO & CFSR & 0.73 & 4840 \\
\hline STO074 & 1985110700 & 1985111614 & 1985111900 & NO & CFSR & 1.27 & 5792 \\
\hline ST0075 & 1985111300 & 1985112212 & 1985112500 & NO & CFSR & 1.24 & 6260 \\
\hline STO076 & 1986112300 & 1986120206 & 1986120500 & NO & CFSR & 1.25 & 6260 \\
\hline ST0077 & 1986112900 & 1986120822 & 1986121100 & NO & CFSR & 1.33 & 6440 \\
\hline ST0078 & 1978100700 & 1978101613 & 1978101900 & NO & NNM & 1.33 & 6230 \\
\hline ST0079 & 1987030100 & 1987031003 & 1987031300 & YES & CFSR & 0.74 & 5780 \\
\hline ST0080 & 1987120600 & 1987121515 & 1987121800 & NO & CFSR & 1.10 & 5840 \\
\hline ST0081 & 1988010100 & 1988011022 & 1988011300 & Drop & & 0.81 & 5710 \\
\hline ST0082 & 1989020800 & 1989021700 & 1989022000 & YES & CFSR & & 5410 \\
\hline ST0083 & 1989101000 & 1989101915 & 1989102200 & NO & CFSR & 0.51 & 5150 \\
\hline ST0084 & 1975030500 & 1975031420 & 1975031700 & YES & NNM & 0.57 & 5440 \\
\hline ST0085 & 1990102700 & 1990110520 & 1990110800 & NO & CFSR & 1.00 & 5440 \\
\hline ST0086 & 1990112400 & 1990120317 & 1990120600 & NO & CFSR & 0.64 & 5385 \\
\hline ST0087 & 1990122200 & 1990123114 & 1991010300 & NO & CFSR & 0.59 & 5380 \\
\hline ST0088 & 2004122800 & 2005010607 & 2005010900 & YES & CFSR & 0.69 & 5279 \\
\hline ST0089 & 1991102000 & 1991102905 & 1991110100 & NO & CFSR & 0.48 & 4674 \\
\hline ST0090 & 1991112400 & 1991120305 & 1991120600 & NO & CFSR & 0.53 & 5450 \\
\hline ST0091 & 1992102400 & 1992110209 & 1992110500 & NO & CFSR & 0.49 & 5525 \\
\hline ST0092 & 1993010100 & 1993011016 & 1993011300 & NO & CFSR & 0.76 & 5345 \\
\hline ST0093 & 1993091700 & 1993092604 & 1993092900 & NO & CFSR & 0.86 & 5260 \\
\hline ST0094 & 1993122800 & 1994010611 & 1994010900 & YES & CFSR & 0.68 & 5020 \\
\hline ST0095 & 1994111800 & 1994112718 & 1994113000 & NO & CFSR & 0.39 & 4870 \\
\hline ST0096 & 1995021800 & 1995022708 & 1995030200 & YES & CFSR & 0.69 & 5780 \\
\hline \begin{tabular}{|l|l|} 
STO097 \\
\end{tabular} & 1995092700 & 1995100603 & 1995100900 & NO & CFSR & 0.59 & 5060 \\
\hline ST0098 & 1995121000 & 1995121921 & 1995122200 & Drop & & 0.67 & 5538 \\
\hline ST0099 & 1996031100 & 1996032007 & 1996032300 & YES & CFSR & 0.54 & 5190 \\
\hline ST0100 & 1996032600 & 1996040419 & 1996040700 & NO & CFSR & 0.62 & 5660 \\
\hline ST0101 & 1996042100 & 1996043002 & 1996050300 & NO & CFSR & 0.46 & 4960 \\
\hline ST0102 & 1995121000 & 1995121923 & 1995122200 & YES & CFSR & 0.58 & 4896 \\
\hline ST0103 & 1997022300 & 1997030403 & 1997030700 & YES & CFSR & 0.51 & 5340 \\
\hline ST0104 & 1997030500 & 1997031409 & 1997031700 & YES & CFSR & 1.13 & 5675 \\
\hline
\end{tabular}




\begin{tabular}{|c|c|c|c|c|c|c|c|}
\hline \multirow[b]{2}{*}{$\begin{array}{l}\text { STORM } \\
\text { No. }\end{array}$} & \multicolumn{3}{|c|}{ STORM DATES (YYYMMMDDHH) } & \multirow[b]{2}{*}{ ICE } & \multirow[b]{2}{*}{ WIND } & \multirow{2}{*}{$\begin{array}{l}\text { Water } \\
\text { Level } \\
\text { Adj. (m) }\end{array}$} & \multirow[b]{2}{*}{$\begin{array}{l}\text { Mon. Flow } \\
\text { Rate (m3/s }\end{array}$} \\
\hline & START DATE & $\begin{array}{l}\text { STORM PEAK } \\
\text { DATE }\end{array}$ & END DATE & & & & \\
\hline ST0105 & 1997101800 & 1997102705 & 1997103000 & NO & CFSR & 1.15 & 5780 \\
\hline ST0106 & 1997110500 & 1997111411 & 1997111700 & NO & CFSR & 1.06 & 6230 \\
\hline ST0107 & 1997123100 & 1998010905 & 1998011200 & YES & CFSR & 0.99 & 6090 \\
\hline ST0108 & 1998020900 & 1998021802 & 1998022100 & NO & CFSR & 0.95 & 5640 \\
\hline ST0109 & 1998033100 & 1998040922 & 1998041200 & NO & CFSR & 1.02 & 5620 \\
\hline ST0110 & 1998123100 & 1999010913 & 1999011200 & YES & CFSR & 0.59 & 5640 \\
\hline ST0111 & 1999010500 & 1999011409 & 1999011700 & YES & CFSR & 0.61 & 4900 \\
\hline ST0112 & 1999022500 & 1999030615 & 1999030900 & YES & CFSR & 0.81 & 4900 \\
\hline ST0113 & 1999033100 & 1999040913 & 1999041200 & NO & CFSR & 0.52 & 5108 \\
\hline ST0114 & 1999120500 & 1999121418 & 1999121700 & NO & CFSR & 0.54 & 5210 \\
\hline ST0115 & 2000022000 & 2000022923 & 2000030300 & YES & CFSR & 0.24 & 5010 \\
\hline ST0116 & 2000041100 & 2000042020 & 2000042300 & NO & CFSR & 0.09 & 4424 \\
\hline ST0117 & 2000121900 & 2000122817 & 2000123100 & YES & CFSR & 0.29 & 4900 \\
\hline ST0118 & 2001020600 & 2001021501 & 2001021800 & YES & CFSR & & 4550 \\
\hline ST0119 & 2001100700 & 2001101614 & 2001101900 & NO & CFSR & 0.21 & 4500 \\
\hline ST0120 & 2002012200 & 2002013114 & 2002020300 & YES & CFSR & 0.27 & 5040 \\
\hline ST0121 & 2002012300 & 2002020108 & 2002020400 & Drop & & 0.25 & 4989 \\
\hline ST0122 & 1993032300 & 1993040109 & 1993040400 & YES & CFSR & 0.25 & 4989 \\
\hline ST0123 & 2003032900 & 2003040720 & 2003041000 & YES & CFSR & & \\
\hline ST0124 & 2003042600 & 2003050513 & 2003050800 & NO & CFSR & 0.91 & 5140 \\
\hline ST0125 & 2003112600 & 2003120516 & 2003120800 & NO & CFSR & 0.23 & 4650 \\
\hline ST0126 & 2003122700 & 2004010506 & 2004010800 & YES & CFSR & 0.30 & 4765 \\
\hline ST0127 & 1993050300 & 1993051221 & 1993051500 & NO & CFSR & 0.19 & 4875 \\
\hline ST0128 & 2004052200 & 2004053102 & 2004060300 & NO & CFSR & 0.23 & 4575 \\
\hline ST0129 & 2004111500 & 2004112421 & 2004112700 & NO & CFSR & 0.96 & 5640 \\
\hline ST0130 & 2005121600 & 2005122522 & 2005122800 & YES & CFSR & 0.60 & 5017 \\
\hline ST0131 & 2006030400 & 2006031308 & 2006031600 & YES & CFSR & 0.36 & 5230 \\
\hline ST0132 & 2006030800 & 2006031708 & 2006032000 & NO & CFSR & 0.24 & 4770 \\
\hline ST0133 & 2006112200 & 2006120111 & 2006120400 & NO & CFSR & 0.34 & 4820 \\
\hline ST0134 & 2007032000 & 2007032911 & 2007040100 & NO & CFSR & 0.35 & 4820 \\
\hline ST0135 & 2007040300 & 2007041201 & 2007041500 & NO & CFSR & 0.38 & 4813 \\
\hline ST0136 & 2008010200 & 2008011101 & 2008011400 & NO & CFSR & 0.47 & 4530 \\
\hline ST0137 & 1972032900 & 1972040714 & 1972041000 & YES & NNM & 0.48 & 4860 \\
\hline ST0138 & 2008050200 & 2008051118 & 2008051400 & NO & CFSR & 0.15 & 4430 \\
\hline ST0139 & 2008121000 & 2008121914 & 2008122200 & YES & CFSR & 0.76 & 5478 \\
\hline
\end{tabular}




\begin{tabular}{|l|l|l|l|l|l|l|l|}
\hline \multirow{2}{*}{$\begin{array}{l}\text { STORM } \\
\text { No. }\end{array}$} & \multicolumn{3}{|c|}{ STORM DATES (mYYMMDHH) } & & & $\begin{array}{l}\text { Water } \\
\text { Level } \\
\text { Adj. (m) }\end{array}$ & $\begin{array}{l}\text { Mon. Flow } \\
\text { Rate (m3/s) }\end{array}$ \\
\hline ST0140 & 2008122200 & 2008123105 & 2009010300 & YES & CFSR & 0.54 & 4870 \\
\hline ST0141 & 1992010700 & 1992011600 & 1992011900 & NO & CFSR & 0.38 & 4790 \\
\hline ST0142 & 2009030300 & 2009031218 & 2009031500 & YES & CFSR & 0.45 & 4715 \\
\hline ST0143 & 2009101400 & 2009102317 & 2009102600 & NO & CFSR & 0.51 & 5250 \\
\hline ST0144 & 2009113000 & 2009120909 & 2009121200 & NO & CFSR & 0.59 & 4780 \\
\hline ST0145 & 2009121600 & 2009122516 & 2009122800 & YES & CFSR & 0.55 & 5300 \\
\hline ST0146 & 1975032500 & 1975040300 & 1975040600 & NO & NNM & 0.44 & 5280 \\
\hline ST0147 & 1978111800 & 1978112710 & 1978113000 & NO & NNM & 0.42 & 5280 \\
\hline ST0148 & 1999041400 & 1999042319 & 1999042600 & NO & CFSR & 1.05 & 5635 \\
\hline ST0149 & 2003040800 & 2003041708 & 2003042000 & NO & CFSR & 0.59 & 5660 \\
\hline ST0150 & 2004030700 & 2004031620 & 2004031900 & NO & CFSR & 0.60 & 5210 \\
\hline
\end{tabular}

The length of storm simulation was limited to a 12-day period. The storm simulation was initiated 9 days prior to the storm peak, and was run 3 days after the storm peak. This allowed for proper initialization of the surge model, and phasing of local wind-wave specification for Lake St. Clair.

\subsection{Wind field production}

As described in Chapter 1 and in Jensen et al. (2012), the identical wind field production methodology applied for Lake Michigan was used for Lake St. Clair. The CFSR wind fields were used for all storms after 1979 and NNM wind fields were used for storms older than 1979. The difference between the results from wave validation using NNM and CFSR were small, so the choice was based more on precedent and operational simplicity.

\subsection{Ice field production}

All ice field production was described in detail in Jensen et al. (2012). In Table 6-1, all events which included ice, are labeled with a YES. Any time Lake St. Clair was completely ice free during a storm, the ice category is labeled as NO. Storms with a drop in the ice field were removed because of complete ice coverage on the US coastline. The maximum water level of individual storms was found to reduce significantly after the top 20 events measured at each water level station, so events with full ice over the entire 
lake below the top 20 events were dropped. Some of these storms were replaced with ice free events of a similar magnitude to fulfill event numbers.

\subsection{Offshore wave production}

The original WAM grid (Chapter 3) was developed from a 3-arc-sec digital data base, where the water depths were scaled to the mean lower lake level. The lake level for each storm event was evaluated and the WAM water depth grid was re-generated. The assumption of vertical walls at the shoreline was made so that land would remain land, and water would remain water. However, all water points were re-specified for each event. This required an additional step in the production to calculate all variables dependent on the water depth (wavelength, phase and group speeds, refraction and shoaling coefficients).

Each storm in the storm suite (see Table 6-1) is treated independent of any other in the list; hence, multiple storm events can be run simultaneously under one operational shell script. WAM requires two time steps, propagation (CFL stability criteria), and source term integration. These were set to 6- and 300-sec, respectively. Twenty eight frequency bands were used starting at $0.06116 \mathrm{f}(1)$, and based on the equation: $f(n+1)=1.1 \cdot f(n)$, and seventy two direction bins starting at 7.5-deg.

The last step is to select the special output locations where two-dimensional (frequency, direction) wave spectra are to be saved (Figure 6-2). These were selected based on proximity to the shoreline. Each point was determined to be two grid cells from the land boundary. STWAVE boundary points were also output for 4 nearshore computational grids. The locations of the STWAVE output locations are identified in Figures 6-3 through 6-5.

Once the input wind and ice fields have been processed, the production can be initiated. For all storm simulations, WAM Cycle 4.5.1C used all shallow water options, including shoaling, refraction, wave-bottom effects, and depth induced wave breaking. As part of this procedure, the atmospheric input was adjusted so that the full dispersion relationship was applied and the nonlinear wave-wave interaction (Discrete Interaction Approximation) was modified based on the Herterich and Hasselmann (1980) scaling. 


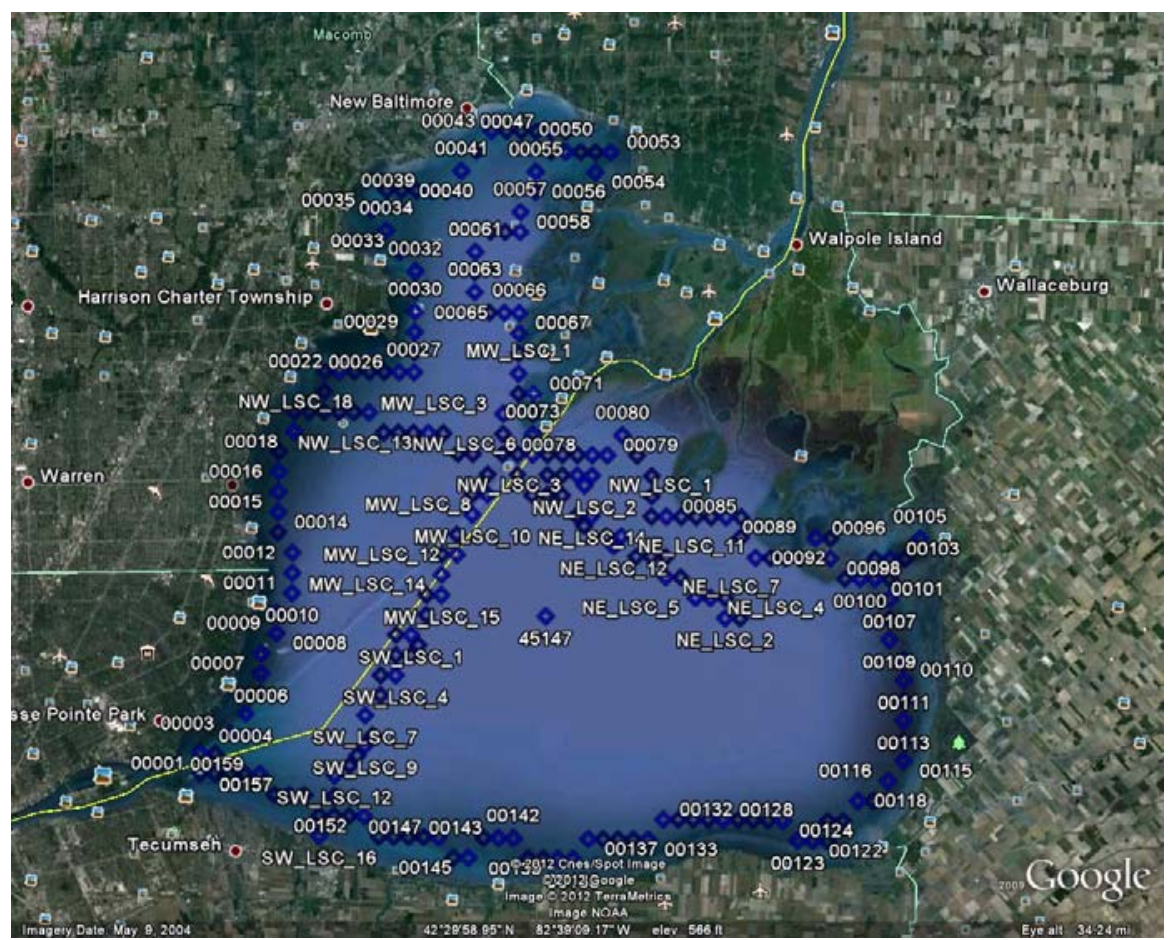

Figure 6-2. Special output locations for the WAM simulations.

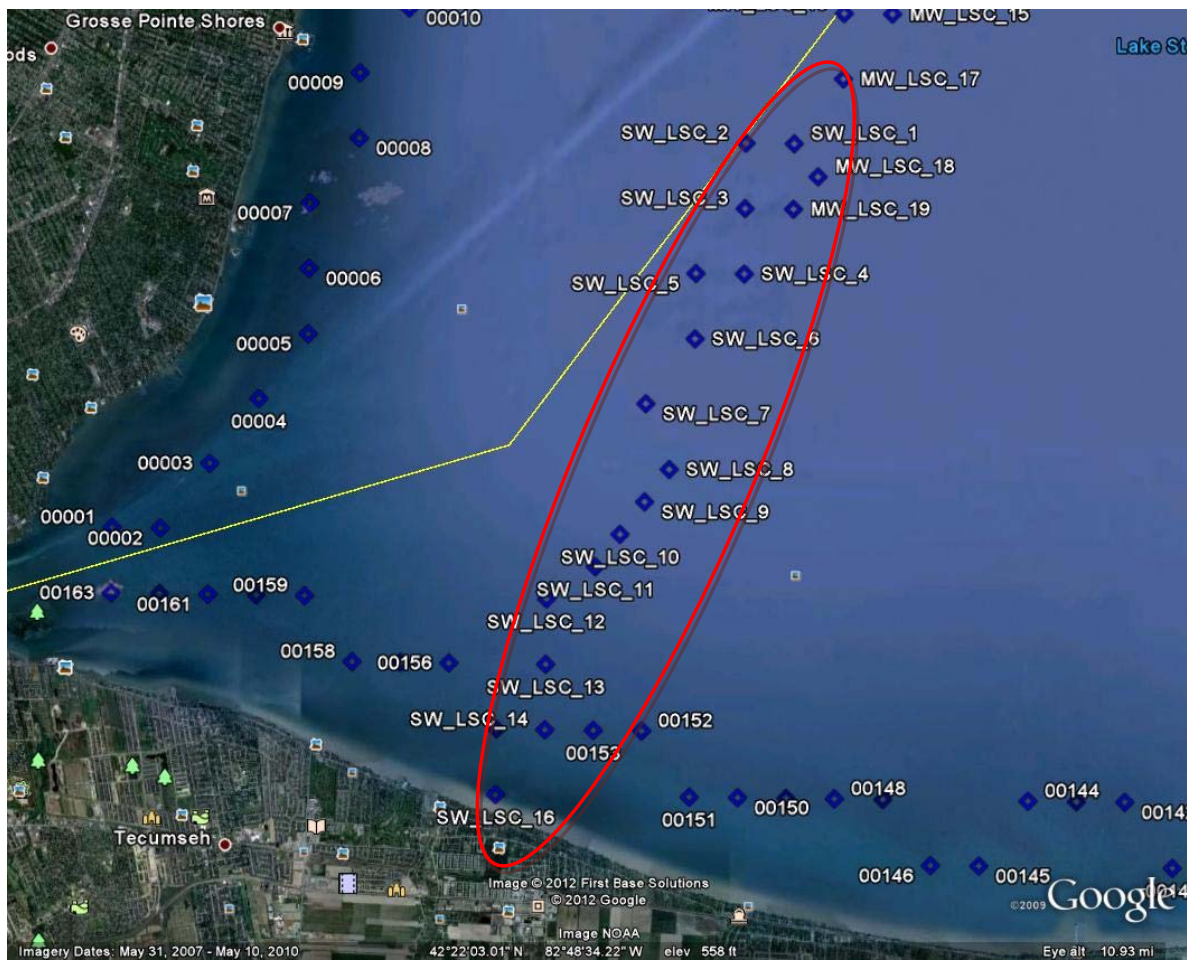

Figure 6-3. Zoom of the Southwestern area. The STWAVE boundary is identified by the red circle. 


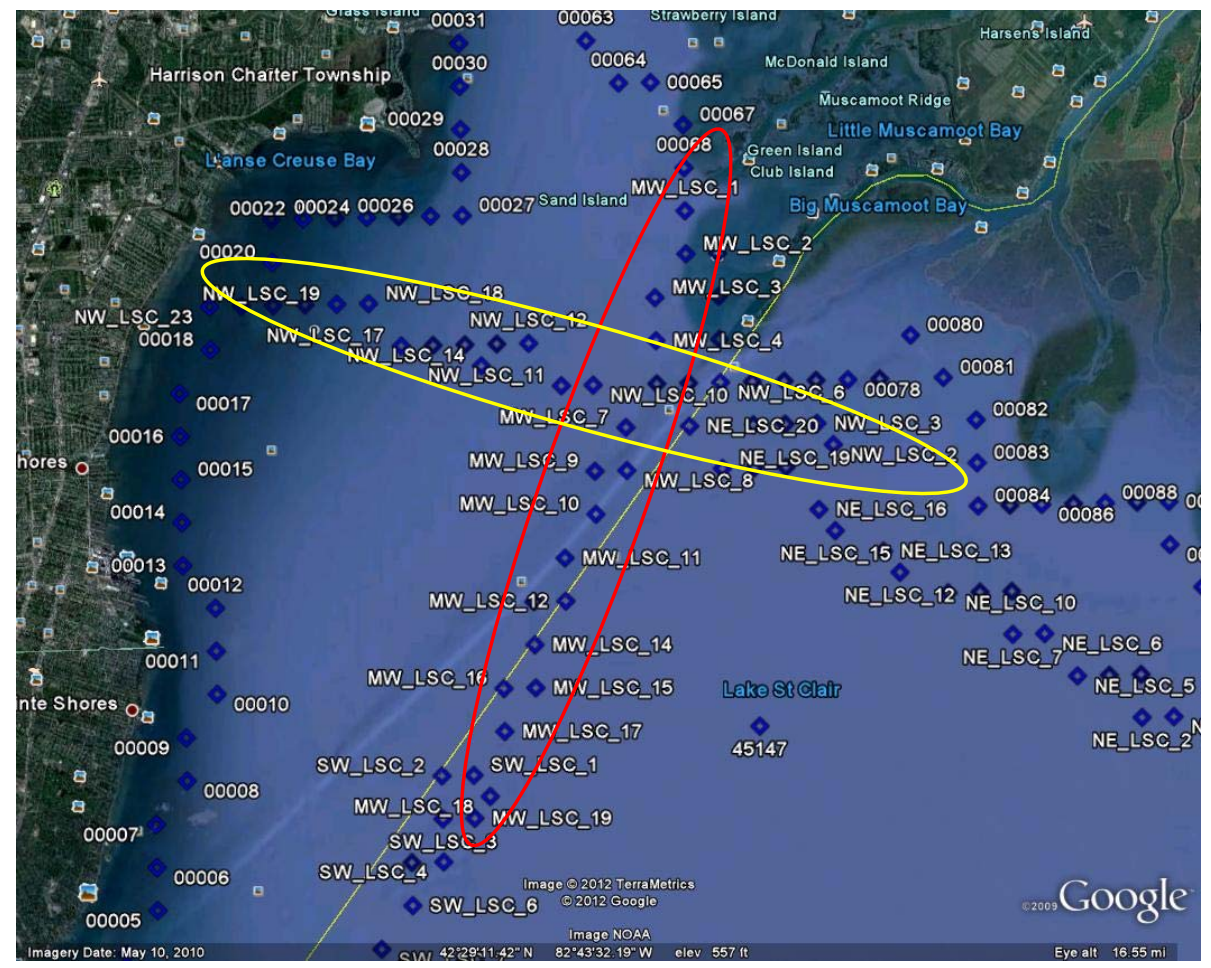

Figure 6-4. Zoom view of the northwestern domain of Lake St. Clair, red and yellow ovals identify the boundary input locations for STWAVE simulations.

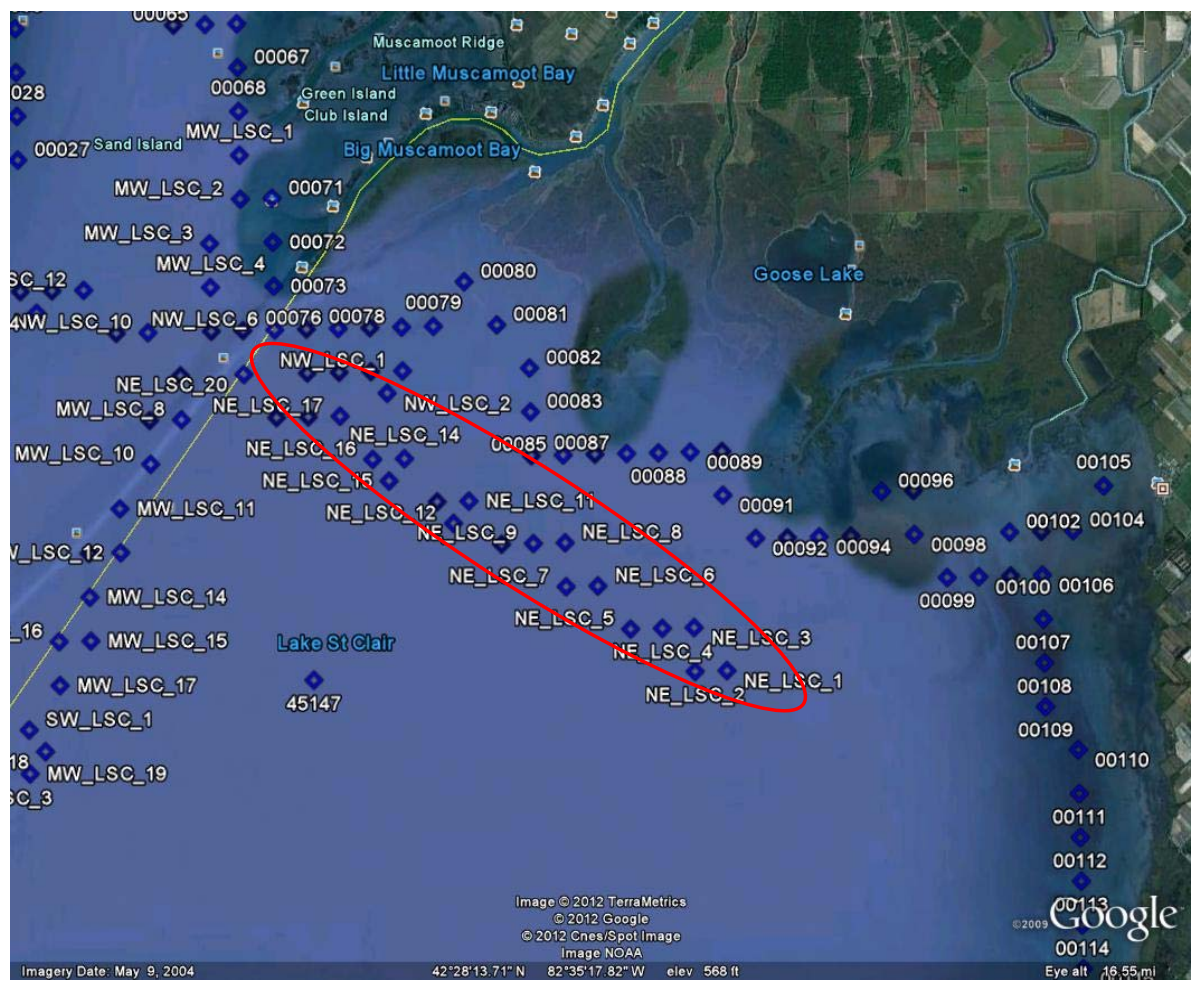

Figure 6-5. Zoom view of the northeastern domain of Lake St. Clair, red oval identifies the boundary input locations for STWAVE simulations. 
The automated system executes the following steps:

- Input the WAM water depth grid, adjust for lake level

- Output the time independent, depth and spatially dependent parameters

- Format the wind fields for WAM

- Generate the storm specific general input file (start date, end date, wind field name, and if appropriate ice field name)

- Run WAM

o Output the field information, spectral information (special output locations a priori defined)

o Output the 2D spectra at the STWAVE boundary (three sets)

- Post-Process Phase I

o Generate the integral wave parameter file for each station at 30-min intervals

o Generate flat ASCII files containing the field information for integral wave parameters (30-min intervals).

o Generate 2D spectral estimates for all special output locations including the locations set for STWAVE boundary condition information

- Post-Process Phase II (Quality Control/Quality Assurance, QA/QC)

o If appropriate evaluate the wave model results based on available wave measurements (a total of one location). Generate time, scatter and Quartile-Quartile graphics; perform statistical tests and tabulate

o Generate Maximum and Mean wave parameter plots for the specified storm (wave height, peak and mean wave period, for the total, wind-sea and swell contribution), wind speed.

o Evaluate all results for consistency and accuracy, and when appropriate ice field specification.

- Archive

o Archive all output information to:

- Mass Storage Facility (ERDC HPC)

- External hard drive on resident PC

o Make all files available to the group

- ADCIRC / STWAVE production

- CSTORM-DB 


\subsubsection{Post-processing QA/QC}

After completing each WAM model run, a series of graphical files were generated to examine the proper completion of each run. The maximum and mean of the field files for wind speed, wave height, and wave period are calculated. An example for Storm 143 of the maximum wind speeds and wave heights for all grid points in the basin are shown in Figures 6-6 and 6-7, respectively.

When applicable, the WAM results were evaluated to the existing point source measurements in the form of time, scatter, Quartile-Quartile (Q-Q) graphical products. In Lake St. Clair only two production runs had point source measurements because the limited measurement sights and the time frame of retrieval and deployment of the buoy. A battery of statistical tests was also conducted including:

- Bias

- Absolute Error

- Root Mean Square Error

- Scatter Index

- Skill Score

- Linear Regression

o symmetric correlation

o principle correlation

o Slope / intercept

o Systematic error analyses

Examples for Storm 143 are shown in Figures 6-8 through 6-11. The first is a time plot of model to measurement comparison at 45147 (Figure 6-8). The wave heights for the model results were calculated using the entire range of frequencies available in the energy density spectrum used in WAM. There is an obvious over-estimation of the wave height by the model as compared with the measured results in the top panel of Figure 6-8. However, the wind speeds in Panel 5 show good agreement between the model wind speeds and the measured wind speeds. This implies the wind forcing is probably not the problem. In Figure 6-9, the bulk parameters from the model results are calculated using only frequencies between 0.2 and 0.3 which is the available range from the measurements. The early peak calculated from the WAM results is still a slight over-estimation, but the peak of the storm as recorded from the water levels is much closer to the measured wave heights. 


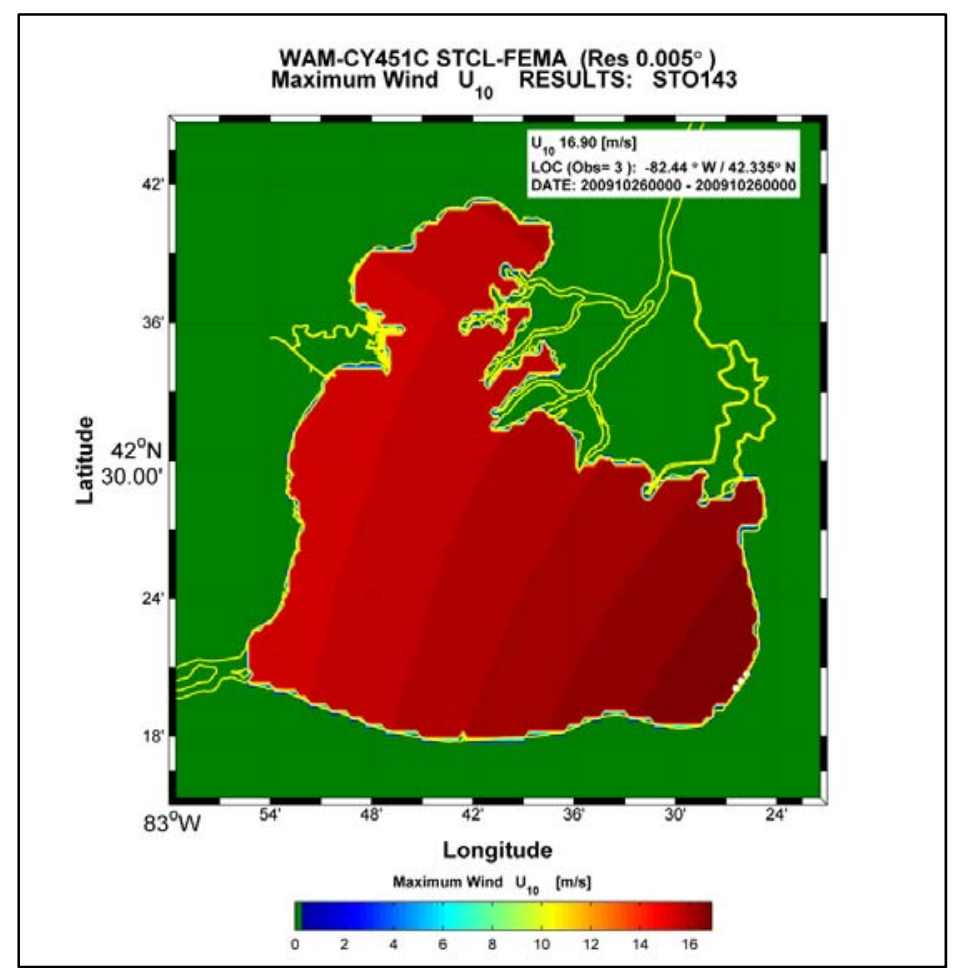

Figure 6-6. Maximum wind speed envelope for ST0143 (14-26 Oct 2009).

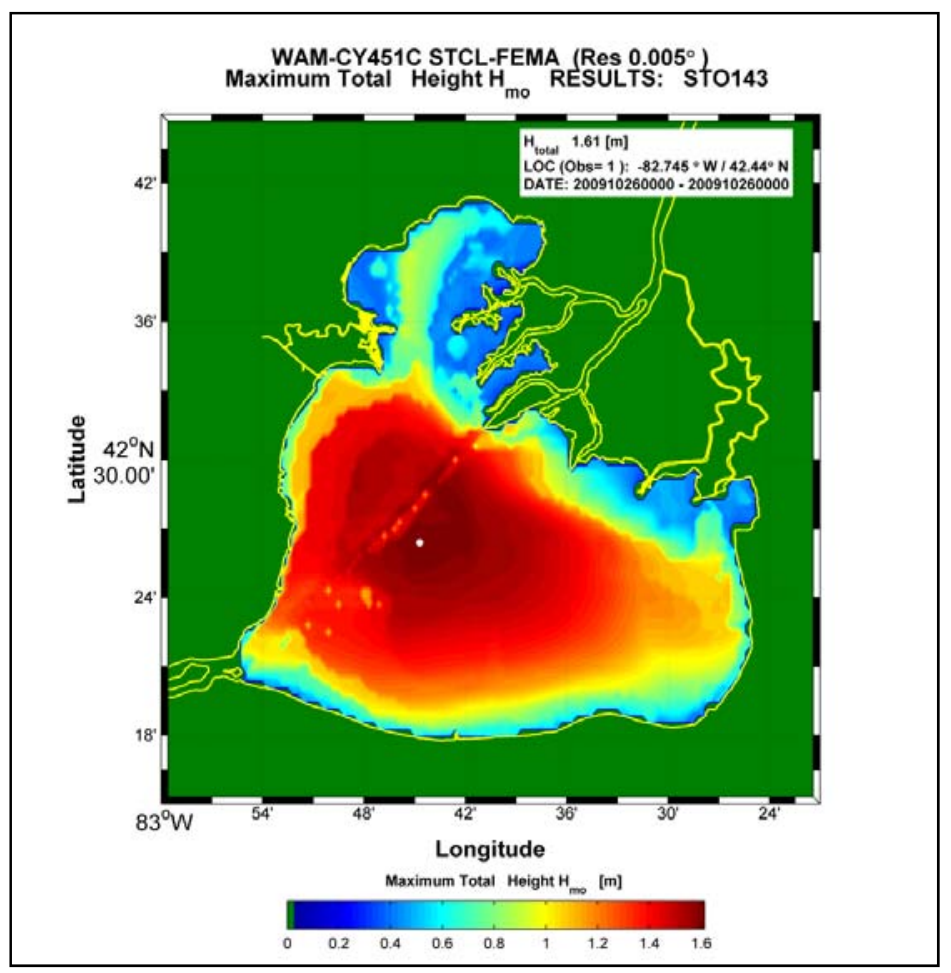

Figure 6-7. Maximum significant wave height envelope for ST0143 (14-26 Oct 2009). 


\section{Lake St. Clair FEMA Study [CFSR]}

NDBC $=45147\left[-82.68^{\circ} / 42.43^{\circ}\right]$, Depth $=6 \mathrm{~m}$ WAM4.5.1C $\left(\right.$ Res $\left.=0.005^{\circ}\right)\left[-82.68^{\circ} / 42.43^{\circ}\right]$
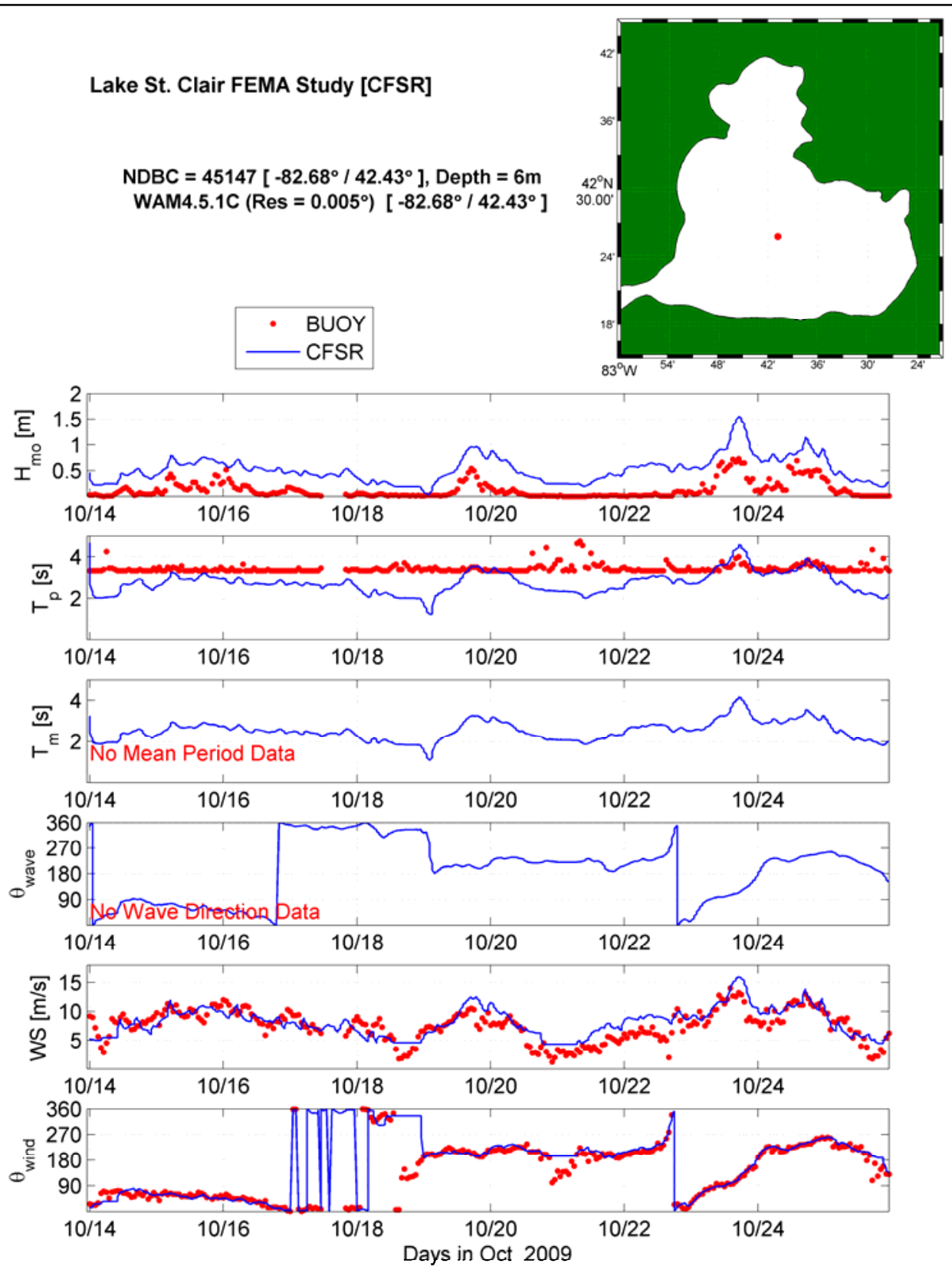

Figure 6-8. Time plot of WAM (blue line) versus measurements at 45147 for Storm 143. The top panel is the significant wave height, next is the parabolic fit peak wave period, mean wave period, vector mean wave direction, wind speed and direction. 


\section{Lake St. Clair FEMA Study [CFSR]}

NDBC $=45147\left[-82.68^{\circ} / 42.43^{\circ}\right]$, Depth $=6 \mathrm{~m}$ WAM4.5.1C $\left(\operatorname{Res}=0.005^{\circ}\right)\left[-360^{\circ} / 42.43^{\circ}\right]$
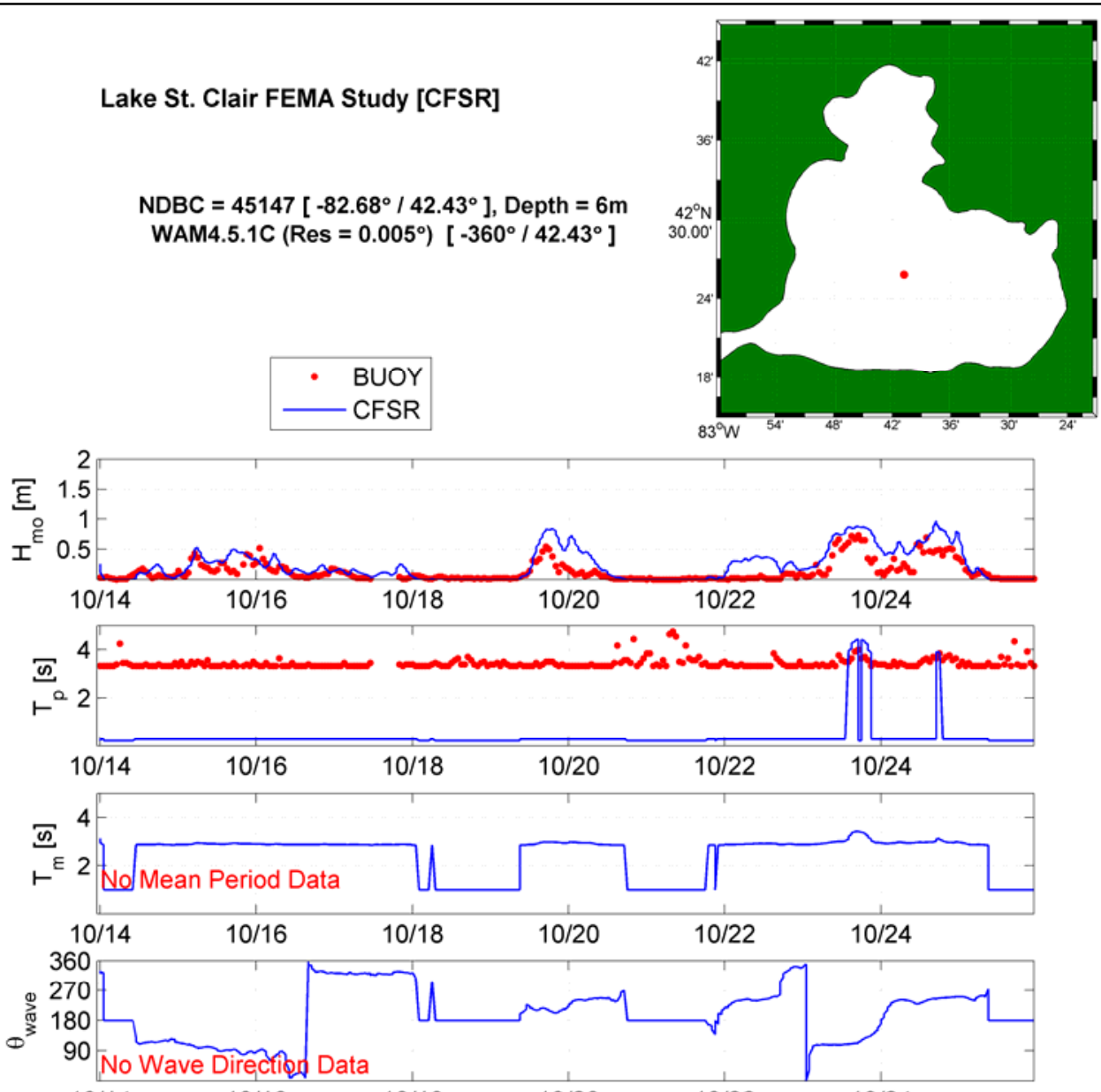

$\begin{array}{llllll}10 / 14 & 10 / 16 & 10 / 18 & 10 / 20 & 10 / 22 & 10 / 24\end{array}$
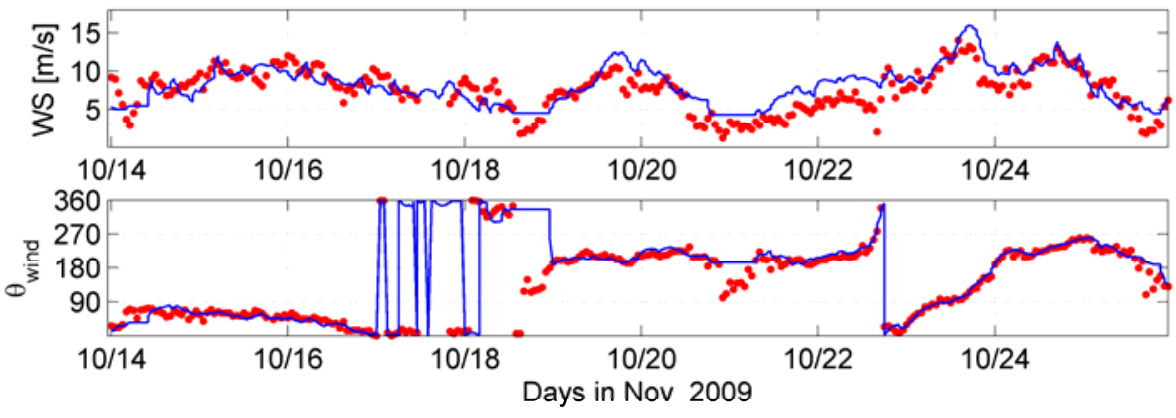

Figure 6-9. Time plot of WAM (blue line) versus measurements at 45147 for Storm 143 using $0.2-0.3$ frequency range. The top panel is the significant wave height, next is the parabolic fit peak wave period, mean wave period, vector mean wave direction, wind speed and direction. 

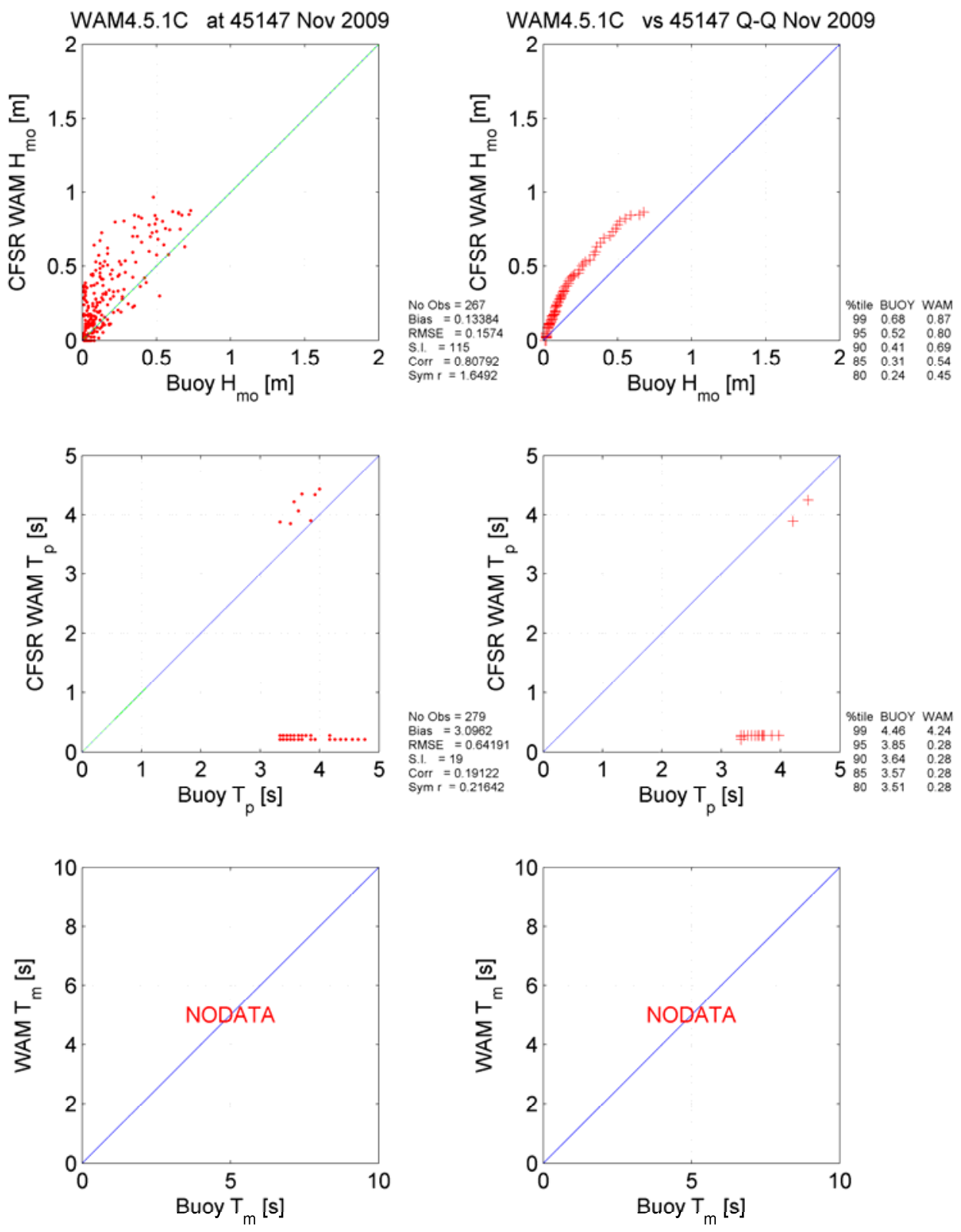

Figure 6-10. Scatter and Q-Q plots of WAM versus measurements at 45147 for Storm 143. Top two panels: significant wave height, followed by parabolic fit peak wave period and mean wave period. Statistical test results are given between the plots. 

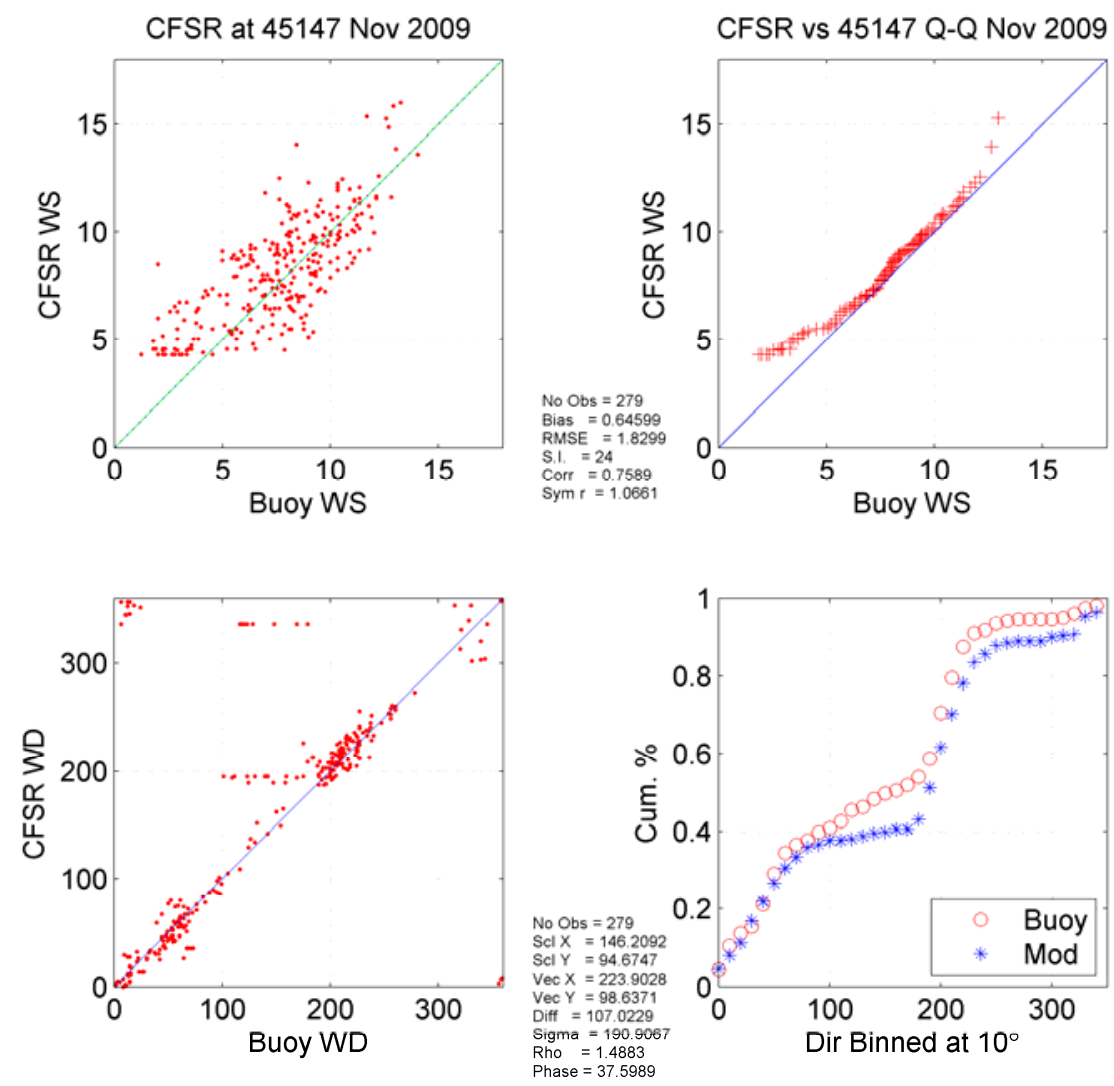

Figure 6-11. Scatter and Q-Q plots of WAM versus measurements at 45147 for Storm 143. Top two panels: wind speed, followed by wind and wave direction. Q-Q analyses are based on scalar values, hence a cumulative distribution replaces this test for the wind and wave directions. Statistical test results are given between the plots.

The Scatter and Quartile-Quartile plots for Storm 143 are presented in Figure 6-11. The wave parameters in Figure 6-11 are calculated after a time pair is performed between the model and buoy wave heights. The scatter plot on the top left panel shows how small most of the wave heights are in this data set. A positive bias as seen in the time series is also apparent in the scatter set. The positive bias is reinforced with the Q-Q plot on the top right panel. This plot shows the cumulative distribution of a given parameter based on a pre-determined bin where both the model and measurements can be plotted in a consistent fashion. The Q-Q values from the WAM model are higher than the respective wave heights on the measurement side, so the positive bias is confirmed. The calculated statistics in between the two panels confirm the previous graphical descriptions with a bias of 0.13 and an RMSE of 0.16 . 
The final graphic provides the wind evaluation (speed and direction) and whenever possible the vector mean wave direction as shown in Figure 6-11. Similar information are provided (blue circle), however in terms of the directional comparisons, Q-Q analyses are based on scalar information (magenta circle).

The conditional information again is to have the model to measurements follow the line of perfect fit as was the case for the wave parameters. A cumulative distribution of the wind and wave direction bins is generated to determine how favorably the model results compare to the measurements. In this case the wind speeds in Figure 6-11 show good agreement between model and buoy.

\subsubsection{Summary of Lake St. Clair offshore wave model production}

In the previous section, the results from Storm 143 were used to demonstrate the difficulty involved in point source comparisons in Lake St. Clair. An alternative approach to understand the production data set is to evaluate the entire set of storms against itself. The location and intensity of each storm can give insight in the extreme climate in Lake St. Clair.

The maximum wind speed and wave height location for the 145 extreme storm events is presented in Figure 6-12. The set of storms is broken up into the pre-1979 storms which used NNM and the 1979-2009 storms which used CFSR to force the wave model. This analysis does not assume that the maximum wave height occurred at the same time in the storm as the maximum wind speed, but rather the maximum value for each variable through the lifespan of the storm.

The maximum wind speeds for both NNM and CFSR were focused more on the coastal region of Lake St. Clair. The coastal location of the CFSR wind speeds is likely caused by the interpolation between grid points performed on the 0.5-deg CFSR wind field grid. There is likely only one grid point from the original CFSR grid in Lake St. Clair, so the interpolation down to the finer resolution grid makes it hard for the maximum values to sit in the lake instead of closer to the original 0.5-deg grid points. The NNM maximum wind speeds are located on the coastline because of the dependency to the meteorological stations. The older NNM storms only had 2-3 meteorological stations which were located on the western banks and to the north east of Lake St. Clair. The location of these stations along with the Natural Neighbor interpolation technique places the maximum wind speeds closer to the land boundary. 


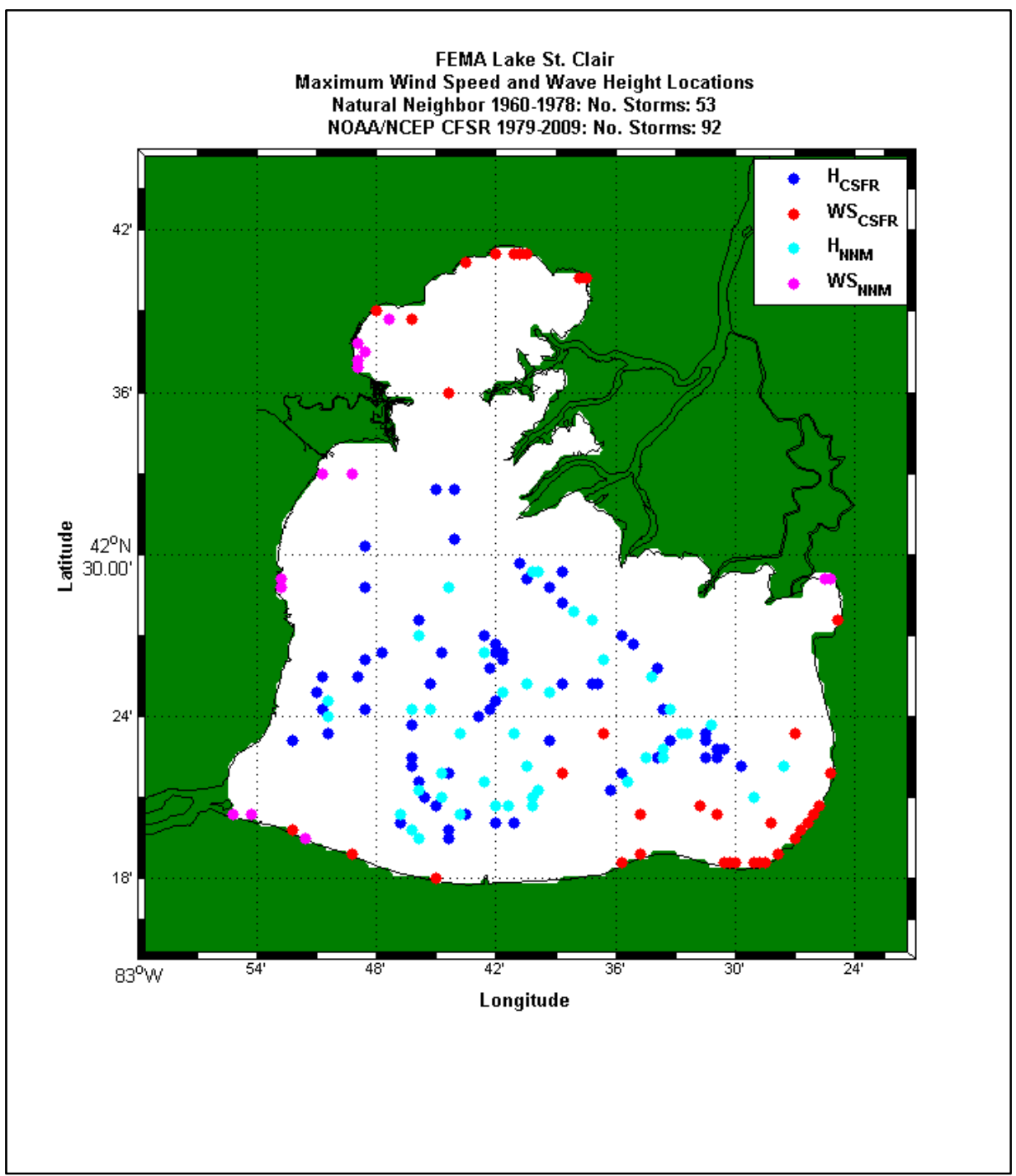

Figure 6-12. Overall maximum wind speed and significant wave height locations for the 145 extreme storm event population.

The maximum wave heights for both NNM and CFSR are located in the middle of the lake where the depths are greatest. There does not seem to be any trend to distinguish differences in the wave heights produced from WAM forced with CFSR or NNM. There does not appear to be a trend to distinguish the dominate direction for the winds at the peak of the production storms.

The magnitudes of the maximum wind speed and wave height are shown in a pseudo-time series in Figure 6-13. In the top panel, maximum wind speeds for each storm are generally between $10-$ and $20-\mathrm{m} / \mathrm{sec}$ with a few extreme events near $25-\mathrm{m} / \mathrm{sec}$. The maximum wind speed calculated over all the storms was $25 \cdot 73-\mathrm{m} / \mathrm{sec}$ in Storm 113. 


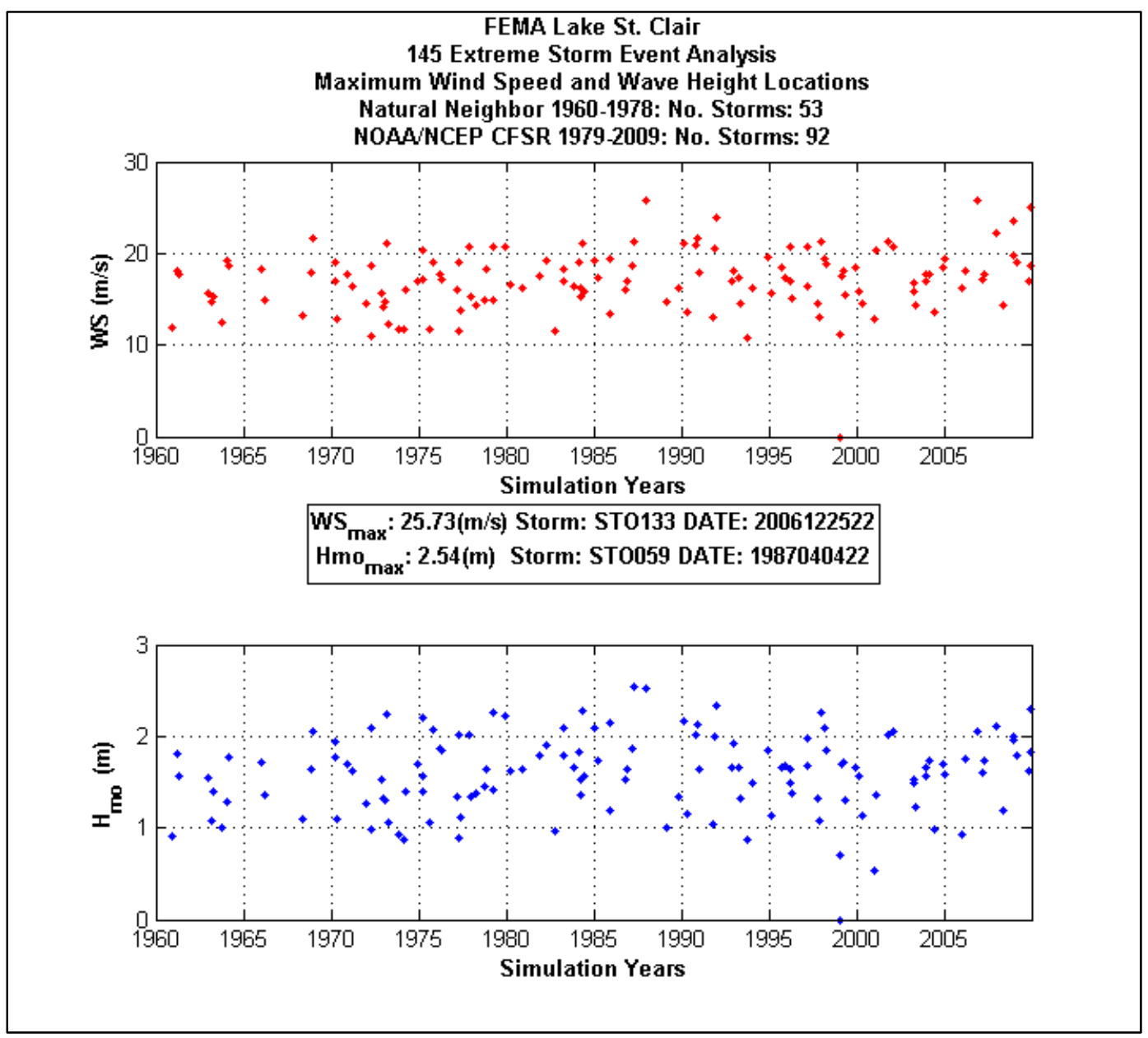

Figure 6-13. Magnitudes of the maximum wind speed (upper panel) and significant wave height (lower panel) for the 145 extreme storm events.

The maximum wave heights in the bottom panel show a similar trend to the wind speeds with the bulk of the maximum wave height events between 1- 2-m. The largest maximum wave height was 2.54-m during Storm 59. There does not appear to be much change in the maximum wave height through the time series. However, the mean maximum wave height for the NNM storms is $1.5-\mathrm{m}$ while it is $1.69-\mathrm{m}$ for the CFSR storms. The variance of the maximum wave heights are 0.15 and 0.14 for NNM and CFSR, respectively. The increased mean maximum wave height in CFSR is confirmed by the finding of a mean maximum wind speed of $17.8-\mathrm{m} / \mathrm{sec}$ for CFSR as compared to $15.95-\mathrm{m} / \mathrm{sec}$ for NNM. The ratio of the increase for the wind speeds is $1.12-\mathrm{m} / \mathrm{sec}$ while the ratio of the CFSR to NNM wave heights is $1.13-\mathrm{m}$. Extensive wave model evaluations could not be performed because only two storms selected fell within the buoy's deployment cycle. 


\subsection{Water level production}

The ADCIRC mesh (Chapter 4) for Lake St. Clair was developed from NOAA ENCs, 3- and 9-arc-sec data files from NOAA's National Environmental Satellite Data, and from the Information Service Lake St. Clair digital bathymetry data base. These data were processed to a consistent IGLD 1985 vertical water level datum. In addition, the NOAA's IGLD 1985 zero-depth coastline file was incorporated into the data set. The validation process was described in Chapter 4. As with the WAM model domain, the assumption of vertical walls at the shoreline was made and overland flow was postprocessed by FEMA based on wave and water level information provided by WAM, ADCIRC, and STWAVE within the main water bodies.

Each storm in the 145 extreme storm suite (see Table 6-1) is simulated independently. Based on the validation simulations, production simulations applied a model time-step of $0.5 \mathrm{sec}$. As previously mentioned, the bottom friction in ADCIRC is a quadratic function of depth-averaged velocity and the model applies a quadratic (Chezy) friction coefficient of 0.0019 for Lake St. Clair. No adjustments to the time-step or friction parameter were required for the production storm suite, as there were no stability issues with any of the model simulations. CFSR wind and pressure fields were applied whenever available and NNM wind and pressure fields were applied when CFSR was not available. Monthly mean flow rates (Fay and Noorbakhsh 2010) were applied at the St. Clair River boundary and hourly water levels were applied at the Detroit River boundary.

Another ADCIRC input requirement is the set of locations (save points) where model time series of water surface level and water velocity results are to be saved and applied as forcing for other model applications (Figure 6-14). These locations were selected based on the proximity to the shoreline in a water depth of approximately $2-m$ for Lake St. Clair. The alongshore spacing of the save points in Lake St. Clair was approximately $1.5 \mathrm{~km}$. Save points were also placed around the northern portion of Lake St. Clair, where the St. Clair River empties into the lake, and at the St. Clair Shores, Windmill Point, and New Baltimore NOAA NOS water level measurement sites. The total number of save point locations was 224. Water level data were available for the St. Clair Shores and Windmill Point gauges for 130 of the 145 simulation time periods. For the New Baltimore gauge, water level data were only available for the time period June to November 2008. 


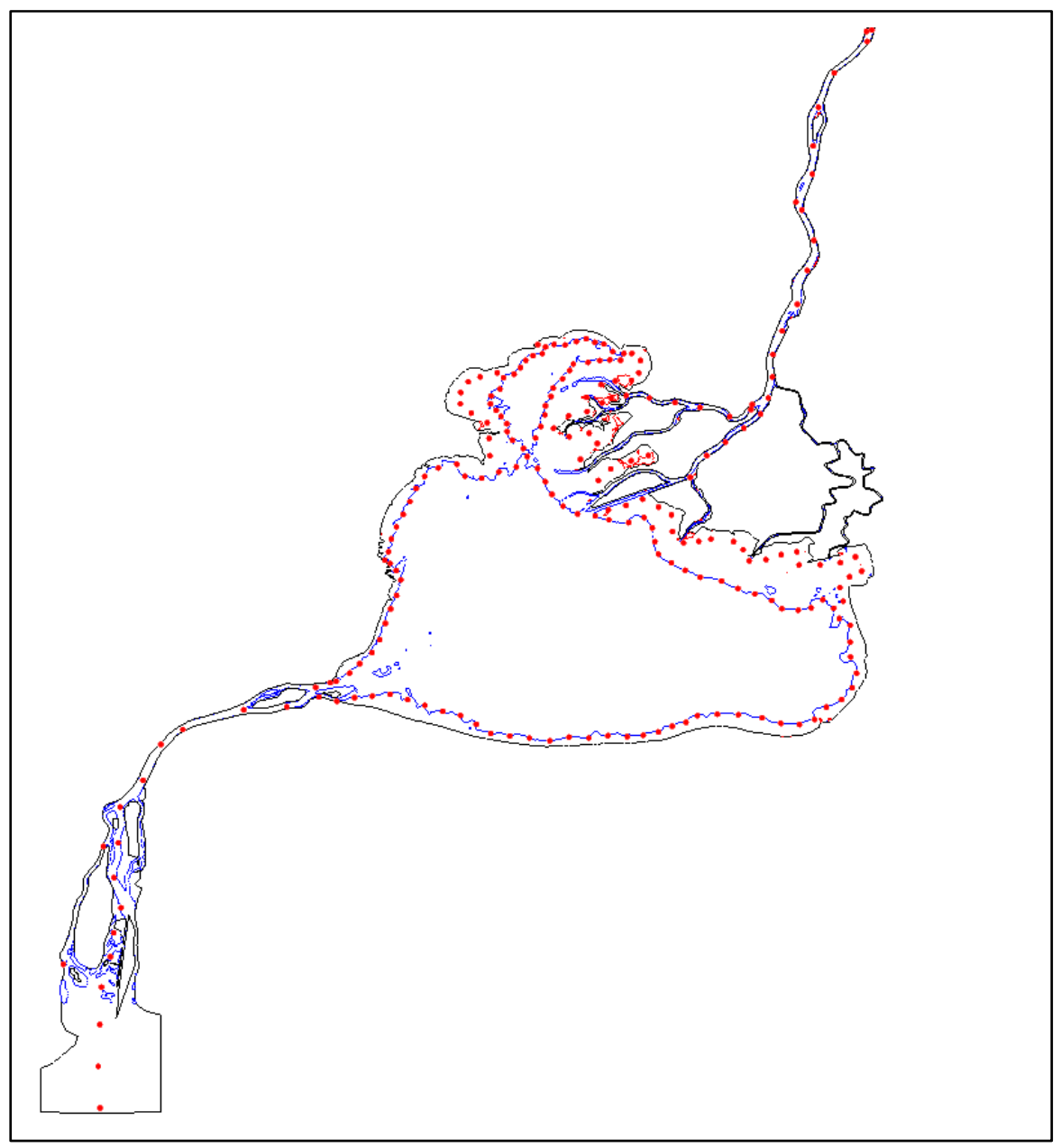

Figure 6-14. ADCIRC Save point locations for Lake St. Clair.

With the wind, wave, and ice fields processed, the ADCIRC (or CSTORMMS) production was initiated. For all storm simulations, ADCIRC applied a two-dimensional, depth-integrated nonlinear bottom stress of 0.0019 and included finite amplitude and advective terms in the model computations. As previously mentioned, the model applications assumed vertical walls at the shoreline; therefore, wetting and drying was turned off in the model applications.

The ADCIRC/CSTORM-MS applications included the following steps:

Pre-processing of ADCIRC simulation forcing parameters:

- Input the ADCIRC mesh (fort.14) and the water level adjustment to the synoptic lake level (fort.13) for a specific storm event

- Generate the general input file (fort.15) 
- Generate the storm specific control file (mf_config) including the start and end times for ADCIRC and STWAVE, ADCIRC and STWAVE grid names, and coordinate systems.

- Apply the storm-specific, time-dependent wind (fort.222) and pressure (fort.221) fields previously formatted for the WAM applications

- Apply the storm-specific, time-dependent ice fields (fort.225) previously formatted for the WAM applications

- Run ADCIRC (or CSTORM-MS)

o Output the time-dependent water level, water velocity, pressure, wind velocity, and ice distribution field files at all ADCIRC computational nodes

o Output the time-dependent water level, water velocity, pressure, wind velocity, and ice distribution time-series files at the 224 save point locations

- Post-Process Phase I

o Ensure simulation completion by checking output duration and values, $\log$ file messages, production of maximum envelopes of water level, water velocity, wind speed, and ice coverage, as well as the minimum pressure envelope

o Generate preliminary plots of water level time-series files at the several save point locations to ensure model completion.

- Post Process Phase II (Quality Control/Quality Assurance, QA/QC)

o From the time-dependent water level time-series files at the 224 save point locations, generate water level time-series plots for the locations corresponding to the 10 NOAA stations and compare to the measured water level time series for all 145 storm events

o Generate plots of the maximum wave envelope of water levels during the entire storm simulation for a subset of the storm events

o Generate animations of water level, wind speed, atmospheric pressure, and water velocity for a subset of the storm events

o Compute water level statistics (root-mean-square error and bias) for all storm events

- Archive

o Archive model results to

- Mass Storage Facility (ERDC HPC) (full set)

- External hard drive on resident PC (subset)

o Make all files available to the team 
- CSTORM-DB

\subsubsection{Post-processing QA/QC}

Upon completion of the ADCIRC simulations, a series of graphical and statistical products are generated to visually and numerically evaluate the model's skill in simulating the hydrodynamic response of the system to atmospheric forcing. Maximum water level envelopes provide an overall view of the extreme response of the water body to atmospheric forcing. The next level of evaluation of model performance is to examine the temporal variation of water level and compare it to measurements at several locations throughout Lake St. Clair. Time series of water levels are saved for the latter 6 days of each model simulation and are compared to NOAA NOS water level gauges for the same time period to determine if the temporal and spatial variation in water level is captured by the model. The first 6 days were considered the model spin up time period and modeled time-series were not saved during that time period. Lastly, the ADCIRC water level time series results are numerically evaluated and compared to measured NOAA water levels at two-to-three locations. The statistical comparisons tabulated for each storm and each location are the Bias and root-mean-square error. The statistical tests are performed on the time series of water levels for the final 6 days of the storm simulation.

\subsubsection{Synopsis of Lake St. Clair water level modeling}

The post-processing comparisons described in the preceding section were done for all model simulations. Rather than present results from all storm simulations, ADCIRC estimates of water level are shown for a select set of storms and statistics are shown for all storms. For example, Figures 6-15 through 6-17 show the maximum surge envelopes for Storms 080, 086, and 108 , respectively. These figures provide an overall visual synopsis of the extreme response of the water body to atmospheric forcing. Storm 080 (December 1987) shows maximum water levels in the northwestern, northeastern, and eastern portions of Lake St. Clair as captured in the simulated surge envelope where water levels are over 176 m IGLD 1985. The second storm (Storm 086) corresponds to December 1990 which produced the highest recorded water level at the NOS Station in Green Bay as reported in Jensen et al (2012). This storm also produced maximum water levels in the northwestern portion of Lake St. Clair as captured in the simulated surge envelope where water levels are 175.2 to 175.6 m IGLD 1985 at the gauges and $175.8 \mathrm{~m}$ IGLD 1985 in the northwest region. By contrast, 


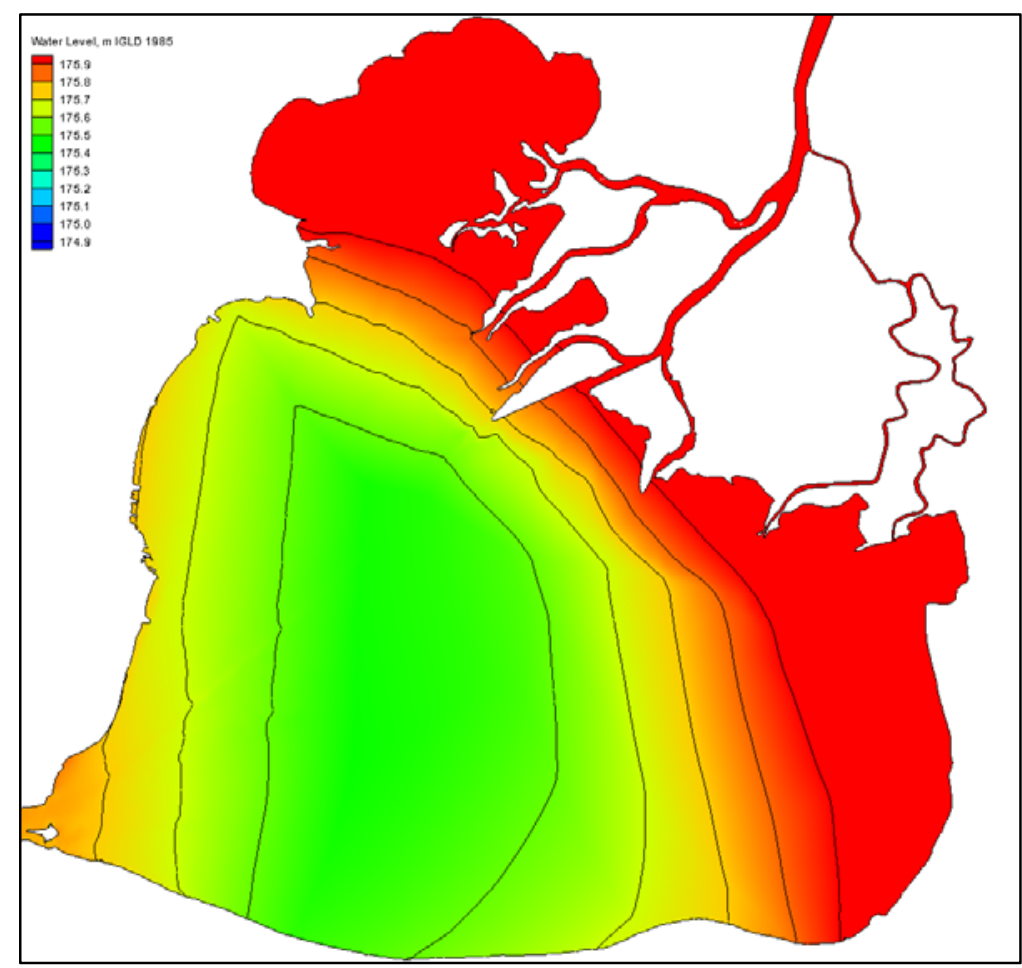

Figure 6-15. ADCIRC maximum water level envelope for Storm 080 (December 1987) indicating high water levels along northwestern shoreline of Lake St. Clair.

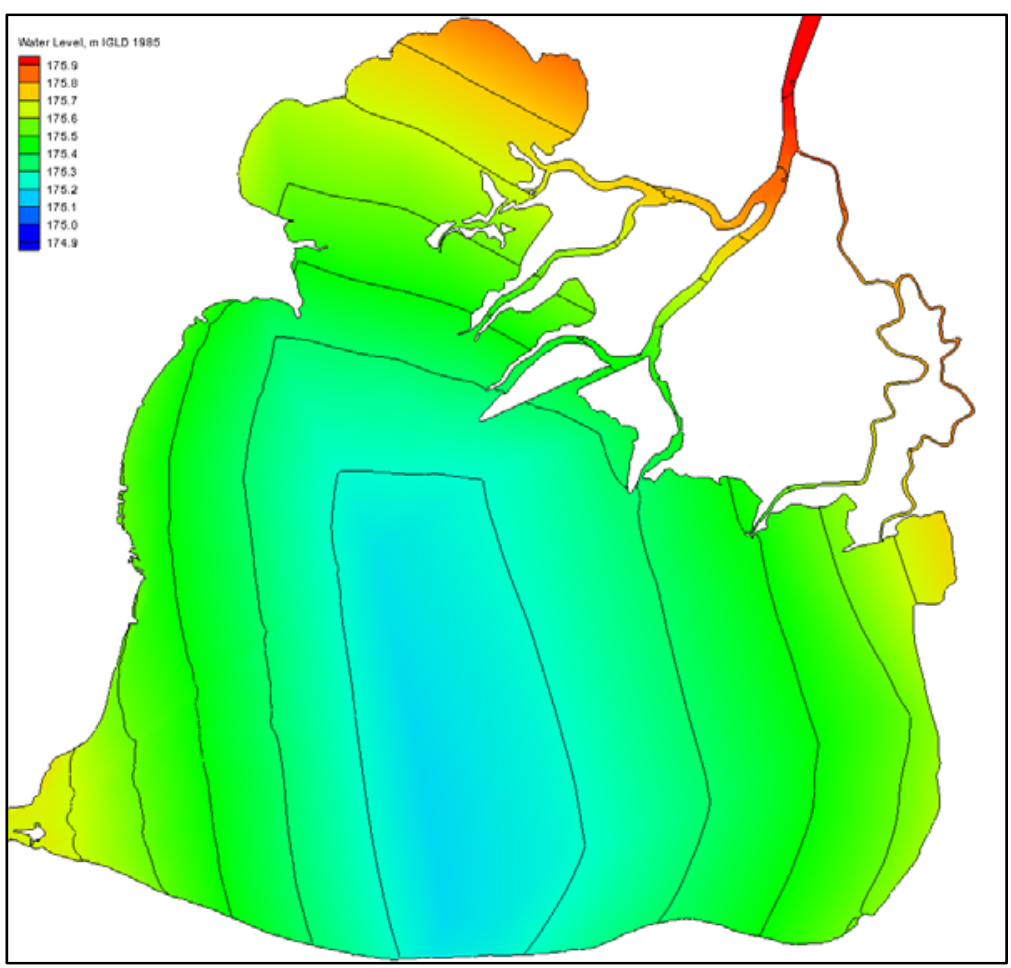

Figure 6-16. ADCIRC maximum water level envelope for Storm 086 (December 1990) indicating high water levels along northwestern shoreline of Lake St. Clair. 


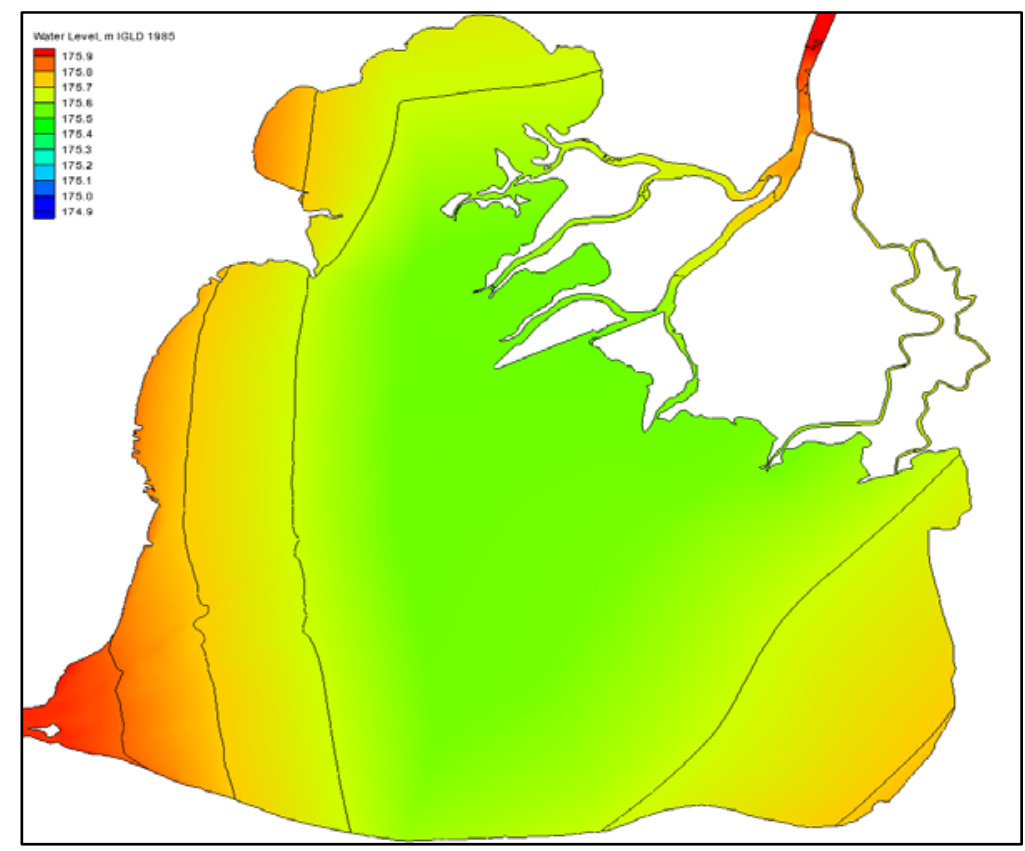

Figure 6-17. ADCIRC maximum water level envelope for Storm 108 (February 1998) indicating high water levels along northwestern shoreline of Lake St. Clair.

Storm 108 (February 1998) shows higher water levels in the southwestern portion of Lake St. Clair. As shown in Figure 6-17 water levels for this storm are $175.8 \mathrm{~m}$ in the southwestern portion of the lake and 175.6 to $175.8 \mathrm{~m}$ in the northwestern portion of the lake.

For a more detailed evaluation of model performance, the temporal variation of water level is compared to measurements at two locations in Lake St. Clair. As previously noted, time series of water levels were saved at over 200 save point locations for all 12 days of each model simulation, including the NOAA NOS water level gauge locations. ADCIRC water level time series were compared to NOAA NOS water level gauge time series for the last 6 days of the simulation to determine if the temporal and spatial variation in water level is captured by the model.

\subsubsection{December 1990 storm}

Four storms were selected to show various aspects of the hydrodynamic response observed in nature and the ability to reproduce those responses by the model. Storm 086 (December 1990) was selected because of the maximum water levels focused on the northwestern portion of the lake (Figure 6-16) and because this was a significant storm discussed in the Lake Michigan companion report (Jensen et al. 2012). The time series of water levels for this storm do not show a large spatial variability in 
response for the two lake gauge locations (St. Clair Shores and Windmill Point, Figures 6-18 and 6-19, respectively). The two gauges are on the western (US) side of Lake St. Clair and are approximately $14 \mathrm{~km}$ apart. The temporal variability in response at St. Clair Shores and Windmill Point is captured in magnitude, duration, and the post-storm seiching (Figures 618 and 6-19). The simulated storm peak is within $0.2 \mathrm{~m}$ of the observed storm peak at both locations. No adjustments were made to the St. Clair River mean monthly inflow, applied at the northern boundary of the mesh, for this storm. For both locations, the model was able to capture the trend in surge response magnitude and duration. The ability to simulate the range of responses, particularly the storm peak and duration for this storm, displays the skill of ADCIRC in simulating the storm surge hydrodynamics in Lake St. Clair. Small scale oscillations that are finer than the temporal and spatial scales of the forcing conditions were not captured in the simulated responses.

\subsubsection{December 1972 storm}

The second storm selected for discussion is Storm 031 (December 1972). This storm was selected because it included ice and had maximum surge levels on the north and east lake boundaries of 175.9 m IGLD 1985 and is less of a surge event on the western side of Lake St. Clair where the water level gauges are located (Figure 6-20). A five percent adjustment (increase) was made to the St. Clair River mean monthly inflow applied to the northern boundary of the mesh for this storm to increase the water level in the lake slightly for this time period to what is observed in the measured water level time series. The time series at St. Clair Shores and Windmill Point for this storm show long time periods of slow rise and fall that are captured extremely well by the model. Water levels at the storm peak are within $0.05 \mathrm{~m}$ of the observed water level peak at St. Clair Shores and are within $0.01 \mathrm{~m}$ of the observed water level peak at Windmill Point (Figures 6-21 and 6-22). The ability to simulate the range of responses, particularly the slow rise and fall in water level for this storm, displays the skill of ADCIRC in simulating the storm surge hydrodynamics in Lake St. Clair for a variety of storm events.

\subsubsection{April 1979 storm}

The third storm selected for discussion is Storm 054 (April 1979). This storm was selected because it showed a significant set down at St. Clair

Shores and Windmill Point that is captured by the model (Figure 6-23). 


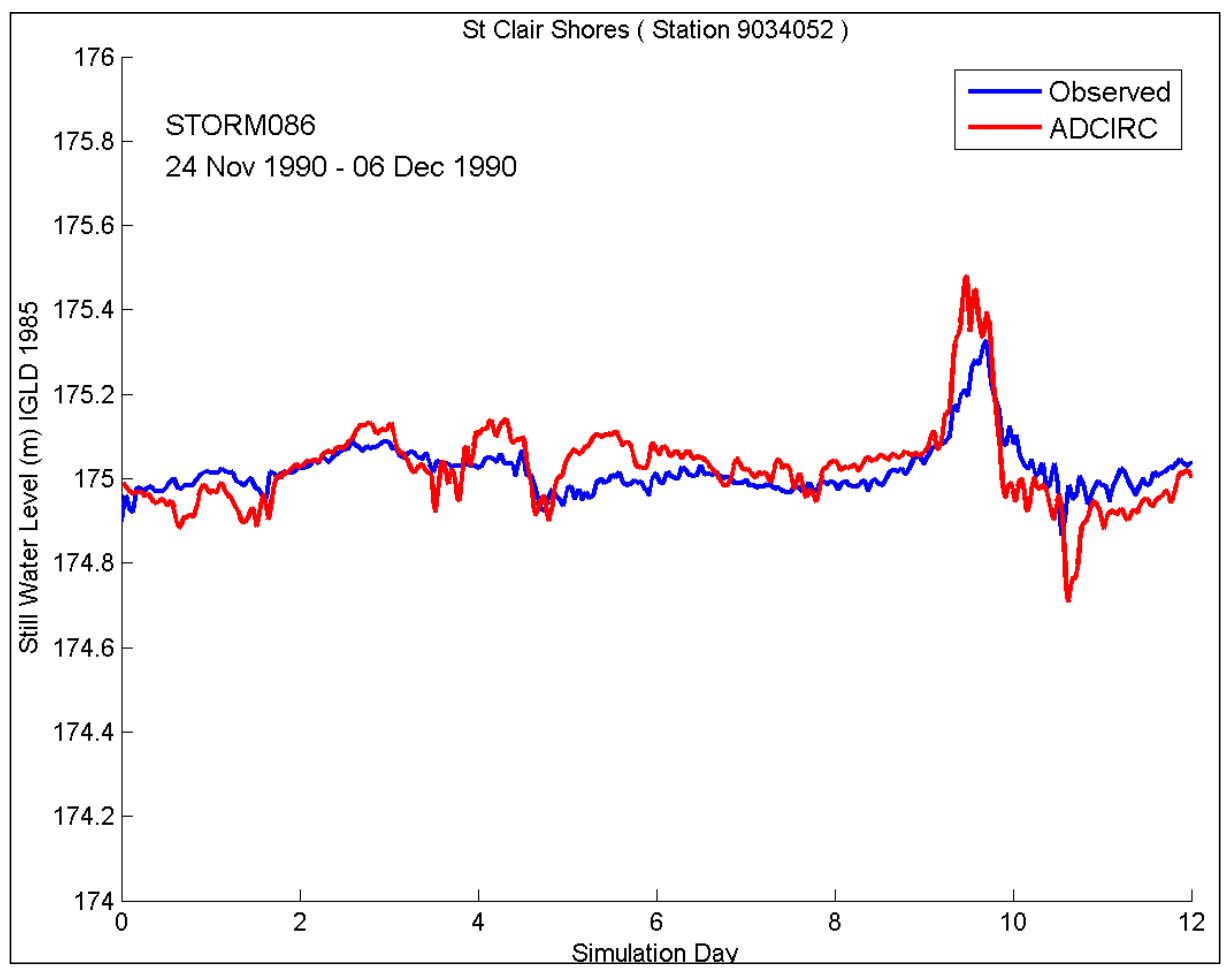

Figure 6-18. Time series of water levels for Storm 086 (December 1990) at St. Clair Shores.

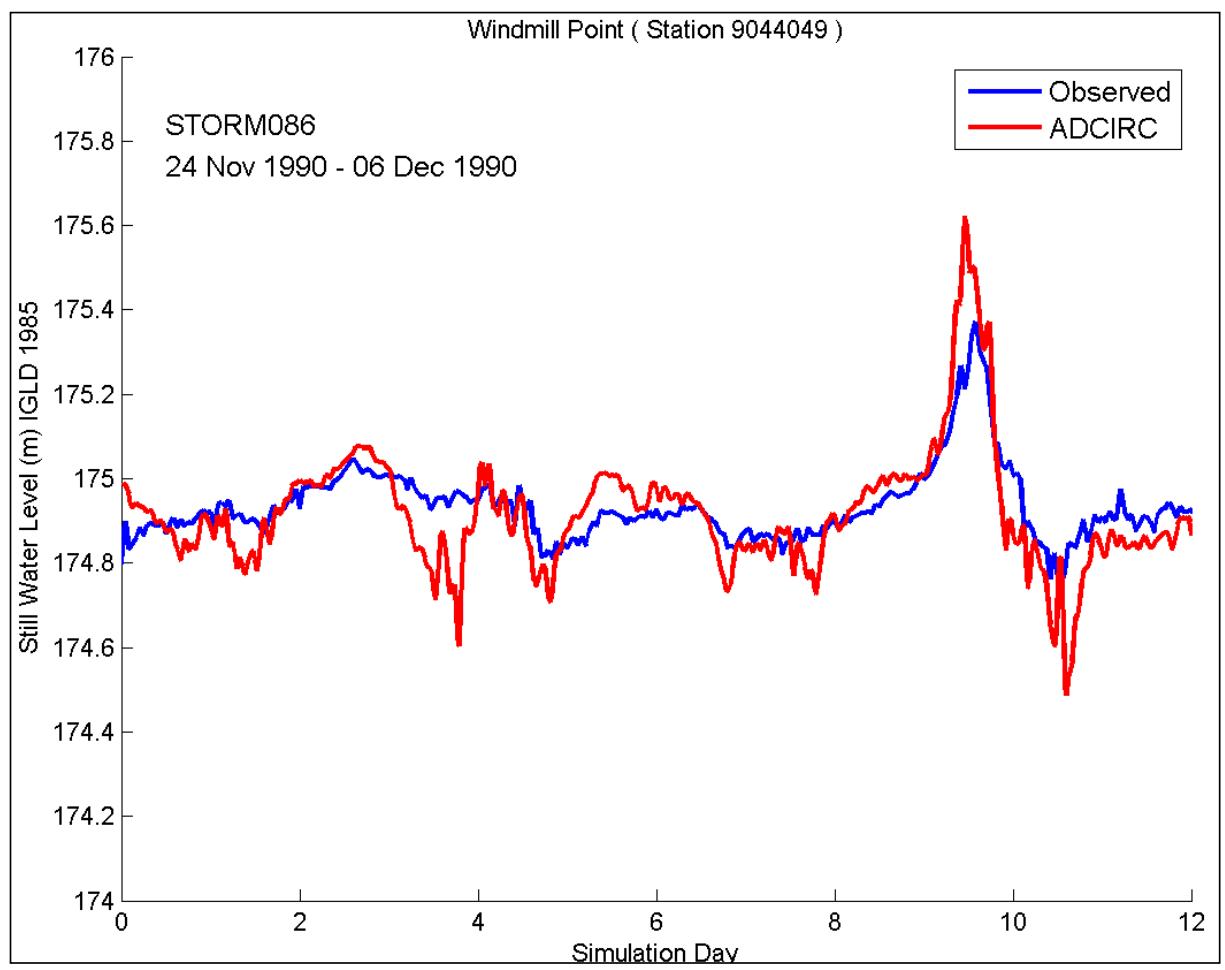

Figure 6-19. Time series of water levels for Storm 086 (December 1990) at Windmill Point. 


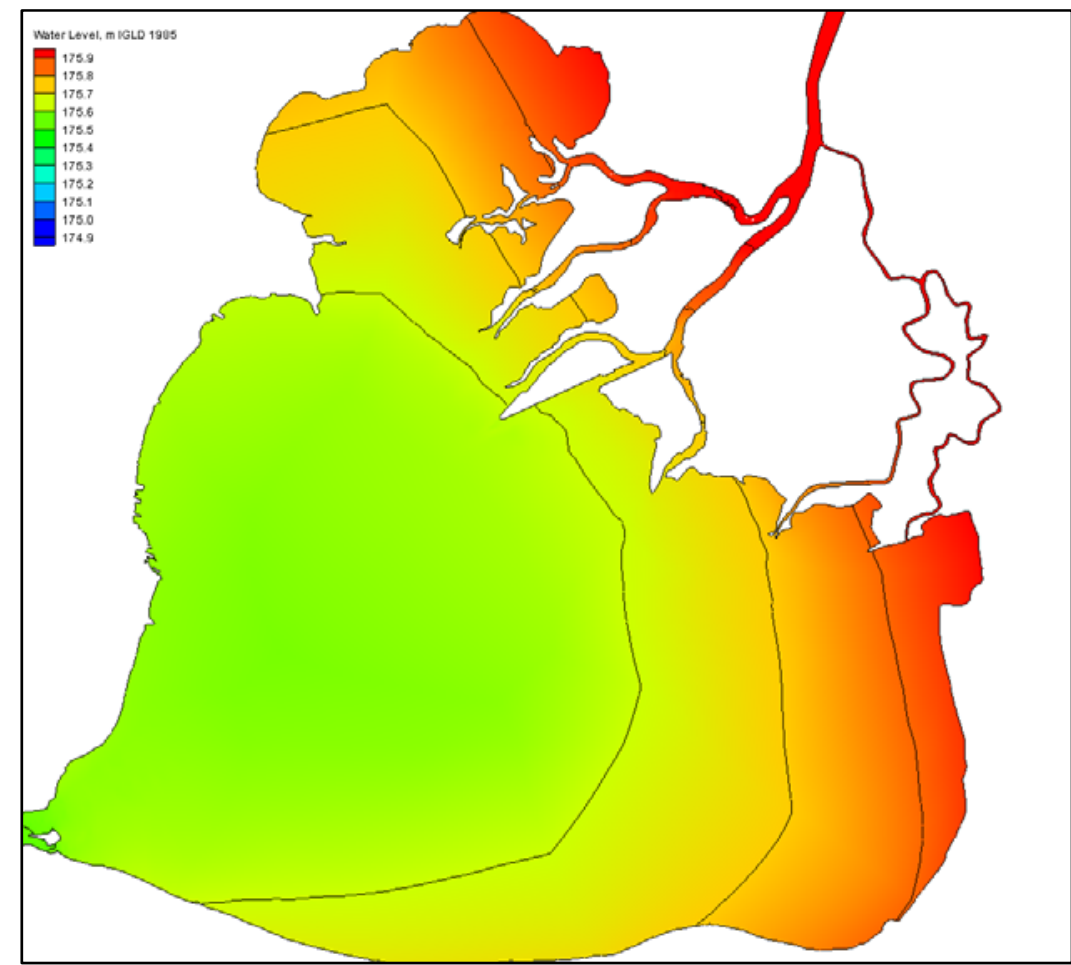

Figure 6-20. ADCIRC maximum water level envelope for Storm 031 (December 1972) indicating high water levels along northern and eastern shorelines of Lake St. Clair.

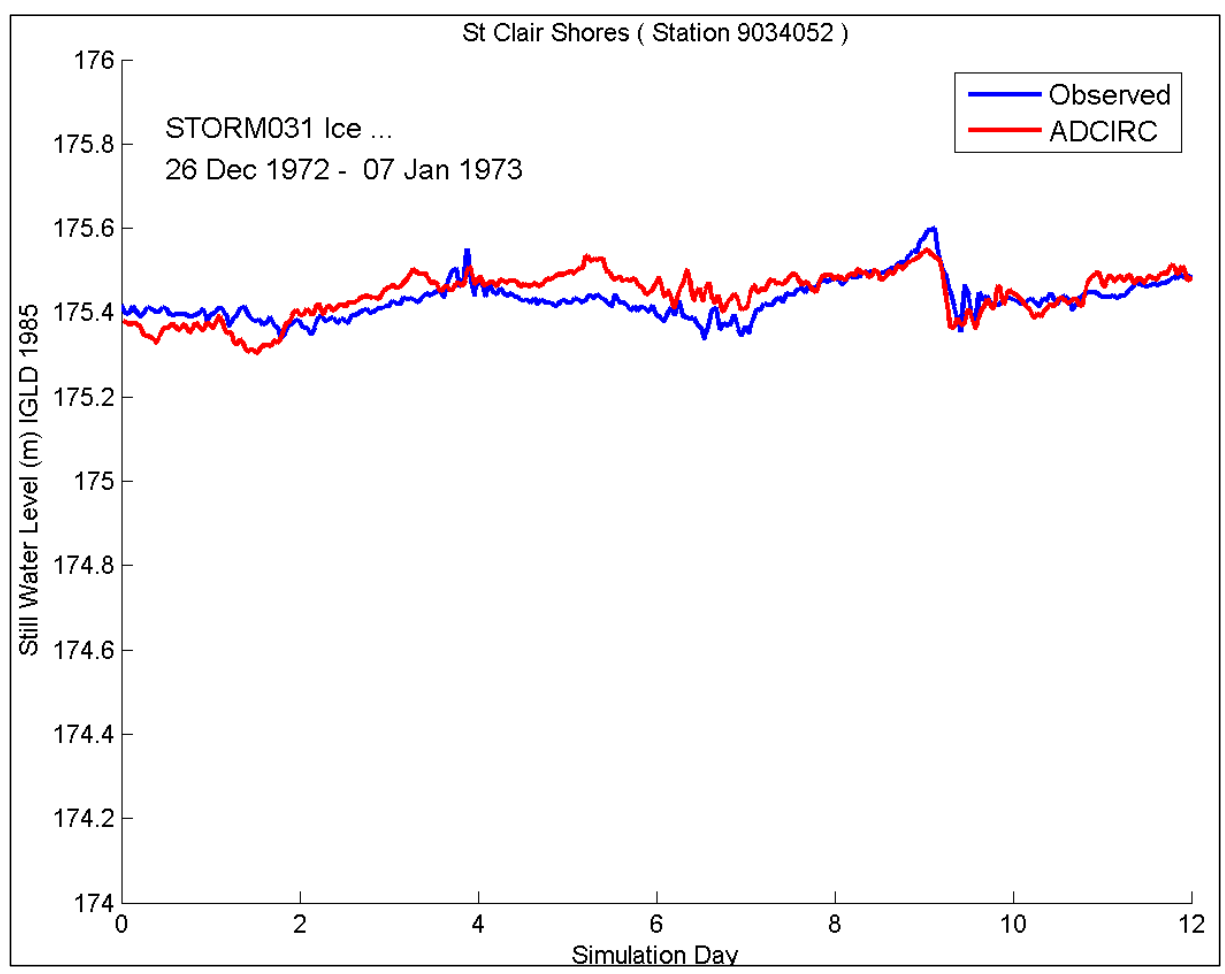

Figure 6-21. Time series of water levels for Storm 031 (December 1972) at St. Clair Shores. 


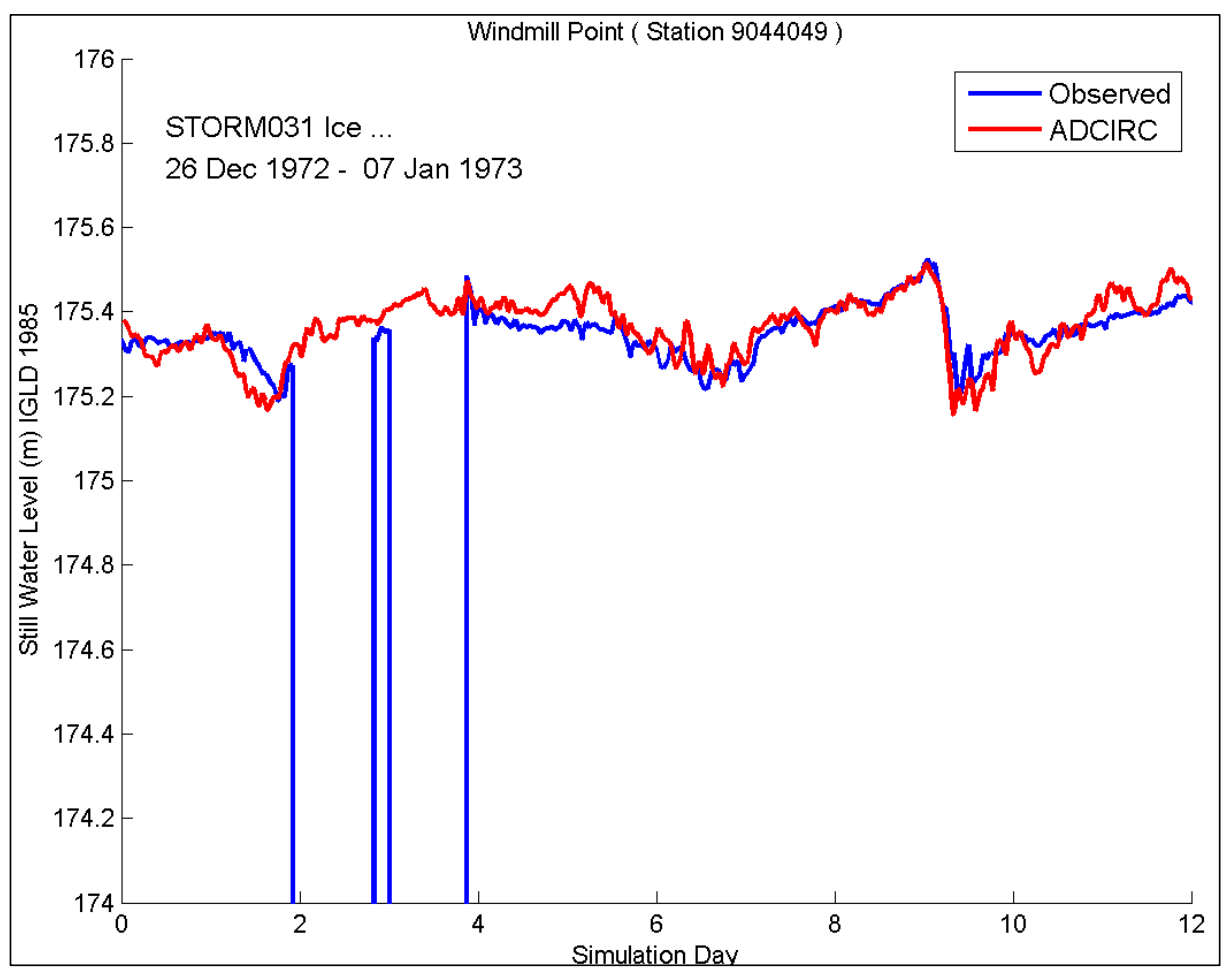

Figure 6-22. Time series of water levels for Storm 031 (December 1972) at Windmill Point.

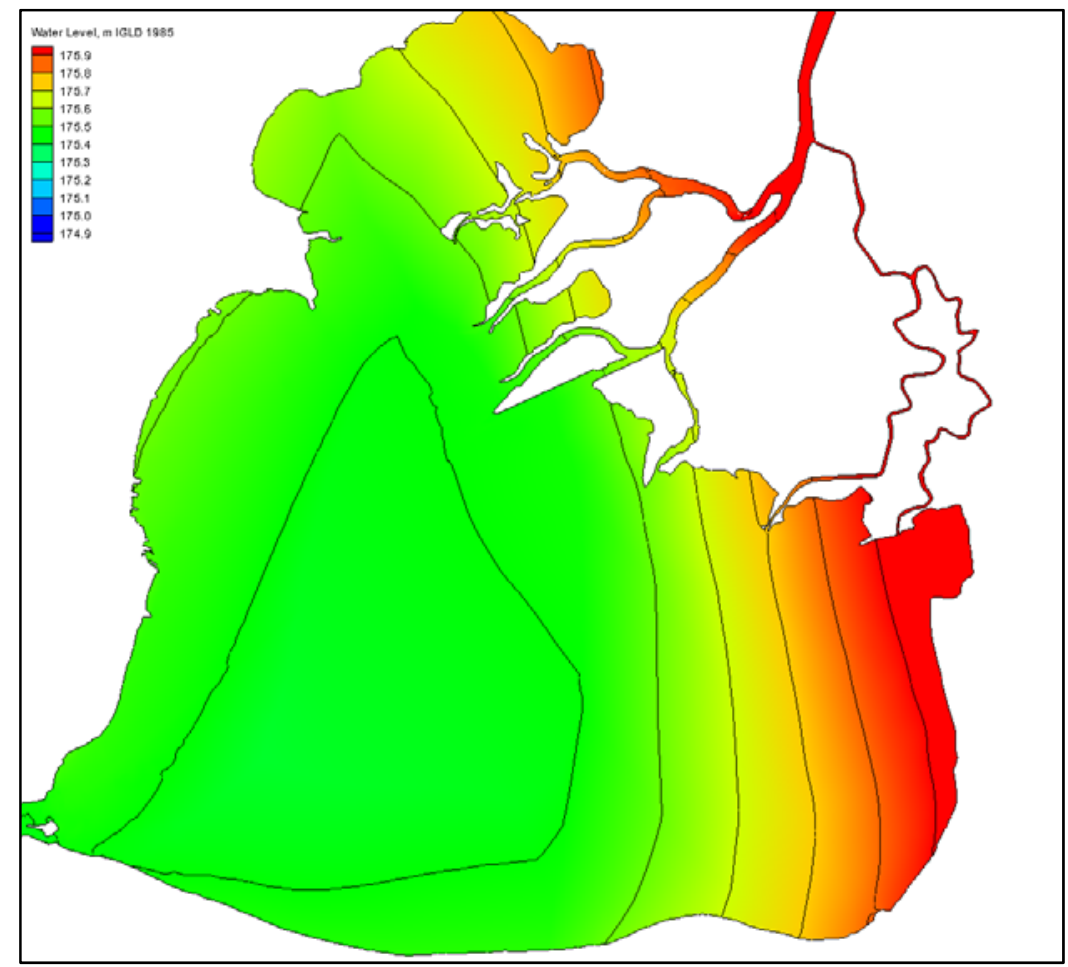

Figure 6-23. ADCIRC maximum water level envelope for Storm 054 (April 1979 ) indicating high water levels along eastern shoreline of Lake St. Clair. 
During Day 3 of the selected storm time period, there is a $0.5-\mathrm{m}$ drop in water level observed at both NOAA NOS stations and the model captures this large drop in water level to within $0.1 \mathrm{~m}$ of the observations (Figures 6-24 and 6-25). A 10 percent adjustment (increase) was made to the St. Clair River mean monthly inflow applied to the northern boundary of the mesh for this storm to increase the water level in the lake slightly for this time period to what is observed in the measured water level time series. The ability to simulate the range of responses, particularly the set down observed for this storm, displays the skill of ADCIRC in simulating the storm surge hydrodynamics in Lake St. Clair.

\subsubsection{October 1997 storm}

The last storm selected for discussion is Storm 105 (October 1997). This storm was selected because it had maximum water levels in the south and southeast portions of the lake (Figure 6-26). The time series of water levels for this storm show some spatial variability in response for the two lake gauge locations (St. Clair Shores and Windmill Point, Figures 6-27 and 6-28, respectively). The storm peak is more pronounced at Windmill Point, which is located further south than St. Clair Shores. In addition, the temporal variability in response at St. Clair Shores and Windmill Point is

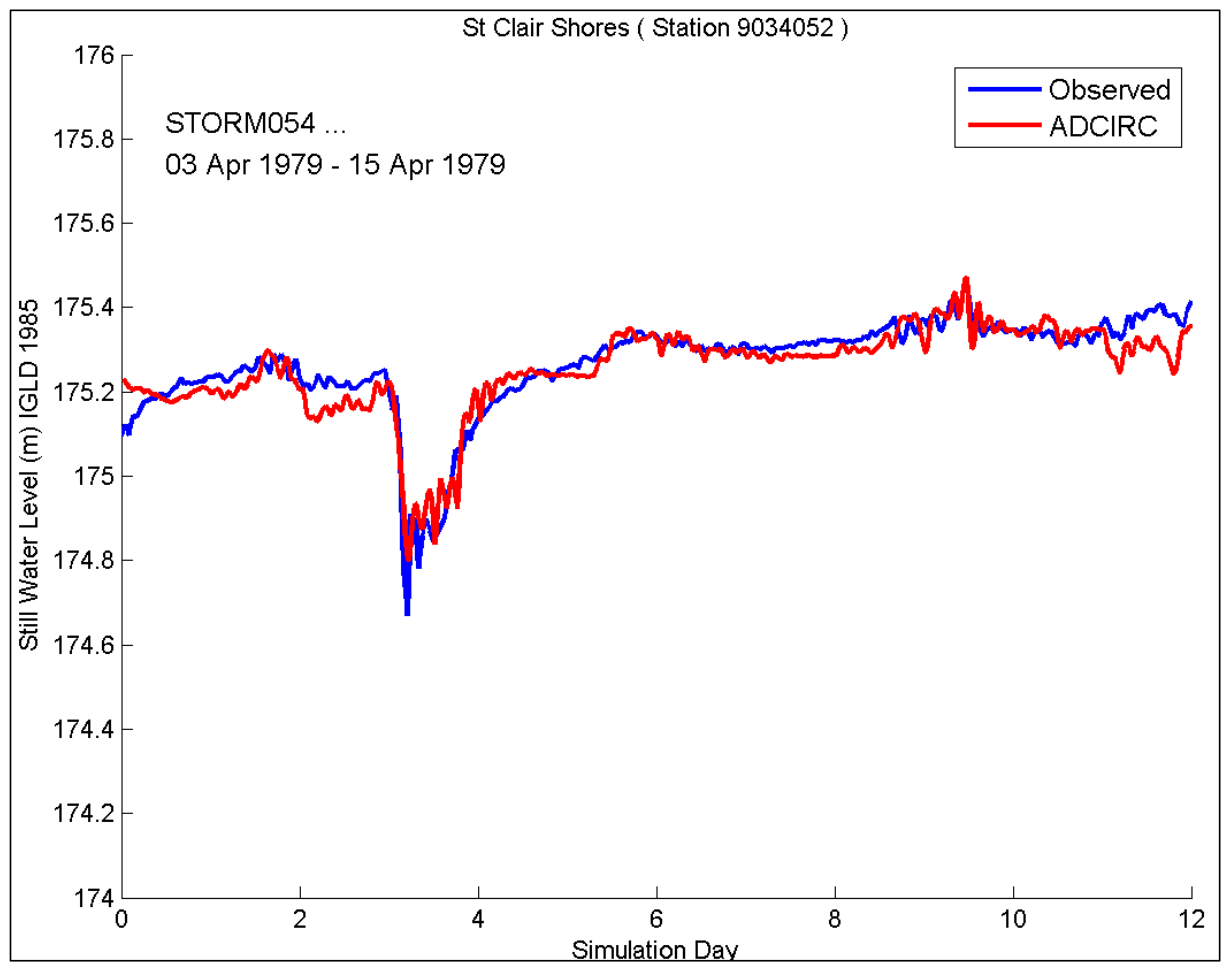

Figure 6-24. Time series of water levels for Storm 054 (April 1979) at St. Clair Shores. 


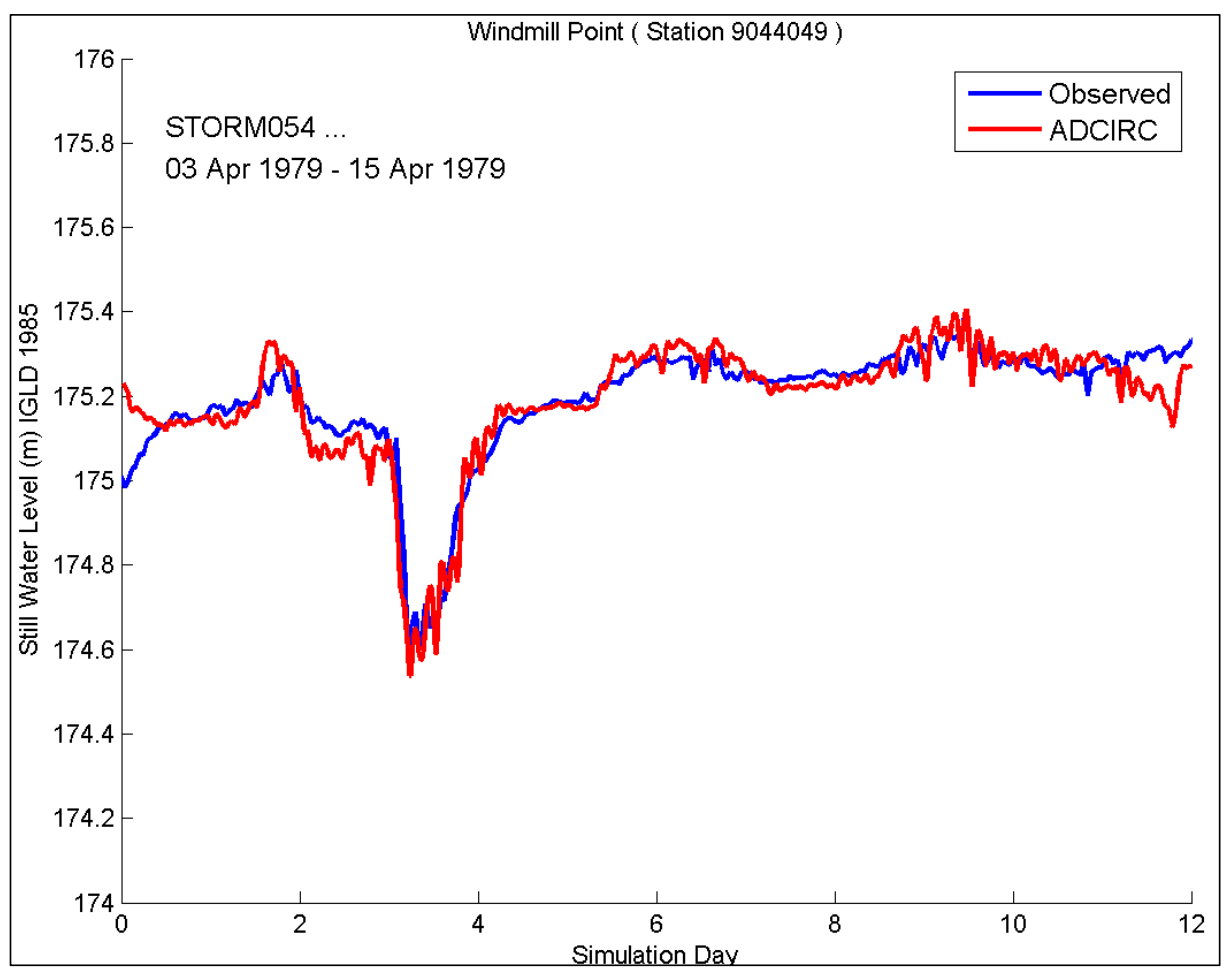

Figure 6-25. Time series of water levels for Storm 054 (April 1979) at Windmill Point.

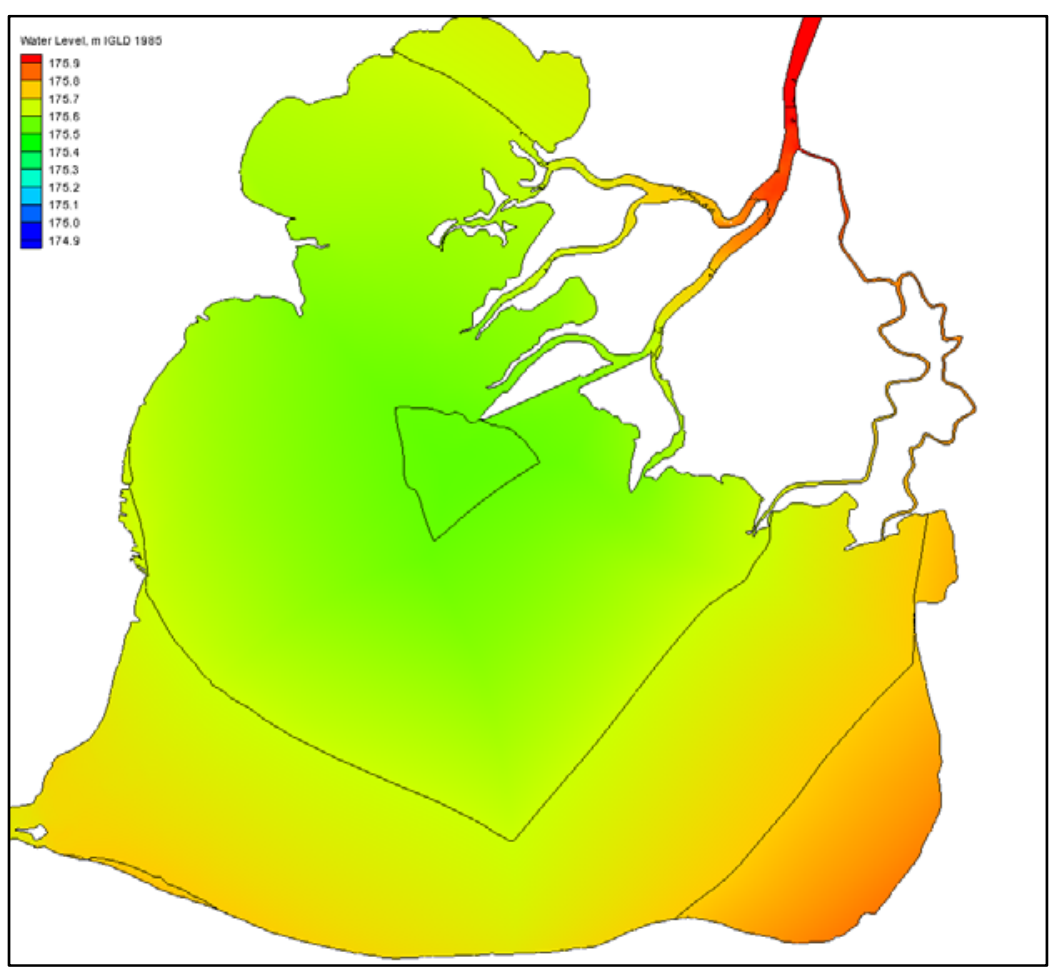

Figure 6-26. ADCIRC maximum water level envelope for Storm 105 (October 1997) indicating high water levels along southern and southeastern shorelines of Lake St. Clair. 


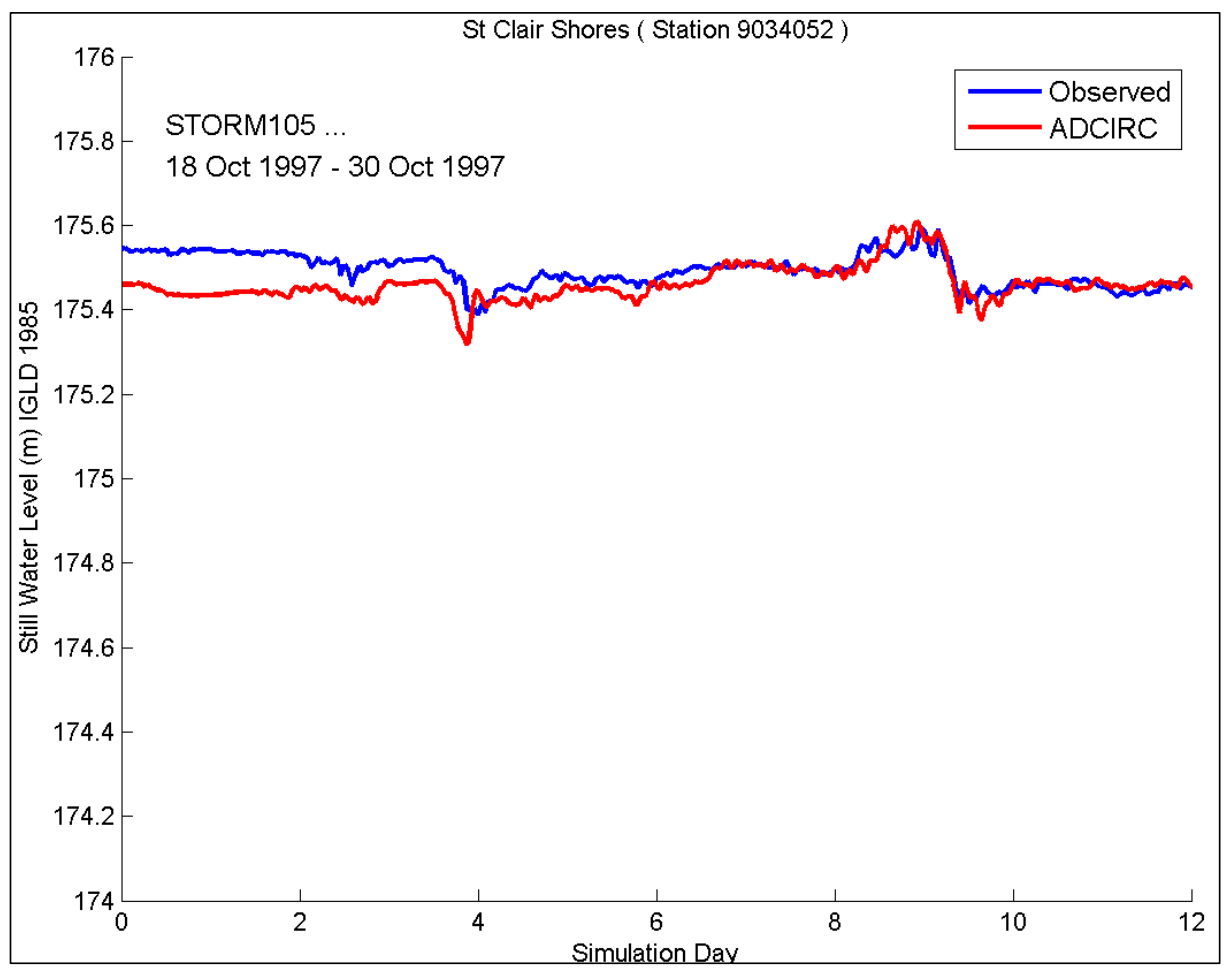

Figure 6-27. Time series of water levels for Storm105 (October 1997) at St. Clair Shores.

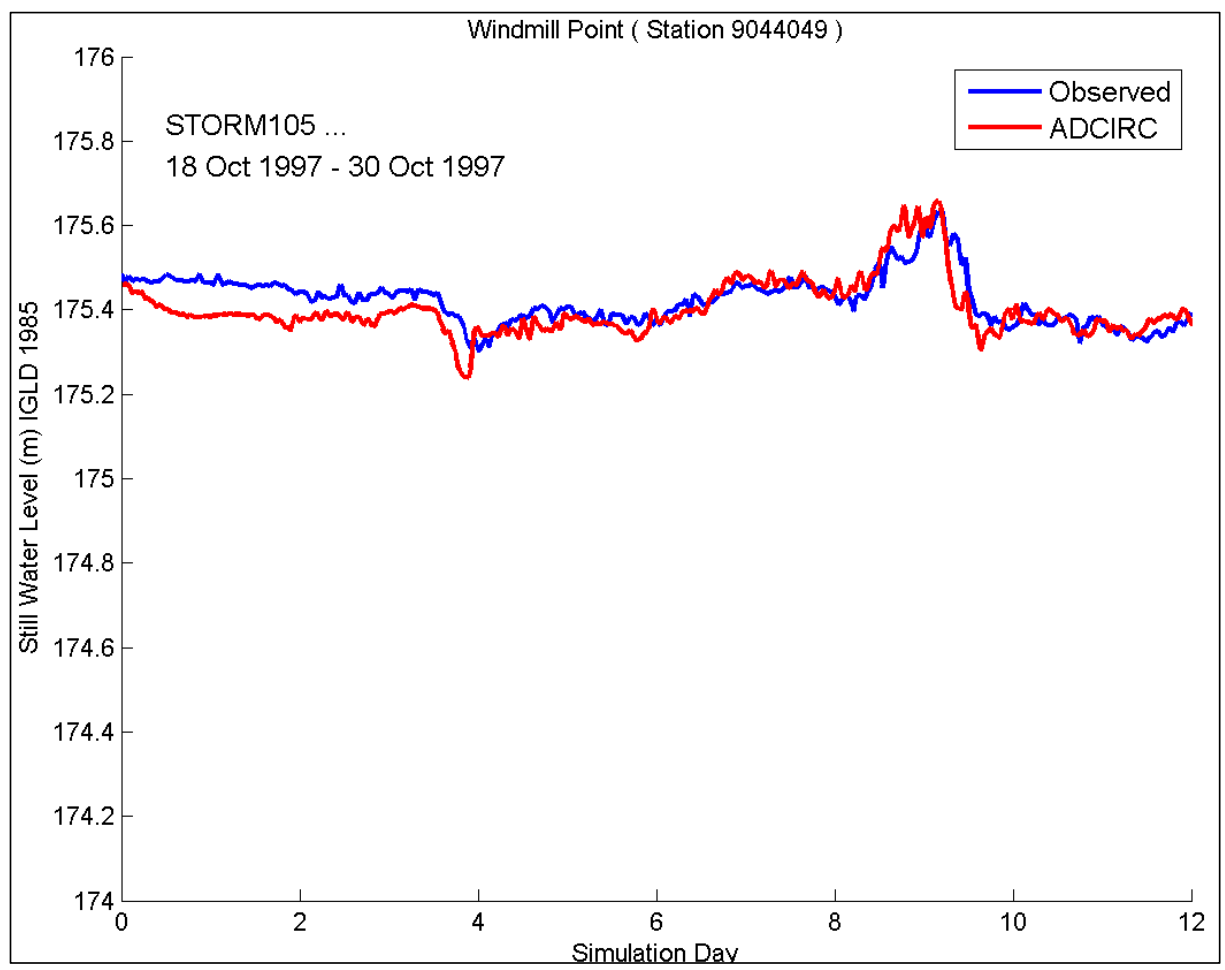

Figure 6-28. Time series of water levels for Storm105 (October 1997) at Windmill Point. 
captured in magnitude, duration, and in the post-storm water level decay (Figures 6-27 and 6-28). Simulated water levels are within 0.05 $\mathrm{m}$ of the observed water levels for the final 8 days of the simulation. A five percent adjustment (increase) was made to the St. Clair River mean monthly inflow applied to the northern boundary of the mesh for this storm to increase the water level in the lake slightly for this time period to what is observed in the measured water level time series. For both locations, the model was able to capture the trend in surge response magnitude and duration. The ability to simulate the range of responses displays the skill of ADCIRC in simulating the storm surge hydrodynamics in Lake St. Clair.

\subsection{Statistics}

The ADCIRC water level time series results were evaluated and compared to measured NOAA water levels at two locations. This was accomplished by querying the NOAA tides and currents web site (http://tidesandcurrents. noaa.gov) for hourly water level data at the St. Clair Shores and Windmill Point stations and comparing those data to hourly time series of simulated water levels at the same geographical locations. The modeled water levels were simulated at the lake level at the time of the storm plus a Basis of Comparison (BOC) correction. In the comparative analysis, that BOC correction was applied to the measured data so that both time series were based on the same mean water level. The statistical comparisons tabulated for each storm and each location are the bias (model minus measurements) and root-mean-square error (RMSE). The statistical tests are performed on the time series of water levels for the final 6 days of the storm simulation. (The first 6 days were considered the model spin up time period and modeled time-series were not saved during that time period.)

With 145 storm simulations having two measurements available to compare to, there were approximately 300 statistical bias and RMSE values calculated. An examination of all storm comparisons shows that 86 percent of the bias values are within +/- 0.05 $\mathrm{m}$. Figures 6-29 and 6-30 show the bias values for each individual station for all storms. In general, the simulated water levels compare fairly well with measured water levels. Bias values are generally within $+/-0.05 \mathrm{~m}$ and have a bias of no more than $0.16 \mathrm{~m}$. Only storms that occurred after 1970 are shown in the figures because of the complexity with the initialization of ADCIRC for events in the 1960s described earlier. 


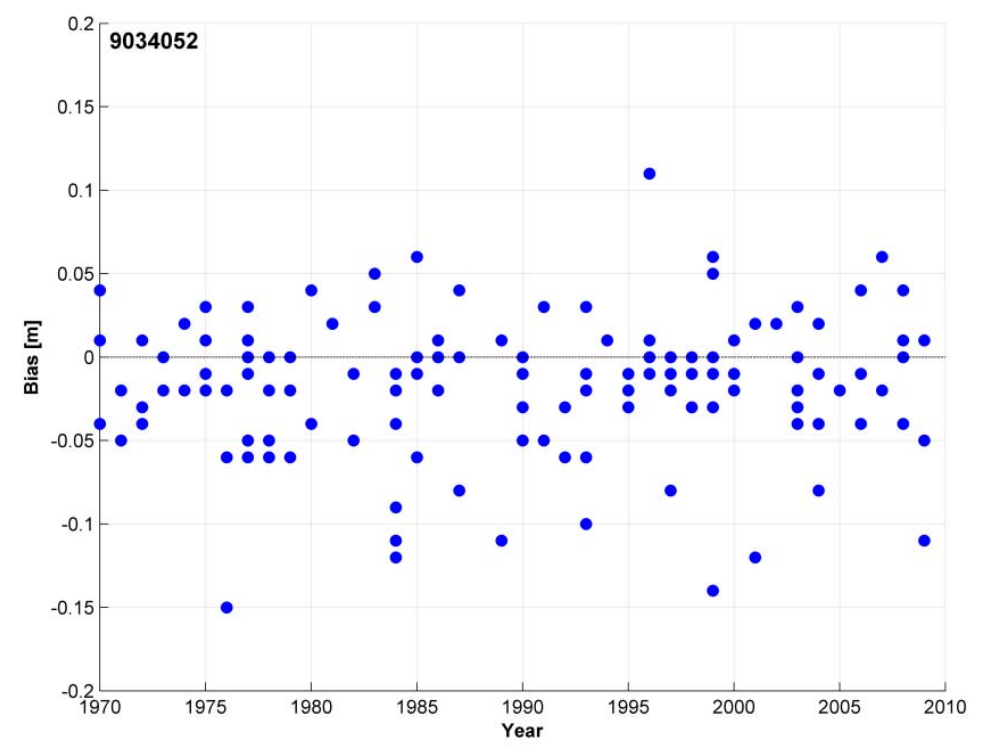

Figure 6-29. Water level bias at Station 9034052 (St. Clair Shores).

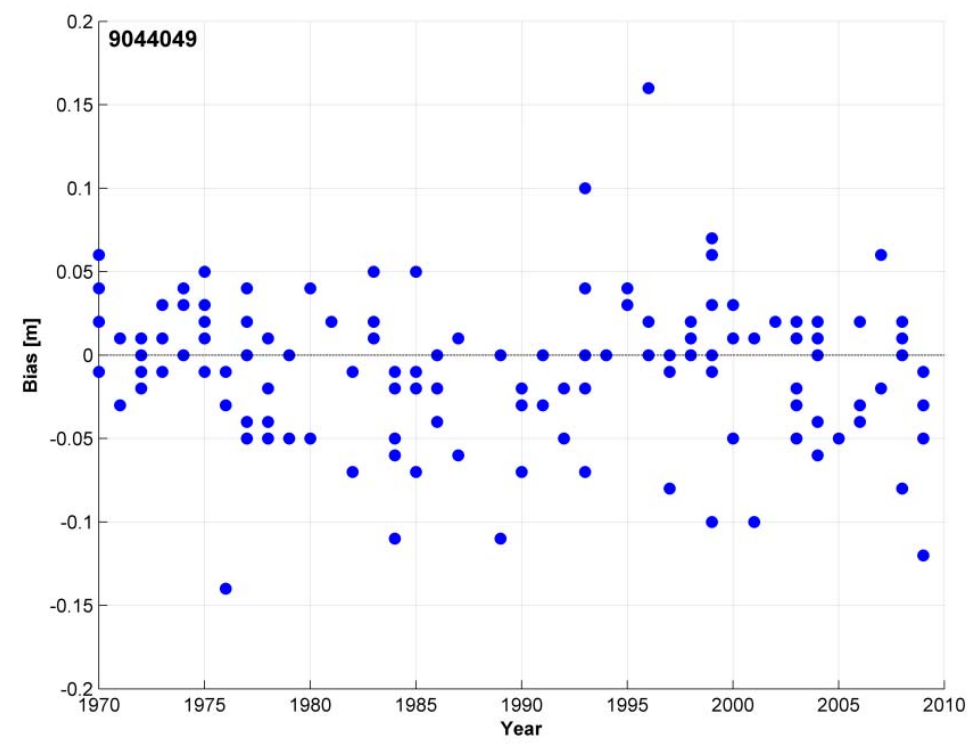

Figure 6-30. Water level bias at Station 9044049 (Windmill Point). 


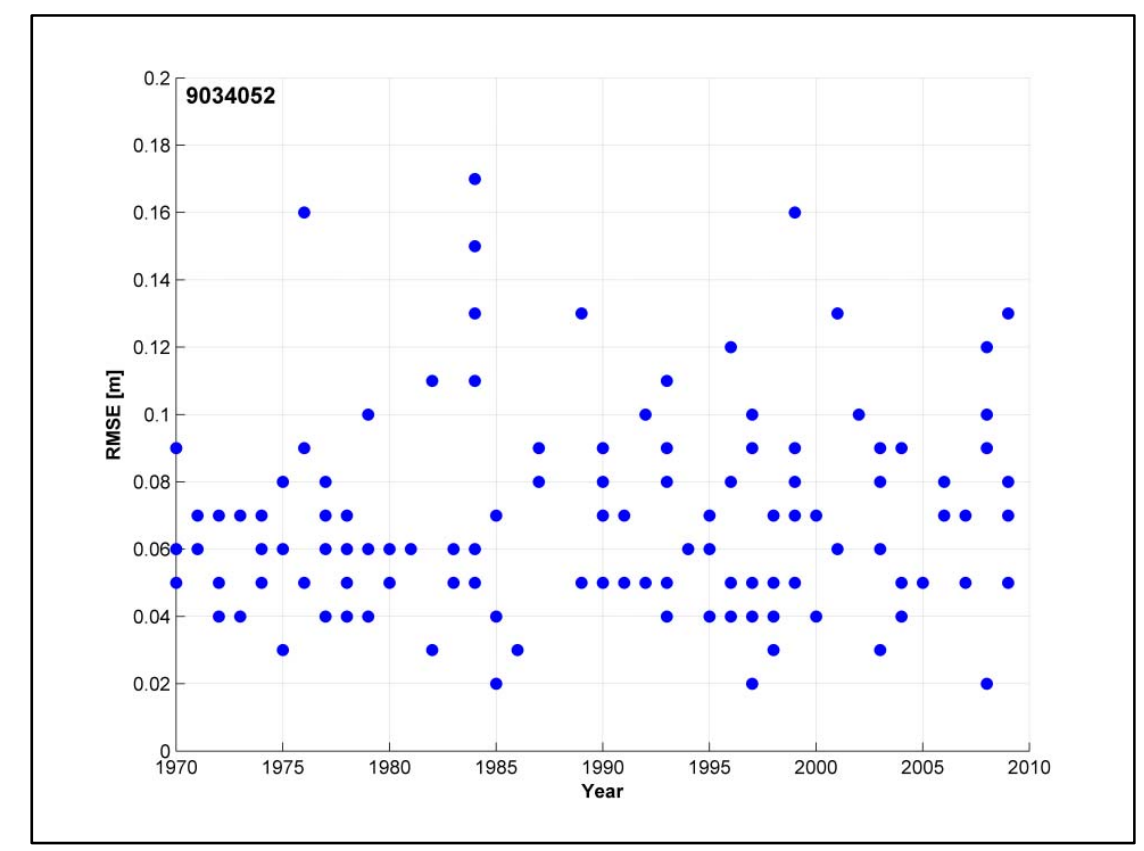

Figure 6-31. Water level RMSE at Station 9034052 (St. Clair Shores).

Figures 6-31 and 6-32 show the RMSE values for all storms and both gauges. In general the RMSE is within $0.10 \mathrm{~m}$. An examination of all comparisons shows that 90 percent of the RMSE values are within $0.10 \mathrm{~m}$. Overall, the model performs well in simulating water levels over Lake St. Clair for a large number of storms of varying size, intensity, and duration. The model's ability to estimate water levels at many locations under various conditions provides a strong degree of confidence in the model to predict water levels at other locations around Lake St. Clair as well.

A second statistical analysis was performed to focus on the accuracy of the ADCIRC water level estimation compared to the measured peak of each event. The bias calculated at the peak removes the time dependency and focuses on the maximum water level values during the storm's highest intensity. The peak water level estimated from ADCIRC was determined from the maximum water level within a 24-hr window centered on the time of the measured peak of each event. The scatter plot of ADCIRC and Station 9034052 in Figure 6-33 show very good agreement between maximum water levels. The bias calculated using the peak water levels shows a higher percentage of events have a positive bias, or an over-estimation of the peak water level by the model, than an under-estimation of peak water level (Figure 6-34). The estimated peak water level from ADCIRC range from a $30-\mathrm{cm}$ over-estimation to a $20-\mathrm{cm}$ under-estimation. The events were further separated into NNM (red) and CFSR (blue) to distinguish the wind 
forcing method. There appears to be no difference in the model's ability to estimate the water level during the storm peak at Station 9034052 when forced with NNM or CFSR winds.

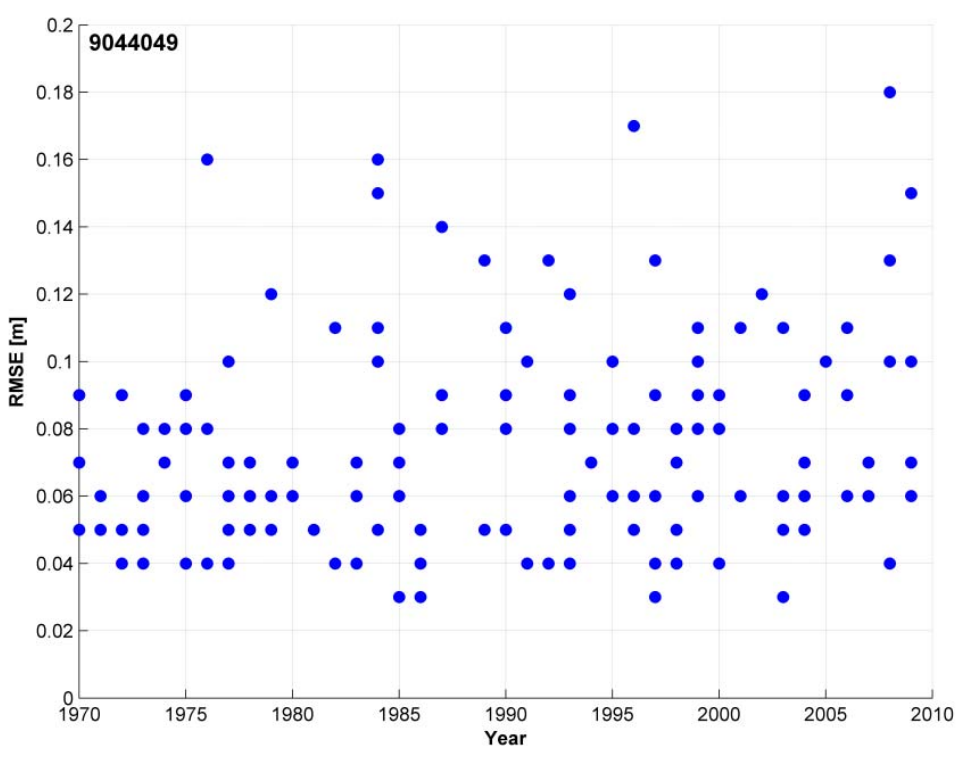

Figure 6-32. Water level RMSE at Station 9044049 (Windmill Point).

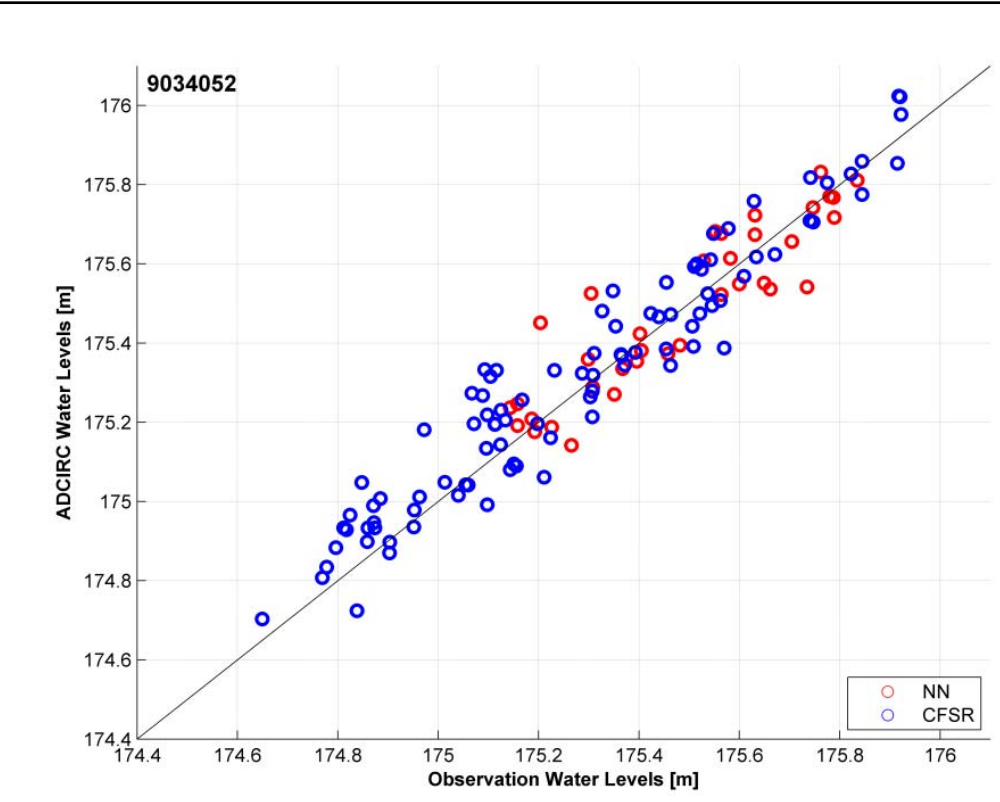

Figure 6-33. Scatter of maximum ADCIRC water levels within 24-hrs (+/- 12hrs) of the peak of the event at Station 9034052 (St. Clair Shores). 


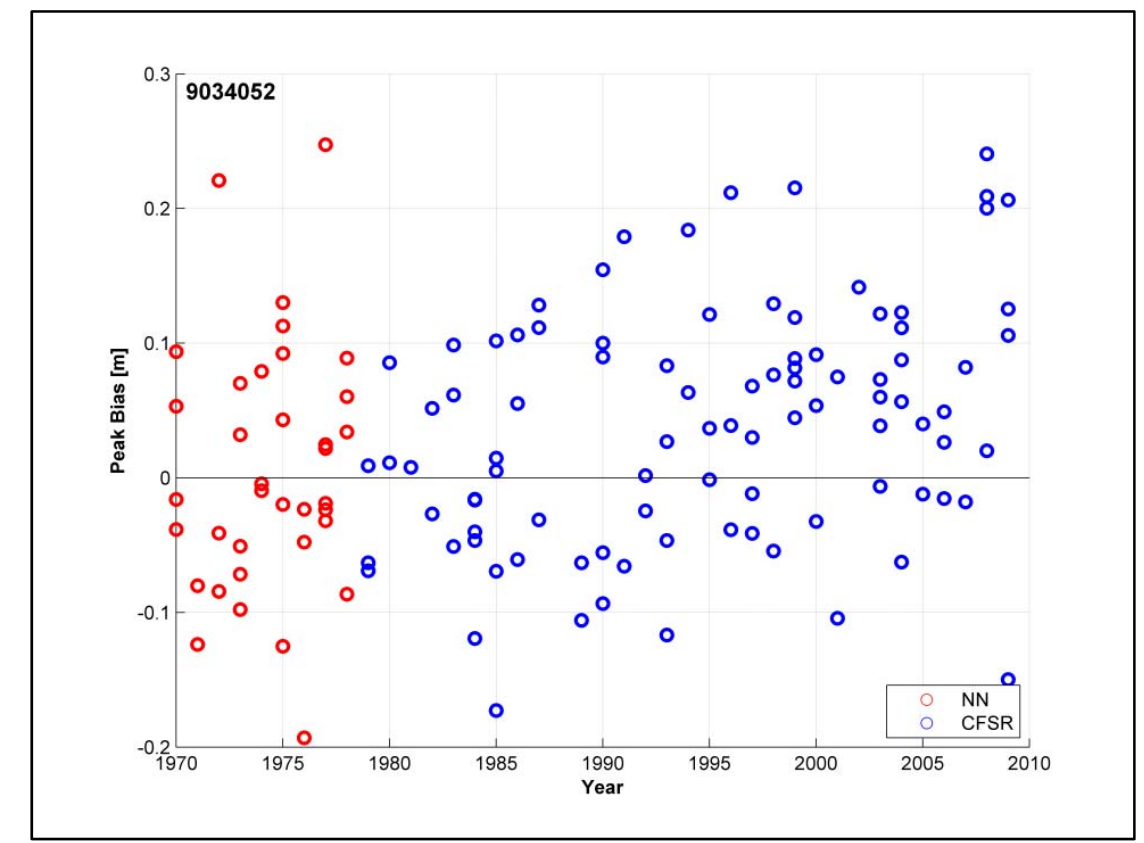

Figure 6-34. Bias calculated from the maximum ADCIRC water level within 24-hrs (+/-12-hrs) of the peak of the event and the measured peak of the event at Station 9034052 (St. Clair Shores).

The scatter of maximum water levels predicted at Station 9044049 compared to measured peak water levels at this location shows that the majority of the points are above the best fit line (Figure 6-35) and that the peak bias values (Figure 6-36) are higher at Station 9044049 than at Station 9034052. The bias range at Station 9044049 was between 50-cm of overestimation by the model and $20-\mathrm{cm}$ of under-estimation. The larger bias values for Station 9044049 as compared to Station 9034052 may be associated with the location of Station 9044049 close to the outlet from Lake St Clair and entrance into the Detroit River. A water level boundary condition is applied at the Detroit River based on water levels at the Gibraltar gauge. Any over-estimation of water levels applied at the model boundary would result in an over-estimation of water levels along the Detroit River, including Windmill Point (Station 9044049). Locations further removed from the river, such as St Clair Shores (Station 90340520), would have somewhat less impact associated with river stage. As with Station 9034052, the NNM (red) and CFSR (blue) identified points do not have different trends at Station 9044049, implying that these wind field development methods are interchangeable. 


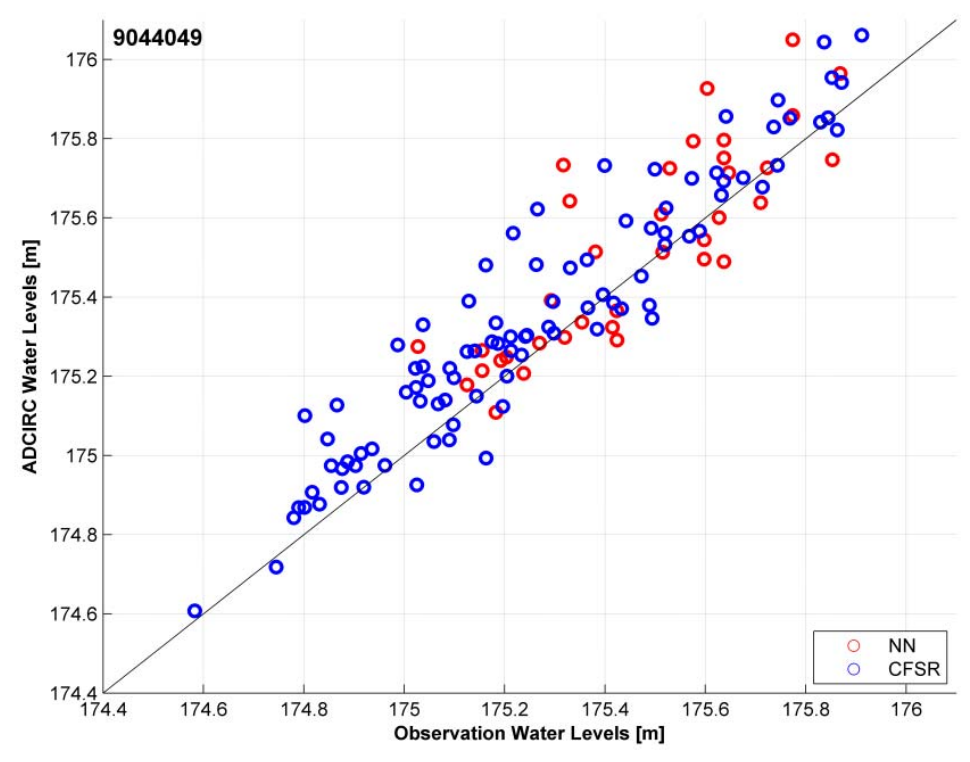

Figure 6-35. Scatter of maximum ADCIRC water levels within 24-hrs (+/- 12hrs) of the peak of the event at Station 9044049 (Windmill Point).

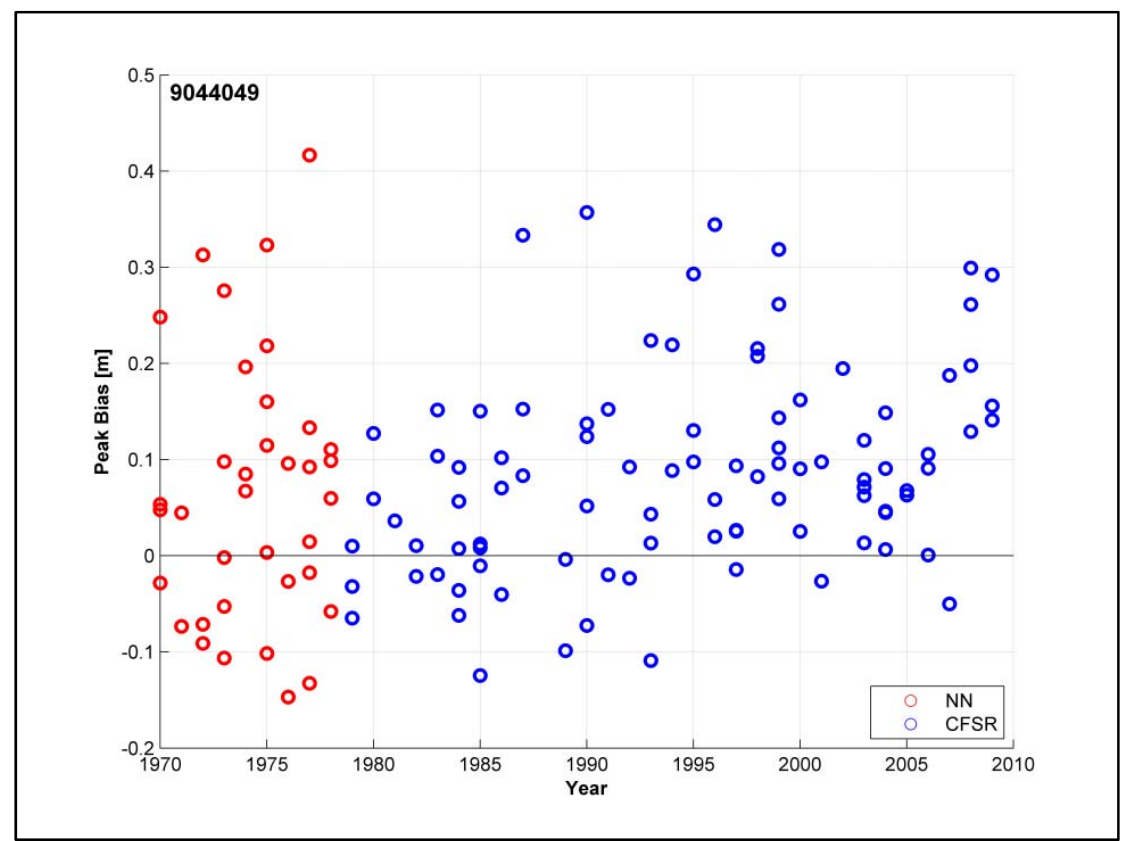

Figure 6-36. Bias calculated from the maximum ADCIRC water level within 24-hrs (+/- 12-hrs) of the peak of the event and the measured peak of the event at Station 9044049 (Windmill Point).

\subsection{Nearshore wave production}

Following the methodology of Jensen et al. (2012), STWAVE was run at 30-min time steps for 6 days ( 3 days prior to the storm peak, the peak day, 
and 2 days following the storm peak). Exported datasets include the zeromoment wave height $H_{m o}$, mean wave period $T_{m}$, mean wave direction $\alpha_{m}$, and 2D spectra at specific cell locations as well as $H_{m o}, T_{m}$, and $\alpha_{m}$ at each grid cell throughout the entire domain. Peak wave periods $\left(T_{p}\right)$ for the grids were saved at each time step to a separate file.

During the execution of the 145 extreme storm events, quality assurance and control for all 145-storms included overlaying the maximum wave height field with the bathymetry and reviewing the final iteration criteria for solution convergence. Only the reasonableness of the solution was reviewed as there were no gauges contained within the domains and comparisons to wave measurements were not possible.

\subsubsection{QA/QC for all storms}

Figures 6-37 to 6-40 present the maximum wave height in each domain for all modeled storm events where red and blue circles indicate events forced with NNM or CFSR winds, respectively. Storm events prior to 1970 are not plotted as water level boundary conditions were unavailable and only the range of response was generated considering multiple synthetic boundary conditions. The smallest wave heights occurred during ice storms (i.e, Storm 117 with peak date 12/28/2000 and maximum wave height of $0.15 \mathrm{~m}$ ). The largest wave height occurred during Storm 059 (peak date 04/04/1987) in the MW and SW grid and during Storm 080 (peak date 12/15/1987) in the NW and NE grid. However, this maximum wave height in the MW and SW grid resulted from a boundary condition provided by WAM where the wave direction was parallel to the domain or offshore (i.e., the waves did not propagate into the domain). Thus, these larger wave heights were found only along the cells comprising the offshore boundary. Figure 6-41 presents this behavior for Storm 059 in the SW grid. Upon further inspection, it was found the largest wave heights that propagate into the MW and SW domains occurred during Storm 080, the event that also generated the largest waves in the NW and NE domains.

In addition to plotting the maximum wave height of each storm event, the maximum wave height field for each storm was plotted with the bathymetry to identify errors or discontinuities in the STWAVE wave height solution. Figures 6-42 through 6-45 provide examples of these plots for the NW, MW, SW, and NE grid, respectively, where the shown storm, Storm 080, yielded the largest wave heights to propagate into the domain. 


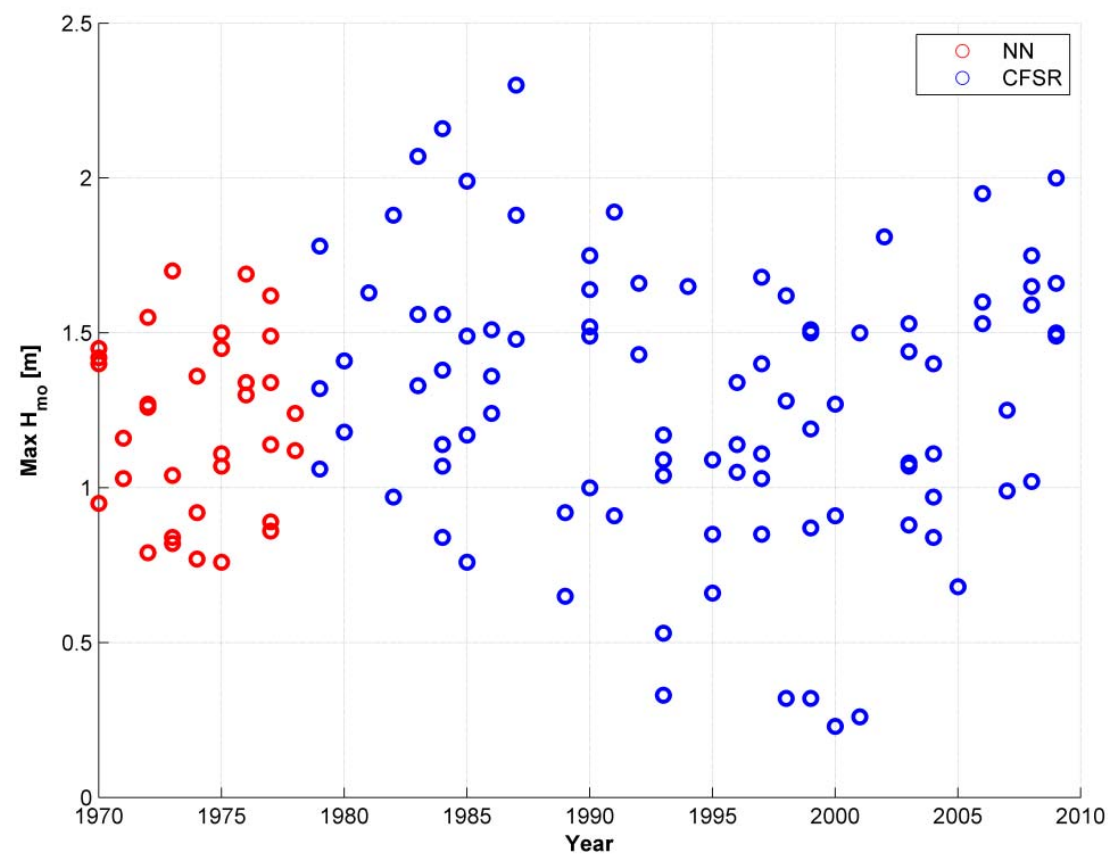

Figure 6-37. Maximum wave heights for all post-1970 modeled storm events for NW grid.

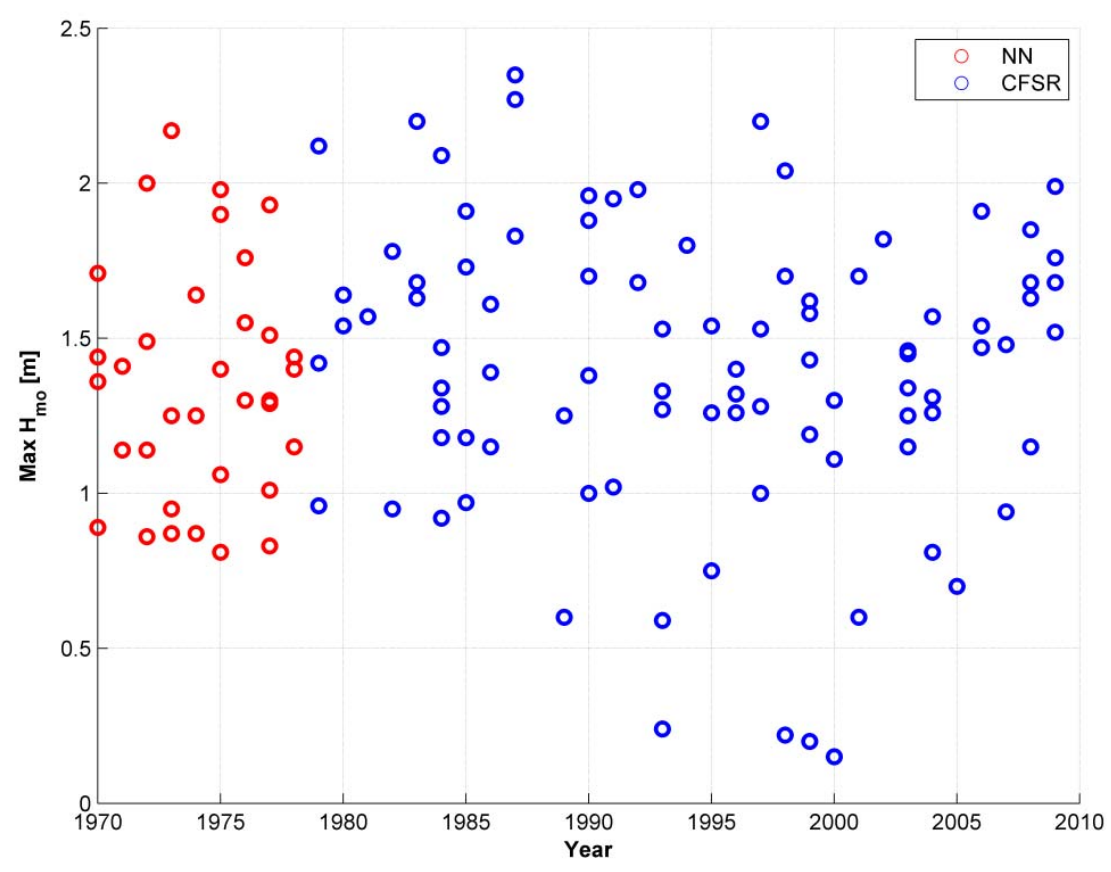

Figure 6-38. Maximum wave heights for all post-1970 modeled storm events for MW grid. 


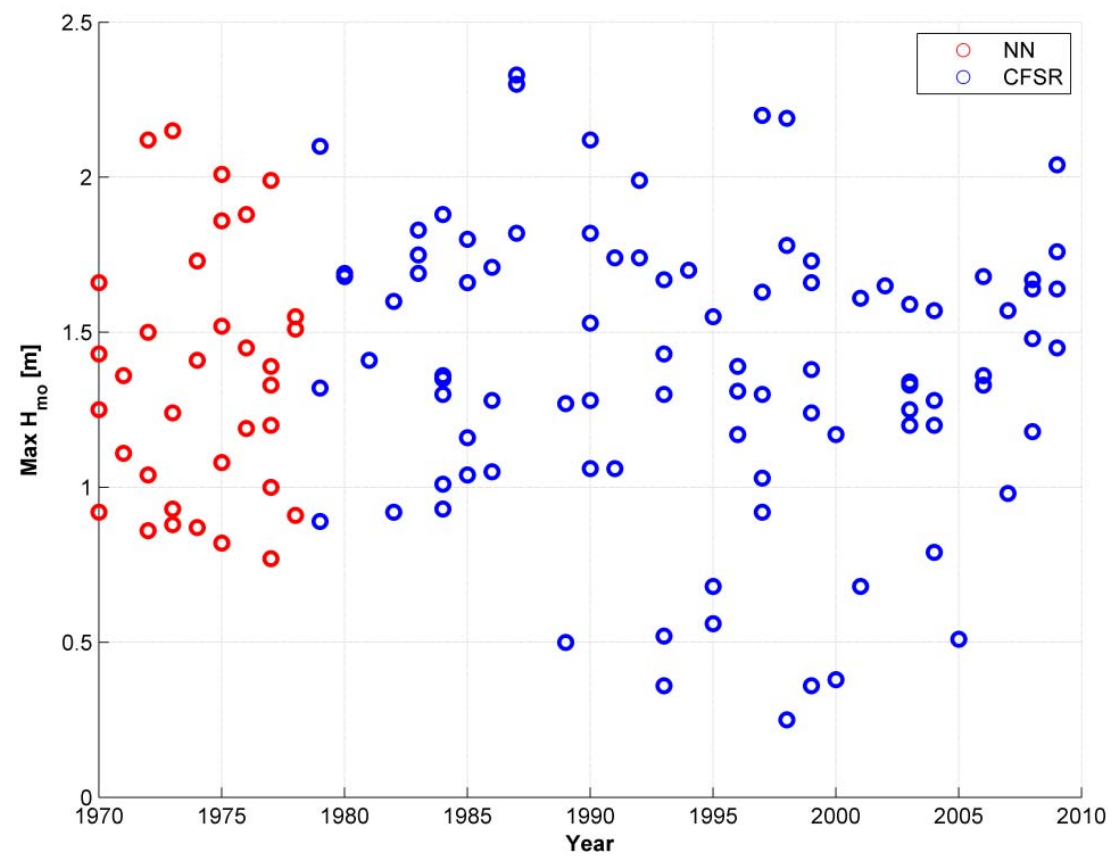

Figure 6-39. Maximum wave heights for all post-1970 modeled storm events for SW grid.

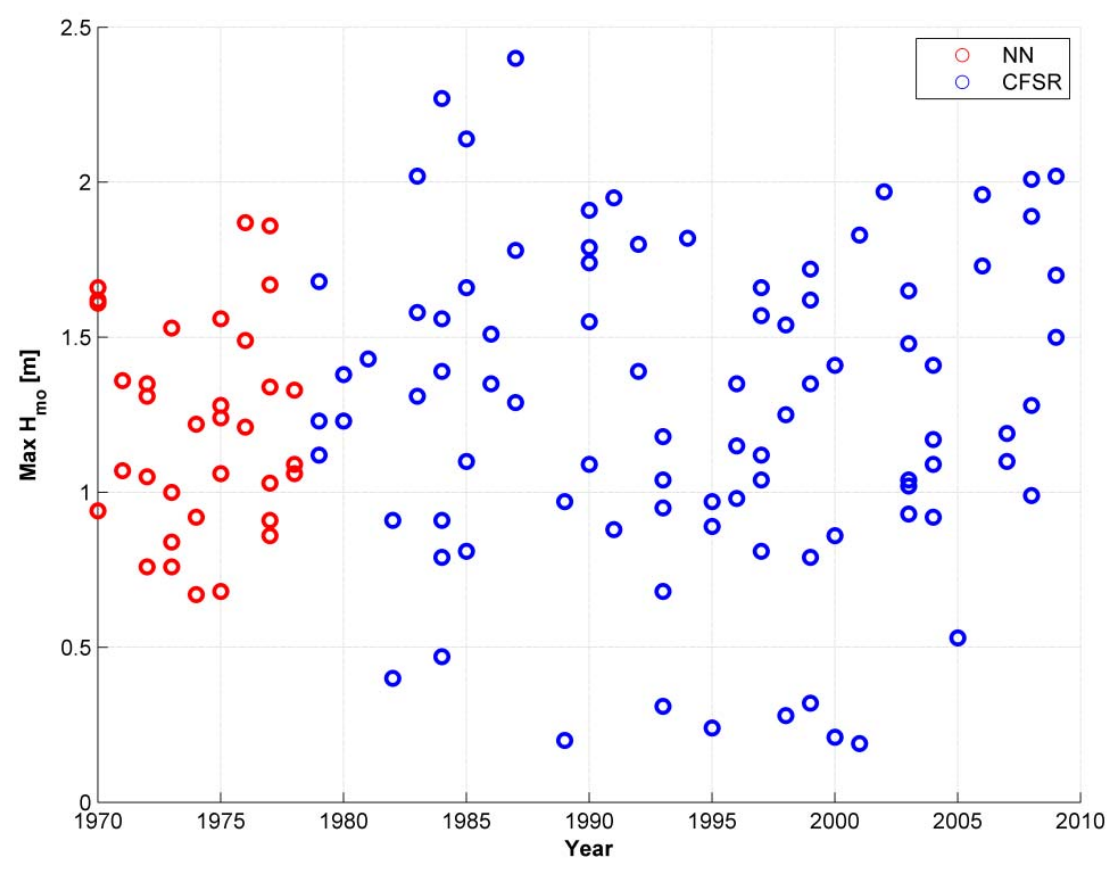

Figure 6-40. Maximum wave heights for all post-1970 modeled storm events for NE grid. 


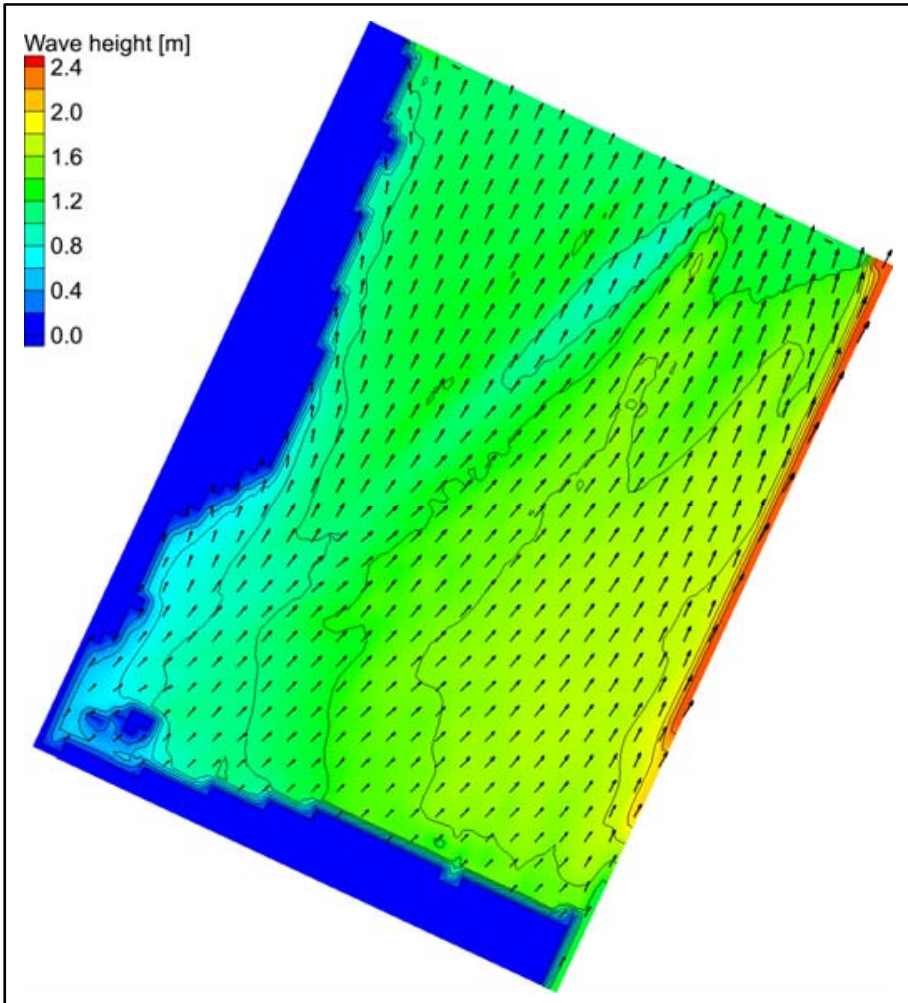

Figure 6-41. Time step of maximum wave heights for Storm 059 in SW grid. Contours indicate wave height and vectors indicate wave direction. Note the boundary spectra are traveling parallel to the domain.

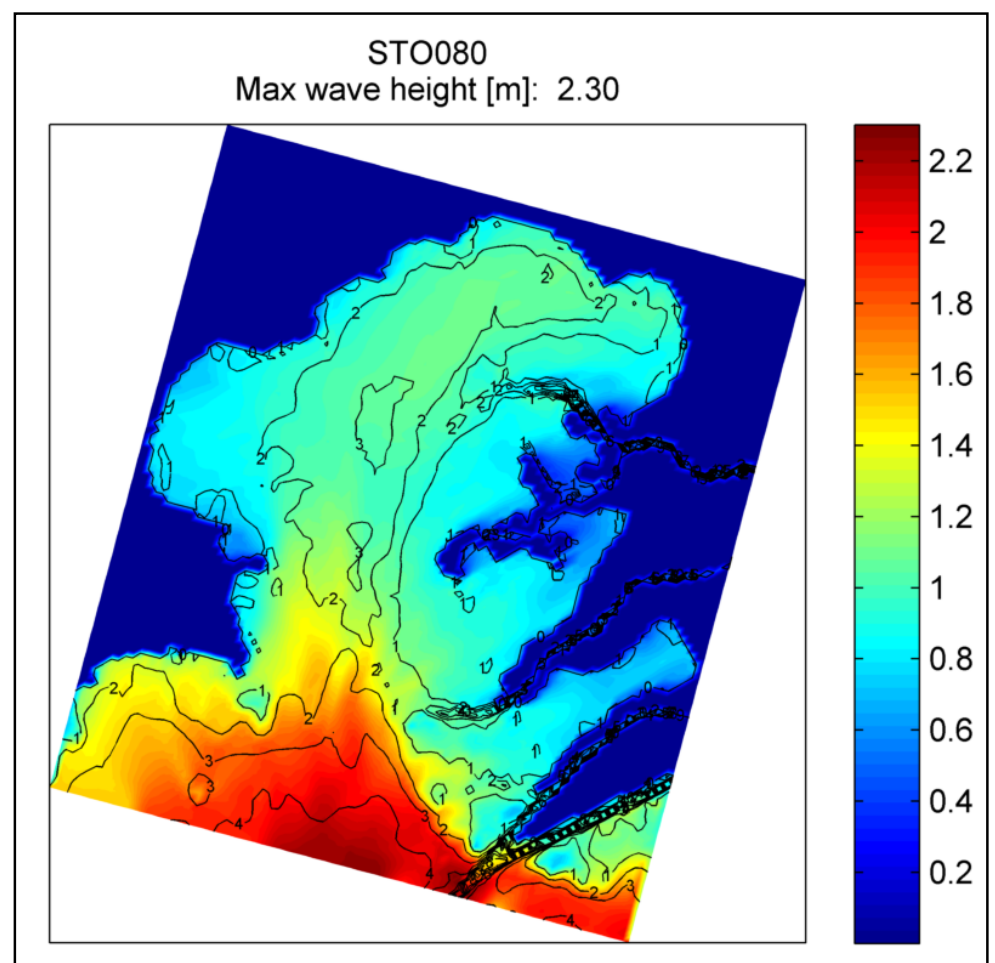

Figure 6-42. Maximum wave height field for Storm 080 for NW grid. 


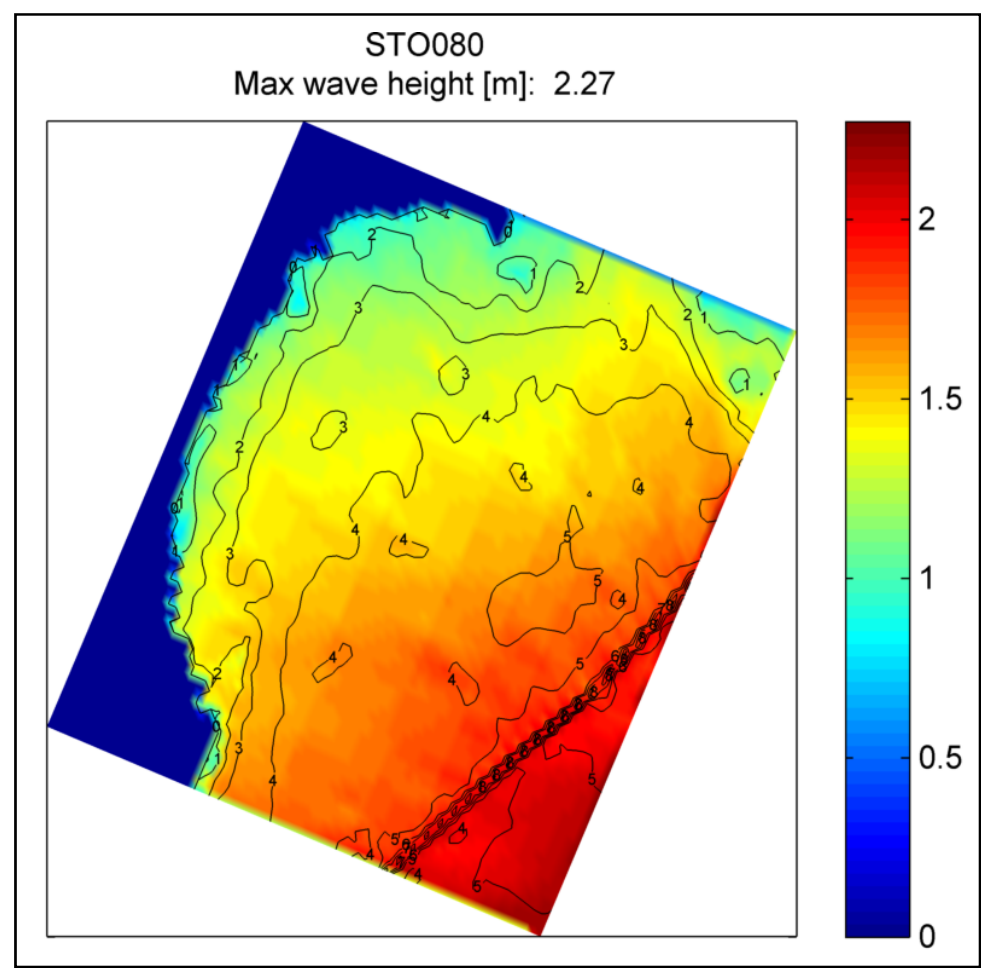

Figure 6-43. Maximum wave height field for Storm 080 for MW grid.

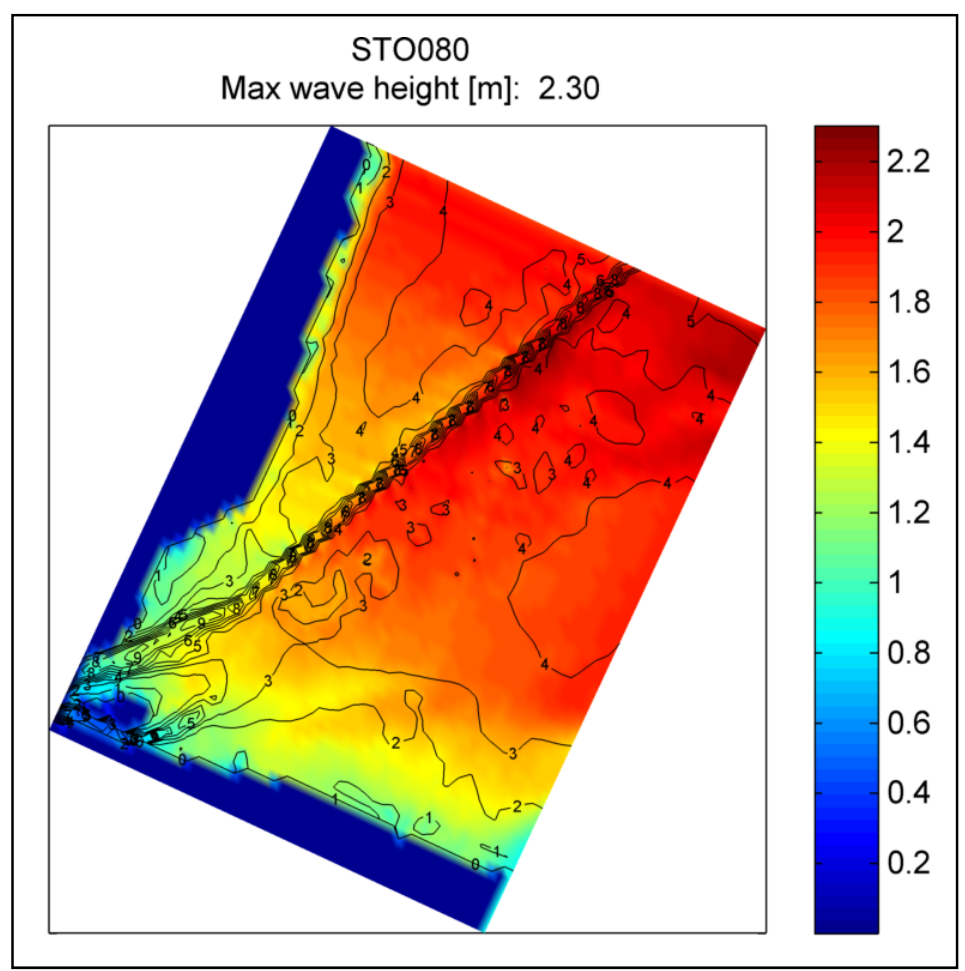

Figure 6-44. Maximum wave height field for Storm 080 for SW grid. 


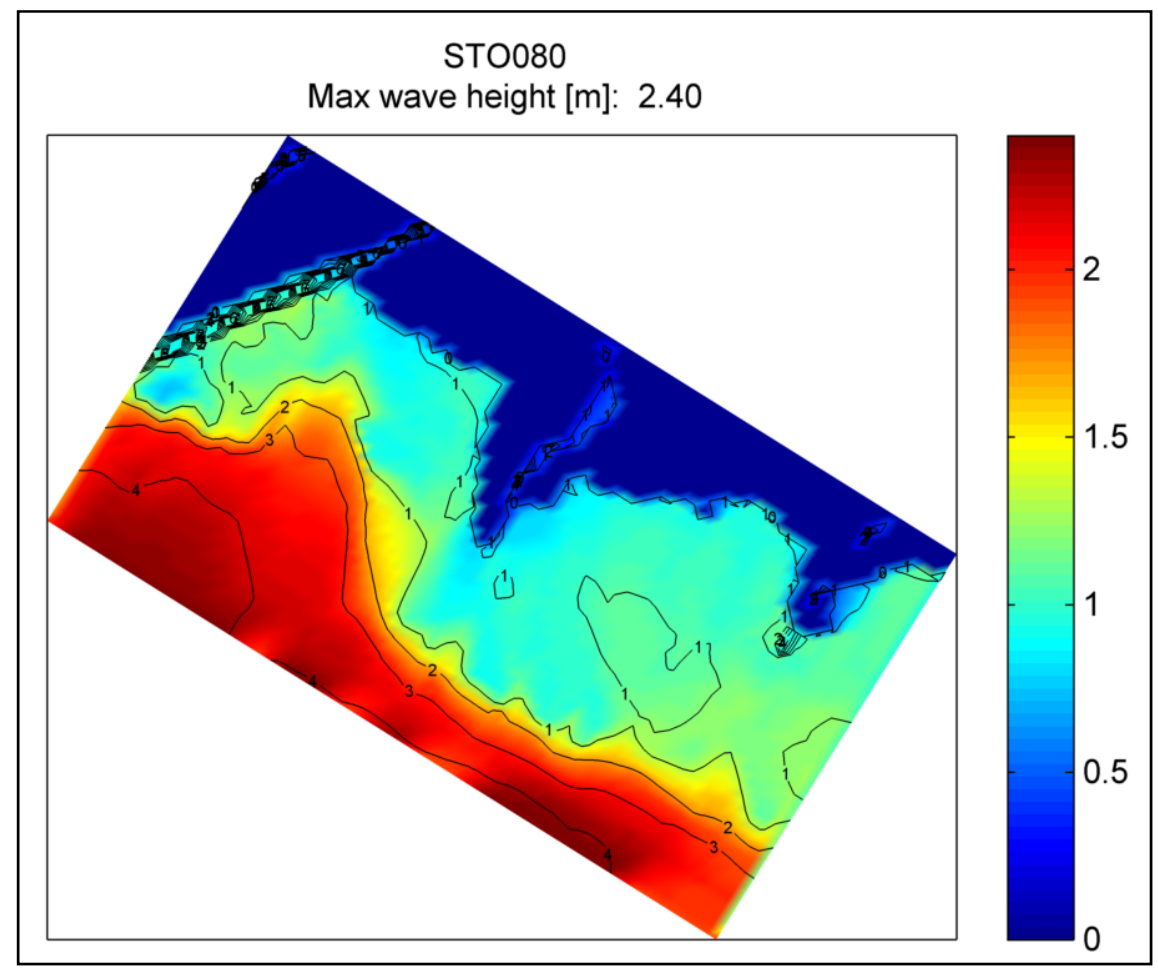

Figure 6-45. Maximum wave height field for Storm 080 for NE grid.

For this particular storm, the largest wave height in the domains ranged from 2.27-2.40 $\mathrm{m}$, and the maximum wave height variation depended on bathymetry, particular in the NW and NE grids. The largest wave heights are always located further offshore in depths of 4-5 $\mathrm{m}$ with the wave field closely mimicking the bathymetry contours. The effect of the shipping channel is seen only in the SW grid; the maximum wave heights behind the channel are about 0.4-0.6 m smaller than in front it for Storm 080. The shipping channel played a larger role in influencing the wave climate in the SW grid as it is closer to the shoreline and divides the domain.

Also seen in Jensen et al. (2012), the apparition of blocks appears in some of the STWAVE wave height solutions (see Figure 6-43). This "blocking" is an artifact of the iteration scheme within STWAVE, and it occurs when the final value of individual grid partitions do not completely match the values of their neighbors' boundaries. This artifact does not affect the integrity of the solution as the "blocking" occurs in deep water (offshore of the save points) and the difference between partitions is very small (on the order of centimeters).

In addition to plotting the maximum wave field, the time steps for all 145 storms were concatenated and reviewed for final convergence. The final 
convergence criterion for all four domains was identical where at least 99.8 percent of the cells had to have a relative difference in average wave height of $0.05 \mathrm{~m}$ or less. Considering all modeled storms, non-converged time steps accounted for less than one percent of the total final time steps for each grid. These non-converged time steps were not limited to one storm and typically occurred before or after the storm peak. In the few instances where non-converged time steps occurred near the peak condition, the percentage of cells satisfying the stopping criteria was still 99.6 percent and greater. As this study is focused on extreme storm events, these storms were not rerun as the non-converged time steps were extremely limited and reached a high percentage extremely close to the criteria. 


\section{Summary and Conclusion}

The difficulties involved in the estimation of wind, pressure, ice, surge, and waves for Lake St. Clair have been described in detail in this report. Lake St. Clair is a small shallow lake with maximum depths outside the shipping channel of 6-m. The coastline consists of long stretches of marsh to the northeast and marinas with residential population to the west, and the city of Detroit to the southwest. The majority of the storms are dominated by rapidly moving low pressure synoptic-scale systems that can cause conditions to go from calm to extreme in a matter of hours. These meteorological events generally come from the west pushing waves and surge to the east/northeast regions of the lake. To add more difficulty, Lake St. Clair water level is controlled by input coming from Lake Huron down the St. Clair River and outflow to Lake Erie down the Detroit River. A change in the flow rate of either of these rivers can change the water level in the lake which can impact the overall effect of storms as they hit the shorelines of Lake St. Clair. All of these complexities, among others, have driven an extensive modeling effort to better understand the extreme events in Lake St. Clair using advanced wave and hydrodynamic models.

The Natural Neighbor Method (NNM) and NOAA/NCEP Climate Forecast System Reanalysis (CFSR) wind and pressure field generation methods were both tested and used in this study. The NNM consists of using a collection of point source meteorological stations to interpolate a wind field on a specified grid. The precision of the entire wind field is dependent on the number of stations available during a particular time period. For the range of this study between 1960 and 2009, the maximum number of meteorological stations is 19 and the minimum is two. The storms when only 2 stations are available have less details than the times with more stations but all tests showed the NNM wind fields generated with two stations produce adequate winds and pressures.

The CFSR wind fields in the Great Lakes were originally developed on a 0.5-deg grid and interpolated down to 0.02-deg for this study. The original low resolution grid (relative to the size of Lake St. Clair) for the CFSR wind fields causes a lack of detail in the local wind effects over Lake St. Clair. Another issue with the CFSR wind fields was the location of Lake St. Clair in the land-sea mask which was used to determine the friction factor in the 
generation of wind speeds. The marine exposure winds speeds are greater than the over-land wind speeds. To resolve this issue, the wind speeds from 2001-2009 were compared with a CMAN station in the middle of Lake St. Clair, and the wind speeds were increased to account for the change from over-land to marine exposure.

The ice fields for each storm were implemented similar to the Lake Michigan FEMA study (Jensen et al. 2012). Ice concentration fields were interpolated to fit the WAM grid with concentrations greater than 70 percent damping out all wave energy. The threshold was developed from work on the Western Alaska wave hindcast, and was confirmed during testing in Jensen et al. (2012). Three ice concentration field archives were used in this study, pre-1973 used the National Snow and Ice Date Center, 1973-2002 used the Digital Ice Atlas from Assel (2005), and 2003-2009 used the NOAA's GLERL archive.

The WAM Cycle 4.5.1.C wave model was evaluated using a two step approach. First, the grid and refraction were tested by running constant winds from the eight compass directions for $24 \mathrm{hr}$ to determine the growth rates in Lake St. Clair. From these tests, the best grid was determined to be an 18-sec grid with refraction turned on. Next, six of the largest wave height events measured at Canadian buoy 45147 were selected as validation storms. All of these storms were run with both NNM and CFSR wind fields to determine the difference in the results.

The validation of the WAM model test results relied heavily on the quality of the buoy data. Unfortunately, the buoy measurements were determined to be of low quality, so detailed spectral comparisons were used to compare bulk parameters calculated from similar frequency ranges. The validation wave height events showed good agreement between the modeled and measured wave heights while comparing bulk parameters from similar frequency ranges. The NNM and CFSR wave height results showed similar trends with differences consisting of the location of peak events as opposed to the magnitude of the peak events. At the validation site, Canadian buoy 45147 , the two model result showed good agreement. From this study and based on the precedent set by Jensen et al. (2012) in Lake Michigan, CFSR wind fields were used for all storms after 1979 and NNM wind fields were used for storms before 1979 . 
Extremal analysis of water levels and wave heights in Lake St. Clair identified 145 storms to be run for production of this study. All storms were analyzed for ice to determine the amount of ice present at the peak of the storm. The winds were generated by either NNM or CFSR given the time period of the storm. All storms were run for 12 days starting nine days prior to the peak and finishing two days after the peak. WAM Cycle 4.5.1.C was run for each of the storms. The spectra and wave parameters were output at 233 points in and around Lake St. Clair for every storm at 30-min intervals. The WAM coastal output points were located two grid points from the land boundary on the 18 -sec grid. The points were labeled o0001-00163 starting at the southwest corner of the lake at the mouth of the Detroit River increasing in a clockwise direction. The spectra was also output at select locations to be used as boundary conditions for four STWAVE nearshore grids.

The production storms were all checked to ensure an acceptable computational run by analyzing the maximum and mean of the wave height, wind speeds, and wave period fields for the complete grid. For the two storms when buoy 45147 was available, advanced validation was performed which consisted of scatter plots, Q-Q analysis, and the calculation of bias, RMSE, and scatter index. The results displayed a similar result to the initial validation wave test. When the bulk parameters were calculated based on similar frequency ranges, the statistics showed good agreement between the model and measurements. The evaluation of the maximum wave heights and wind speeds for all the storms showed that the majority of the maximum wind speeds were between 10 and $20-\mathrm{m} / \mathrm{sec}$ while the maximum wave heights were between 1-and 2-m. The maximum extreme events had wind speeds of approximately $26-\mathrm{m} / \mathrm{sec}$ and the maximum wave height was 2.5 -m.

The ADCIRC model for Lake St. Clair was developed using bathymetry from NOAA's Electronic Navigation Charts, 3- and 9-arc-sec data files from NOAA's National Environmental Satellite Data, and the Information Service Lake St. Clair digital bathymetry data base. Eleven ranked storm events measured at NOAA NOS Station 9044049 and/or Station 9034052 were selected as validation storms. Storms were simulated with both CFSR and NNM wind development methods for a comparative analysis of resulting water level response. 
The validation consisted of a comparison of water levels at NOAA NOS Station 9044049 and Station 9034052 to simulated water levels at those locations. The validation process revealed that the prevalence of complete ice coverage in Lake St. Clair produced a muted response at the gauge compared to the modeled water levels. Production storms were therefore screened for the degree of shore-fast ice on the US coastline. Storms with the coastline completely ice covered were eliminated from the production process if the maximum water level for the event falls outside the top 20 for both gauges. Water levels simulated for storms with partial or no ice coverage compared well with measured water levels at both NOAA NOS stations. The measured water levels indicate a response to the storm winds that replicate the measured water levels in both magnitude and duration of the surge event with the exception of small post-surge seiche discrepancies. The water level time-series comparisons of simulated and observed prestorm oscillations as well as the storm surge magnitude and duration, demonstrate the ability of ADCIRC to simulate storm surge hydrodynamics in Lake St. Clair. Small scale oscillations that are finer than the temporal and spatial scales of the forcing conditions were not captured in the simulated responses.

Tests to determine the sensitivity of simulated water levels to forcing conditions and model parameters; such as wind type, wind magnitude, ice coverage, inflow, and bottom friction; provided insight into the significance of properly representing physical parameters to reproduce the hydrodynamic response to those parameters. Water level response was most sensitive to the inflow rate at the St. Clair River and to the friction parameter applied to the model domain. A fairly large range in water level response (0.3-0.4 m) was associated with 5-15 percent changes in mean flow applied at the river inflow boundary. The sensitivity of the simulated water levels to bottom friction produced a large range $(0.6 \mathrm{~m})$ of water level responses. Simulated water levels compared best to measured water levels when a Chezy friction coefficient of 0.0019 was applied.

Sensitivity to the wind type (CFSR or NNM) applied in the model indicates that the peak storm surge value associated with the main surge event is reasonably well simulated with both wind sources. However, the CFSR winds better represent the spatial and temporal coherence in storm wind fields. Therefore, the CFSR winds were adopted as the preferred source for wind input, when they were available. To examine the effect that a bias in wind speed may have on calculated water levels, several events were 
simulated with a nine percent adjustment in wind speed, resulting in a very slight effect on water level for all storm events. For all Great Lakes ADCIRC applications, a wind multiplier of 1.09 is applied to change the 30-min averaged winds to 10-min winds required by ADCIRC. A sensitivity test was also conducted to examine the effect of the presence of ice on simulated water levels in Lake St. Clair by modeling storms with and without freefloating ice coverage applied to the entire lake. For this example the change was less than $0.1 \mathrm{~m}$.

The validated model was then applied during production for a suite of 145 storm events. Based on the validation simulations, all production storm simulations applied a two-dimensional, depth-integrated nonlinear bottom friction coefficient of 0.0019 and included finite amplitude and advective terms in the model computations. The model applications assumed vertical walls at the shoreline, therefore wetting and drying was turned off in all model applications. For some simulations, a 5-15 percent adjustment was made to the St. Clair River mean monthly inflow applied at the northern boundary of the mesh because the estimated monthly mean did not match the actual inflows at the time of the storm.

From the production simulation results, a series of graphical and statistical products were generated to visually and numerically evaluate the model's skill in simulating the hydrodynamic response of the system to atmospheric forcing. Maximum water level envelopes provide an overall view of the extreme response of the water body to atmospheric forcing. Animations of water level, wind speed, atmospheric pressure, and water velocity provide a more detailed visualization of model performance and stability. Post processing of model results also included a comparison of water level time series measured at NOS Station 9034052 (St. Clair Shores) and 9044049 (Windmill Point) to simulated water levels for all production storms. The time series of water levels for most storms do not show a large spatial variability in response for the two lake gauge locations which are located $14 \mathrm{~km}$ apart. For most storms, the temporal variability in response at St. Clair Shores and Windmill Point is captured in magnitude, duration, and the post-storm seiching. The ability to simulate the range of responses, particularly the storm peak and duration for this storm, displays the skill of ADCIRC in simulating the storm surge hydrodynamics in Lake St. Clair. Small scale oscillations that are finer than the temporal and spatial scales of the forcing conditions were not captured in the simulated responses. 
The statistical analysis tabulated from the final 6 days of the storm simulation for each storm and each location is the bias and root-meansquare error. An examination of all storm comparisons shows that 86 percent of the Bias values are within $+/-0.05 \mathrm{~m}$. The most extreme low and high bias values are $-0.11 \mathrm{~m}$ and 0.06 , possibly due to the quality of the wind forcing. An examination of all comparisons shows that 90 percent of the RMSE values are within $0.10 \mathrm{~m}$.

A secondary statistical analysis focused on a comparison of measured and simulated water level peaks and showed good agreement between maximum water levels for both measurement locations. (The ADCIRC peak water level was extracted for the 24 -hr time period centered around the time of the measured peak of each event.) The bias calculated using the peak water levels shows a higher percentage of events have a positive bias, or an over-estimation of the peak water level by the model, than an underestimation of peak water level. The estimated peak water level from ADCIRC range from a $30-\mathrm{cm}$ over-estimation to a $20-\mathrm{cm}$ under-estimation for Station 9034052. The bias range at Station 9044049 was between $50-\mathrm{cm}$ of over-estimation by the model and $20-\mathrm{cm}$ of under-estimation. The larger bias values for Station 9044049 as compared to Station 9034052 may be associated with the location of Station 9044049 close to the outlet from Lake St. Clair and entrance into the Detroit River. The analysis of peak statistics also indicates that there appears to be no difference in the model's ability to capture storm peaks when forced with NNM or CFSR winds.

The nearshore wave climate of Lake St. Clair was modeled using full-plane STWAVE. Four 200-m resolution grids were interpolated from the ADCIRC mesh to UTM NAD 83 Zone 17, and STWAVE was run at 30-min time steps for 6 days ( 3 days prior to the peak, the peak day, and 2 days following the peak). Offshore wave spectra from WAM served as the boundary conditions while information between ADCIRC and STWAVE was exchanged using the tight two-way coupling capabilities of CSTORM-MS. Water levels and ice coverage were passed from ADCIRC to STWAVE and wave radiation stress gradients passed from STWAVE to ADCIRC. Ice was implemented into STWAVE according to Jensen et al. (2012) with cells exceeding 70 percent ice coverage set as land. Output for each storm included the wave parameters and 2D wave spectra at 133 special save points and wave parameter field files. 
Solution checks for all simulations included plotting the maximum wave height envelope and reviewing the final iteration criteria for solution convergence. For some storm events the maximum wave height appeared only along the offshore boundary as the wave direction was either parallel to or directed offshore of the domain. Less than one percent of the total time steps considering all modeled storms did not converge, and these nonconverged time steps were not limited to one storm event. Apparitions of blocks appeared in some of the wave height solutions due to discontinuities along grid partitions. However, this artifact does not affect the integrity of the solution as these blocks appear in deep water and the difference between partitions is on the order of centimeters. No gauges were present in any of the STWAVE domains, preventing the evaluation of model results to wave observations. The largest wave height occurred during Storm 080 for all domains and varied from 2.27 to $2.4 \mathrm{~m}$. 


\section{References}

Assel, R. A. 1983. GLERL Great Lakes ice concentration data base, 1960-1979. Boulder, Colorado USA: National Snow and Ice Data Center.

Assel, R. A. 2003. NOAA Atlas. An Electronic Atlas of Great Lakes Ice Cover, Winters: 1973-2002. Ann Arbor, MI: NOAA, Great Lakes Environmental Research Laboratory. (http://www.glerl.noaa.gov/data/ice/atlas/)

Assel, R. A. 2005. Great Lakes weekly ice cover statistics. NOAA, Technical Memorandum GLERL-133. Ann Arbor, MI: NOAA, Great Lakes Environmental Research Laboratory.

Birnbaum, G., and C. Lupkes. 2002. A new parameterization of surface drag in the marginal sea ice zone. Tellus (54A)107-23.

Bunya, S., J. C. Dietrich, J. J. Westerink, B. A. Ebersole, J. M. Smith, J. H. Atkinson, R. Jensen, D. T. Resio, R. A. Luettich, C. Dawson, V. J. Cardone, A. T. Cox, M. D. Powell, H. J. Westerink, and H. J. Roberts. 2010. A high resolution coupled riverine flow, tide, wind, wind wave and storm surge model for southern Louisiana and Mississippi: Part I - model development and validation. Monthly Weather Review (138)2:345-77. Chapman, R. S., D. Mark, and A. Cialone. 2005. Regional tide and storm-induced water level prediction study for the West Coast Alaska. Draft Report to POA. Vicksburg, MS: US Army Engineer Waterways Experiment Station.

Chapman, R. S., S-C. Kim, and D. J. Mark. 2009. Storm-induced water level prediction study for the Western Coast of Alaska. Draft Report to POA Vicksburg, MS: US Army Engineer Waterways Experiment Station.

Danard, M. B., M.C. Rasmussen, T. S. Murty, R. F. Henry, Z. Kowalik, and S. Venkatesh. 1989. Inclusion of ice cover in a storm surge model for the Beaufort Sea. Natural Hazards (2)153-71. Donelan, M. A., M. Skafel, H. Graber, P. Liu, D. Schwab, and S. Venkatesh. 1992. On the Growth Rate of Wind-Generated Waves. AtmosphereOcean 30(3):457-78.

Fay, D., and N. Noorbakhsh. 2010. Revision of Historic Monthly Mean Flow Estimates and Development of Lake-to-Lake Stage-Fall-Discharge Equations for the St. Clair and Detroit Rivers 1987-2009. Environment Canada and US Army Corps of Engineers, Burlington, ON, and Detroit, MI. 28 May 2010.

Garratt, J. R. 1977. Review of drag coefficients over oceans and continents. Monthly Weather Review 105, 915-929. 
Garbrecht, T., C. Lupkes, J. Hartmann, and M. Wolff. 2002, Atmospheric drag coefficients over sea ice-validation of a parameterization concept. Tellus (54A)205-19. Hasselmann, K., T. P. Barnett, E. Bouws, H. Carlson, D. E. Cartwright, K. Enke, J. A. Ewing, H. Gienapp, D. E. Hasselmann, P. Kruseman, A. Meerburg, P. Muller, D. J. Olbers, K. Richter, W. Sell, and H. Walden. 1973. Measurement of wind-wave growth and swell decay during the Joint North Sea Wave Project (JONSWAP). Deutches Hydrographisches Institut Suppl. A 8(12): $1-95$.

Henry, R. F., and N. S. Heaps. 1976. Storm surges in the southern Beaufort Sea. Journal of the Fisheries Research Board of Canada 33:2362-76.

Herterich, K., and K. Hasselmann. 1980. A similarity relation for the nonlinear energy transfer in a finite depth gravity-wave spectrum. Journal of Fluid Mechanics (97)215-24.

Holthuijsen, L. H. 2007. Waves in ocean and coastal waters. Cambridge: Cambridge University Press.

Interagency Performance Evaluation Task Force (IPET). 2007. Performance Evaluation of the New Orleans and Southeast Louisiana Hurricane Protection System, Volume IV-The Storm. US Army Corps of Engineers, Washington, DC, 26 March. /https://ipet.wes.army.mil/

Jensen, S. R. E., M. A. Cialone, R. S. Chapman, B. A. Ebersole, M. Anderson, and L. Thomas. 2012. Lake Michigan Storm: Wave and Water Level Modeling. Technical Report, US Army Engineer Research and Development Center, Vicksburg, MS.

Jonsson, I. G. 1990. The sea. Wave-current interactions. (9)3:A,B. . New York: John Wiley \& Sons, Inc.

Komen, G. J., L. Cavaleri, M. Donelan, K. Hasselmann, S. Hasselmann, and P. A. E. M. Janssen. 1994. Dynamics and Modelling of Ocean Waves. New York: Cambridge University Press.

Kowalik, Z. 1984. Storm surges is the Beaufort and Chukchi Seas. JGR (89)C6:10,570578. Luettich, R. A., Jr., J. J. Westerink, and N. W. Scheffner. 1992. ADCRIC: An advanced three-dimensional circulation model for shelves, coasts, and estuaries. Technical Report DRP-92-6. Vicksburg, MS: US Army Engineer Waterways Experiment Station.

Macklin, S. A. 1983. Wind Drag Coefficient Over First-Year Sea Ice in the Bering Sea. Journal of Geophysical Research 88(C5):2845-52.

Massey, T. C., M. E. Anderson, J. M Smith, J. Gomez, and R. Jones. 2011. STWAVE: Steady-state spectral wave model user's manual for STWAVE, version 6.o. ERDC/CHL SR-11-1. Vicksburg, MS: US Army Engineer Research and Development Center.

Melby, J. A., N. C. Nadal-Caraballo, U. Pagan-Albelo, and B. A. Ebersole. 2012. Wave height and water level variatibility on Lakes Michigan and St. Clair Vicksburg, MS: U.S.Army Cops of Engineers TR-12-23. 
Miche, M. 1951. Le pouvoir reflechissant des ouvrages maritimes exposes a l'action de la houle. Annals des Ponts et Chaussess 121e Annee, 285-319 (translated by Lincoln and Chevron, University of California, Berkeley, Wave Research Laboratory, Series 3, Issue 363, June 1954).

Nadal-Caraballo, N. C., J. A. Melby, and B. A. Ebersole. 2012. Statistical analysis and storm sampling approach for Lakes Michigan and St. Clair. Vicksburg, MS: U.S. Army Corps of Engineers, TR-12-19.

Padilla-Hernandez, R., and J. Monbaliu. 2001. Energy balance of wind-waves as a function of the bottom friction formulation. Coastal Engineering (43)131-48.

Pease, C. H., S. A. Salo, and J. E. Overland. 1983. Drag Measurements for First-Year Sea Ice Over a Shallow Sea. Journal of Geophysical Research 88(C5):2853-62.

Resio, D. T. 1987. Shallow-water waves. I: Theory. Journal of Waterway, Port, Coastal, and Ocean Engineering 113(3):264-81.

Resio, D. T. 1988. Shallow-water waves. II: Data comparisons. Journal of Waterway, Port, Coastal, and Ocean Engineering 114(1): 50-65.

Resio, D. T., and W. Perrie. 1989. Implications of an $f^{-4}$ equilibrium range for windgenerated waves. Journal of Physical Oceanography (19)193-204.

Saha, S., S. Moorthi, Hua-Lu Pan, X. Wu, J. Wang, S. Nadiga, P. Tripp, R. Kistler, J. Woollen, D. Behringer, H. Liu, D. Stokes, R. Grumbine, G. Gayno, J. Wang, Y. Hou, H. Chuang, H. Juang, J. Sela, M. Iredell, R. Treadon, D. Kleist, P. Delst, D. Keyser, J. Derber, M. Ek, J. Meng, H. Wei, R. Yang, S. Lord, H. Dool, A. Kumar, W. Wang, C. Long, M. Chelliah, Y. Xue, B. Huang, J. Schemm, W. Ebisuzaki, R. Lin, P. Xie, M. Chen, S. Zhou, W. Higgins, C. Zou, Q. Liu, Y. Chen, Y. Han, L. Cucurull, R. Reynolds, G. Rutledge, and M. Goldberg. 2010. The NCEP Climate Forecast System Reanalysis. Submitted to Bulletin of the American Meteorological Society.

Schafer, P. J. 1966. Computation of storm surge at Barrow, Alaska. Archives for Meteorology, Geophysics, and Bioclimatology (A)15(3-4):372-93.

Schwab, D. J. 1978. Simulation and forecasting of Lake Erie storm surges. Monthly Weather Review 106(10):1476-87.

Schwab, D. J., G. A. Meadows, J. R. Bennett, H. Schultz, P. C. Liu, J. E. Cambell, and H. H. Dannelongue. 1984. The response of the coastal boundary layer to wind and waves: Analysis of an experiment in Lake Erie. Journal of Geophysical Research 89:8043-8053.

Schwab, D. J., and D. Beletsky. 1998. Lake Michigan Mass Balance Study: Hydrodynamic modeling project. NOAA Technical Memorandum ERL GLERL-108, Great Lakes Environmental Research Laboratory, Ann Arbor, MI, 53pp.

Smith, J.M., A.R. Sherlock, and D.T. Resio. 2001. STWAVE: Steady-state spectral wave model user's manual for STWAVE, version 3.0. ERDC/CHL SR-01-1. Vicksburg: MS: US Army Engineer Research and Development Center. 
Smith, J.M. 2007. Full-plane STWAVE with bottom friction: II. Model overview. ERDC/CHL CHETN-I-75. Vicksburg, MS: US Army Engineer Research and Development Center. 


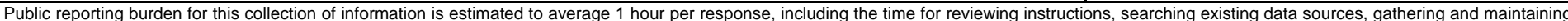

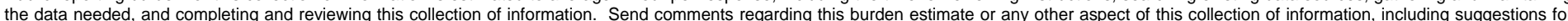

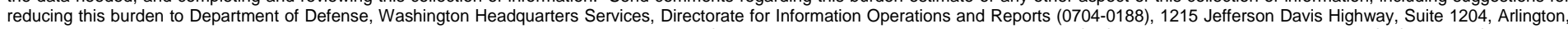

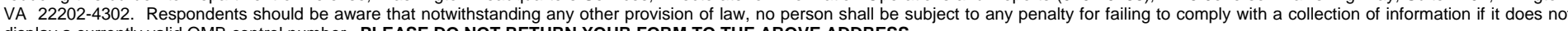
display a currently valid OMB control number. PLEASE DO NOT RETURN YOUR FORM TO THE ABOVE ADDRESS.

\begin{tabular}{|l|l|l|} 
1. REPORT DATE (DD-MM-YYYY) & 2. REPORT TYPE & 3. DATES COVERED (FrOm - To)
\end{tabular} June 2013

\section{TITLE AND SUBTITLE} Final

Lake St. Clair: Storm Wave and Water Level Modeling

5a. CONTRACT NUMBER

5b. GRANT NUMBER

5c. PROGRAM ELEMENT NUMBER

\section{AUTHOR(S)}

5d. PROJECT NUMBER

Tyler J. Hesser, Mary A. Cialone, and Mary Anderson

5e. TASK NUMBER

5f. WORK UNIT NUMBER

\section{PERFORMING ORGANIZATION NAME(S) AND ADDRESS(ES)}

8. PERFORMING ORGANIZATION REPORT

US Army Engineer Research and Development Center

Coastal and Hydraulics Laboratory NUMBER

3909 Halls Ferry Road

ERDC/CHL TR-13-5

Vicksburg, MS 39180-6199

9. SPONSORING I MONITORING AGENCY NAME(S) AND ADDRESS(ES)

10. SPONSOR/MONITOR'S ACRONYM(S)

11. SPONSOR/MONITOR'S REPORT NUMBER(S)

\section{DISTRIBUTION I AVAILABILITY STATEMENT}

Approved for public release; distribution is unlimited.

\section{SUPPLEMENTARY NOTES}

\section{ABSTRACT}

Lake St. Clair is a shallow water body located between Lake Huron and Lake Erie in the Great Lakes complex with coastline in both US and Canada. The numerical modeling of waves and water levels was performed to capture storm conditions along the US coastline. The methodology presented in Jensen et al. (2012) for Lake Michigan was followed for the majority of the project. The NOAA/NCEP Climate Forecast System Reanalysis wind fields were adjusted for marine exposure wind speeds. The WAM wave model was validated and applied for production of all wind generated wave results, including ice when applicable. The ADCIRC model was forced with wind fields, flow rates at the St. Clair River boundary, and water levels at the Detroit River boundary and validated to water levels at St. Clair Shores and Windmill Point. The ADCIRC model was tightly coupled with four near-shore Full-Plane STWAVE model grids using CSTORM-MS. The results show good agreement between all validation data sets, and low errors in the production storms with which data was available. In total, 145 storm events were run with the full numerical system to quantify the water level response to extreme events In Lake St. Clair.

\begin{tabular}{|lll}
\hline 15. SUBJECT TERMS & Great Lakes & Storm Surge \\
CSTORM & Hindcast & WAM \\
Extremes & Lake St. Clair & Wind Waves \\
\hline
\end{tabular}

\begin{tabular}{|c|c|c|c|c|c|}
\hline \multicolumn{2}{|c|}{ 16. SECURITY CLASSIFICATION OF: } & $\begin{array}{l}\text { 17. LIMITATION } \\
\text { OF ABSTRACT }\end{array}$ & $\begin{array}{l}\text { 18. NUMBER } \\
\text { OF PAGES }\end{array}$ & $\begin{array}{l}\text { 19a. NAME OF RESPONSIBLE } \\
\text { PERSON Tyler Hesser }\end{array}$ \\
\cline { 1 - 2 } $\begin{array}{c}\text { a. REPORT } \\
\text { UNCLASSIFIED }\end{array}$ & $\begin{array}{c}\text { b. ABSTRACT } \\
\text { UNCLASSIFIED }\end{array}$ & $\begin{array}{c}\text { c. THIS PAGE } \\
\text { UNCLASSIFIED }\end{array}$ & UNCLASSIFIED & 170 & $\begin{array}{l}\text { 19b. TELEPHONE NUMBER (include } \\
\text { area code) } \\
601-634-3007\end{array}$ \\
\hline
\end{tabular}

